\title{
"MACROINVERTEBRADOS BENTÔNICOS COMO INDICADORES DE POLUIÇÃO NA REPRESA DO GUARAPIRANGA - SP “
}

SOLANGE MARTONE ROCHA

Dissertação apresentada ao Departamento de Saúde Ambiental da Faculdade de Saúde Pública da Universidade de São Paulo para obtenção do Grau de Mestre em Saúde Pública

Área de Concentração: Saúde Ambiental

ORIENTADOR: PROF' DR. ROQUE PASSOS PIVELI

São Paulo

1999 


Autorizo, exclusivamente para fins acadêmicos e
científicos, a reprodução total ou parcial desta
dissertação, por processos fotocopiadores.
Assinatura:
Data:




\section{RESUMO}

0 presente trabalho foi desenvolvido na Represa do Guarapiranga, situada na Região Metropolitana de São Paulo - RMSP, $\left(23^{\circ} 43^{\prime} \mathrm{S}\right.$ e $\left.46^{\circ} 32^{\prime} \mathrm{W}\right)$; visando a utilização dos macroinvertebrados bentônicos como organismos indicadores de poluição. No período de março/96 a fevereiro/97, foram realizadas coletas mensais em dez estações de amostragem. Obteve-se amostras de água para análise de parâmetros físicos e químicos (superfície, meia profundidade e fundo) e de macroinvertebrados bentônicos.

No que se refere aos parâmetros colimétricos os resultados de Números Mais Prováveis de bactérias coliformes fecais e totais em algumas das coletas ultrapassaram o padrão da Resolução CONAMA no 20/1986 para águas de Classe 2 (1.000 coliformes fecais/100 mL e 5.000 coliformes totais $/ 100 \mathrm{~mL}$ ).

Quanto à comunidade bentônica analisou-se: densidades numéricas, abundâncias relativas, índices de diversidade, eqüitatividade e riqueza. Elaborou-se um dendrograma de agrupamento para as estações de coleta (espacial) com os valores das densidades numéricas dos organismos bentônicos. Para as estações de coleta verificou-se as correlações (por meio do teste não paramétrico de correlação por "rank" de spearman entre os dados referentes à comunidade bêntica e às variáveis abióticas e bióticas. 
A análise da fauna bentônica durante 0 período de estudo, permitiu evidenciar um gradiente trófico tanto em relação aos parâmetros físicos e químicos quanto para os organismos bentônicos, sendo que as estações mais afastadas da barragem mostraram-se menos eutróficas, enquanto que a poluição orgânica acentuada caracterizou as estações mais próximas à barragem, com predominância do grupo Tubificidae. 
The present study was carried out in Guarapiranga Reservoir, in the Metropolitan Region of São Paulo - MRSP $\left(23^{\circ} 43^{\prime} \mathrm{S}\right.$ and $\left.36^{\circ} 32^{\prime} \mathrm{W}\right)$, aiming to utilize benthic macroinvertebates as pollution indicators. From March 1996 through February 1997, water samples were collected monthly and analyzed for its physico and chemical parameters (in the surface, middle and bottom of the water column) as well as for benthic macroinvertebates.

The analysis of MPN of total and faecal coliform bacteria revealed that in some of the samples the number of these organisms exceeded the standards in CONAMA Resolution number 20/1986 for class 2 waters (1.000 faecal coliforms $/ 100 \mathrm{~mL}$ and 5.000 total coliforms/100 mL).

Concerning the benthic community, the following parameters were studied: numeric densities, numeric abundances, diversity, equitativity and richness indexes. A cluster dendrogram with data of numeric abundances of benthic organisms was constructed considering the sampling sites (spatial). In each sampling site, the correlations between benthic organisms and biotic and abiotic variables were evaluated by means o Sperman's non-parametric test.

The results obtained for the benthic fauna during the research, showed a trophyc gradient not only for the abiotic parameters but for the benthos as well. Those sites further from the dam were the least eutrophic, while a strong organic pollution was observed in the sampling sites located closer to the dam, with a clear predominance of Tubificidae. 


\section{ÍNDICE}

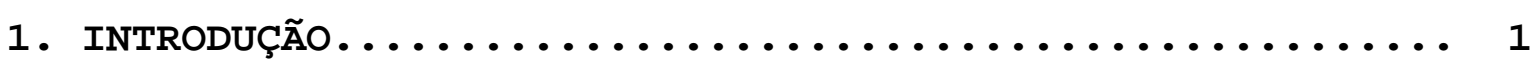

1.1 Características da Área de Estudo............. 5

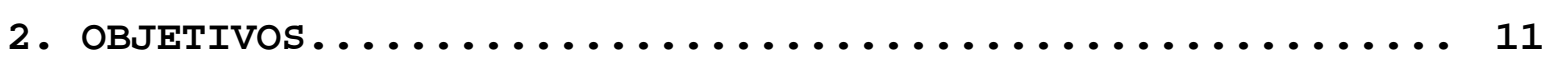

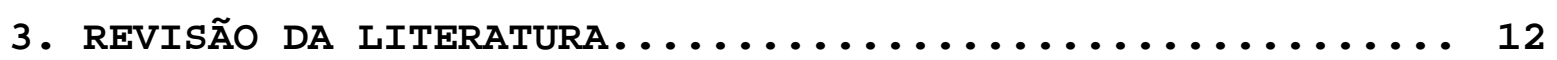

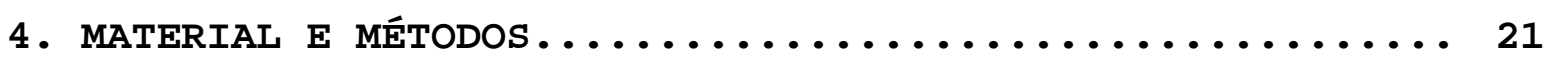

4.1 Variáveis Abióticas.................... 24

4.2 Coliformes Totais e Fecais................ 25

4.3 Comunidade Bentônica.................... 26

4.4 Tratamento dos Dados..................... 26

4.4.1 Parâmetros Físicos e Químicos............. 26

4.4.2 Coliformes Totais e Fecais.............. 27

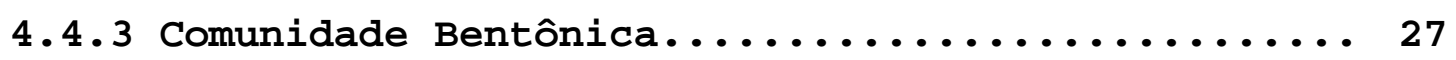

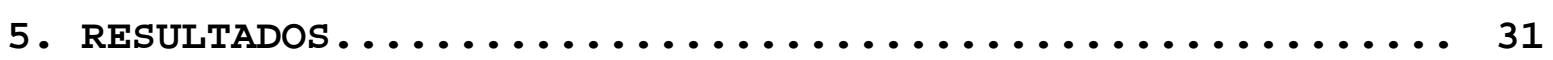

5.1 Parâmetros climáticos.................. 31

5.1 .1 Pluviosidade...................... 31

5.1 .2 Temperatura do Ar................. 32

5.2 Variações Abióticas....................... 32

5.2 .1 Temperatura da Água................. 32

5.2.2 Profundidade e Transparência.............. 33

5.2 .3 Turbidez e cor.................... 34

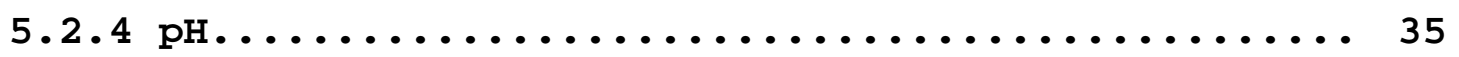

5.2 .5 Condutividade $\ldots \ldots \ldots \ldots \ldots \ldots \ldots \ldots \ldots \ldots \ldots, 36$

5.2 .6 0xigênio Dissolvido................... 36

5.2.7 Demanda Bioquímica de 0xigênio............. 40

5.2.8 Nitrogênio Total e Fósforo Total........... 43

5.2.9 Correlações Estatísticas................ 44

5.3 Coliformes Totais e Fecais................. 44

5.4 Macroinvertebrados Bentônicos................ 44

5.4 .1 Composição......................... 44

5.4 .2 Densidade Total..................... 45

5.4.3 Análise da Comunidade Bentônica............ 45

5.4.4 Diversidade, Eqüitatividade e Riqueza......... 48 
5.4 .5 Correlações Estatísticas................ 50

5.4.6 Análise de Agrupamento - Espacial (Dendrograma) ............................. 50

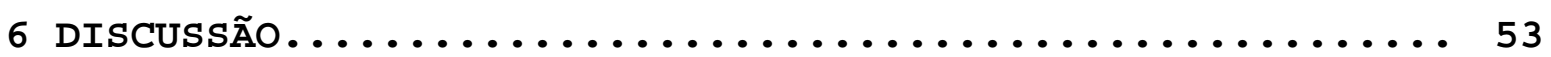

6.1 Parâmetros Físicos e Químicos............... 53

6.2 Coliformes Totais e Fecais................. 56

6.3 Comunidade Bentônica..................... 56

6.3.1 Densidade Total..................... 59

6.3.2 Abundância Relativa................... 62

6.3.3 Diversidade, Eqüitatividade e Riqueza........ 63

6.3.4 Correlações Estatísticas................ 66

6.3.5 Macroinvertebrados Bentônicos como Indicadores.. 69

6.3.6 Agrupamento Espacial (Dendrograma)............ 78

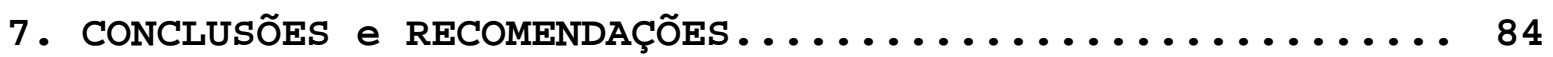

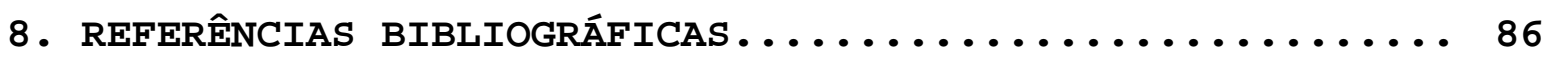




\section{ANEXO I \\ TABELAS}

1. Valores mensais da temperatura do ar $\left({ }^{\circ} \mathrm{C}\right)$ dos 10 pontos de amostragem superfície (S), à meia profundidade (M) e fundo (F) no período de março/96 a fevereiro/97 na Represa do Guarapiranga - SP.................. A 2. Valores mensais da temperatura da água $\left({ }^{\circ} \mathrm{C}\right)$ dos 10 pontos de amostragem superfície (S), à meia profundidade (M) e fundo (F) no período de março/96 a

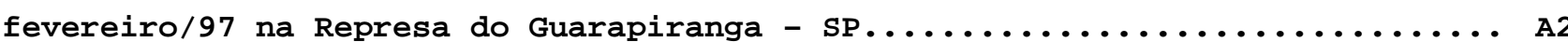

3. Valores mensais da profundidade e transparência (m) dos 10 pontos de amostragem no período de março/96 a fevereiro/97 na Represa do Guarapiranga - SP.

4. Valores mensais de turbidez (UNT) dos 10 pontos de amostragem - superfície (S), à meia profundidade (M) e fundo (F) no período de março/96 a fevereiro/97 na Represa do Guarapiranga - SP................... A4

5. Valores mensais de cor $(\mathrm{mgPt} / \mathrm{L})$ dos 10 pontos de amostragem - superfície (S), à meia profundidade (M) e fundo (F) no período de março/96 a fevereiro/97 na Represa do Guarapiranga - SP.................. A5 6. Valores mensais do $\mathrm{pH}$ dos 10 pontos de amostragem - superfície (S), à meia profundidade (M) e fundo (F) no período de março/96 a fevereiro/97 na Represa

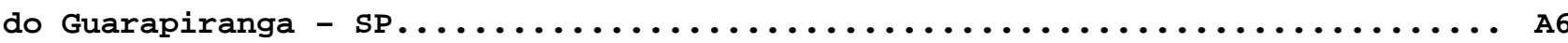

7. Valores mensais da condutividade elétrica $(\mu \mathrm{S} / \mathrm{cm})$ dos 10 pontos de amostragem - superfície (S), à meia profundidade (M) e fundo (F) no período de março/96 a fevereiro/97 na Represa do Guarapiranga -

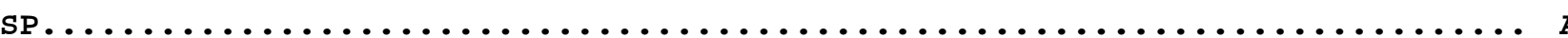

8. Valores mensais do oxigênio dissolvido $(\mathrm{mg} / \mathrm{L})$ dos 10 pontos de amostragem superfície (S), à meia profundidade (M) e fundo (F) no período de março/96 a

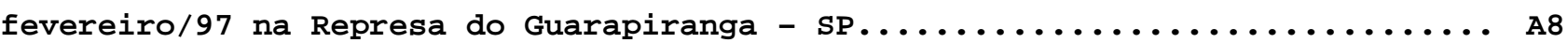

9. Valores mensais da demanda bioquímica de oxigênio (mg/L) dos 10 pontos de amostragem - superfície (S), à meia profundidade (M) e fundo (F) no período de março/96 a fevereiro/97 na Represa do Guarapiranga - SP............ A9 10. Valores mensais de nitrogênio total $(\mathrm{mg} / \mathrm{L})$ dos 10 pontos de amostragem superfície (S) no período de maio/96 a dezembro/96 na Represa do

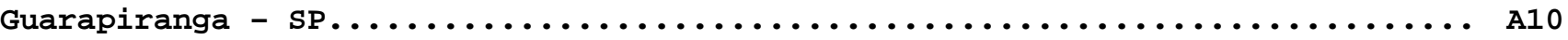
11. Valores mensais de fósforo total $(\mathrm{mg} / \mathrm{L})$ dos 10 pontos de amostragem superfície (S) no período de maio/96 a dezembro/96 na Represa do

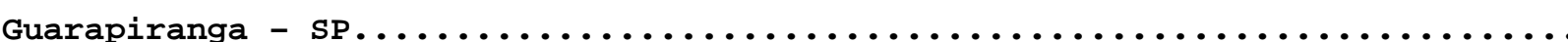


12. Densidade total acumulada dos Macroinvertebrados Bentônicos na Represa do

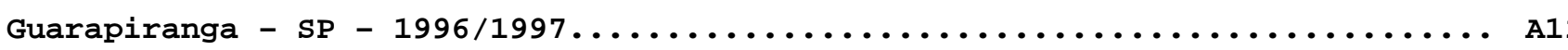

13. Variação temporal da densidade total acumulada e abundância relativa dos Macroinvertebrados Bentônicos na Represa do Guarapiranga - SP $1996 / 1997$

14. Densidades numéricas e abundância relativa dos Macroinvertebrados Bentônicos do ponto 01 no período de março/96 a fevereiro/97 na Represa do

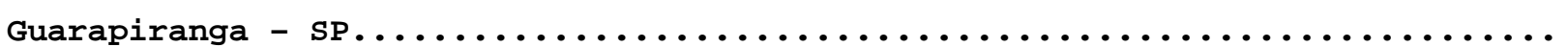

15. Densidades numéricas e abundância relativa dos Macroinvertebrados Bentônicos do ponto 02 no período de março/96 a fevereiro/97 na Represa do Guarapiranga - SP . . . . . . . . . . . . . . . . . . . . . . . . .

16. Densidades numéricas e abundância relativa dos Macroinvertebrados Bentônicos do ponto 03 no período de março/96 a fevereiro/97 na Represa do

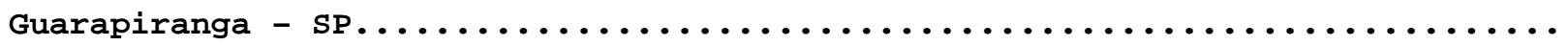

17. Densidades numéricas e abundância relativa dos Macroinvertebrados Bentônicos do ponto 04 no período de março/96 a fevereiro/97 na Represa do

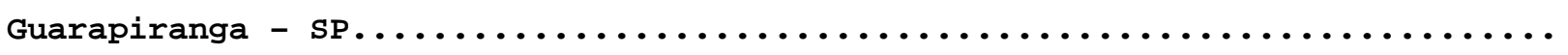

18. Densidades numéricas e abundância relativa dos Macroinvertebrados Bentônicos do ponto 05 no período de março/96 a fevereiro/97 na Represa do Guarapiranga - SP ................................

19. Densidades numéricas e abundância relativa dos Macroinvertebrados Bentônicos do ponto 06 no período de março/96 a fevereiro/97 na Represa do Guarapiranga - SP . . . . . . . . . . . . . . . . . . . . . . . . .

20. Densidades numéricas e abundância relativa dos Macroinvertebrados Bentônicos do ponto 07 no período de março/96 a fevereiro/97 na Represa do Guarapiranga - SP . . . . . . . . . . . . . . . . . . . . . . .

21. Densidades numéricas e abundância relativa dos Macroinvertebrados Bentônicos do ponto 08 no período de março/96 a fevereiro/97 na Represa do Guarapiranga - SP . . . . . . . . . . . . . . . . . . . . . . .

22. Densidades numéricas e abundância relativa dos Macroinvertebrados Bentônicos do ponto 09 no período de março/96 a fevereiro/97 na Represa do Guarapiranga - SP . . . . . . . . . . . . . . . . . . . . . . . .

23. Densidades numéricas e abundância relativa dos Macroinvertebrados Bentônicos do ponto 10 no período de março/96 a fevereiro/97 na Represa do

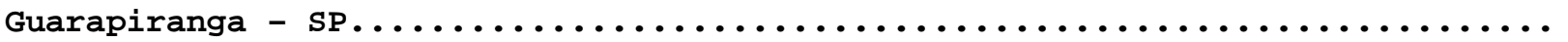

24. Variação espacial da densidade total acumulada e abundância relativa dos Macroinvertebrados Bentônicos na Represa do Guarapiranga - SP - 
$1996 / 1997$

25. Densidades numéricas e abundância relativa dos Macroinvertebrados Bentônicos dos 10 pontos de amostragem na Represa do Guarapiranga - SP Março/96.

26. Densidades numéricas e abundância relativa dos Macroinvertebrados Bentônicos dos 10 pontos de amostragem na Represa do Guarapiranga - SP Abril/96.

27. Densidades numéricas e abundância relativa dos Macroinvertebrados Bentônicos dos 10 pontos de amostragem na Represa do Guarapiranga - SP Maio/96.

28. Densidades numéricas e abundância relativa dos Macroinvertebrados Bentônicos dos 10 pontos de amostragem na Represa do Guarapiranga - SP Junho/96

29. Densidades numéricas e abundância relativa dos Macroinvertebrados Bentônicos dos 10 pontos de amostragem na Represa do Guarapiranga - SP -

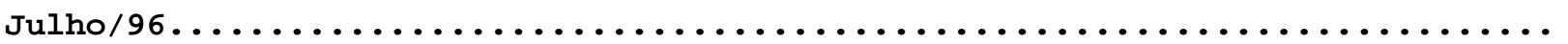

30. Densidades numéricas e abundância relativa dos Macroinvertebrados Bentônicos dos 10 pontos de amostragem na Represa do Guarapiranga - SP -

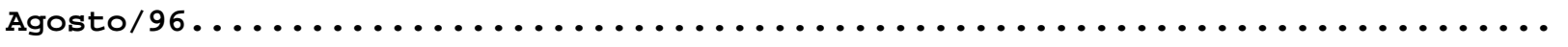

31. Densidades numéricas e abundância relativa dos Macroinvertebrados Bentônicos dos 10 pontos de amostragem na Represa do Guarapiranga - SP -

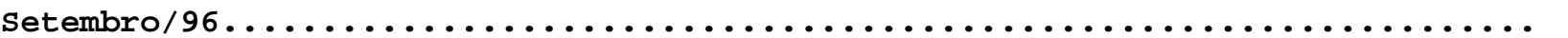

32. Densidades numéricas e abundância relativa dos Macroinvertebrados Bentônicos dos 10 pontos de amostragem na Represa do Guarapiranga - SP outubro/96.......................................

33. Densidades numéricas e abundância relativa dos Macroinvertebrados Bentônicos dos 10 pontos de amostragem na Represa do Guarapiranga - SP Novembro/96.

34. Densidades numéricas e abundância relativa dos Macroinvertebrados Bentônicos dos 10 pontos de amostragem na Represa do Guarapiranga - SP -

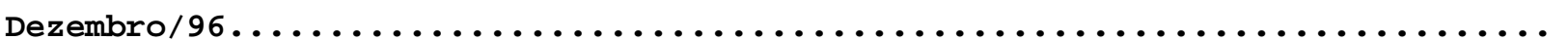

35. Densidades numéricas e abundância relativa dos Macroinvertebrados Bentônicos dos 10 pontos de amostragem na Represa do Guarapiranga - SP Janeiro/97.

36. Densidades numéricas e abundância relativa dos Macroinvertebrados Bentônicos dos 10 pontos de amostragem na Represa do Guarapiranga - SP Fevereiro/97

37. Valores mensais do índice de diversidade dos Macroinvertebrados 
Bentônicos dos 10 pontos de coleta no período de março/96 a fevereiro/97 na

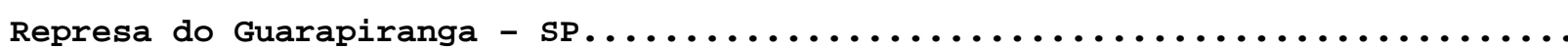

38. Valores mensais da eqüitatividade dos Macroinvertebrados Bentônicos dos 10 pontos de coleta no período de março/96 a fevereiro/97 na Represa do

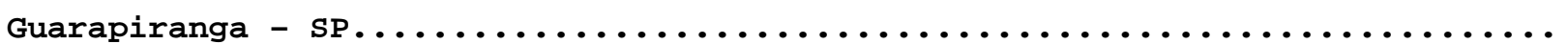

39. Valores mensais do índice de riqueza dos Macroinvertebrados Bentônicos dos 10 pontos de coleta no período de março/96 a fevereiro/97 na Represa do

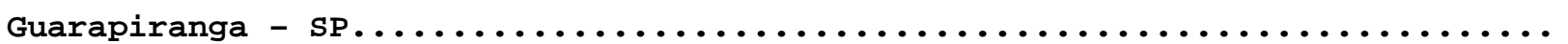

40. Valores dos coeficientes de correlação de Spearman $\left(r_{s}\right)$ no ponto 01 na

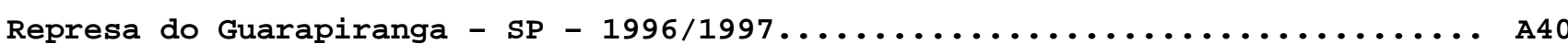

41. Valores dos coeficientes de correlação de Spearman $\left(r_{s}\right)$ no ponto 02 na

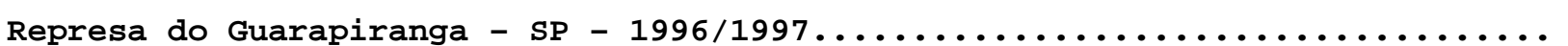

42. Valores dos coeficientes de correlação de Spearman $\left(r_{s}\right)$ no ponto 03 na

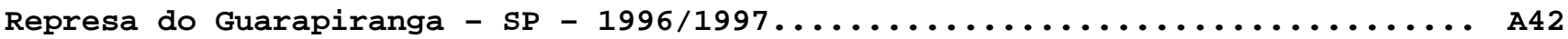

43. Valores dos coeficientes de correlação de Spearman $\left(r_{s}\right)$ no ponto 04 na

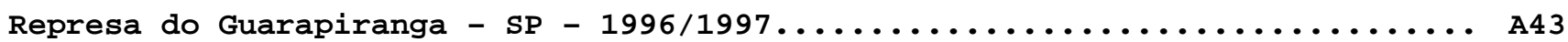

44. Valores dos coeficientes de correlação de Spearman $\left(r_{s}\right)$ no ponto 05 na

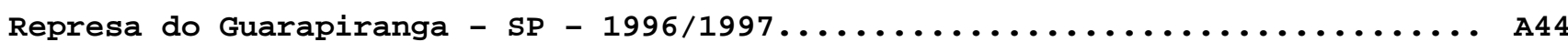

45. Valores dos coeficientes de correlação de Spearman $\left(r_{s}\right)$ no ponto 06 na

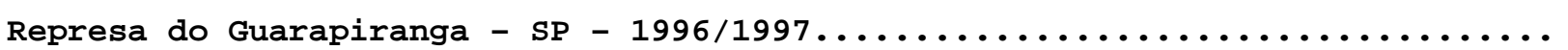

46. Valores dos coeficientes de correlação de Spearman $\left(r_{s}\right)$ no ponto 07 na.

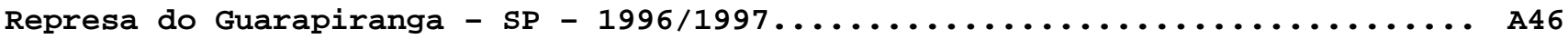

47. Valores dos coeficientes de correlação de Spearman $\left(r_{s}\right)$ no ponto 08 na

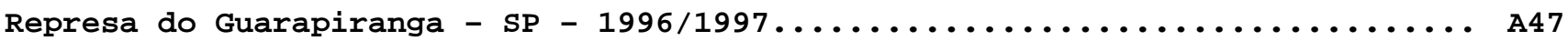

48. Valores dos coeficientes de correlação de Spearman $\left(r_{s}\right)$ no ponto 09 na

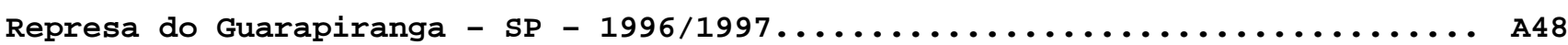

49. Valores dos coeficientes de correlação de Spearman $\left(r_{s}\right)$ no ponto 10 na

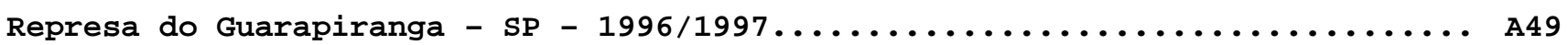
50. Concentrações de Coliformes Totais (CT) e Coliformes Fecais (CF) na Represa do Guarapiranga nos 10 pontos de amostragem no período de março/96 a

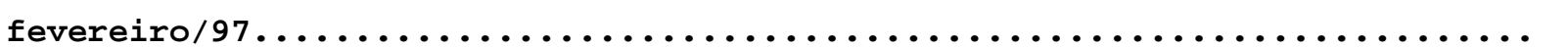

51. Datas e Horários das coletas realizadas nos 10 pontos de amostragem no período de março/96 a fevereiro/97 na Represa do Guarapiranga -SP.......... 
1. Ponto 01 Distribuição temporal dos índices da estrutura da comunidade

de Macroinvertebrados Bentônicos na Represa do Guarapiranga-SP-1996/1997.... Figura 01

2. Ponto 02 Distribuição temporal dos índices da estrutura da comunidade

de Macroinvertebrados Bentônicos na Represa do Guarapiranga-SP-1996/1997.... Figura 02

3. Ponto 03 Distribuição temporal dos índices da estrutura da comunidade

de Macroinvertebrados Bentônicos na Represa do Guarapiranga-SP-1996/1997.... Figura 03

4. Ponto 04 Distribuição temporal dos índices da estrutura da comunidade

de Macroinvertebrados Bentônicos na Represa do Guarapiranga-SP-1996/1997.... Figura 04

5. Ponto 05 Distribuição temporal dos índices da estrutura da comunidade

de Macroinvertebrados Bentônicos na Represa do Guarapiranga-SP-1996/1997.... Figura 05

6. Ponto 06 Distribuição temporal dos índices da estrutura da comunidade

de Macroinvertebrados Bentônicos na Represa do Guarapiranga-SP-1996/1997.... Figura 06

7. Ponto 07 Distribuição temporal dos índices da estrutura da comunidade

de Macroinvertebrados Bentônicos na Represa do Guarapiranga-SP-1996/1997.... Figura 07

8. Ponto 08 Distribuição temporal dos índices da estrutura da comunidade

de Macroinvertebrados Bentônicos na Represa do Guarapiranga-SP-1996/1997.... Figura 08

9. Ponto 09 Distribuição temporal dos índices da estrutura da comunidade

de Macroinvertebrados Bentônicos na Represa do Guarapiranga-SP-1996/1997.... Figura 09

10. Ponto 10 Distribuição temporal dos índices da estrutura da comunidade

de Macroinvertebrados Bentônicos na Represa do Guarapiranga-SP-1996/1997...

11. Março/96 - Distribuição espacial dos índices da estrutura da comunidade

de Macroinvertebrados Bentônicos na Represa do Guarapiranga-SP.......... Figura 11

12. Abril/96 Distribuição espacial dos índices da estrutura da comunidade

de Macroinvertebrados Bentônicos na Represa do Guarapiranga-SP.......... Figura 12

13. Maio/96 Distribuição espacial dos índices da estrutura da comunidade

de Macroinvertebrados Bentônicos na Represa do Guarapiranga-SP......... Figura 13

14. Junho/96 Distribuição espacial dos índices da estrutura da comunidade

de Macroinvertebrados Bentônicos na Represa do Guarapiranga-SP.......... Figura 14

15. Julho/96 Distribuição espacial dos índices da estrutura da comunidade

de Macroinvertebrados Bentônicos na Represa do Guarapiranga-SP.......... Figura 15

16. Agosto/96 Distribuição espacial dos índices da estrutura da comunidade

de Macroinvertebrados Bentônicos na Represa do Guarapiranga-SP......... Figura 16

17. Setembro/96 Distribuição espacial dos índices da estrutura da comunidade

de Macroinvertebrados Bentônicos na Represa do Guarapiranga-SP.......... Figura 17

18. Outubro/96 Distribuição espacial dos índices da estrutura da comunidade

de Macroinvertebrados Bentônicos na Represa do Guarapiranga-SP.......... Figura 18

19. Novembro/96 Distribuição espacial dos índices da estrutura da comunidade 
de Macroinvertebrados Bentônicos na Represa do Guarapiranga-SP.......... Figura 19 20. Dezembro/96 Distribuição espacial dos índices da estrutura da comunidade de Macroinvertebrados Bentônicos na Represa do Guarapiranga-SP.......... Figura 20 21. Janeiro/97 Distribuição espacial dos índices da estrutura da comunidade de Macroinvertebrados Bentônicos na Represa do Guarapiranga-SP.......... Figura 21 22. Fevereiro/97 Distribuição espacial dos índices da estrutura da comunidade de Macroinvertebrados Bentônicos na Represa do Guarapiranga-SP... Figura 22 23. Dendrograma de Similaridade entre as estações de coleta na Represa do

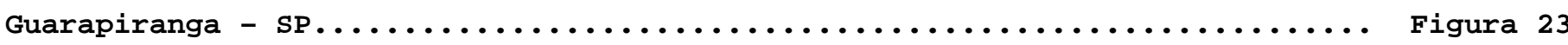
24. Variação temporal da temperatura do ar na Represa do Guarapiranga - SP.. Figura 24 25. Variação temporal da temperatura da água na Represa o Guarapiranga - SP. Figura 25 26. Variação temporal da transparência e profundidade da água na Represa do Guarapiranga - SP Figura 26 27. Variação temporal da turbidez da água na Represa do Guarapiranga - SP... Figura 27 28. Variação temporal da cor da água na Represa do Guarapiranga - SP....... Figura 28 29. Variação temporal do ph da água na Represa do Guarapiranga - SP....... Figura 29 30. Variação temporal da condutividade elétrica da água na Represa do

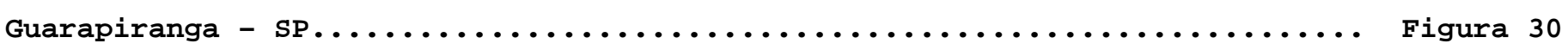
31. Variação temporal do oxigênio dissolvido na água na Represa do

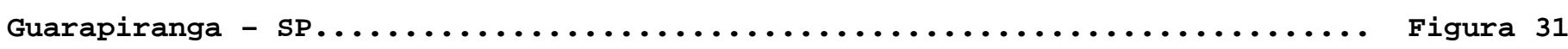
32. Variação temporal da demanda bioquímica de oxigênio na água na Represa

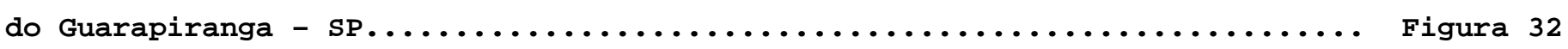
33. Variação temporal do nitrogênio total na água na Represa do Guarapiranga - SP. . . . . . . 34. Variação temporal do fósforo total na água na Represa do

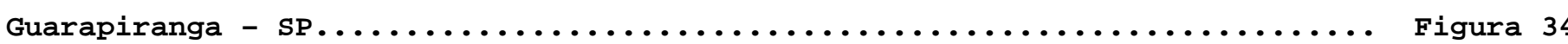


Dedico esta Dissertação

À minha mãe, Ana, exemplo de força $e$ dedicação, que nunca fraquejou, ensinando-me a lutar sempre; a conquistar o espaço que cada um de nós tem direito, sem ultrapassar limites e respeitando o próximo.

A Antônio, meu pai, que me deu suporte moral e material, sem os quais não poderia ter trilhado este caminho.

Ao Dr. Aristides Almeida Rocha, o "Tio Aristides", meu paradigma e mentor. 


\section{AGRADECIMENTOS}

Ao meu orientador Professor Doutor Roque Passos Piveli pela orientação segura e imparcial, sem jamais interromper a corrente de minhas idéias e sem alterar o prazer de uma amizade.

À amiga e companheira Maria do Carmo Dória Pereira pelo apoio espontâneo, 6om humor e por toda força dada desde o início de nossa amizade..

À Silvana Audrá Cutolo, pelo companheirismo em todos os momentos deste trabalho e de minha carreira.

À Professora Doutora Zuleika Beyruth pelos valiosos conselhos, atenção e cuidado durante este trabalho, bem como pelo grande apoio e amizade.

À Sueli Caleffi pela contribuição e apoio na informação de análises estatísticas, conselhos e amizade.

À Vilma Maria Cavinatto, pelo grande apoio e amizade, desde do início de minha carreira.

Ao Professor Doutor José Luís Negrão Mucci pela amizade, 6om humor, tornando mais divertidos estes anos de convivência.

À Francisca Alzira dos Santos Peternella pelo auxílio e que jamais recusou esforços para que as coletas pudessem ser realizadas.

À Mariza Pereira pelo carinho, amizade e pelas intermináveis horas de desabafos.

Ao Professor Dr. João Vicente de Assunção (Chefe do Departamento de Saúde Ambiental) e à Professora Dra. Helena Ribeiro (Vice-Chefe do Departamento de Saúde Ambiental), pela permissão de dedicar-me, quase que exclusivamente, a esta dissertação.

Aos Professores e Funcionários do Departamento de Saúde Ambiental da Faculdade de Saúde Pública, pela colaboração e convivência amiga, que direta e indiretamente contribuíram para a realização deste trabalho. 
Ao Sr. Silvio Serrão e seu Edgar (in memorian) e demais motoristas da Faculdade de Saúde Pública por facilitar o transporte da equipe e equipamentos de coleta.

Aos funcionários da Pós-Graduação e Aprimoramento, que sempre me auxiliaram com presteza.

Aos Funcionários da Biblioteca, pelo auxílio e procura incansável de livros e artigos.

Ao Professor Titular Aristides Almeida Rocha pelo apoio irrestrito, principalmente nos momentos mais difícieis, pela amizade e caminhos que se abriram.

À minha Família, principalmente à minha mãe, meu pai e minha sobrinha Thatiana, por todo carinho e apoio que me proporcionaram

À Deus, por ter permitido cruzar mais uma batalha...

Agradeço também

A Fundação de Amparo à Pesquisa do Estado de São Paulo - FAPESP, pelo auxílio com o qual foi possivel realizar parte deste trabalho.

À Associação Brasileira de Ecologia e de Prevenção à Poluição do Ar ABEPPOLAR, em especial ao jornalista Sr. Randolpho Marques Lobato, pelo empréstimo dos 6arcos, facilitando as atividades de campo.

Ao Clube Naútico Paulista pelo apoio logístico, especialmente ao Herbert Riga (Puk), Geraldão e Geraldinho, que nos auxiliou nos trabalhos de campo. 


\section{INTRODUÇÃO}

Segundo ESPINOSA (1993) "o expressivo crescimento econômico nas últimas décadas está sendo atualmente uma preocupação mundial, fato que tem sido considerado como uma das principais causas de deterioração ambiental, devido ao uso intensivo de energia fóssil e utilização da água, ar e solo como receptores de rejeitos e dejetos".

Também, a expansão de zonas urbanas e os problemas decorrentes do crescimento populacional em grandes cidades alcançaram uma tal dimensão, exigindo infra-estrutura adequada; como escolas, hospitais, abastecimento de água, energia elétrica etc, e originando como decorrência resíduos sólidos, líquidos e gasosos, que devem ser tratados devidamente.

Particularmente, no que se refere à água a maioria das bacias hidrográficas, é utilizada para múltiplos fins; abastecimento público, produção de energia elétrica, recreação, irrigação, etc.

No caso específico da cidade de São Paulo, o abastecimento de água vem sendo objeto de preocupação para os profissionais ligados ao saneamento e à saúde pública, devido à crescente degradação da qualidade da água dos mananciais atualmente utilizados. Assim pois, verifica-se a necessidade urgente de investir em estudos e pesquisas básicas e aplicadas relacionadas à proteção ambiental (BEYRUTH, 1996) .

Indiscutivelmente, a qualidade da água dessas bacias hidrográficas reflete os usos e a ocupação desordenada do solo, de modo que os corpos d'água em geral, por não possuírem grandes dimensões em relação ao 
recebimento da carga poluente, passam a suportar uma sobrecarga constante, apresentando alterações nas condições ecológicas e sanitárias (ROCHA, 1993).

Neste sentido, os estudos ecológicosanitários identificando as fontes poluidoras são de grande valia na caracterização de coleções $\mathrm{d}^{\prime}$ água, no intuito de avaliar sua qualidade quando estas são utilizadas para abastecimento.

Assim, no controle ambiental, em primeiro lugar deve ser considerado, o uso para o abastecimento de água que é feito por meio da exploração de mananciais localizados em torno da RMSP. Essas águas utilizadas para suprir a população são reservadas em represas, que apresentam situações diferentes de preservação e conservação da qualidade. ocorrem desde sistemas oligotróficos até outros em diversos graus de eutrofização e com múltiplas fontes de poluição e contaminação nas respectivas bacias.

A bacia hidrográfica do Guarapiranga, constitui um exemplo das considerações anteriores, não só por ser responsável pelo sistema de abastecimento de significativa parcela da população da RMSP, mas também por receber efluentes domésticos como resultado da desordenada ocupação da bacia que também é em parte afetada por resíduos industriais, além de estar sendo degradada pela disposição de resíduos sólidos (lixo) às margens e no próprio manancial (CETESB, 1995).

A represa do Guarapiranga está perdendo a função original como reservatório, em decorrência do assoreamento, pois apesar da existência da Lei de Proteção de Mananciais, a qualidade da água vem sofrendo, como comentado, forte deterioração. Isto porque a população residente e/ou flutuante distribuí-se além dos 
clubes, em residências e favelas, e de acordo com dados do CENSO de 1980 já atingia 30.388 habitantes, apenas na região do entorno do reservatório.

Este fato tem gerado inúmeras medidas corretivas principalmente relacionadas à fiscalização conforme esclarecimentos pessoais do Dr. Antônio Eduardo Giasanti da SABESP.

Portanto, um programa destinado ao controle e adoção de medidas preventivas e corretivas nesses sistemas pode e deve envolver a análise de uma série de parâmetros físicos-químicos e biológicos.

Dentre esses, a identificação e estudo das correlações dos macroinvertebrados bentônicos (organismos de fundo), com a dinâmica da poluição, constitui um importante instrumento para a avaliação da qualidade ecológico-sanitária dos ambientes aquáticos (BEYRUTH, 1989) .

WILHM (1975) também relata que a avaliação da poluição deve ser centralizada em parâmetros biológicos. Esta afirmação está fundamentada no fato de que alterações ambientais acarretam mudanças detectáveis no sistema biológico (WILHM \& DORRIS apud SHIMIZU, 1978), pois os diferentes organismos não estão igualmente bem adaptados a viver num ambiente poluído (HAMILTON \& SAETHER, 1971).

Os macroinvertebrados bentônicos são aceitos como um dos grupos de organismos mais favoráveis ao monitoramento biológico em ecossistemas aquáticos por apresentarem algumas vantagens ecológicas (ROSENBERG \& RESH, 1993) descritas a seguir: (1) podem existir em diferentes tipos de sistemas e em diversos habitats dentro dos sistemas; (2) apresentar uma natureza sedentária, permitindo a análise espacial do efeito da 
perturbação; (3) possuir ciclo de vida relativamente longo, possibilitando analisar as variações temporais e, consequentemente, avaliar os distúrbios ambientais; (4) exercer papel importante no processamento da matéria orgânica de corpos d' água, acelerando a decomposição, promovendo assim a reciclagem de nutrientes e a transferência de energia aos níveis tróficos superiores, sendo um elo fundamental na cadeia decompositora dos detritos (KUHLMANN, 1993); (5) participar da reciclagem de nutrientes principalmente de fósforo e nitrogênio inorgânicos, através do biorrevolvimento do substrato e de suas atividades metabólicas de excreção.

Entretanto, como enfatiza ODUM (1983), poucos estudos haviam sido realizados até o final da década dos anos $7 \odot$ do século XX. ODUM op. cit. relata que "Anos atrás, sugeriu-se que os animais invertebrados traziam benefícios nas instalações de tratamento de esgoto (HANKES, 1963), porque, presumivelmente, ajudam a quebrar o material do substrato e a acelerar a ação bacteriana. Mas foram feitos poucos estudos porque os engenheiros consideravam, geralmente que as "minhocas" e outros bichos eram um incômodo, imaginando que a ação bacteriana era a única coisa importante".

Posteriormente inúmeras observações, estudos e pesquisas viriam demonstrar que organismos fagótrofos realmente tem participação na decomposição dos esgotos como por exemplo, WELLS et al (1957) verificou que um verme de $0,5 \mathrm{~cm}$ de espessura, aumenta de 0,2 a 1,2 $\mathrm{g} / \mathrm{m}^{2} /$ hora o material reciclado, o que significa grande e positiva influência na possibilidade de metabolização do material sedimentado, bem como a introdução por difusão do ar contendo oxigênio dissolvido.

Nos programas de monitoramento com emprego de parâmetros biológicos, para avaliação qualitativa e 
quantitativa das condições ecológicas-sanitárias das águas de qualquer ecossistema lêntico e lótico, a atenção com a fauna bêntica, em especial os macroinvertebrados está tendo, portanto, ampla difusão nos vários continentes.

Desta forma, o estudo da macrofauna bentônica juntamente com os parâmetros físicos e químicos, possibilita um melhor entendimento dos efeitos das variações ambientais.

\subsection{Características da área de estudo}

A represa do Guarapiranga, situada a $23^{\circ}$ $43^{\prime} \mathrm{S}$ e $46^{\circ} 32^{\prime} \mathrm{W}$, até os anos 40 deste século conhecida como Lago de Santo Amaro, teve sua construção autorizada pela Lei Estadual no 1061-B, de 28 de dezembro de 1906, sancionada pelo Dr. Jorge Tibiriçá (SAVELLI, 1964).

A bacia do Guarapiranga, sub-bacia do Alto Tietê, localiza-se na Região Metropolitana de São Paulo (23.315,75 ha correspondendo a $36,60 \%$ da área total da bacia), Embu-Guaçu (15.451,26 ha, 24,26\% da bacia) e Itapecirica da Serra (14.471,89 ha, 22,72\% da bacia), abrangendo ainda os municípios de: Embu (3.995,50 ha, $6,27 \%)$; São Lourenço $(3.317,49,5,21 \%)$; Cotia $(2.347,37$ ha, 3,69\%); Juquitiba $(739,27$ ha, 1,16\%); Itanhaém $(59,3 \odot, \odot, 09 \%)$ e São Vicente $(\odot, 38$ ha, $\odot, \odot \odot \%)$ (MELCHOR et al, 1974).

A topografia na área de drenagem é fortemente acidentada, principalmente a oeste onde os pontos mais elevados situam-se à aproximadamente $930 \mathrm{~m}$ e os baixos a $700 \mathrm{~m}$. o vale principal é de natureza fechada, caracterizando um reservatório de forma alongada. A leste e sul o relevo é marcado por algumas 
planícies que margeiam a represa, assentadas sobre terrenos plenos de micaxistos e gnaisses de funções cambrianas (MELCHOR et al, 1974).

A drenagem é dendrítica, padrão típico, desenvolvido sobre rochas de resistência uniforme ou em estruturas sedimentares horizontais. Esse modelo de represa de morfologia dendrítica, estreita e alongada, formada na base de bacia de drenagem e vale de rios, segundo WETZEL (1990) concorre para magnificar os usos e ocupação do solo, favorecendo à ação antrópica; fato que por sinal no caso da represa do Guarapiranga vem ocorrendo desde a implantação desse reservatório ao início do século.

Inaugurada em 1912, represando águas dos rios Guarapiranga e outros afluentes, destacando-se o Lavras, Santa Rita, Embu-Guaçu, Embu-Mirim e, cerca de 17 cursos $\mathrm{d}^{\prime}$ água de menor caudal, como o ribeirão Itaim. 0 reservatório teve inicialmente como finalidade precípua a função de regularizar a vazão do rio Tietê, de modo a garantir o pleno funcionamento da antiga usina hidroelétrica de Santana de Parnaíba.

Entretanto, o Lago de Santo Amaro, na ainda provinciana cidade de São Paulo, compondo uma nova paisagem, em local de clima ameno (Umidade Relativa do Ar média de 83\%, Temperatura média do $\operatorname{Ar} 17,8^{\circ} \mathrm{C}$ sendo a média máxima diária $24,3^{\circ} \mathrm{C}$ e média mínima diária $17,8^{\circ}$ $c$, em geral com predominância de ventos brandos de sudoeste) servindo como área de lazer, passou a atrair a população, principalmente àquele tempo das classes mais abastadas, transformando-o em permanente local de recreação de contatos primário e secundário. Inúmeros clubes e restaurantes instalaram-se às suas margens; no que foram acompanhados de rápida especulação imobiliária. 
A desordenada ocupação na orla da represa, já nos anos 30 preocupava as autoridades induzindo a que a então Sub-Prefeitura de Santo Amaro, baixasse os Atos $\mathrm{n}^{\circ}$ 7, de 10 de agosto de 1932 e, $\mathrm{n}^{\circ}$ 14, de 02 de janeiro de 1934, proibindo a criação de suínos dentro de um perímetro de $3 \mathrm{~km}$ a partir de quaisquer das margens e instituindo a obrigatoriedade do uso de fossas sépticas nas residências (PARANHOS, 1937).

Mais recentemente os registros estatísticos indicam que, desde 1988, 9,9\% da área da bacia do Guarapiranga está ocupada pela população urbana e, os dados demográficos da COBRAPE (1991) possibilitam estimar uma população de 577.000 habitantes em toda bacia, mas agora na sua maior parcela pertencente aos estratos mais carentes da sociedade. Esse enorme contingente de seres humanos aglomera-se nas favelas e bairros pobres, muitos dos quais assentados em loteamentos clandestinos, destituídos das mínimas condições de infra-estrutura sanitária, lançando dejetos e esgotos sanitários diretamente nos corpos d' água formadores ou no próprio corpo central da represa e, dispondo os resíduos sólidos na orla do manancial, atitude esta que é acompanhada por outras disposições clandestinas de empresas e moradores de bairros distantes da região.

A bacia do Guarapiranga, com área total de 636, 98 km², entre 1989 e 1996, sofreu crescimento urbano da ordem de $50 \%$ e, mais de $65 \%$ da ocupação registrada nos sete municípios da bacia é passível de restrições; encostas íngremes, regiões de aluvião, de várzea etc. Apenas $7,7 \%$ da mancha urbana se deu em área favorável ( COHEN, 1996).

Os índices de urbanização passaram de 10,36\% do total da bacia, em 1986, para 15,83\% em 1996. 
No topo das ocorrências irregulares estão os movimentos de terra, como abertura de estradas e terraplanagem, correspondendo a $21 \%$ dos 1497 registros efetuados no período de 1989 a 1996. Em segundo lugar (17,3\%) aparecem os casos de invasão e loteamentos irregulares seguidos dos desmatamentos (15\%) e distribuição irregular de lixo $(12,5 \%)$ numa listagem de 12 tipos de ocorrência (COHEN, 1996).

Mas ao lado desses problemas BEYRUTH, 1994 relata os efeitos provocados pela atividade de extração mineral na bacia e dos desmatamentos levando à intensos processos de erosão do solo e ao conseqüente assoreamento do reservatório, fazendo diminuir quantitativa e qualitativamente a fauna íctica.

0 acelerado crescimento populacional decorrente da industrialização na capital paulista, provocaria também, ao longo dos anos, constantes demandas por disponibilidades cada vez mais acentuadas de recursos hídricos para abastecimento público, obrigando quase compulsoriamente à captação e uso das águas da represa do Guarapiranga. 0 imenso reservatório (área inundada atingindo $33,918 \mathrm{~km}^{2}$, perímetro de $85 \mathrm{~km}$, profundidade média 6 m, máxima de 13 a $15 \mathrm{~m}$ ) passou então, já em 1926 a ser utilizado como manancial de água para abastecimento público, inicialmente retirando-se volume de $1 \mathrm{~m}^{3} / \mathrm{s}$, vazão essa subseqüentemente elevada para $9,5 \mathrm{~m}^{3} / \mathrm{s}$, na década de $6 \odot$ (PEDROSO, 1960) e $10,2 \mathrm{~m}^{3} / \mathrm{s}$, na década de $7 \odot$ (SALVADOR $\mathrm{F}^{\circ}$ et $\mathrm{al}, 1972$ ).

Porém, não tendo sido os projetos para abastecimento de água, ao devido tempo contemplados em paralelo com efetivos programas de manutenção ou recuperação das redes de distribuição, de controle de perdas e de preservação de mananciais, cada vez mais crescente foi se tornando a demanda. Vários estudos foram 
conduzidos no sentido de compensar as retiradas efetuadas no Guarapiranga. Dentre outros idealizou-se a reversão dos rios São Lourenço, Mandú e Alto Juquiá (OLIVEIRA, 1961; CASTRO, 1963). Nos anos 80, após receber contribuição adicional de $500 \mathrm{~L} / \mathrm{s}$, por bombeamento de águas do Alto Capivari, a represa do Guarapiranga passou a fornecer 10,6 $\mathrm{m}^{3} / \mathrm{s}$ (SILVA et al, 1986) e, na década de $90,13,79 \mathrm{~m}^{3} / \mathrm{s}$ (MANCUSO, 1992) sendo responsável por atender à demanda hídrica de uma significativa parcela da população da Região Metropolitana de São Paulo, suprindo 21 bairros das cidades de São Paulo, Taboão da Serra e Carapicuiba, perfazendo cerca de 3,5 milhões de habitantes.

o reservatório do Guarapiranga, ao lado das funções já especificadas, por volta dos anos 70, passou também a atender ao programa de controle de enchentes (HELOU et al, 1987).

Quanto à macrofauna bentônica, como indicadora de poluição no Brasil, segundo ROCHA (1997) as informações bibliográficas existentes até cerca de 20 anos atrás eram restritas a estudos de taxonomia de certos grupos de organismos, efetuados em institutos de pesquisa, universidades etc.

Entretanto, como menciona esse mesmo autor, a partir da década de 70, vários pesquisadores passaram a ter o interesse despertado para a importância dos organismos bentônicos como possível instrumento na avaliação da qualidade ambiental, permitindo um melhor conhecimento da biologia e entendimento do comportamento e distribuição das espécies no meio.

A partir de então, outros trabalhos foram realizados, destinados à avaliação limnológico-sanitária, utilizando especificamente as determinações qualitativas 
e quantitativas dos organismos bentônicos. Várias represas foram estudadas, como as da Cia Energética de São Paulo - CESP (dados infelizmente não divulgados), os lagos dos Parques Municipais da Prefeitura de São Paulo e outros.

Muitos dados foram obtidos durante o mesmo período desta pesquisa quando se trabalhou na Aplicação de um Sistema de Informações Geográficas (SIG) no projeto financiado pela Fundação de Amparo à Pesquisa do Estado de São Paulo - FAPESP. Nessa oportunidade foi possível além do bentos fazer determinações do fitoplâncton e zooplâncton, bem como parâmetros físicos e químicos. 


\section{OBJETIVOS}

Em vista das considerações antes efetuadas objetivou-se com este estudo:

a) realizar um levantamento qualitativo e quantitativo dos macroinvertebrados bentônicos da Represa do Guarapiranga；

b) conhecer as possíveis relações destes com os parâmetros físicos e químicos das águas analisadas;

c) discutir a importância desses organismos como indicadores de poluição da água. 


\section{REVISÃO DA LITERATURA}

Dada a importância da Represa do Guarapiranga para o contexto da Região Metropolitana de São Paulo(RMSP), vários técnicos e pesquisadores procuraram estudar e analisar não só a qualidade das águas reservadas, mas também proceder a uma abordagem global verificando as condições de ocupação do entorno, enfim da área de abrangência da bacia de drenagem.

Como manancial de abastecimento, os estudos de (THOMPSON, 1940; AMARANTE et al, 1958; QUEIROZ, 1964; PONTES, 1965; CASTRO, 1965; BORBA JR. et al, 1968) foram alguns dos quais pioneiramente enfatizaram o seu potencial hidráulico e a necessidade de preservação como recurso hídrico. Todavia, os primeiros dados físico-químicos relativos à qualidade sanitária publicados em revista especializada datam de 1934, quando CUNHA determinou junto à captação de água, o teor de gases dissolvidos (CUNHA, 1936).

$\mathrm{Na}$ mesma ocasião, WRIGHT (1936) estudou sumariamente as condições físicas e químicas do manancial, concluindo que o lago não apresentava estratificação térmica, de vez que o vento atuava provocando a homogeneização da água. Havia uma mistura anual, podendo considerar-se o lago como polimítico.

Além da ação dos ventos, a mistura decorre das correntes internas dos canais dos rios formadores e ainda é influenciada pelos efeitos das atividades náuticas bastante difundidas na represa (BRANCO \& ROCHA, 1977).

Em outra observação, WRIGHT registrou a presença de alguns gêneros de microcrustáceos 
copépodos calanóides na represa, o que indicou à época uma satisfatória diversidade.

No ano seguinte, KLEEREKOPER verificou a composição fitoplanctônica da represa ressaltando que as algas apareciam distribuídas em equilíbrio, não causando problemas sanitários ou ecológicos, embora tivesse registrado intenso desenvolvimento de algas cianofíceas e de microcrustáceos em uma das estações de coleta (KLEEREKOPER, 1937). Esse mesmo pesquisador estudaria acuradamente a represa, não só como recurso ao abastecimento, mas sobretudo como ecossistema que alberga fauna e flora aquáticas. Assim pois, procedeu a estudo limnológico bastante completo, analisando indicadores físicos-químicos, bacteriológicos e hidrobiológicos, compreendendo o fitoplâncton, zooplâncton e os macroinvertebrados bentônicos (KLEEREKOPER, 1939). Outros dados complementares foram publicados em 1944 (KLEEREKOPER, 1944).

Ao final dos anos 50 e começo de 60, como parte de um levantamento efetuado nos mananciais da Grande São Paulo, as algas da represa seriam estudadas (PALMER, 1960). Alertava-se então sobre o lançamento de resíduos sanitários que escoavam-se para o manancial e o conseqüente acúmulo de nutrientes minerais. Preconizavase como medida de segurança que a bacia fosse transformada em Reserva Florestal (PEDROSO, 1960).

Nos anos posteriores, CUNHA

(1955)

apresentou novos resultados de análises físicas e químicas e, como os problemas de poluição começassem a intensificar-se, cinco anos após, a 12 de março, foi instituída uma comissão para proteger a bacia do Guarapiranga (OLIVEIRA, 1961). 
Decorreram dez anos, quando ROCHA (1970) efetivamente verificou as conseqüências prejudiciais à qualidade da água em decorrência do crescente processo de eutrofização. A partir do ano seguinte a Companhia de Tecnologia de Saneamento Ambiental (CETESB), atendendo a convênio firmado com a Companhia de Saneamento Básico do Estado de São Paulo (SABESP) iniciou trabalho de monitoramento sistemático da represa, com amostragens físicas e químicas, bacteriológicas e hidrobiológicas (CETESB, 1972). A esse tempo BRANCO (1973) apresentou trabalho à SABESP, propondo medidas de proteção do manancial do Guarapiranga.

Os aspectos limnológicos e sanitários e a macrofauna bentônica da represa do Guarapiranga seriam exaustivamente estudados por ROCHA (1976) que, dentre outras observações verificou que:

a) por meio da aplicação de índices de diversidade houve indicação de que a macrofauna bentônica estava sendo afetada pela poluição e contaminação das águas e do lodo; b) o gradativo aumento dos elementos minerais nutrientes denunciava o incremento do processo de eutrofização;

c) os metais pesados e agrotóxicos analisados, dado ao caráter cumulativo, representavam risco potencial aos organismos aquáticos e à saúde pública e,

d) embora as algas predominantes na represa, segundo 0 sistema indicador de Palmer, não fossem indicadoras de poluição orgânica, havia considerável número de gêneros que sugeriam a presença de resíduos sanitários.

Durante o ano de 1979, a Fundação de Amparo à Pesquisa do Estado de São Paulo (FAPESP), apoiou pesquisa limnológica comparando 52 reservatórios do Estado de São Paulo, sendo a represa do Guarapiranga contemplada (TUNDISI, 1981). Desse mesmo projeto vários 
estudos mereceram publicação: SENDACZ \& KUBO (1982) procedendo a estudo de microcrustáceos copepodos da represa; ARCIFA (1984) discutindo a distribuição dos organismos zooplanctônicos; MATSUMURA-TUNDISI (1984) analisando a ocorrência do gênero Daphnia sp; SENDACZ et al (1985) avaliando a comunidade zooplanctônica; ESTEVES \& SENDACZ (1988) discorrendo sobre as relações dos valores médios de biomassa anual de cada grupo da comunidade zooplanctônica, e o índice de Estado Trófico de Carlson (IET) baseado nos valores médios anuais de clorofila-a.

As algas da represa e os episódios de massivas florações tem motivado inúmeros estudos e pesquisas visando o controle e a manutenção da qualidade da água para abastecimento. Assim, XAVIER et al (1985) e PEREIRA (1987) dedicaram-se à determinação dos gêneros e espécies de maior significado sanitário no manancial.

Para se ter uma idéia de como a degradação do manancial está afetando não só ao usuário e morador da região, mas praticamente toda a sociedade paulistana, basta recorrer a algumas cifras fornecidas pelas próprias autoridades constituídas. Observa-se por esses dados que o problema extrapola os limites da qualidade sanitária da água, da saúde pública e enfim do estrito âmbito ambiental para transformar-se também em óbice econômico.

Em 1990 houve um surto de gastroenterite que foi associado à presença da alga Anabaena solitaria (CETESB, 1992). Todavia, os constantes transtornos ao tratamento das águas do Guarapiranga ocasionados pela presença das algas já vinham ocorrendo desde o final dos anos 70, tornando-se recorrentes a partir de 1992, exigindo uma crescente aplicação de sulfato de cobre para o controle algáceo. Houve mesmo, um incremento em progressão geométrica; 1,5 ton em 1981; 123, ๑ ton em 1982 
e 63, 0 ton em 1983 (CETESB, 1983). Em agosto de 1993, para o controle de algas cianofíceas a SABESP passa a utilizar também peróxido de hidrogênio, mas em 1994 acontece nova floração.

Assim, a par dos problemas antes mencionados, há no entanto, que se considerar os custos dessas operações. Na década de 80 gastava-se 1 milhão de dólares com produtos químicos destinados ao combate das algas (CALEFFI, 1994). Contudo, em 1996 foram consumidos 8,4 milhões de dólares com esses mesmos produtos, o que corresponde a $25 \%$ do custo total de produtos químicos aplicados na potabilização da água.

A agravante situação na represa obrigou à adoção de medidas preventivas de maior alcance e profundidade visando o controle ambiental. Desde 1991 e até presentemente há o Programa de Saneamento Ambiental da Bacia do Guarapiranga, que é financiado pelo Banco Mundial e Governo do Estado de São Paulo. Este é executado e operacionalizado por meio das empresas e institutos estaduais intervindo com ações específicas e produção de inúmeros relatórios (COBRAPE, 1994 a: COBRAPE, 1994 b).

Trabalho importante, mas baseado em apenas duas campanhas de amostragem em 10 pontos de coleta, procurou evidenciar alterações nas características físicas, químicas e biológicas e a heterogeneidade espacial do ecossistema aquático, concluindo pela existência de um gradiente trófico que se estende da barragem em direção às cabeceiras do reservatório (DOMINGOS, 1993).

CALEFFI (1994), trabalhando junto ao Departamento de Saúde Ambiental da Faculdade de Saúde Pública da USP, apresentou os resultados de uma 
pormenorizada pesquisa baseada em levantamento contínuo, abrangendo período sazonal completo, dissertando sobre a comunidade zooplanctônica relacionada ao processo evolutivo da eutrofização e registrando de maneira inédita a presença de certas espécies indicadoras de poluição.

Mais recentemente, ainda na Faculdade de Saúde Pública - Departamento de Saúde Ambiental - USP, BEYRUTH (1996) apresentou tese de doutorado na qual à saciedade discutiu e analisou o comportamento da comunidade fitoplanctônica da represa do Guarapiranga entre os anos 1991-92, concluindo que a represa apresenta uma alta capacidade de depuração, devido ao elevado potencial oxidativo, favorecido por uma alta taxa de renovação e pela mistura das águas promovida pelos ventos, ondas, correntes e atividades náuticas.

0 estudo da comunidade fitoplanctônica permitiu demonstrar os efeitos da eutrofização, através da acentuada produção em densidade e biomassa totais; como também possibilita considerar a represa um ambiente de alta transferência de matéria e energia por receber grandes aportes de nutrientes, apresentar uma produtividade biológica elevada e por perder rapidamente grande parte não só de seu volume d' água, e incluindo a biomassa planctônica (devido ao baixo tempo de retenção) exportando esse conteúdo para outros ecossistemas. Esses fatores caracterizam um ambiente bastante instável, adaptável e favorável ao desenvolvimento de espécies oportunistas.

Diante do exposto, e também em função de uma maior mobilização da sociedade, houve o estabelecimento de projetos e programas de amplo espectro no sentido de minimizar e recuperar a região e em especial o manancial em questão. Destacam-se o "Projeto 
Ecoscambio", idealizado durante a Eco-92, uma cooperação entre ONGs brasileiras e italianas, para estudar cinco áreas do território nacional incluindo a bacia do Guarapiranga e, o Programa de Saneamento Ambiental do Guarapiranga, como parte das ações do Governo do Estado de São Paulo para a recuperação deste importante manancial contando com auxílio do Banco Mundial. Embora o convênio/contrato tenha sido firmado em 1992, prevendo um investimento de R\$ 262 milhões de reais na bacia, dos quais $R \$ 119$ milhões obtidos junto àquele Banco; até 1994 apenas R\$ 3 milhões haviam sido gastos. Somente a partir de 1995 o Programa foi retomado.

No "Projeto Ecoscambio" efetivamente, até novembro de 1996, para o Dignóstico Guarapiranga haviam sido liberados US\$35.000,00, participando do mesmo as seguintes instituições: Fundação sos Mata Atlântica; Instituto Vitae Civilis; Espaço-Formação, Assessoria e Documentação; CESMA; Sociedade dos Amigos do Santo Eduardo; Sociedade Ecológica Amigos do Embu; SOS Mananciais Guarapiranga e Sos Represa Guarapiranga.

A primeira fase desse Projeto foi concluída com a apresentação do trabalho intitulado "Diagnóstico Socioambiental Participativo Preliminar da Bacia Hidrográfica do Guarapiranga" indicando que entre 1989 e 1996 a área de vegetação densa (Mata Atlântica, matas e florestas naturais ou secundárias) que correspondiam a $33,51 \%$ da bacia diminuíram para 25,43\%, isto é, cerca de 10\% (MANTOVANI, 1996).

Para a execução da nova fase do Programa de Saneamento Ambiental da Bacia do Guarapiranga foi criada uma Unidade de Gerenciamento do Projeto, a cargo da Secretaria de Recursos Hídricos, Saneamento e obras. As ações de saneamento e recuperação urbana vem sendo executadas pela SABESP, CDHU e PMSP (SMA, 1996). À 
Secretaria do Meio Ambiente cabe a execução dos seguintes projetos e obras:

1 - Repovoamento Vegetal das Margens dos Corpos d' Água da Bacia do Guarapiranga;

2 - Projeto de Repovoamento Vegetal das Faixas de Domínio do DNER e FEPASA;

3 - Diagnose da Vegetação e Modelos para Recomposição;

4 - Projeto de Arborização Urbana;

5 - Parque Ecológico do Guarapiranga;

6 - Parque dos Eucaliptos;

7 - Parque Várzea do Embu-Guaçu;

8 - Recuperação de Áreas Degradadas pela Mineração Giosa Município de Embu;

9 - Programação Visual para o Sistema de Parques do Guarapiranga;

10 - Implantação do Parque Ecológico da Represinha Município de Itapecirica da Serra;

11 - Incentivo ao Turismo em Itapecirica da Serra Parque Temático;

12 - Programa de Revitalização do Centro Histórico e Turístico do Embu;

13 - Pesca e Aquicultura;

14 - Adequação e Controle da Mineração na Bacia do Guarapiranga;

15 - Diagnóstico Limnológico e Ecológico do Reservatório Guarapiranga;

16 - Avaliação da poluição por Fontes Difusas Afluentes ao Reservatório Guarapiranga;

17 - Educação Sanitária e Ambiental; 
18 - Recadastramento de Fontes de Poluição Industrial;

19 - Plano Modelo de Fiscalização para a Bacia do Guarapiranga；

20 - Apoio à Fiscalização da Bacia do Reservatório do Guarapiranga .

Em face do exposto fica clara a necessidade da realização de estudos e pesquisas que possam subsidiar as ações de controles preventivo e corretivo atualmente conduzidas no sentido de minimizar impactos e poluição e preservar o ecossistema hídrico Guarapiranga .

Dentre os vários programas e projetos, ora em andamento, é importante salientar que se deve conhecer acuradamente a atual estrutura da comunidade de macroinvertebrados bentônicos. Por sinal mereceu uma última apreciação há mais de 20 anos quando foi estudada por ROCHA (1976). Portanto, no período que separa essas duas décadas inúmeras e apreciáveis foram as mudanças ocorridas nas condições ambientais do entorno e na qualidade sanitária na água da própria represa, tornando interessante, verificar as alterações ocorridas na fauna de invertebrados.

Quanto aos macroinvertebrados bentônicos como indicadores de poluição procede-se uma discussão aprofundada no item 6.3.5. 


\section{MATERIAL E MÉTODOS}

0 trabalho de campo iniciou-se em 14/03/96, tendo sido finalizado em 18/02/97, perfazendo o total de dados 12 coletas mensais (datas e horários das coletas são apresentados na Tabela 51 no Anexo I. Coletaram-se amostras, em dez (10) pontos de amostragem descritas a seguir:

Ponto 01 - à jusante da desembocadura do Rio Embu-Guaçu;

Ponto 02 - na desembocadura do Córrego Fundo;

Ponto 03 - em frente ao Clube de Campo Palmeiras;

Ponto 04 - na desembocadura do Ribeirão Itaim e Córrego Barro Branco;

Ponto 05 - imediatamente a jusante da desembocadura do braço do Rio Embu-Mirim;

Ponto 06 - na porção central da represa em linha reta com a desembocadura do Córrego São José;

Ponto 07 - à jusante da desembocadura do Córrego Rio das Pedras; em frente ao Clube de Campo Castelo;

Ponto 08 - em frente ao Batalhão do Corpo de Bombeiros;

Ponto 09 - próximo da desembocadura do Córrego Itupu, em frente ao Clube Naútico Paulista;

Ponto 10 - junto à captação de água da SABESP, próximo à barragem.

os pontos de coleta estão representados no mapa a seguir. 


\section{REPRESA DO GUARAPIRANGA}

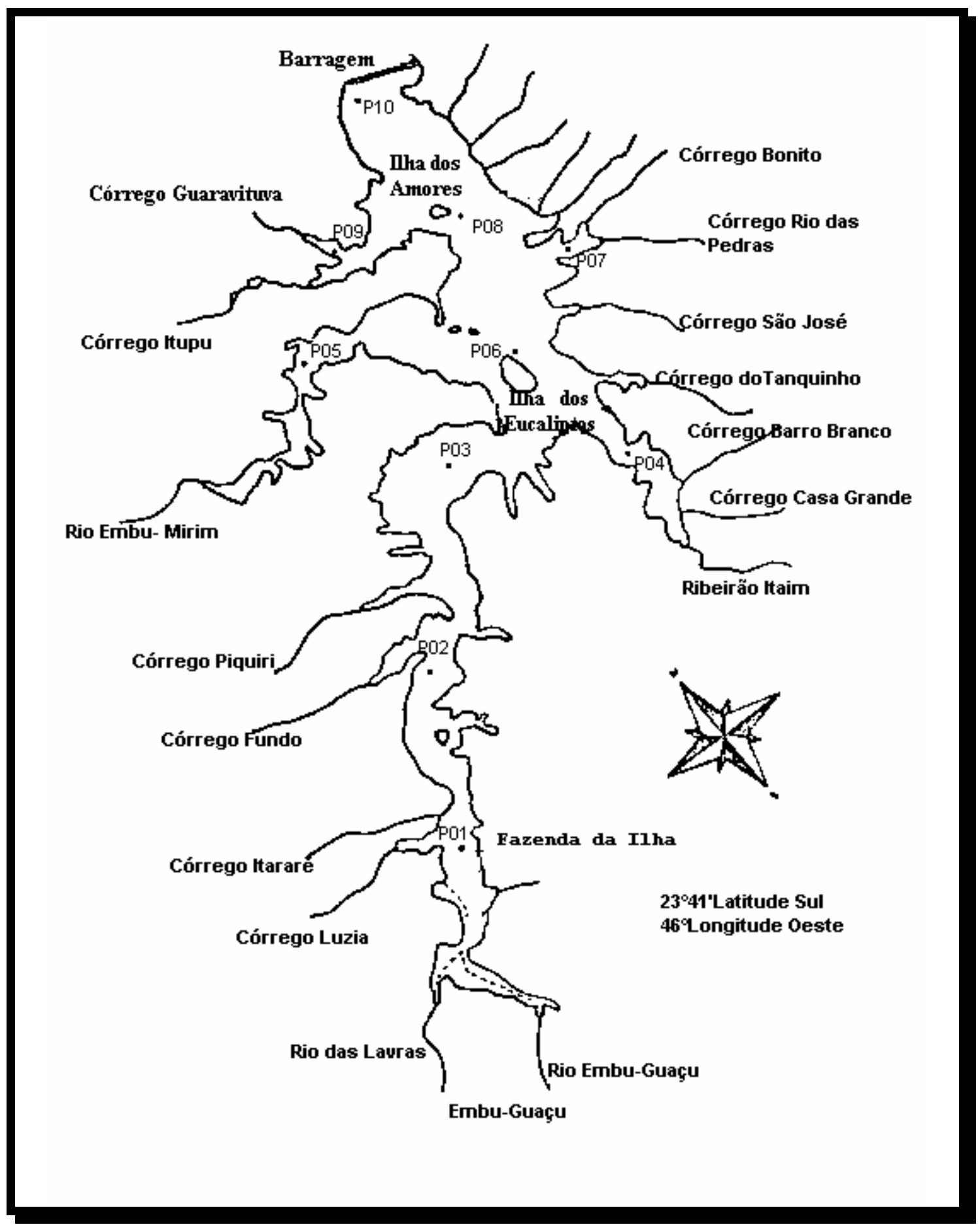


As análises físico-químicas e biológicas foram realizados no laboratório de Qualidade da Água do Departamento de Saúde Ambiental da Faculdade de Saúde Pública da USP. 


\subsection{Variáveis abióticas}

Para determinação dos dados físicos e químicos foram obtidas amostras colhidas abrangendo os seguintes parâmetros: pluviosidade $(\mathrm{mm})$, temperatura do ar $\left({ }^{\circ} \mathrm{C}\right)$, profundidade $(\mathrm{m})$, transparência $(\mathrm{m})$. Foram tomadas à superfície da água, à meia profundidade e fundo: temperatura da água $\left({ }^{\circ} \mathrm{C}\right)$, cor (mg/LPt), turbidez (UNT), $\mathrm{pH}$, condutividade elétrica $(\mu \mathrm{S} / \mathrm{cm})$, oxigênio dissolvido $(\mathrm{mg} / \mathrm{L})$, demanda bioquímica de oxigênio ( $\mathrm{mg} / \mathrm{L})$.

Dadas as dificuldades encontradas em laboratório, as análises de nitrogênio e fósforo foram realizadas, apenas com amostras de água de superfície nos meses de maio/96 a dez/96.

Para as coletas de água à meia profundidade e fundo utilizou-se uma garrafa de Van Dorn, com capacidade de 2 litros.

Dados obtidos no campo durante as coletas:

Temperaturas do ar e água na sombra, utilizando termômetro de mercúrio graduado em décimo de grau centígrado $\left({ }^{\circ} \mathrm{C}\right)$;

Transparência ao Disco de Secchi, utilizando disco de 25 $\mathrm{cm}$ de diâmetro (m);

Profundidade da coluna d'água com cordas de poliuretano com marcação a cada $\odot, 5 \mathrm{~m}$.

Para análise de oxigênio dissolvido e demanda bioquímica de oxigênio, as amostras foram coletadas em frascos aferidos com tampa chanfrada; as amostras para determinação das concentrações de oxigênio dissolvido iniciais foram preservadas no campo, levadas ao laboratório e analisadas imediatamente. As amostras para as determinação das concentrações de oxigênio 
dissolvido finais, foram levadas para o laboratório e mantidas em incubadora e após 5 dias analisadas. Para a determinação da concentração de oxigênio dissolvido utilizou-se o método de Winkler modificado pela azida sódica;

- Nitrogênio total Kjeldahl por digestão química, destilação de amônia e titulação de amônia destilada com ácido sulfúrico. (APHA; AWWA, WPCF, 1993);

- Fósforo total por digestão química e colorimetria com reagente combinado (método do ácido ascórbico) (APHA; AWWA, WPCF, 1993).

As amostras destinadas às demais análises foram transportadas em frascos de polietileno previamente lavados com ácido clorídrico e enxaguados com água destilada. Foram determinados:

- Cor com comparador Hellige Acqua Tester, provido de disco de cloro platinato de potássio e cloreto de cobalto (mg/L Pt);

- Turbidez com turbidímetro HACH-modelo 2100A (UNT);

- pH com medidor DMPH-2-DIMIMED;

- Condutividade elétrica com condutivímetro Metrohn AGCH $(\mu \mathrm{S} / \mathrm{cm})$;

\subsection{Coliformes totais e fecais}

Para cada amostra de água coletada, o Número Mais Provável (NMP/100 mL) de bactérias coliformes totais e fecais foi determinado através da técnica de tubos múltiplos descrita no APHA;AWWA, WPCF, 1993. 


\subsection{Comunidade Bentônica}

As amostras da macrofauna bentônica foram obtidas com auxílio de um pegador tipo Eckman-Birge, de área padrão de $0,0225 \mathrm{~m}^{2}$. Em decorrência da quebra e/ou perda, deste aparelho no campo, não foram obtidas amostras do bentos, em março/96 (Ponto 04); abril/96 (Ponto 08); dezembro/96 (Ponto 05); como também houve impossibilidade de coleta no mês de janeiro de 1997 nos pontos 08,09 e 10, devido às chuvas intermitentes.

Em cada estação de amostragem foram realizadas três (3) pegadas; sendo os sedimentos recolhidos, fixados em campo (solução de formalina neutralizada a 4\%) e, acondicionados em sacos plásticos devidamente etiquetados.

No laboratório, as amostras foram lavadas com água corrente, passando em rede de malha de abertura $250 \mathrm{\mu m}$ e colocadas em frascos de polietileno com capacidade de $500 \mathrm{ml}$.

Após a lavagem, as amostras foram triadas sob lupa em aumento de 50 vezes, tendo sido os animais contados e identificados quando possível ao nível taxonômico de sub-família.

\subsection{Tratamento dos dados}

\subsubsection{Parâmetros físicos e químicos}

os dados referentes aos parâmetros físicos e químicos da água na Represa do Guarapiranga são apresentados em tabelas e analisados quanto à variação espacial/temporal, pois são importantes para 0 
conhecimento do funcionamento do reservatório, além de fornecer subsídios às investigações relacionadas à fauna bêntica.

\subsubsection{Coliformes totais e fecais}

Os dados referentes as bactérias coliformes foram utilizados para caracterizar a poluição de origem doméstica e auxiliar na discussão sobre a disponibilidade de material nutritivo para a macrofauna bêntica .

\subsubsection{Comunidade Bentônica}

Com base nos dados da comunidade bentônica obtidos calculou-se: a densidade de cada grupo de organismos (d), densidade total dos organismos (D), abundância relativa (\%), número de taxa (riqueza-S), índice de diversidade $\left(H^{\prime}\right)$, eqüitatividade $(e)$, teste de correlação não paramétrico de spearman e nível do agrupamento (dendrograma), conforme descrito a seguir:

Para o cálculo da densidade (d) utilizouse o número de organismos por metro quadrado.

A densidade total (D) é dada pela soma das densidades (d) de cada táxon identificado, por amostra.

A abundância relativa corresponde à porcentagem de indivíduos pertencentes a um grupo taxonômico em relação ao número total de organismos na amostra. Para discussão dos dados referentes à abundância relativa, adotou-se a nomenclatura apresentada por Mc 
CULLOUGH \& JACSON (1985) apud BRANDIMARTE (1991) na qual os grupos com a abundância entre 50-100\% são considerados dominantes; entre 30-49\%, abundantes; entre 10-29\%, comuns; entre 1-9\%, ocasionais e < 1\%, raros.

Calculou-se a riqueza (S) das amostras pela somatória dos táxon presentes.

0 índice de diversidade muito útil quando se quer analisar e comparar dados da comunidade bentônica de lagos e reservatórios, foi calculado para cada amostra por meio do Índice de Shannon-Weaner, amplamente utilizado para caracterizar comunidades e ecossistemas (SHANNON-WEANER, 1949 apud ODUM, 1983).

Utilizou-se a fórmula: $H^{\prime}=-{ }^{s} \sum_{i=1}$ piLog 2 pi.

onde:

$H^{\prime}=$ medida de informação por indivíduo (bits/org);

$\mathrm{S}=$ número de grupos taxonômicos reconhecíveis;

pi = proporcão de espécimes pertencentes a espécie $i$ em relação ao total de indivíduos (pi é estimado através de $\mathrm{ni} / \mathrm{N}$.

onde ni é o número de indivíduos da espécie $i$ e $N$ é 0 número total de indivíduos na amostra.

A eqüitatividade ou uniformidade que se refere à distribuição dos taxa é uma medida importante para auxiliar na compreensão do aumento ou diminuição da diversidade numa comunidade.

Para observar a relação entre as variáveis abióticas e bióticas, aplicou-se o teste de correlação não paramétrico de spearman, indicado por MARGALEF (1974), segundo SIEGEL (1975), aos pares de variáveis, (os taxa, a densidade, diversidade, eqüitatividade, riqueza e parâmetros físico-químicos de fundo: como 
temperatura do ar; profundidade, temperatura da água, pH, turbidez, condutividade, oxigênio dissolvido, demanda bioquímica de oxigênio e a precipitação com base nos valores mensais acumulados e com valores diários cumulativos referentes ao dia anterior e a própria coleta).

Considerou-se somente aquelas correlações positivas e negativas, nas quais $r_{s} \geq 0,50$ e que apresentaram nível de significância $\alpha \leq 0,05$. Apresentouse nas tabelas de resultados dos cálculos de correlações, a seguinte convenção:

Em cada célula de resultado representou-se:

- sinal da correlação/coeficiente da correlação

- probabilidade de erro

1. para o sinal da correlação: (+) positivo ou (-) para negativo;

2. o coeficiente da correlação - numérico;

3. a probabilidade de erro da correlação encontrada, foi indicada da seguinte forma:

*** correspondendo à correlação cuja probabilidade de erro está entre $\odot, 0 \odot 1$ e $\odot, 0 \odot 5$;

* * correspondendo à correlação cuja probabilidade de erro está entre 0,006 e 0,025 ;

* correspondendo à correlação cuja probabilidade de erro está entre 0,026 e $\odot, 050$;

correspondendo à correlação com probabilidade de erro igual ou maior que $\odot, 050$.

Para os cálculos dos coeficientes de correlação utilizou-se o pacote estatístico STATGRAPHICS - Statistical Graphics System, versão 5, $\odot$. 
0 nível de similaridade entre as comunidades (espacial) foi verificado através da construção de um dendrograma. 0 coeficiente de similaridade empregado foi o de Bray-Curtis, que varia linearmente com mudanças no número e abundância de espécies (NORRIS E GEORGES, 1993). A técnica de agrupamento escolhida foi a média ponderada (WPGMA), que impede que eventuais problemas de amostragem, tenham grande interferência na forma do dendrograma (PIELOU, 1984). As análises de agrupamento foram elaboradas usando-se o programa estatístico FITOPAC1, versão 1, 0 de 1994. 


\section{RESULTADOS}

Os dados obtidos dos parâmetros físicos e químicos estão inseridos nas tabelas 01 a 11 (Anexo I) e as figuras 24 a 34 (Anexo II).

Todos os resultados dos parâmetros biológicos (macroinvertebrados bentônicos e bacteriológicos) estão inseridos nas tabelas 12 a 50 (Anexo I) e as figuras 1 a 23 (Anexo II).

\subsection{Parâmetros Climáticos}

\subsubsection{Pluviosidade}

Os dados de precipitação pluviométrica mensal (Quadro 01), bem como os valores diários cumulativos referentes ao dia anterior da coleta e no dia da coleta (Quadro 02 ), apresentados a seguir foram cedidos pelo Instituto Astronômico e Geofísico (IAG) e demonstraram marcante comportamento sazonal, atingindo marcas inferiores a $10 \mathrm{~mm}$ em julho/96, isto é, um inverno extremamente seco; enquanto picos pronunciados em março/96, dezembro/96 e janeiro/97 (verão), atingindo as marcas de $343,7 \mathrm{~mm} ; 386,4 \mathrm{~mm}$ e $341,4 \mathrm{~mm}$, respectivamente. 
Quadro 01 - Acumulado mensal da precipitação

pluviométrica amostrada $(\mathrm{mm})$, no período de março/96 a fevereiro/97 na Represa do Guarapiranga - SP.

\begin{tabular}{|l|c|c|c|c|c|c|c|c|c|c|c|c|}
\hline & Mar/96 & Abr/96 & Mai/96 & Jun/96 & Jul/96 & Ago/96 & Set/96 & Out/96 & Nov/96 & Dez/96 & Jan/97 & Fev/97 \\
\hline $\mathrm{mm}$ & 343,7 & 34,4 & 50,1 & 50,0 & 7,8 & 22,0 & 146,8 & 158,8 & 85,7 & 386,4 & 341,4 & 108,9 \\
\hline
\end{tabular}

Fonte: Instituto Astronômico e Geofísico (IAG)

Quadro 02: - Acumulado do dia anterior mais o dia da coleta da precipitação pluviométrica amostrada na Represa do Guarapiranga - SP.

\begin{tabular}{|c|c|c|c|c|c|c|c|c|c|c|c|c|c|c|c|c|c|c|c|c|c|c|c|c|}
\hline & \multicolumn{2}{|c|}{ Mar/96 } & \multicolumn{2}{|c|}{ Abr/96 } & \multicolumn{2}{|c|}{ Mai/96 } & \multicolumn{2}{|c|}{ Jun/96 } & \multicolumn{2}{|c|}{ Jul/96 } & \multicolumn{2}{|c|}{ Ago/96 } & \multicolumn{2}{|c|}{ Set/96 } & \multicolumn{2}{|c|}{ Out/96 } & \multicolumn{2}{|c|}{ Nov/96 } & \multicolumn{2}{|c|}{ Dez/96 } & \multicolumn{2}{|c|}{ Jan/97 } & \multicolumn{2}{|c|}{ Fev/97 } \\
\hline & $13 / 3$ & $14 / 3$ & $9 / 4$ & $10 / 4$ & $6 / 5$ & $7 / 5$ & $11 / 6$ & $12 / 6$ & $17 / 7$ & $18 / 7$ & $12 / 8$ & $13 / 8$ & $17 / 9$ & $18 / 9$ & $14 / 10$ & $15 / 10$ & $11 / 11$ & $12 / 11$ & $25 / 12$ & $26 / 12$ & $14 / 1$ & $15 / 1$ & $17 / 2$ & $18 / 2$ \\
\hline $\mathrm{m}$ & 0,0 & 15,0 & 1,5 & 2,8 & 0,0 & 0,0 & 0,1 & 0,0 & 0,0 & 0,0 & 0,4 & 0,0 & 3,1 & 0,1 & 5,4 & 0,0 & 0,1 & 0,4 & 0,0 & 0,0 & 4,9 & 3,9 & 43,5 & 0,6 \\
\hline
\end{tabular}

Fonte: Instituto Astronômico e Geofísico (IAG)

\subsubsection{Temperatura do ar}

Durante todos os períodos de coleta a temperatura do ar oscilou entre 10 a $36^{\circ} \mathrm{C}$. Conforme os dados apresentados na tabela 1 e figura 24, verifica-se que embora as temperaturas do ar nos dias de coleta tenham mostrado variações espaciais, devido aos diferentes horários em que foram tomadas, estas apresentaram um período bem definido de queda de temperatura (março/96 a setembro/96), com subseqüente elevação progressiva nos meses seguintes.

\subsection{Variações abióticas}

\subsubsection{Temperatura da água}

A temperatura da água, manteve-se quase sempre abaixo da temperatura do ar, ocorrendo uma menor diferença nos meses frios. 
Observou-se uma variação de cerca de $1^{\circ} \mathrm{C}$ de temperatura de acordo com a profundidade, registrandose menores temperaturas no fundo.

As maiores temperaturas da água (coluna da água), ocorreram nos meses mais quentes, enquanto as mais baixas foram registradas nos meses de julho/96 a setembro/96. Estes resultados podem ser verificados na tabela 2 e figura 25.

De maneira geral os valores mais elevados de temperatura aconteceram nos pontos situados próximo ao centro do reservatório, onde as coletas foram efetuadas na maioria das vezes, em períodos mais quentes (12:00 às $14: 30$ horas).

\subsubsection{Profundidade e Transparência}

A profundidade entre os pontos e coletas do reservatório variou de 1,2 a 11, $\odot \mathrm{m}$, observando-se um aumento de montante para jusante do manancial. Esta variação decorre tanto das diferenças dos índices pluviométricos, como da localização da medição.

$\mathrm{Na}$ maioria das estações de amostragem encontrou-se quase sempre um período no qual se detectou maior profundidade; fosse durante $o$ inverno fosse no verão. Contudo em alguns pontos localizados no trecho de jusante do reservatório (onde as profundidades são bem maiores) quase não foram notadas variações de profundidade ao longo dos 12 meses.

A transparência esteve mais acentuada nos meses frios (período de seca). Na maioria dos meses notou-se tendência de elevação desta de montante para 
jusante do reservatório, em alguns permaneceu praticamente inalterada.

Os resultados de transparência e profundidade, podem ser vistos na tabela 3 e figura 26.

\subsubsection{Turbidez e Cor}

Os índices de turbidez (tabela 4 e figura 27) foram baixos nos meses de inverno e mais elevados no período subsequente, até fevereiro/97 nos pontos 01 e 02 (sul do reservatório). Nestes pontos, nos meses em que foram verificados valores de turbidez inferiores a 10 UNT, não se observou variação significativa com a profundidade, isto é na coluna d'água da superfície ao fundo. Enquanto isso, nos meses seguintes houve resultados de turbidez mais elevados ocorrendo aumento com a profundidade, principalmente nos meses de dezembro/96 a fevereiro/97.

Nos pontos 03 e 04 , foram verificados valores baixos de turbidez durante o período de estudo, principalmente nos meses de verão. Em algumas oportunidades, notou-se turbidez relativamente maior quando próximo ao fundo da represa se comparada à superfície, indicando a continuidade do processo de sedimentação, nestes pontos $\odot 3$ e $\odot 4$.

Já nos pontos de 05 a 10, os resultados de turbidez foram em média ainda menores que nos pontos anteriores. A tendência de elevação dos valores ao longo dos meses do ano e a variação com a profundidade foi quase inexistente.

Os dados de turbidez mostraram uma nítida redução de montante para jusante do reservatório, apesar 
das contribuições advindas de córregos poluídos ao longo da represa. Devido à baixa velocidade das águas, o processo de sedimentação de boa parte dos sólidos em suspensão dos esgotos descarregados nos córregos contribuintes, parece ocorrer de forma rápida ao entrar na represa (tabela 4 ).

0 padrão de variação da cor teve comportamento similar ao de turbidez. Durante os meses de inverno ocorreu uma certa tendência de aumento da concentração de cor para os meses de verão. Nestes últimos, observou-se algum aumento de cor com a profundidade, enquanto que nos primeiros, a variação foi quase nula. Entretanto, nos pontos mais a jusante em que foram encontrados menores valores de cor, a tendência de elevação de cor do inverno para o verão foi menor (tabela 5 e figura 28).

\section{$5.2 .4 \mathrm{pH}$}

Os índices de $\mathrm{pH}$ variaram de 5,0 e 8,6 em todas as estações de coleta ao longo dos meses de estudo, e podem ser observados na tabela 6 e figura 29.

Os resultados de $\mathrm{pH}$ nos pontos 01 e 02 foram similares. Nestes pontos, o pH oscilou de 5,0 e 6, 9, apresentando uma ligeira tendência de aumento com a profundidade.

Já os pontos 03 e 04 apresentaram uma pequena elevação em relação aos anteriores e também dos meses de inverno para os de verão. Possivelmente nos meses mais quentes ocorra uma elevação da taxa de fotossíntese e consequentemente maior saldo relativo à respiração promovendo maior depleção de gás carbônico o 
que resulta em elevação do pH. Deste modo, observou-se pequena redução de $\mathrm{pH}$ com a profundidade, motivada pelo consumo de gás carbônico próximo à superfície onde a concentração de algas é maior. Resultados semelhantes ocorreram nos demais pontos.

Pode-se observar que nos pontos localizados mais à jusante tem-se valores de $\mathrm{pH}$ mais elevados, principalmente nos meses de verão.

\subsubsection{Condutividade}

Durante os meses de estudo, foram observados valores mais elevados de condutividade entre o período de novembro/96 a fevereiro/97; os valores obtidos no fundo foram levemente mais elevados do que na superfície, principalmente nos meses mais quentes.

Um aumento progressivo da condutividade ocorreu nos demais pontos de coleta ao longo dos meses de estudo (tabela 7 e figura 30 ).

Nota-se uma nítida tendência de elevação da condutividade elétrica da água de montante para jusante até cerca da metade do reservatório. A partir de então ocorre tendência de estabilidade que se estende até o ponto mais à jusante.

\subsubsection{Oxigênio Dissolvido}

As variações dos resultados de oxigênio dissolvido são apresentadas na tabela 8 e figura 31. 
Os resultados obtidos no ponto 01 revelaram maiores concentrações (sempre superiores a 5,0 $\mathrm{mg} / \mathrm{L}$ ) entre os meses de março a setembro de 1996.

Essas concentrações mais elevadas neste período podem estar associadas à ocorrência de temperaturas mais baixas e, consequentemente, à maior solubilidade ao oxigênio na água.

Variações muito pequenas na concentração de oxigênio dissolvido ao longo da profundidade, aconteceram neste mesmo período, demonstrando a ocorrência de elevado grau de mistura das águas. Enquanto que nos meses de outubro de 1996 a fevereiro de 1997, encontrou-se valores mais baixos nas concentrações da superfície em direção ao fundo, revelando certo grau de estratificação relativamente a este parâmetro.

As concentrações de oxigênio dissolvido no ponto 02 foram muito semelhantes ao ponto 01 , com valores superiores a $5,0 \mathrm{mg} / \mathrm{L}$ em todas as coletas realizadas de março a setembro de 1996.

A partir deste período, as concentrações de oxigênio dissolvido foram menores, registrando-se apenas $3,1 \mathrm{mg} / \mathrm{L}$ no mês de outubro de 1996. Neste período de temperaturas mais altas, verificou-se maior grau de estratificação da concentração de oxigênio dissolvido em relação à profundidade, ainda que pouco significativa.

No ponto 03 , no período compreendido entre março/96 a setembro/96 as concentrações de oxigênio dissolvido foram sempre superiores a $6,0 \mathrm{mg} / \mathrm{L}$. Não foram observadas variações significativas de oxigênio dissolvido ao longo da profundidade neste mesmo período.

Nos meses seguintes as concentrações de oxigênio dissolvido foram semelhantes aos pontos anteriores. 
No período de dezembro de 1996 e janeiro de 1997, foram observados maiores graus de estratificação de oxigênio dissolvido ao longo da profundidade.

Os mesmos comentários referentes ao ponto 03 são válidos para o ponto 04 . Vale lembrar que nesses quatro primeiros pontos localizados ao sul do reservatório, foram registradas as menores profundidades (aproximadamente $3,0 \mathrm{~m}$ ).

Não foi registrado, decréscimo progressivo da concentração de oxigênio dissolvido em razão do aumento do número de contribuintes representado pelos córregos poluídos.

Os resultados no ponto 05 foram um pouco diferentes do que nos pontos anteriores. Neste, o período de elevadas concentrações de oxigênio dissolvido foi mais curto (junho/96 a setembro/96). Não houve variação significativa de concentração deste gás ao longo da profundidade nos meses de inverno. Após este período, as concentrações encontradas foram mais baixas, com algum grau de estratificação ao longo da profundidade nos meses de janeiro e fevereiro de 1997. o valor mínimo de oxigênio dissolvido no período foi de $2,6 \mathrm{mg} / \mathrm{L}$, ocorrido no fundo da represa no mês de janeiro de 1997.

No período de maio a setembro de 1996 no ponto 06, o oxigênio dissolvido manteve-se sempre superior a 6,6 mg/L, não ocorrendo variação significativa com a profundidade. As concentrações de oxigênio dissolvido obtidas a partir de outubro de 1996, foram relativamente baixas, com valor mínimo de $3,5 \mathrm{mg} / \mathrm{L}$. ocorreu, neste ponto a partir de novembro de 1996, certa redução na concentração de oxigênio dissolvido ao longo da profundidade. 
No ponto 07 ocorreu a mesma tendência que no ponto anterior, permanecendo as concentrações muito elevadas de oxigênio dissolvido entre maio e setembro de 1996 (> 7,0 mg/L) sem variar significativamente com a profundidade. 0 mês de outubro caracterizou-se mais uma vez por apresentar os valores mínimos, com apenas 3, 4 $\mathrm{mg} / \mathrm{L}$ de oxigênio dissolvido à superfície. Os meses seguintes apresentaram recuperação no teor deste gás, mantendo-se sempre acima de $5,0 \mathrm{mg} / \mathrm{L}$ e sem grande variação com a profundidade.

No período entre maio e setembro de 1996 no ponto 08 , a concentração de oxigênio dissolvido manteve-se sempre elevada (> 6,9 mg/L), não ocorrendo variação com a profundidade. A partir de outubro de 1996 as concentrações ficaram mais reduzidas, ocorrendo uma nítida variação da superfície para o fundo, especialmente no mês de novembro e dezembro de 1996 .

Vale ressaltar que no mês de novembro de 1996, a concentração de oxigênio dissolvido no fundo da represa foi de apenas $0,5 \mathrm{mg} / \mathrm{L}$, ou seja, aproximando-se bastante de condições de anoxia.

0 ponto 09 , revelou as mesmas características do ponto 08 , com concentrações superiores a $6,7 \mathrm{mg} / \mathrm{L}$ nos meses de maio a setembro de 1996. Nos meses subseqüentes, ocorreram reduções nos resultados de oxigênio dissolvido e um grau significativo de estratificação com a profundidade. 0 valor mínimo deste gás $(2,5 \mathrm{mg} / \mathrm{L})$ foi encontrado no mês de novembro de 1996.

0 ponto 10 apresentou comportamento similar aos pontos 08 e 09 , com valores de oxigênio dissolvido superiores a $6,9 \mathrm{mg} / \mathrm{L}$ nos meses de maio a setembro de 1996, não ocorrendo uma variação significativa com a profundidade. Mas uma brusca queda 
foi observada no mês de outubro de 1996 com subseqüente recuperação.

Por meio dos dados obtidos, pode-se melhor visualizar a variação do oxigênio dissolvido com a profundidade ao longo da represa no mês de abril de 1996, o que porém foi interrompido com uma melhor oxigenação das águas no período de maio a setembro de 1996.

0 mês de outubro evidenciou comportamento diverso, registrando os menores valores de oxigênio dissolvido nas águas da represa e, paradoxalmente, concentrações maiores no fundo do que na superfície em diversos pontos. Talvez por uma mistura das camadas mais superficiais das águas ou ação de águas com temperaturas mais baixas propiciando a maior retenção do gás no fundo.

A partir do mês de novembro de 1996, observa-se novamente a tendência de redução da concentração com a profundidade.

\subsubsection{Demanda Bioquímica de Oxigênio}

Todos os resultados das variações da demanda bioquímica de oxigênio estão apresentados na tabela 9 e figura 32 .

As concentrações da demanda bioquímica de oxigênio (DBO) durante o período de estudo no ponto 01 , foram um pouco mais elevadas nos meses de inverno. Este fato pode estar associado ao menor grau de diluição que ocorre nesta época, devido à ocorrência de menores índices pluviométricos, e pelo menor grau de decomposição de compostos orgânicos nos poluídos córregos contribuintes. 
Os meses de março a maio de 1996, apresentaram neste ponto as concentrações mais elevadas $(3,0 \mathrm{mg} / \mathrm{L})$. A partir de outubro de 1996 até fevereiro de 1997, os valores encontrados foram sempre inferiores a $1,5 \mathrm{mg} / \mathrm{L}$, o que representa uma melhor condição para a sobrevivência dos organismos aquáticos.

Notadamente nos meses de abril e maio de 1996, ocorreu uma certa tendência de aumento de DBO com a profundidade $e$, os meses seguintes os resultados são semelhantes nas três posições ao longo da profundidade, tendência esta que se manifesta até novembro de 1996.

No período de dezembro de 1996 a fevereiro de 1997, os valores de DBO são mais baixos, devido a uma maior demanda exercida pelos microrganismos decompositores, levando à concentração de oxigênio dissolvido mais baixas.

No entanto, deve ser ressaltado que também no caso da DBo, as imprecisões do método analítico dificultam esta análise, especialmente por tratar-se de valores baixos e muito próximos entre si.

No ponto 02 , os resultados de DBO encontrados foram similares ao ponto 01 .

Também neste ponto, os maiores valores de DBO ocorreram nos meses de inverno, com valor máximo de $3, \odot \mathrm{mg} / \mathrm{L}$. Do mês de setembro de 1996 a fevereiro de 1997, os valores obtidos foram inferiores a $2,0 \mathrm{mg} / \mathrm{L}$, com maior variação com a profundidade.

De maneira análoga podem ser interpretados os resultados de DBO obtidos para o ponto 03 .

Como os pontos $01, \quad 02$ e 03 estão alinhados, os resultados semelhantes indicam que a redução de concentração de DBO esperada ao longo da 
represa neste trecho devido à estabilização bioquímica de matéria orgânica é compensada pelo efeito de novas descargas de córregos poluídos no trecho considerado.

Já o ponto 04 , onde três córregos descarregam suas águas, os resultados de DBO não obedeceram a tendência dos pontos anteriores. Evidenciase que a DBO variou de forma diferente ao longo dos 12 meses neste ponto, tendo sido observados valores mais elevados em meses quentes e valores baixos em meses de inverno. Valores inferiores a $2,0 \mathrm{mg} / \mathrm{L}$ foram encontrados na maioria das coletas e não se verificou tendência de variação da DBO com a profundidade.

0 ponto 05 apresentou valores de DBO mais altos nos meses de inverno, mas a diferença é pouco significativa. Este ponto também não revelou variação de DBO ao longo da profundidade.

Foram encontradas em média maiores concentrações de DBO nos meses de inverno e nos meses de verão no ponto 06 . Neste ponto observou-se baixas concentrações à superfície e alguns valores mais elevados em torno de $3, \odot \mathrm{mg} / \mathrm{L}$ no fundo.

0 ponto 07 de um modo geral foi semelhante ao ponto 06

Nos meses mais frios ocorreram valores mais altos, chegando a $4,0 \mathrm{mg} / \mathrm{L}$ no mês de maio de 1996. Nestes meses não houve variação significativa de DBO com a profundidade. Nos meses de temperatura mais elevada os valores de DBO são menores, e ocorreram em algumas oportunidades valores mais elevados no fundo, tendo atingido $3,2 \mathrm{mg} / \mathrm{L}$.

Os resultados de DBO obtidos no ponto 08 , evidenciam que valores mais altos aconteceram durante o inverno, sem qualquer tendência de variação de 
concentração com a profundidade ao longo dos 12 meses de coleta.

0 ponto 09 apresentou comportamento semelhante ao ponto 08 . Neste ponto houve menor variação de DBO durante todas as coletas mas, sem tendência definida de variação com a profundidade.

Baixos valores de DBO foram identificados no ponto 10 no decorrer do estudo, quase sempre inferiores a 2, $\odot \mathrm{mg} / \mathrm{L}$. Nos meses de inverno foram obtidos valores mais elevados, sem variação significativa com a profundidade.

Através dos resultados obtidos pode-se confirmar a distribuição uniforme das cargas poluidoras por matéria orgânica ao longo do reservatório, uma vez que não se observa redução da DBO de montante para jusante, devido ao processo de auto depuração natural.

\subsubsection{Nitrogênio total e Fósforo total}

Os valores obtidos de nitrogênio e fósforo estão contidos nas tabelas 10 e 11 e figuras 33 e 34, respectivamente.

Nos dez pontos de amostragem, observou-se que a variação dos resultados de uma coleta para outra é muito significativa e que ocorreu redução nos valores apenas nos dois últimos meses, especialmente nos pontos localizados à jusante da represa. 0 fato de se obter menores concentrações de nitrogênio total somente no trecho à jusante indica possivelmente que é necessário quase todo o percurso para se ter um grau expressivo de nitrificação das águas do reservatório. Entretanto, o 
reservatório pode ser considerado meso-eutrófico e politrófico.

Realmente, segundo pesquisa da Cia de Tecnologia de Saneamento Ambiental (CETESB, 1995) com amostragens realizadas em 1993, o reservatório de acordo com os critérios de WOLLENVEIDER, 1968 apud CETESB, 1995) utilizados naquele estudo encontra-se na maioria dos pontos amostrados meso-eutrófico $(\odot, 342-\odot, 618 \mathrm{mg} / \mathrm{L}$ de nitrogênio inorgânico total) e politrófico $(\odot, 420-2,370$ $\mathrm{mg} / \mathrm{L}$ nitrogênio inorgânico total).

Tais dados corroboram a situação atualmente vigente conforme antes relatado.

As concentrações de fósforo total mais baixas ocorreram nos meses de novembro e dezembro de 1996. Não foi observado para este parâmetro tendência de redução ou aumento de concentração de montante para jusante.

\subsubsection{Correlações Estatísticas}

As correlações estatísticas entre os parâmetros físicos e químicos estão contidos nas tabelas 40 a 49 .

\subsection{Coliformes Totais e Fecais}

Os dados referentes as bactérias coliformes são apresentados na tabela 50 .

\subsection{Macroinvertebrados Bentônicos}




\subsubsection{Composição}

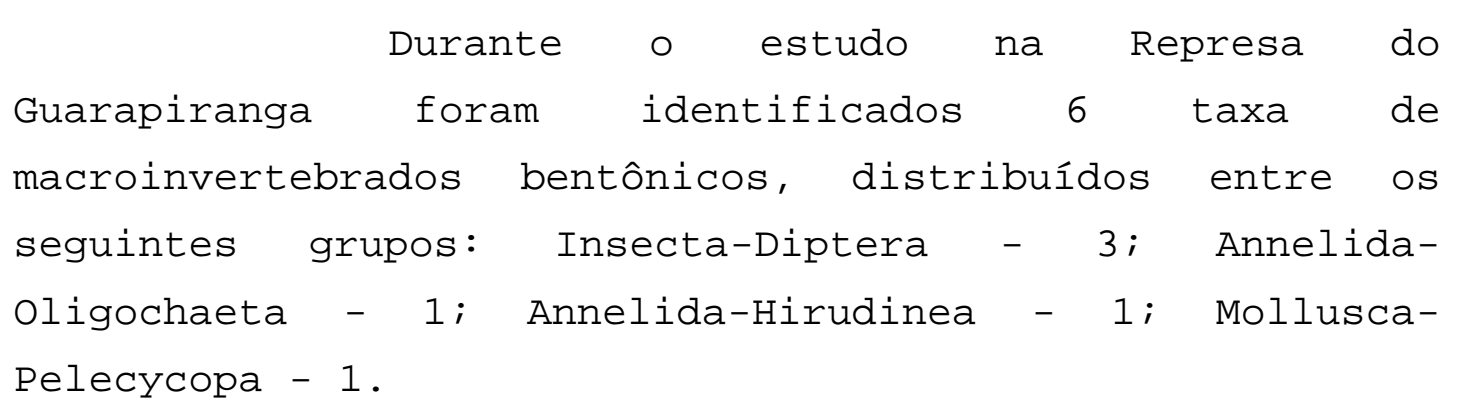

\subsubsection{Densidade Total}

Conforme os dados da tabela 12, a densidade total acumulada dos macroinvertebrados bentônicos foi relativamente alta durante o período de estudo $\left(42.082\right.$ organismos $\left./ \mathrm{m}^{2}\right)$, quando comparada com os dados obtidos por ROCHA, 1976 no mesmo reservatório.

Pode-se observar que no ponto 07 , de modo geral, houve a maior densidade (9.576 organismos $\left./ \mathrm{m}^{2}\right)$, em relação as demais estações de coleta. Como também na coleta realizada no mês de julho/96, revelou a maior densidade desses organismos com 19.792 organismos $/ \mathrm{m}^{2}$.

\subsubsection{Análise da Comunidade Bentônica}

Os dados obtidos conforme enfatizado, inseridos nas tabelas em Anexo I, permitiram a elaboração de 23 figuras conforme é referendado no texto e que se encontram no Anexo II.

Através dos dados da tabela 13, foi verificado que os grupos com maior densidade e abundância relativa durante todo 0 período de estudo foram Tubificidae (20549 orgs $\left./ \mathrm{m}^{2}\right)$ com 48,8\% e Chaoboridae (14881 orgs $/ \mathrm{m}^{2}$ ) com $35,8 \%$. 
Os dados de densidades mensais e abundâncias relativas para os grupos de macroinvertebrados bentônicos estão expressos nas tabelas 14 a 23. Nas 10 (dez) áreas de amostragem, a densidade total destes organismos tende a aumentar no período de maior estiagem, sendo que este aumento é mais pronunciado no ponto 07 (Figura 7 ).

Verificando-se os gráficos referentes às variações de densidade dos macroinvertebrados bentônicos de cada área de coleta, observa-se que no ponto 01 a primeira elevação máxima de densidade total da comunidade relaciona-se à presença de Chaoboridae e a segunda a Chironomidae. (Figura 1).

No ponto 02 , nota-se que de março/96 a junho/96 a densidade total (Figura 2) expressa a densidade de Chaoboridae; em julho/96 ocorre um grande aumento da densidade total, que está relacionado com 0 aumento de Chaoboridae, Tubificidae e Chironomidae; nos meses seguintes o aumento da densidade total ocorreu principalmente devido ao aumento de Tubificidae (Figura 2).

Já o ponto 03 , a densidade total expressa a dominância de Chironomidae, Chaoboridae e Tubificidae até junho/96, ocorrendo aguda elevação (julho/96) devido ao aumento significativo de Chaoboridae (Figura 3).

A única conspícua elevação observada na densidade total no ponto $\odot 4$ da comunidade, relacionou-se novamente ao grupo Chaoboridae (Figura 4).

0 ponto 05 apresentou três evidentes e acentuadas elevações de densidade total da comunidade, a primeira (junho/96) relacionada à presença de Tanypodinae, Chaoboridae e Tubificidae, a segunda 
(julho/96) a Tubificidae e a terceira (agosto/96) a Chironomidae, Chaoboridae e Tubificidae (Figura 5).

No ponto 06, como pode ser observado na (Figuras 6), março/96 ocorreu a primeira elevação máxima de densidade total da comunidade, relacionada à presença de Tubificidae, a segunda (junho/96) a Chaoboridae, e a terceira (julho/96), relacionada ao aumento dos números de Chironomidae, Chaoboridae e principalmente de Tubificidae.

Analisando-se a variação de densidade dos grupos taxonômicos no ponto 07 , nota-se que o pico da densidade total da comunidade (julho/96), relacionou-se exclusivamente à presença de Tubificidae (Figura 7) .

Através da Figura 8 do ponto 08 , percebese que em março e julho/96 a densidade total segue 0 padrão da densidade de Chaoboridae, enquanto que setembro/96 e fevereiro/97 segue o padrão de Tubificidae.

o comportamento da macrofauna bentônica no ponto 09 parece ser um pouco diferente que os pontos anteriores. Neste, os picos ou elevações aconteceram em períodos mais próximos entre uma coleta e outra (Figura 9). 0 primeiro ocorreu em março/96 e relaciona-se à presença de Tubificidae e Chaoboridae; o pico de abril/96 com Tubificidae. A partir de julho/96 os picos representam uma somatória do comportamento das densidades de Chironomidae, Tanypodinae e Tubificidae. A alta densidade total ocorrida em dezembro/1996 está relacionada à presença de Tubificidae.

Observou-se que no ponto 10, a máxima densidade em março/96, diretamente relacionada com a presença de Chaoboridae e Tubificidae, e a segunda (julho/96) a Chaoboridae (Figura 10). 
As variações espaciais da estrutura da comunidade bentônica podem ser observadas nas tabelas 24 a 36 e Figuras 11 a 22 .

Através da tabela 24, percebe-se que as estações que apresentaram maiores densidades totais foram ๑2, 07 e 08 , onde estas densidades estão relacionadas diretamente com a presença dos Tubificidae e Chaoboridae.

Em relação à abundância relativa, observase que Chaoboridae e Tubificidae são os grupos mais importantes, e na maioria das vezes os mais representativos. Em algumas ocasiões destacaram-se Chironomidae e Pelecycopa, enquanto Glossiphoniidae e Tanypodinae raras vezes foram destacados.

\subsubsection{Diversidade, Eqüitatividade e Riqueza}

os valores mensais dos índices de diversidade, eqüitatividade e riqueza podem ser vistos, respectivamente nas tabelas 37,38 e 39.

0 índice de diversidade desses organismos variou entre < 1 e 1,92 bits.ind ${ }^{-1}$ em todo período de estudo, caracterizando em algumas oportunidades água poluída e em outras água moderadamente poluída.

Em março/96 registrou-se índice máximo de 1,89 bits.ind ${ }^{-1}$ (ponto 03 ) e mínimo de 0,14 bits.ind ${ }^{-1}$ (ponto 08 ). 0 mesmo comentário pode ser feito com relação a coleta de abril/96, onde o valor máximo também ocorreu no ponto 03 .

0 padrão de variação dos índices de diversidade na coleta de junho/96 mostrou-se irregular, oscilando de $0,0 \odot$ (ponto 07 ) a 1,56 bits.ind ${ }^{-1}$ (ponto ๑5), respectivamente. 
Em julho e agosto/96 os valores para os índices de diversidade em relação as coletas anteriores, apresentaram em geral um aumento substancial na maioria das estações de amostragem, registrando o maior valor 1,82 bits.ind ${ }^{-1}$ em agosto de 1996 no ponto 08 e o menor $\odot, 43$ bits.ind ${ }^{-1}$ em julho/96 no ponto $\odot 7$.

$\mathrm{Na}$ coleta de setembro/96 também ocorreram valores relativamente elevados, entretanto nos pontos 02 e 04 houve uma grande diminuição.

Nas coletas de outubro e novembro de 1996 foram observados altos valores nos índices de diversidade no ponto $05,1,91$ e 1,92 bits. ind $^{-1}$, respectivamente.

0 mesmo comentário referente a coleta de junho/96 é válido para a última coleta (fevereiro/97), onde os valores oscilaram entre 0,44 (ponto 09) a 1,41 bits. ind ${ }^{-1}$ (ponto 06 ).

A eqüitatividade ou uniformidade analisada, apresentou em março/96 no ponto $08(0,14)$, o menor valor observado durante o período de estudo.

$\mathrm{Na}$ segunda coleta (abril/96) os valores de eqüitatividade variaram entre 0,52 (ponto 09 ) e 1,00 (ponto 05), enquanto na coleta de maio e junho de 1996 mostrou-se irregular da mesma forma que a diversidade, oscilando entre 1,00 (pontos 03 e 04) e 0,29 (ponto 06), respectivamente.

Os menores valores nas coletas de julho/96 $(\odot, 27)$ e agosto/96 $(\odot, 31)$ ocorreram no ponto 07 , enquanto que setembro de 1996 apresentou no ponto 03 o maior valor registrado 1,37 , durante todo o período de amostragem.

Como pode ser observado na tabela 38, os valores das coletas de outubro/96 (pontos 01 e 09 ) e novembro/96 (pontos 2, 3 e 8 ), demonstraram não haver uma 
uniformidade na amostra. Já nas demais áreas amostradas não foram observados valores menores que $\odot, 69$.

$\mathrm{Na}$ coleta de dezembro de 1996 não houve uniformidade nos ponto $03,04,09$ e 10, enquanto os pontos da parte central do reservatório (ponto 06, 07 e ๑8) registraram 1,00 de uniformidade.

A penúltima coleta (janeiro/97) seguiu o mesmo padrão que a coleta de outubro/96, com exceção do ponto 05 , que não apresentou uniformidade.

Em fevereiro de 1997, os valores variaram entre 0,44 (ponto 09 ) e 1,00 (ponto 05 ).

De maneira geral, durante o período de estudo, foram registrados baixos valores para riqueza em todo o reservatório.

No ponto 04 , freqüentemente observou-se, os menores valores para riqueza, durante todo o período de amostragem.

Nos meses de estiagem, também de modo geral verificaram-se maiores valores para riqueza, com exceção do mês de março/96 que registrou um período de maior precipitação pluviométrica.

As figuras 01 a 10 mostram as variações temporais e as de 11 a 22 as variações espaciais dos índices de diversidade, eqüitatividade e riqueza.

\subsubsection{Correlações Estatísticas}

os valores significativos dos coeficientes de correlação de spearman $\left(r_{s}\right)$, entre os parâmetros ambientais e dos grupos faunísticos estão listados nas tabelas 40 a 49 . 


\subsubsection{Análise de Agrupamento - Espacial (Dendrograma)}

A análise de agrupamento das estações de coletas (espacial) aplicada para a comunidade de macroinvertebrados bentônicos revelou dois grupos (Figura 23). O primeiro grupo denominado $\underline{\mathbf{A}}$ é formado pelas estações de coleta $02,03,08$ e 10. 0 segundo grupo chamado $\underline{\mathbf{B}}$, é constituído pelos pontos 05, 06 e 09 .

As estações $01, \quad 04$ e $\quad 07$ não formaram agrupamentos nos níveis considerados, apresentando comportamento diferenciado. 


\section{DISCUSSÃO}

\subsection{Parâmetros Físicos e Químicos}

As variações da qualidade das águas ocorridas ao longo dos meses do ano, foram em grande parte decorrentes das oscilações da temperatura e índices pluviométricos.

HENRY (1993) apud CETESB (1995) considera que as águas com transparência inferior a 3 metros de profundidade devem ser consideradas como eutróficas; 3 a 6 metros mesotróficas, e acima de 6 metros oligotróficas.

Segundo CETESB (1995) a transparência da água tem sido utilizada como uma ferramenta complementar na avaliação do nível de eutrofização das águas.

Ao se considerar os resultados de transparência da água no reservatório do Guarapiranga, este pode ser classificado como eutrófico.

ROCHA (1972) dentre outros autores, relata que a temperatura é um importante fator ecológico, tanto pela influência direta que pode exercer sobre os organismos, como pela relação existente entre esta e a solubilidade dos gases e interferência na viscosidade da água .

Os menores valores na concentração de oxigênio dissolvido nas águas, aconteceram nos meses mais quentes, podendo-se concluir que durante este período houve uma diminuição da solubilidade desse gás na água acompanhado do aumento da temperatura, e do maior consumo devido à aceleração dos processos respiratórios. Tal fato verificado também por ROCHA, 1972 e 1976 na represa de Americana e Guarapiranga, e também por, CALEFFI, (1994) e BEYRUTH, (1996) no mesmo reservatório. 
Esses resultados são comprovados pelas associações negativas ocorridas na maioria das estações de coleta entre o oxigênio dissolvido e a temperatura.

As correlações negativas existentes entre o oxigênio dissolvido com o índice pluviométrico levam a supor que as chuvas promoveram a diluição dos nutrientes, contribuindo também para a diminuição da produção fotossintética deste gás por volume de água superficial, e também podem ter levado ao aumento do consumo, por carrear matéria orgânica para o reservatório.

As concentrações da demanda bioquímica de oxigênio apresentaram-se mais elevadas no inverno devido à redução da taxa de degradação dos compostos orgânicos, aos esgotos lançados nos córregos contribuintes e, principalmente porque no período de seca, ocorre um menor efeito de diluição decorrente do baixo índice de pluviosidade.

A cor e a turbidez da água também apresentaram valores inferiores nos meses de baixa temperatura e menor pluviosidade. A turbidez associou-se positivamente com o índice pluviométrico e temperatura da água. Tal situação faz pressupor que os maiores índices pluviométricos acarretando maiores afluxos de água contendo material particulado, contribuíram para o aumento da turbidez, principalmente nos pontos a jusante do reservatório.

Entretanto, a turbidez apresentou correlação negativa com a DBO. Talvez nas épocas mais secas e frias do ano, tenha ocorrido maior contribuição de material particulado inorgânico. Portanto, ao que parece, a maior parcela da turbidez da água poderia ser de origem mineral, explicando essa correlação. Fato ressaltado por BEYRUTH, (1989) onde relata que este 
material particulado inorgânico é proveniente principalmente de portos de areia.

$$
\text { Associações positivas entre a }
$$

condutividade e temperatura da água juntamente com a elevada pluviosidade, podem ser explicadas pelo aumento dos valores condutividade elétrica nos meses mais quentes, devido ao maior grau de mineralização das águas.

Os registros elevados de $\mathrm{pH}$, obtidos nos meses de altas temperaturas, corroborados pelas suas associações positivas, podem refletir um saldo da fotossíntese com relação à respiração nesses períodos de intensa insolação, quando há elevação do consumo de gás carbônico e conseqüente elevação de $\mathrm{pH}$.

0 fato de existirem diversos pontos de descarga de córregos poluídos ao longo da represa do Guarapiranga torna suas características físicas e químicas mais ou menos uniformes espacialmente, compensando em parte as variações de montante para jusante, variações estas esperadas devido ao fenômeno de autodepuração natural. Apesar disso, de montante para jusante ocorreram algumas reduções de certos parâmetros sendo mais evidentes as do nitrogênio total, fósforo total, cor e turbidez, levando também a um aumento da condutividade elétrica.

BEYRUTH, (1997) também verificou que os pontos mais a jusante do reservatório apresentaram elevados valores de condutividade elétrica, devido a maior concentração de nutrientes nesta área da represa.

ROCHA (1976) e BEYRUTH (1996) salietam que o reservatório possui um potencial de auto-depuração. Entretanto, comparando os resultados ora obtidos com os de KLEEREKOPER (1939); ROCHA (op cit); MAIER \& TAKINO (1985) fica demonstrado que a eutrofização esta 
aumentando consideravelmente durante as últimas décadas; conforme enfatiza BEYRUTH, 1997.

\subsection{Coliformes Totais e Fecais}

Considerando-se os coliformes totais e fecais, verificou-se freqüentemente, valores muito superiores, (principalmente nos meses com elevados índices pluviométricos e nos pontos que recebem maiores cargas poluidoras), tanto aos estabelecidos na legislação CONAMA, 1986, quanto aos encontrados por ROCHA, 1976 no mesmo reservatório.

CALEFFI, 1994 também observou altas concentrações de coliformes totais e fecais nas mesmas estações do reservatório.

Pode-se notar, que mesmo o aumento do volume de água na represa, como já citado anteriormente, parece não estar sendo suficiente para proporcionar uma boa diluição, pois o recebimento de cargas poluidoras advindos dos córregos adjacentes e os resíduos sólidos lançados no entorno do reservatório, ocorrem em maiores proporções.

\subsection{Comunidade Bentônica}

Vários fatores ambientais tanto de caráter natural quanto advindos da presença do homem, influem direta ou indiretamente sobre a densidade e composição da macrofauna bentônica. Vale ressaltar que grande número dos processos naturais são às vezes acelerados pela atividade antrópica. 


\section{Certos fatores, como o índice}

pluviométrico além de influenciarem o nível da água, podem determinar mudanças na fauna bêntica (PETR, 1974). Nesse sentido RADFORD, 1971 verificou variações em rio do Canadá.

$\mathrm{Na}$ represa do Guarapiranga, as oscilações dos índices pluviométricos foram acompanhados da alterações da coluna d'água (profundidade-máximo $11 \mathrm{~m}$ ). Além do mais há que se considerar o volume significativo de água que é retirado diariamente para o abastecimento público exercendo também influência nos níveis de água reservada.

0 tipo de substrato é outro fator que interfere na fauna bentônica, pois esta dele depende essencialmente como fonte de alimento sob a forma de substâncias autóctone ou alóctone ricas em energia ( LELLAK, 1965) .

STRIXINO (1973), cita que os restos vegetais acumulados no fundo permitem o aparecimento e proliferação de inúmeros animais, que dependem do substrato e de alguma forma, auxiliam no processo de decomposição.

Embora a qualidade do substrato não tenha sido analisada, pode-se inferir apenas pela observação que existem diferenças marcantes entre as estações de coleta, como será discutido mais adiante.

Os efeitos da variação da temperatura sobre as populações bentônicas são geralmente exercidos de maneira indireta, mas de grande importância, pois esta interfere na solubilidade dos gases na água principalmente o oxigênio; este mantém uma relação indireta com a temperatura. ROCHA, 1972 e 1976 observou respectivamente na represa de Americana e do Guarapiranga 
no Estado de São Paulo, que as temperaturas mais baixas favorecem o desenvolvimento de vários organismos bentônicos. Tais registros parecem corroborar observações anteriores de GAUFIN et al, 1955.

Portanto, a variação da temperatura juntamente com a precipitação pluviométrica são fatores naturais importantes para os seres aquáticos bentônicos, se bem que de difícil interpretação principalmente em regiões tropicais e sub-tropicais, pois as estações do ano não são perfeitamente definidas (ROCHA, 1976).

A disponibilidade de alimento é de fundamental importância, e a entrada de material autóctone e/ou alóctone, favorece não só os animais detritívoros, mas também os herbívoros e carnívoros predadores (BEYRUTH, 1989).

A predação também pode influenciar na distribuição do bentos. Entre os predadores estão os peixes que tem sido analisados por uma série de estudos comparativos de lagos diversos.

REICE \& WOHLENBERG apud POPE et al (1973) comparam os Chaoborus de 26 lagos do Canadá, mostrando que a presença ou ausência dos peixes alteravam drasticamente sua distribuição.

A turbidez, pH, oxigênio dissolvido (OD) e demanda bioquímica de oxigênio (DBO) etc, são outros fatores que podem influenciar na distribuição da fauna bêntica. Desses o oxigênio dissolvido, apesar de ter apresentado correlação positiva com certos grupos taxonômicos, variável entre as áreas amostradas, de um modo geral não indicou estar havendo ação decisiva sobre os macroinvertebrados bentônicos na Represa do Guarapiranga. Isto pode ser corroborado pelo fato do oxigênio dissolvido não ter atingido concentrações 
inferiores a $5 \mathrm{mg} / \mathrm{L}$ e valores desta ordem só terem ocorrido em algumas ocasiões, e mais especificamente no mês de outubro/96 (Tabela 8). Como na região de localização do reservatório ocorrem ventos fortes e atividades náuticas, os teores mais baixos de oxigênio não foram constantes em todos os meses, indicando ao que parece, portanto, que a profundidade média da represa favorece a oxigenação da água.

As variáveis abordadas no texto constituem uma pequena amostra do conjunto de fatores que podem influenciar a fauna bentônica de um corpo d'água. Em paralelo há inúmeras outras alterações de origem antrópica que também são passíveis de atuar sobre este conjunto.

Os fatores antes citados são discutidos com maior ênfase, e pormenores mais adiante, quando pertinente.

\subsubsection{Densidade Total}

Comparando-se de forma global os dados sobre a fauna bentônica ora apresentados com aqueles obtidos anteriormente por ROCHA (1976) no mesmo reservatório, verifica-se condições bem diferentes caracterizando as duas décadas que os separam. Nesse sentido houve:

1) um aumento significativo em relação a densidade total dos macroinvertebrados bentônicos.

2) um drástico aumento do grupo Oligochaeta (Tubificidae). 
3) uma mudança no grupo mais representativo, com aumento na proporção de Chaoboridae e diminuição significativa das larvas de Chironomidae.

Como já citado anteriormente, vários autores efetuaram estudos na Represa do Guarapiranga, alertando sobre os problemas que já afetavam e continuam afetando o reservatório tais como: entrada de descargas poluidoras; ocupação desordenada do solo; disposição inadequada de resíduos sólidos (lixo). Todos constituindo fatores que induzem à possibilidade de eutrofização.

Corroboram tais afirmativas os dados de CALEFFI, 1994 sobre aplicação de sulfato de cobre de modo intensivo e extensivo, para o controle das algas no reservatório. A autora relata que no ano de 1991 foram aplicadas 51,6 toneladas de sulfato de cobre e apenas no curto período de janeiro a agosto de 1992, as aplicações atingiram 96,6 toneladas.

Conforme foi referido no capítulo Revisão da Literatura, essas aplicações continuaram a ter incremento. Dados mais recentes apresentados por FERRAZ ${ }^{(1)}$ (1998), relatam que a SABESP gastou dez vezes mais recursos do que no ano de 1997 na compra de produtos químicos para combater as algas.

A sulfatação, e até mesmo as causas naturais levam as algas à morte em altas taxas provocando, a liberação de grandes quantidades de nutrientes que se difundem à coluna d' água, consequentemente aumentando a disponibilidade de material nutritivo para outras espécies (BEYRUTH, 1996), inclusive para a fauna de fundo.

(1) Jornalista do Jornal da Tarde- Jornal da Tarde - 12 de outubro de 1998 - Folha 16 A - Ocupação de Mananciais compromete abastecimento. 
Obviamente, o grande número de bactérias coliformes (Tabela 50) que se incrementou ao longo dos anos até chegar aos registros deste estudo, também está associado ao aumento das cargas poluentes orgânicas de origem doméstica, levando não só ao risco sanitário potencial, mas sobretudo tornando disponível uma maior concentração de alimentos para os organismos que vivem no fundo.

Diante do exposto, estes parecem ser elementos básicos que permitem explicar o aumento da densidade dos organismos bentônicos na represa. 0 maior ingresso de esgotos domésticos advindos dos córregos adjacentes tornando disponíveis os alimentos, o que vem ocorrendo durante todos esses anos, pode ter favorecido estes grupos.

Ao se considerar a densidade da macrofauna bêntica em sua totalidade, evidenciou-se um padrão ou tendência comum entre as 10 (dez) estações de amostragem (Tabela 24). Entretanto, nas estações 04 e 07 houve sensíveis diferenças, permitindo que sejam enfocadas como unidades distintas.

Os grupos que consistentemente estiveram presentes em todas as estações de coleta durante todo o período de amostragem foram os Oligochaeta, Chaoboridae e Chironomidae (Tabela 13).

$$
\text { os Tanypodinae, Glossiphoniidae e }
$$

Pelecycopa, embora presentes, ocorreram em densidades de menor amplitude, não constituindo grupos tão importantes como os anteriores. 


\subsubsection{Abundância Relativa}

Quanto à abundância relativa observa-se que Tubificidae e Chaoboridae são os grupos mais representativos, apresentando muitas vezes uma nítida dominância. Chironomidae também se destaca em certas ocasiões. Para os Tanypodinae, Glossiphoniidae e Pelecycopa, obtiveram-se abundâncias relativas pouco expressivas durante o estudo em todas estações de coleta.

Como já citado, WELCH, (1952); HART \& FULLER, (1974); ROCHA (1972 e 1976); ODUM, (1983); BEYRUTH, (1989) enfatizam que a variação sazonal, como um dos fatores de influência principais sobre a abundância dos organismos bentônicos.

No presente trabalho pode ser notado, que o mês de maior estiagem (julho/96) revelou a presença de quase $50 \%$ do total de organismos durante o período de estudo.

0 maior aporte de esgotos domésticos tornando disponíveis os alimentos, podem ter favorecido algumas espécies.

Por sinal, verificou-se que quase $23 \%$ do total dos organismos encontravam-se no ponto 07 embora tenha sido baixa a diversidade.

$\mathrm{Na}$ verdade tem se observado em vários corpos d'água que o recebimento de carga efluente apenas de esgoto sanitário, quando as descargas são compatíveis com a vazão do corpo receptor, que o material orgânico alóctone serve como fonte de alimento a fauna aquática inclusive a peixes. Tal afirmativa pode ser corroborada pelas citações de vários pesquisadores, conforme se relata no item 6.3 .3 à seguir. 


\subsubsection{Diversidade, Eqüitatividade e Riqueza}

o propósito de se analisar o índice de diversidade está geralmente associado ao julgamento das relações de um grupo de organismos com as características destes ou com as condições ambientais às quais está exposto (PIELOU, 1975).

Em relação à poluição, admite-se como base o fato de que as águas de boa qualidade possuem maior número de espécies bentônicas com maior eqüitatividade (HARTMAN, 1974; SALA et al, 1977), enquanto que o inverso é válido para águas poluídas.

MARGALEF (1974) ressalta que a baixa diversidade também pode estar associada à exposição a condições ambientais muito flutuantes.

Por outro lado, MATSUMURA-TUNDISI et al (1990) apud CALEFFI (1994) consideraram que a eutrofização até certo grau contribuiu para o aumento da diversidade na Represa de Barra Bonita - SP com relação ao grupo Rotífera.

ODUM (1983) também enfatiza que a existência de uma perturbação generalizada ou moderada pode causar aumento da diversidade, em vez de declínio.

Este caso pode ser verificado em alguns pontos do reservatório considerados entre os mais atingidos pela poluição orgânica (pontos 05 e 07 ), que deve ter contribuído à ocorrência de maiores valores da diversidade.

No entanto na estação 07 do mês de julho/96 o baixo valor de diversidade esteve associado com a baixa eqüitatividade, e dominância do grupo Tubificidae. 
Outro fator considerado importante na determinação da diversidade da fauna bêntica é a quantidade de oxigênio dissolvido (SALA et al, 1977). Entretanto, no presente estudo não foi observado este tipo de correlação em nenhuma das estações de amostragem, seja porque existem outras variáveis agindo ou seja porque a medida do oxigênio dissolvido foi realizada apenas no momento da coleta.

ROCHA (1976) observou no mesmo reservatório valores mais altos de diversidade durante 0 período de verão e outono e uma homogeneidade entre as estações de coleta.

Contudo, no atual trabalho, essa tendência não foi encontrada; os maiores índices de diversidade de maneira geral, foram durante todo o período de inverno, no início da primavera (outubro/96) e no final do verão (março/96) (Tabela 37).

BEYRUTH (1989) também verificou maiores índices no período de inverno seguidos do outono, em um Lago Marginal ao Rio Embu-Mirim - SP.

A eqüitatividade ou uniformidade é baseada na abundância relativa de espécies e no grau da sua dominância ou falta desta.

PAYNE (1986) assinala que uma forte dominância de um pequeno número de espécies indica uma baixa uniformidade na distribuição de recursos, típica de baixa diversidade.

Tal afirmativa pode ser constatada na represa, onde nos meses de maior precipitação pluviométrica de maneira geral, os índices de diversidade e uniformidade foram baixos, bem como suas densidades totais, tendo havido dominância dos Tubificidae. 
As correlações positivas obtidas na maioria das estações de amostragem, entre os índices de diversidade e eqüitatividade, permitem inferir que a eqüitatividade demonstra ser um componente importante da diversidade, uma vez que as curvas apresentam o mesmo padrão (Figuras 11 a 22).

Os menores valores de riqueza obtidos na comunidade bêntica ocorreram quando houve maiores precipitações pluviométricas e temperaturas mais elevadas, sendo evidenciado pelas associações positivas existentes entre estas variáveis e a riqueza.

$$
\text { As estações que freqüentemente }
$$

apresentaram os maiores índices de riqueza, coincidem com as que já foram consideradas anteriormente com relação a diversidade, onde estas são afetadas pela eutrofização.

Dos fatos analisados, evidenciou-se que na coleta de verão ocorreram condições ambientais muito restritivas (maior índice pluviométrico; elevadas temperaturas, "mínimo de verão") ao desenvolvimento da comunidade bentônica no reservatório do Guarapiranga.

Fatores que podem influir para o "mínimo de verão" são relatados por OLIVEIRA (1985), onde o mais aceito é a emergência dos insetos de ciclo parcialmente aquático, cujo metabolismo é acelerado pelas altas temperaturas, do que resultam revoadas em massa; ou secundariamente da predação intensificada; a de sobrevivência em face do estresse ambiental e a competição. 


\subsubsection{Correlações Estatísticas}

A densidade total dos macroinvertebrados bentônicos, correlacionou-se negativamente com as temperaturas do ar e água, como também com a pluviosidade.

Como já citado, dos fatores naturais, estes são considerados um dos mais importantes, e suas variações podem causar grandes modificações tanto nas suas densidades, diversidades, como no número de taxa presentes.

LEHMUKULL (1979), enfatiza que a temperatura é um dos fatores mais importantes no desenvolvimento da metamorfose dos insetos, desde o ovo até a eclosão das larvas. Essas considerações são tanto mais válidas quando se consideram as condições reinantes no clima tropical onde qualquer oscilação de temperatura, por mais sensível que possa ser concorre para alterações, como por exemplo da densidade numérica e viscosidade da água .

Essa importância da temperatura como "fator ecológico" relacionado aos macroinvertebrados bentônicos, especialmente insetos, também foi ressaltada por OLIVEIRA (1985) quando se refere ao chamado "mínimo de verão ", fato comentado anteriormente.

Assim, o conjunto das condições do inverno, promoveu um aumento da densidade total, confirmando as correlações existentes entre a temperatura da água e pluviosidade.

WELCH (1952); BRINKHURST (1974); HART \& FULLER (1974); OLIVEIRA (1985), indicam que as larvas de Chironomidae constituem um dos grupos mais abundantes da 
comunidade bêntica, por apresentarem uma ampla distribuição nos vários ecossistemas aquáticos e densidades elevadas em qualquer tipo de habitat, principalmente em corpos d'água eutrofizados. Paradoxalmente, contudo no estudo ora realizado estes grupos não chegaram a atingir altos valores de densidade, se comparados com os outros presentes (Tubificidae e Chaoboridae).

Quando foram registradas densidades numéricas mais elevadas o evento ocorreu nos períodos de menor pluviosidade (inverno), quando então as correlações negativas com a temperatura da água e do ar, servem à essa constatação.

As associações positivas entre Chaoboridae, Glossiphoniidae e Tubificidae ocorridos em alguns pontos de amostragem, parecem indicar que não houve competitividade entre esses organismos ou pelo menos que esta não foi acentuada.

As correlações existentes dos grupos Chaoboridae e Tubificidae, parecem ter sido similares estando associadas diretamente com a densidade total dos macroinvertebrados bentônicos, já que estes grupos representaram a maior parte da comunidade.

Da mesma forma que para a densidade total, estes grupos associaram-se negativamente com a temperatura da água e a pluviosidade.

Assim como os Chironomidae, os Chaoboridae correlacionaram-se positivamente com outros organismos da fauna bentônica, com os Tanypodinae no ponto 02 , Tubificidae e Glossiphoniidae no ponto $\odot 3$ e no ponto $\odot 9$ com Pelecycopa, possivelmente também não deve ter ocorrido competitividade entre esses organismos. 


\section{Os Tubificidae}

correlacionaram-se

positivamente e significativamente (sempre $\geq r_{s}=0,70$ ) com a densidade total dos organismos bentônicos, confirmando ser o grupo predominante nesse corpo d'água.

A análise das correlações obtidas através do teste de spearman, mostrou-se útil para auxiliar a constatação de evidências.

Nesse sentido, ainda que as densidades numéricas registradas dos grupos Tanypodinae, Glossiphoniidae e Pelecycopa tenham sido relativamente baixas e, de acordo com a abundância relativa, serem basicamente raras ou ocasionais, permitiram considerar algumas associações ocorridas com estes organismos.

A associação negativa entre os Tanypodinae e a pluviosidade mensal mostra que a pluviosidade elevada pode ter desfavorecido esta espécie quanto as suas densidades. Podendo ser corroboradas com algumas citações na literatura já antes mencionadas.

A maior ocorrência do grupo Glossiphoniidae no ponto 03 , parece ter contribuído tanto para a densidade total dos organismos, quanto para os índices de diversidade e eqüitatividade, sendo constatado pelas associações positivas obtidas.

Segundo PENNAK (1953), o grupo Pelecycopa é mais abundante em lugares com menos de 2 metros de profundidade, entretanto em alguns lagos ocorrem em profundidades de 7 metros ou mais.

A associação positiva entre a profundidade com este grupo no ponto 02 , vem corroborar tal afirmativa.

Vale ressaltar, que embora estes organismos não apresentassem correlações significativas, 
com os índices de diversidade e eqüitatividade, eles contribuíram para o aumento dos mesmos.

\subsubsection{Macroinvertebrados Bentônicos como Indicadores}

Quando se procede a um levantamento não só da literatura especializada, mas sobretudo de textos e relatórios não publicados de monitoramentos de corpos d'água e trabalhos de caracterização ambiental realizados por instituições que se dedicam ao controle da poluição, ou ao fomento dessas ações, como são algumas entidades internacionais (OPS-Organização Panamericana da Saúde/ OMS - Organização Mundial da Saúde/ BID-Banco Interamericano de Desenvolvimento), fica claro a importância da fauna bentônica como indicadora de poluição e/ou contaminação.

Desde o final do século passado, vários são os pesquisadores que se tem dedicado ao estudo da fauna bentônica como indicadora de poluição, tanto no Brasil como no exterior.

ROCHA (1972) procedendo a estudo limnológico-sanitário na Represa de Americana optou por utilizar a macrofauna bentônica como indicadora de poluição. Talvez seja este o primeiro estudo que efetivamente considerou os organismos bentônicos de utilidade para trabalhos de caracterização da poluição em reservatórios no Brasil.

Trabalhando para a Companhia de Tecnologia de Saneamento Ambiental-CETESB, o mesmo autor uma vez mais utilizou 0 bentos como indicador. Esta nova pesquisa, efetuada na Represa do Guarapiranga levou à elaboração da tese de doutorado do pesquisador. ROCHA, 1976 verificou uma maior presença de vermes tubificídeos em relação aos outros organismos encontrados, e já 
alertava sobre os problemas da eutrofização, recomendando a necessidade de controlar as cargas poluidoras, a ocupação do solo etc. 0 presente trabalho corrobora essas informações.

Ainda em 1972 Rocha, trabalhando na Colômbia utilizou além do fitoplâncton e zooplâncton, a macrofauna bentônica como indicadora de poluição, tanto no rio Bogotá, quanto nas represas de Sisga, Guatavita, Neusa e nas Lagoas de Estabilização de Tibabuyes e Tabio.

Esse trabalho realizado para o Organização Panamericana da Saúde permitiu à Corporación Autonoma Regional de la Sabana de Bogotá y de los Valles de Ubaté y Chiquinquira não só caracterizar uma zona de intensa degradação no referido rio, como também a elaboração de uma plano de monitoramento.

No ano seguinte ROCHA (1973 a) prosseguiu o trabalho de caracterização em novo trecho do rio Bogotá e novamente a fauna de fundo foi utilizada como indicadora de poluição. Os vermes tubificídeos indicavam intensa poluição orgânica aparecendo em certos pontos à jusante dos lançamentos de esgotos sanitários da cidade de Bogotá em concentrações superiores ao milhares $/ \mathrm{m}^{2}$. 0 mesmo ocorreu nos pontos de amostragem 05, 07 e 09 no trabalho ora apresentado revelando também intensa poluição orgânica.

De Bogotá passou o pesquisador à cidade de Cali. o mesmo tipo de trabalho foi realizado então nos rios Cali e Cauca, bacia do rio Magdalena. ROCHA (1973 b) utilizando a fauna bêntica como indicadora determinou uma zona que chamou "barreira de poluição" junto à desembocadura do rio cali caracterizada pela presença de milhões de vermes tubificídeos por $\mathrm{m}^{2}$. 
Esse estudo foi retomado em 1979, observando-se também a represa de Salvajina (ROCHA, 1979).

Entre 1973 e 1977 a CETESB (Companhia de Tecnologia e Saneamento Ambiental) efetuou para a CESP (Companhia Energética de São Paulo) um extenso estudo de caracterização das represas do estado. Nesse período ao lado do monitoramento físico e químico foram identificados e quantificados os organismos do fitoplâncton e zooplâncton. À época Rocha utilizando a macrofauna bentônica como indicadora caracterizou 15 represas da CESP coletando sedimento em vários pontos.

Dos relatórios originais foi elaborada uma sinopse publicada em 1980 (ROCHA, 1980) assinalando que na Bacia do Rio Tietê especificamente a represa de Barra Bonita apresentava mais de 1.100 orgs $/ \mathrm{m}^{2}$ (larvas de dípteros quironomídeos e caoborídeos) indicando ambiente em desequilíbrio.

SHIMIZU (1978) voltou a estudar a fauna bêntica da Represa de Americana com o objetivo de verificar as características ambientais refletidas no componente biológico do sistema. Segundo os resultados os grupos que estiveram presentes em todas as estações estudadas durante todo o período de coleta foram os oligochaeta e os Chironomidae. Analisando os dados obtidos, a autora chegou à conclusão de que existem diferenças na composição da fauna bentônica nas estações estudadas devido ao gradiente de auto-depuração, como também o reservatório estava em processo de eutrofização crescente interferindo na composição anteriormente observada. Os resultados da atual pesquisa se comparados à de SHIMIZU op cit revelam a mesma conclusão. 
A Companhia de Tecnologia de Saneamento Ambiental-CETESB em 1987 realizou um trabalho intitulado "Utilização da Macrofauna Bentônica como Indicadora da Qualidade Ambiental do Alto Rio Ribeira do Iguape".

Dentre os métodos utilizados durante o estudo, o da "densidade total de Oligochaeta" (WRIGTH \& TIDD, 1933 apud CETESB, 1987) foi um daqueles que melhor serviu à avaliação da qualidade ambiental, principalmente quanto à poluição orgânica. 0 método considera os seguintes índices:

- menor de 1.000 organismos $/ \mathrm{m}^{2}$ - representa uma poluição desprezível;

- entre 1.000 e 5.000 organismos $/ \mathrm{m}^{2}$ - representa uma poluição moderada;

- mais de 5.000 organismos $/ \mathrm{m}^{2}$ - representa uma forte poluição.

0 trabalho concluiu que embora nenhum dos pontos tenham atingido índices próximos aos referidos para caracterizar ambientes em equilíbrio, e levando-se em conta as baixas densidades populacionais humanas da região, pode-se inferir que a qualidade da água do trecho estudado não é crítica, pelo menos em relação à poluição orgânica; mas alertava-se sobre as evidências de alta contaminação das águas por chumbo (EYSINK et al, 1987 apud CETESB, 1987) não descartando a possibilidade de que também a comunidade bêntica estivesse sendo alterada. Entretanto, no presente estudo, o mesmo não foi verificado no reservatório do Guarapiranga pois, a aplicação desse índice evidenciou ambiente em desequilíbrio.

$\begin{array}{cccc}\text { BEYRUTH } & \text { (1989) } & \text { elaborou um estudo } \\ \text { ecológico-sanitário em um Lago Marginal ao Rio Embu- }\end{array}$ 
Mirim, pertencente à bacia hidrográfica da qual faz parte a Represa do Guarapiranga. Neste estudo, a macrofauna bentônica novamente foi utilizada para auxiliar na caracterização ambiental. oligochaeta (grupo característico de ambiente poluído) foi aquele que apresentou maior densidade numérica em todas as coletas. A pesquisadora demonstrou mais uma vez que a comunidade bentônica, possibilita ampliar os conhecimentos quanto à qualidade ambiental.

CALEFFI \& ROCHA (1989), pesquisando o Lago do Parque Ibirapuera - São Paulo durante o período de um ano, utilizaram a macrofauna bentônica como indicadora de poluição. Conforme os resultados, registrou-se baixa densidade total dos macroinvertebrados havendo, contudo predominância dos vermes tubificídeos. A avaliação permitiu concluir que existem neste corpo hídrico, condições extremamente seletivas, inclusive para aqueles organismos notadamente tolerantes à poluição, devido ao processo de eutrofização acelerado, ao qual a comunidade bentônica responde de uma forma bem evidente.

Trabalho conduzido nos Rios Sorocaba e Ipanema no Estado de São Paulo, procurou avaliar a qualidade da água em uma região situada com significativo parque industrial (indústrias têxteis, papel e celulose, alimentícias, metalúrgicas etc). A pesquisa utilizando a comunidade zoobentônica, permitiu evidenciar dois ambientes distintos. 0 Rio Ipanema apresenta maior riqueza de organismos bentônicos quando comparado ao Rio Sorocaba. Alguns grupos tais como: Odonata, Ephemeroptera, Bivalvia foram raramente encontrados no Rio Sorocaba (FAGUNDES, 1997).

$$
\text { Mais recentemente HENRIQUE }
$$

utilizando a macrofauna bêntica procedeu à avaliação da qualidade ambiental do Rio Ribeira do Iguape no estado de 
São Paulo. Concluindo que os organismos bentônicos constituem realmente um instrumento eficiente para evidenciar às alterações no meio, conforme se observa pelas mudanças na composição e estrutura das comunidades.

Henrique verificou que o impacto da atividade minerária, causando acidificação, afeta a comunidade bêntica principalmente no primeiro trecho do Rio Ribeira do Iguape, situado entre os km 360 e 255 (cidades de Ribeira, Adrianópolis, Iatóca e Iporanga).

A comunidade bêntica foi utilizada como indicadora de zonas de degradação e recuperação no rio Toledo - Uruguai por AROCENA (1996). Neste estudo o autor, observou a abundância e composição da macrofauna comparando locais de controle, degradação e recuperação. A condutividade, $\mathrm{pH}$, temperatura não apresentaram diferenças entre esses locais, enquanto oxigênio dissolvido e demanda bioquímica de oxigênio demostraram diferenças significantes. A fauna foi mais abundante na zona de recuperação. Os 0ligochaeta foram dominantes nas zonas de controle e de degradação.

Mas não é só na América Latina que os organismos aquáticos e em especial os bentônicos tem servido à caracterização, e mesmo à quantificação de danos ambientais decorrentes da ação antrópica. Em outros países de clima temperado, como na América do Norte e Europa muitos pesquisadores têm dedicado atenção aos organismos componentes da comunidade bêntica.

PENNAK (1953) relata que entre os
organismos bênticos, os principais indicadores de
poluição orgânica especialmente por esgotos domésticos,
são os tubificídeos e quironomídeos e que por vezes o
fundo de corpos d'água eutrofizados são literalmente


cobertos com massas de tubificídeos. Isto pode ser notado em algumas ocasiões no presente estudo.

HART \& FULLER (1974) estudaram os organismos bentônicos, descrevendo suas correlações com as variáveis físicas e químicas da água. Essas observações já enfatizavam que por meio de mais estudos de campo e laboratório os oligochaeta poderiam ser considerados indicadores, como também serem utilizados para detectar a fonte e o grau de poluição.

Autores como BRINKHURST (1974) possuem inúmeros trabalhos e livros publicados com ênfase na fauna bentônica e sua interação com o meio aquático.

WETZEL (1975) disserta sobre corpos hídricos que ficando sujeitos a poluição orgânica e tendo a concentração de oxigênio dissolvido reduzida, neles encontram-se tubificídeos em abundância, concomitantemente com uma redução drástica seguida da exclusão da maior parte dos outros organismos bênticos. Relata também que desde que haja disponibilidade de oxigênio de uma forma periódica, a abundância de alimentos, a falta de competição e de predadores permitem aos tubificídeos um desenvolvimento rápido. Parece que algumas das afirmativas acima citadas, vem corroborar 0 que ocorreu no reservatório do Guarapiranga.

Wetzel, comenta também que quando os lagos se tornam mais eutróficos dá-se uma viragem na composição percentual dos dois grupos dominantes, com o declínio das larvas de quironomídeos e o aumento dos vermes oligochaetas-tubificídeos, o único grupo da macrofauna bêntica adaptada à condição de sobrecarga orgânica extremamente elevada. Este fato pode ser confirmado no reservatório do Guarapiranga onde o percentual do grupo Chironomidae foi menor do que o grupo dos Tubificidae. 
HELLAWELL (1986) autor do livro intitulado "Biological Indicators of Freshwater Pollution and Environmental Management" discute a importância dos indicadores biológicos. Examinando várias citações literárias sobre indicadores, demonstra (esquema a seguir) os diferentes grupos que tem sido recomendados para a avaliação da qualidade ambiental. Dentre estes as algas e os invertebrados bentônicos foram definidos como os dois grupos de organismos mais freqüentemente recomendados, sendo que os macroinvertebrados são mais comumente utilizados e efetivos.

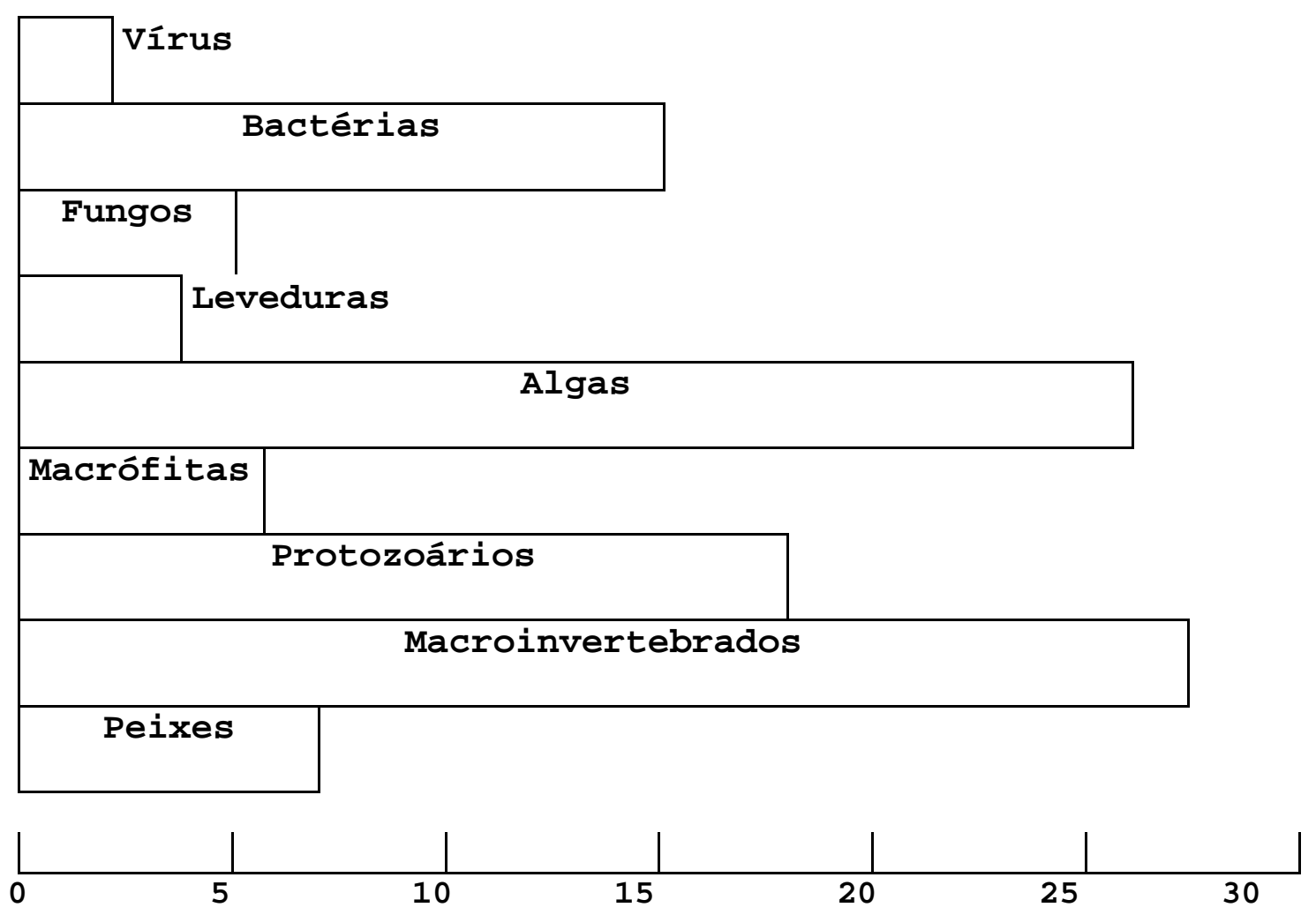

Recomendações para o uso de diferentes grupos taxonômicos como indicadores biológicos. Distribuição percentual de citações na Literatura até 1970.

Fonte: Adaptado de Hellawell (1986). 
ROSENBERG \& RESH (1993) relatam que o biomonitoramento tem sido adotado pelos governos Europeus e Norte Americano em programas de monitoramento e avaliação ambiental, incluindo a biota aquática. Esses programas utilizam uma variedade de "indicadores" de saúde ambiental e, dentre estes os considerados mais promissores e vantajosos são os macroinvertebrados bentônicos.

Como menciona esse mesmo autor, isso não significa que somente esses organismos sejam utilizados no biomonitoramento, mas fornece informações que possibilitam o uso da fauna bêntica com o máximo efeito dentro do contexto do programa de monitoramento da qualidade da água, como também são utilizados para atingir outros objetivos. Nesse caso incluem-se o monitoramento de mudanças na composição genética, testes toxicológicos em laboratório e no campo, medições de mudanças no número de populações e composição da comunidade ou funcionamento do ecossistema.

SAERKKAE (1996) observando organismos bênticos no Lago Ladoga em St. Petersburg - Rússia, demonstra que espécies de Oligochaeta-Tubificidae estiveram mais concentradas em ambientes eutrofizados.

os níveis de poluição por detergentes e sua influência na comunidade bêntica no rio Rio Negro na Colômbia foi investigado por PEREZ \& ROLDAN (1978). Os mesmos autores utilizaram a fauna bentônica como indicadora da qualidade da água. Os resultados mostraram que o índice de diversidade foi baixo em locais com indústrias e alta densidade urbana.

SINHA E RAZ (1993) verificaram o efeito da poluição sobre os organismos bentônicos em um rio da Índia, revelando que ao longo da cidade de Patna no 
território indiano o rio recebia várias pontos de descargas domésticas tornando-se fortemente poluído, notando que o grupo Tubificidae foi predominante, enquanto poucas larvas de insetos foram encontradas. 0 mesmo ocorreu na estação 07 (Clube Castelinho) no presente estudo.

LANG \& REYMOND (1996) investigaram 4 lagos da Suíça quando houve uma limitação da entrada de fósforo nesses corpos d'água, verificando um decréscimo substancial na concentração desse elemento mineral entre 1980 a 1990. Nos lagos Geneva e Neuchatel, os grupos de Tubificidae e Lumbriculidae responderam claramente a esse decréscimo enquanto que houve abundância de espécies típicas de condições oligotróficas na comunidade de Oligochaetas. Em contraste, comunidades de Oligochaetas a dos lagos Morat e Jocex, as quais consistem de espécies tolerantes (Tubifex tubifex e Limnodrillus hoffmeisteri), não indicaram nenhuma melhora nas condições ambientais entre 1980 a 1990 .

\subsubsection{Agrupamento Espacial (Dendrograma)}

Por meio do dendrograma de agrupamento das estações de coleta, à partir dos dados obtidos da análise da macrofauna bentônica houve a formação de dois (2) grupos de estações na represa do Guarapiranga (Figura 23 ) .

0 grupo $\underline{\mathbf{A}}$ compreende as estações 02, 03, 08 e 10, área que é formada pelo eixo principal do reservatório. Estes pontos caracterizaram-se por apresentar uma participação mais efetiva do grupo chaoboridae. 
LEWIS, (1977) cita que apesar dos Chaoboridae possuírem taxas alimentares menores do que os peixes, ocorrem em densidades elevadas, e são predadores de Oligochaeta, Cyclopoida, Calanoida e Chironomidae. Os Chaoboridae podem predar até $20 \%$ de determinadas populações de zooplâncton por dia.

CALEFFI (1994) observou no reservatório do Guarapiranga indícios de que as larvas de Chaoboridae são importantes elementos da comunidade bentônica.

Utilizando dos dados de CALEFFI (1994) que analisou a comunidade zooplantônica é possível inferir que as altas densidades desses organismos no reservatório propicia uma disponibilidade de alimento ao grupo chaoboridae.

Em relação aos parâmetros físicos e químicos, a condutividade elétrica revelou-se elevada em algumas estações de coleta ( 08 e 10) deste grupo; talvez pela influência de material alóctone, isto é, a maior concentração de nutrientes nesta área do reservatório, onde o período de retenção e a profundidade são maiores e também há ingresso das águas muito ricas em nutrientes do córregos de Itupú, Guavirituba, do rio Embu-Mirim e dos córregos rio Bonito e rio das Pedras, acarretando maior disponibilidade de alimento para os organismos, pela decomposição de matéria orgânica.

Nos pontos 02 e 03 , os valores de cor encontraram-se mais altos do que em outros locais do reservatório. BEYRUTH et al (1997) também obtiveram valores mais elevados de cor no mesmo local, citando que a cor de "chá" da água, provavelmente seja devida à alta concentração de Fe e Mn e/ou a liberação de pigmentos das macrófitas aquáticas. Neste caso, a cor pode influir 
sobre as populações bênticas, pois ao diminuir a transparência da água dificulta a predação.

As estações de coleta 05,06 e 09 estão contidas no grupo $\underline{B}$. Essas áreas estão sob a influência direta de constantes descargas orgânicas dos tributários, principalmente os pontos 05 e 09 . Apesar do ponto 06 estar mais próximo da parte central da represa, este foi considerado pertencente a este grupo por receber influência de material autóctone do ponto 05.

Notou-se neste conjunto de estações (grupo B, uma elevada predominância de Tubificídeos. Entretanto, outros grupos, mais especificamente os Tanypodinae atingiram abundâncias significativas em relação as outras estações. Seus gêneros são geralmente considerados carnívoros, predadores de invertebrados, incluindo espécimes da própria espécie (TUDORANCEA, et al; 1979; MERRITT \& CUMMINS, 1984), enquanto algumas espécies alimentam-se de detritos e algas, quando há falta de animais a serem predados no ambiente. Portanto, pode-se supor que este grupo, tenha sido favorecido ou pela disponibilidade de presas ou pela maior concentração de alimentos (detritos).

A quantidade de vermes tubificídeos encontrados nessas áreas é o resultado de uma interação de fatores, tais como; maior quantidade de alimentos (matéria orgânica)(LELLAK, 1965; JONASSON, 1969), advindos de vários tributários; 0 tipo de sedimento (CUMMINS \& LAUFF, 1969; MCLACHLAN \& CARTELL, 1976), no caso, a maioria apresentando um sedimento mole, lodoso, às vezes com odor séptico.

Nesta mesma região da represa do Guarapiranga CALEFFI (1994) obteve maiores densidades numéricas da comunidade zooplanctônica total. A mesma 
autora cita INFANTE (1993) assinalando que em áreas influenciadas pela poluição orgânica há altas densidades dessa comunidade, contribuindo para uma maior quantidade de alimento para os organismos bentônicos.

A estação 09 está sob influência do rio Itupú, sendo classificada como hipereutrófica (CALEFFI, 1994). As elevadas concentrações de bactérias coliformes durante o período de estudo podem corroborar tal afirmativa.

Ainda no grupo $\underline{\mathbf{B}}$ de estações, de maneira geral, a condutividade elétrica apresentou valores mais altos. BRANCO (1986) enfatiza que a variação da condutividade elétrica fornece diretamente um conhecimento à respeito de processos que ocorrem na massa d'água, tais como decomposição, que é refletida pelo aumento de seus valores. Por esta razão, a condutividade elétrica pode auxiliar na detecção de fontes de poluição.

Os pontos 01,04 e 07 constituíram segundo o dendrograma, áreas ou regiões isoladas no reservatório, pelo fato de que essas regiões apresentaram-se com características distintas em relação as outras, conforme descrito a seguir.

Apesar de receber contribuição do Rio Embu-Guaçu (que vem sofrendo ação antrópica nas últimas décadas), a estação 01 é considerada uma das menos atingidas pelas cargas de poluentes. Os resultados das análises de zooplâncton realizados por CALEFFI (1994) na mesma estação, mostraram comunidades que indicam baixas condições de eutrofização.

Essa área apresentou densidades numéricas relativamente baixas do bentos total, mas com uma participação mais efetiva do grupo chaoboridae e 
Chironomidae em relação aos outros que foram quase inexpressivos.

A influência significativa de macrófitas aquáticas, a elevada turbidez e menores concentrações de oxigênio dissolvido, talvez tenham sido desfavoráveis à macrofauna bentônica como um todo.

No ponto 04 onde ocorreu a menor densidade total dos organismos bentônicos - 787 orgs $/ \mathrm{m}^{2}$ (Tabela 17), paradoxalmente foram registrados em média os maiores índices de coliformes fecais e totais; o que pode ser explicado, pelo fato de que este ponto recebe influência do corpo principal e pequenos tributários que chegam ao reservatório; ou também estar relacionado com a presença de aves ou pastos próximos.

A amostra do sedimento neste ponto é constituída por gravetos, restos de folhas etc; substrato considerado instável que, embora com matéria orgânica, ao que parece não está prontamente disponível à alimentação da macrofauna. Portanto, pode ter influenciado negativamente à fauna bêntica .

0 ponto 07 constitui segundo o dendrograma uma outra área ou região isolada do reservatório se comparado às outras regiões antes comentadas.

Nesta há influência da poluição trazida por inúmeros córregos, que segundo BEYRUTH (1997) são considerados como dos maiores contribuintes para a eutrofização no reservatório. CALEFFI (1994) classifica igualmente, este ponto como hipereutrófico.

0 tipo de substrato observado neste ponto é caracterizado pela presença de excessivas quantidades de matéria orgânica decomposta, não consistente, amorfa e areno-argilosa. De qualquer maneira caracteriza ambiente 
passível de albergar a macrofauna bentônica pela existência de material nutritivo.

Considerando-se todo o período de estudo, essa região apresentou um pico de organismos (9.576 orgs $/ \mathrm{m}^{2}$ ) com o predomínio de vermes tubificídeos (8.466 orgs $/ \mathrm{m}^{2}$ ), o que significa $9 \odot \%$ dos organismos amostrados.

A característica do substrato juntamente com a maior disponibilidade de alimento, permitiu que os Tubificidae fossem o grupo dominante, já que estes animais apresentam preferência reconhecida por substratos moles, compostos de silte e argila, dos quais fazem uso como habitat e local de alimentação. A maior parte dos representantes deste grupo, senão toda, alimenta-se de bactérias, ingerindo grandes volumes de sedimento de forma contínua $e$, deste extraem a pequena fração de alimento nele contido (BRINKHURST \& COOK, 1974).

Outro fator importante a ser observado sobre os tubificídeos é o fato destes serem razoavelmente resistentes também à maioria dos poluentes, proliferando e sendo abundantes em áreas onde todos os animais foram extintos ou migraram, sendo por isso freqüentemente associados a ambientes poluídos (WITLEY, 1968).

JONASSON (1969) relata que o estágio final da eutrofização e/ou poluição, quando o número de espécies de organismos bentônicos diminui quase a zero, a fauna local pode tornar-se restrita aos 0ligochaetas. 


\section{CONCLUSÕES E RECOMENDAÇÕES}

A pesquisa permitiu concluir que:

- o reservatório constitui ambiente eutrófico conforme atestam os dados de transparência e nitrogênio total permitindo que a mesma possa ser enquadrada como mesoeutrófica e politrófica;

- as oscilações de temperatura e do índice pluviométrico propiciou alterações na comunidade de macroinvertebrados bentônicos que são refletidos na densidade numérica das populações;

- foram reconhecidos grupos de macroinvertebrados bentônicos que correspodem às seguintes estações de coleta (grupo $\underline{\mathbf{A}}-02,03,08$ e 10) e grupo $\underline{\mathbf{B}}(05,06$ e 09$)$, caracterizando o grupo $\underline{B}$ uma região mais eutrofizada do reservatório;

- os lançamentos "in natura" trazidos por vários córregos adjacentes tem influência direta no ponto 07 (que não se agrupou às outras estações de coleta) onde os Tubificidae foram dominantes corroborando a existência de uma poluição orgânica mais acentuada;

- o aumento significativo na densidade do grupo Oligochaeta-Tubificidae e a queda no número de larvas de Chironomidae, permite inferir que está em curso um intenso processo de seletividade da macrofauna bentônica;

- dentre as análises estatísticas utilizadas; aquele índice que apresentou melhores resultados, permitindo fácil visualização do comportamento da macrofauna bêntica em relação às condições ecológico-sanitárias do reservatório foi a densidade numérica $\left(\right.$ orgs $/ \mathrm{m}^{2}$ );

- a comunidade bêntica confirmou ser um instrumento eficiente na avaliação da qualidade da água, respondendo 
claramente a todas as alterações do meio, através de mudanças na sua estrutura.

- à vista do exposto recomenda-se continuar os programas para melhoria da qualidade sanitária das águas;

- finalmente enfatiza-se a importância da macrofauna bentônica como indicadora de poluição e toxicidade, recomendando a sua utilização em programas de monitoramento conduzidos pelas entidades estatais e/ou particulares. 


\section{REFERÊNCIAS BIBLIOGRÁFICAS}

Amarante, 0 . et al Abastecimento de água da área metropolitana de São Paulo". Rev DAE 1958; 32(19):21-40. APHA;AWWA;WPCF. Standard Methods for the Examination of water and Wastewater. 18th ed. APHA. Washington, D.C., 1993.

Arcifa, MS. Zooplâncton composition of ten reservoirs in Southern Brazil. Hydrobiologia, 1984; 113:137-45.

Arocena, R. The benthic community as degradation and recuperation zones indicator in Toledo stream, Uruguay. Rev. Biol.-Trop. 1996 vol.44, no 2, pp.659-671.

Beyruth, Z. Estudo Ecológico-Sanitário de um Lago Marginal ao Rio Embu-Mirim - Itapecirica da Serra, São Paulo e ensaio sobre a possibilidade de utilização da macrófita aquática Eichhornia crassies (Mart) Solms como indicadora de poluição. São Paulo; 1989. [Dissertação de Mestrado - Departamento de Zoologia - IBUSP].

Beyruth, Z. Avaliação do Impacto Decorrente de Atividade de Portos de Areia para o Rio Embu-Mirim. Brasília-DF; Relatório CNPq, 1994 (Proc. nº 80.4531/90-0).

Beyruth, Z. Comunidade Fitoplanctônica da Represa de Guarapiranga: 1991:92. Aspectos Ecológicos, Sanitários e Subsídios para Reabilitação da Qualidade Ambiental. São Paulo; 1996. [Tese de Doutorado - Departamento de Saúde Ambiental - Faculdade de Saúde Pública da USP].

Beyruth, Z.; Caleffi, S.; Zanardi, E.; Cardoso, E. \& Rocha, AA. Water quality of Guarapiranga reservoir, São Paulo, Brazil, 1991/1992. Verh. Internat Verein Limnol, dezember, 1997 26:675-683.

Borba,JR, EF.; Kokait, F. \& Marincek, W. Programação de obras para aproveitamento integral da capacidade dos 
mananciais Guarapiranga e Baixo Cotia. Rev DAE 1968; $69(28): 17-24$.

Branco, SM. Qualidade das Águas dos Principais Mananciais da Grande São Paulo. São Paulo. (Datilogr), COMASP, 1973. Branco, SM. \& Rocha, AA. Poluição, proteção e usos múltiplos de represas. CETESB/Ed São Paulo: Edgard Blücher, 1977.

Branco, SM. Hidrobiologia aplicada à Engenharia Sanitária - água - São Paulo. CETESB/ACETESB, 1986.

Brandimarte, AL. Macrofauna bentônica da zona litoral da represa de Paraíbuna (SP): a influência de diferentes ecossistemas terrestres perimetrais. São Paulo, 1991 [dissertação de Mestrado Instituto de Biociências da USP ].

Brinkhurst, RO. \& Kennedy, CR. Studies on the biology of the Tubificidae (Annelida:Oligochaeta) in a polluted stream. J Anim Ecol 1965; 34(2):429-443.

Brinkhurst, RO \& Cook, DG. Aquatic earthworms (Annelida:Oligochaeta) In: Hart Jr., CW. \& Fuller, SLH., ed. Pollution ecology of freshwater invertebrates. New York, Academis Press 1974; 143-156.

Brinkhurst, RO. The benthos of lakes. New York. Marmillaw Press, 1974.

Caleffi, S. \& Rocha, SM. Variação sazonal da macrofauna bentônica do lago do Ibirapuera (SP) e sua utilização como indicador de poluição. São Paulo Rev DAE 1993; $170(53): 1-4$.

Caleffi, S. A represa de Guarapiranga: Estudo da comunidade zooplanctônica e aspectos da eutrofização. São Paulo. 1994 [Dissertação de Mestrado Departamento de Saúde Ambiental da Faculdade de Saúde Pública da USP]. 
Castro, PP. Plano de abastecimento de água para a área metropolitana de São Paulo. Rev DAE 1963; 51(24):9-25.

Castro, PP. 0 problema de abastecimento de água para a área metropolitana de São Paulo. Rev DAE 1965; 58(26):511.

CETESB Relatório sobre controle de qualidade de águas de mananciais, ETAs, reservatórios e estações de recalque. São Paulo. Relatório COMASP/FESB-CETESB (Datilogr.), 1972 .

CETESB Controle das fontes de poluição localizadas nas áreas de proteção de mananciais In: Resumos do Congresso Brasileiro de Engenharia Sanitária e Ambiental. Camboriú, SC (ABES), 1983; p.12.

CETESB Utilização da macrofauna bentônica como indicadora da qualidade ambiental do Alto Rio Ribeira de Iguape São Paulo, SP. Relatório Técnico 1987.

CETESB Eutrofização e contaminação por meio de metais no reservatório do Guarapiranga. Dados preliminares, São Paulo. Relatório Técnico 1992 (datilogr).

CETESB Avaliação ecotoxicológica do reservatório do Guarapiranga-SP com ênfase ao problema de algas tóxicas e algicidas. Recuperação da bacia do Guarapiranga. São Paulo, Projeto: 15.13.00 Relatório Técnico, 1995.

COBRAPE Programa de saneamento ambiental em áreas metropolitanas - Bacia do Guarapiranga. Relatório Publ. Secretaria de Estado do Governo de São Paulo, 1991.

COBRAPE Relatório consolidado dos estudos complementares relacionados à qualidade da água. Análises e proposições. Relatório UPG/COBRAPE, novembro/1994 a.

COBRAPE Ações diretamente relacionadas à qualidade da água. Relatório de andamento para avaliação de meio termo 
do Programa de Saneamento Ambiental da Bacia do Guarapiranga. Relatório UPG/COBRAPE, dezembro/1994 b.

Cohen, M. Guarapiranga está Afogada no Descuido. Parabólicas Inst. Socioambiental 1996; 24(3).

CONAMA-20/86. Resolução do Conselho Nacional de Meio Ambiente/Ministério do Desenvolvimento Urbano e Meio Ambiente - Secretaria Especial do Meio Ambiente.

Cummins, KW. \& Laufh, GH. The influence of substrate particle size on the micro-distribution of stream macrobenthos. Hydrobiologia 1969; 34:145-181.

Cunha, A. Perturbação no tratamento das águas de Santo Amaro. Bolm Repart Águas São Paulo 1936; 1(1):39-50.

Cunha, A. Reforma e ampliação da estação de tratamento de água de Santo Amaro (São Paulo). Rev DAE 1955; 26(16):1532.

Domingos, MD. Heterogeneidade espacial (horizontal) da represa de Guarapiranga (São Paulo) e a distribuição da comunidade zooplanctônica. 1993 [Dissertação de Mestrado Escola de Engenharia de São Carlos da USP].

Espinosa, HRM. Desenvolvimento e meio ambiente sob nova ética. Rev Ambiente 1993; 7:(1).

Esteves, FA. Fundamentos da Limnologia. Rio de Janeiro, Ed. Interferência/FINESP, 1988.

Esteves, KE. \& Sendacz, S. Relações entre a biomassa do zooplâncton e o estado trófico de reservatório do Estado de São Paulo. Acta Limnol Brasil, 1988; II:587-604.

Fagundes, RC. Avaliação da Qualidade da Água do Rio Sorocaba, S.P. e seu Afluente Ipanema, através dos organismos Zoobentônicos, SP. São Paulo; 1997. [Dissertação de Mestrado - IBUSP]. 
Ferraz, P. Ocupação de mananciais compromete abastecimento. Jornal da Tarde, São Paulo, 1998 out/12, folha $16 \mathrm{~A}$.

Gaufin, AR. \& Tarzwell, CM. Environmental changes in a polluted stream during winter. Am Midl Nat, Notre Dame, 1955; 54(1):78-88.

Hamilton, AL. \& SAETHER, OA. 1971. The occurence of caracteristic deformities in the chironomid larvae of several Canadian lakes. Can.Ent.103 (3): 363-368.

Hart, JR. \& Fuller, SHL. Pollution ecology of freshwater invertebrates. New York and London, 1974.

Hartman, WN. 1974. Snails (Mollusca: Gastropoda). In: Hart Jr.,CW. \& Fuller, SLH. (eds). Pollution Ecology of Freswater Invertebrates. New York, Academic Press. p.275312.

Hellawell, JM. Biological Indicators of Freshwater Pollution and Environmental Management. Elsevier Science Publishers Ltd, New York, 1986.

Helou, LC. \& Silva, LG. Estudo de Operação do Reservatório de Guarapiranga. In: Congresso Brasileiro de Engenharia Sanitária e Ambiental XIV; Salvador-BA, 1987 setembro $20-25$.

Henrique, RM. Avaliação da Qualidade Ambiental do Rio Ribeira do Iguape (SP, Brasil) através do estudo da Macrofauna Bentônica, SP. São Paulo; 1998. [Dissertaçao de Mestrado - IBUSP].

Infante, AG Annual variations in abundance of zooplankton in Lake Valencia (Venezuela). Arch Hydrobiol 1982; $92(2): 194-208$.

Jonasson, PM. Bottom fauna e eutrophication In: Proceedings of the symposium of the national academy of 
science, Washington. Eutrofication: causes, consequences e correctives. Washington, National Academy of Science $1969 ; 274-305$.

Johnscher-Fornasaro, G.; Dias Filho, MM.; Brassolatti, RC. 1987. "Utilização da Macrofauna Bentônica como Indicadora da Qualidade Ambiental no Alto Rio Ribeira do Iguape". São Paulo, CETESB (Trabalho apresentado a Comissão de Graduação da Universidade Federal de São Carlos. São Paulo- SP, 1987 P.1-48.

Kleerekoper, H. Biologia da represa velha de Santo Amaro (represa do Guarapiranga). Bolm Repart Águas São Paulo 1937; 2(1):151-161.

Kleerekoper, H. Estudo limnológico da represa de Santo Amaro em São Paulo. Bolm Fac Filos Ciênc Univ São Paulo 1939 (Bol) 7(2):9-151.

Kleerekoper, H. Introdução ao estudo da limnologia. Ministério da Agricultura Depto Nac Prod Animal, Divisão de caça e pesca, Rio de Janeiro 1944; publ. no 4 (série didática).

Kuhlmann, ML. Estudo da comunidade de invertebrados bentônicos da zona profunda da Represa de Paraíbuna, SP. São Paulo; 1993. [Dissertação de Mestrado - IBUSP].

Lang, C \& Reymond. 0. Reversal of eutrophication in four Swiss lakes: Evidence from Oligochaete communities. Hydrobiologia, 1996 vol.334, no 1-3. Pp.157-162.

Legendre, C \& Legendre, P. Numerical ecology. developments in environmental modeling. 3. Amsterdan Elsevier Scientific Publish. Co., 1983.

Lehmukull, DM. Environmental disturbance and life histories: principles and examples. J Fish Res Bd Can 1979; 36(3):329-34. 
Lellak, J. The food supply as a factor regulating the population dynamics of bottom animals. Mitt int Verein theorc angew Limnnol 1965; 13:128-138.

Lewis, Jr, WM. Feeding selectivity of a tropical Chaoborus population. Freshwat Biol, 0xford, 1977; $7(4): 311-325$.

Maier, M.H. \& Takino, M. Limnologia de reservatórios do Estado de São Paulo, Brasil. III. Qualidade da Água - B. Inst. Pesca, São Paulo, 12 (1): 103-122, 1985.

Mancuso, PCS. Reuso da água e sua possibilidade na região metropolitana de São Paulo. São Paulo; 1992. [Tese de Doutorado. Departamento de Saúde Ambiental da Faculdade de Saúde Pública da USP].

Mantovani, M. ONGs põem Guarapiranga no Mapa. Jornal da Tarde. São Paulo, 1996 novembro 4; p. 13 A.

Margalef, R. Ecologia Ed. Omega SA Barcelona, 1974.

Margalef, R. Limnologia. Ed Omega SA Barcelona, 1983.

Matsumura-Tundisi, T.; Occurrence of Species of the Genus Dapnhia in Brazil. Hydrobiologia, 112: 161-165, 1984.

Melchor, A.; Silveira, A.; Lopez, GM. 7 Araújo, R. Preservação de Mananciais para abastecimento Guarapiranga, um modelo de preservação. Rev. DAE-SABESP $1974 ; 35: 14-25$.

Merrit, RW. \& Cummins, KW. (eds) Na Introduction to the aquatic insects of North America. $2^{\text {nd }}$ ed. Kendall Hunt Publ Co, 1984; 722 p.

Norris, RH. \& Georges, A. Analysis and interpretation of benthic macroinvertebrates surveys In: Rosenberg, DM. \& Resh, VH. eds Freshwater biomonitoring and benthic macroinvertebrates. New York, Chapman e Hall, 1993; p. $234-286$. 
Odum, EP. Ecologia. Trad. R.I. Rios $1^{\mathrm{a}}$. Rio de Janeiro: Interamericana, 1983.

Oliveira, JEC. Barragem Santa Barbará, Pelotas, Rio Grande do Sul: Observações sobre o bentos profundal. 1985. [Tese de Doutorado Instituto de Biociências/USP]. Oliveira, WE. Proteção as águas da Bacia do Guarapiranga. Rev DAE 1961; 42(22):86-93.

Palmer, CM. Algas e suprimento de água na área de São Paulo Rev DAE 1960; 21:11-15.

Paranhos, H. Saneamento do lago de Santo Amaro. Bolm. Repart Águas, São Paulo-SP 1937; 177-193.

Payne, AI. the ecology of tropical lakes and rivers. New York, John Wiley e Sons, London, 1986.

Pedroso, JSo. Medidas d proteção das águas do reservatório do Guarapiranga Rev DAE 1960; 36(21):53-56.

Pedroso, JSo. Medidas de Proteção das Águas do Reservatório do Guarapiranga. Rev DAE 1960; 36(21):53-56. Pennak, RW. Freshwater invertebrates of United States. Ronald Press Comp. New York, 1953.

Pereira, HASL. Aspectos ecológicos-sanitários e 0 fitoplâncton de represas da área metropolitana de são Paulo utilizadas como mananciais. São Paulo. Relatório Conselho Departamento de Saúde Ambiental da Faculdade de Saúde Pública da USP, 1987 (datilogr).

Perez, R. \& Roldan, PG. "Niveles de contaminacion por detergentes y su influencia em las comunidades benticas del Rio Rio Negro". Univ. Antioquia, Dep. Biol., Medellin, Colômbia. 1978, vol7, no 24, pp.27-36.

Perez, RG. Guia para el estudio de los macroinvertebrados acuáticos del Departamento de Antioquia. Editorial Presencia Ltda. Bogota, Colômbia, 1988. 
Petr, T. Dynamics of benthic invertebrates in a tropical man-made lake (Volta Lake, 1964-1968): standing crop and bathmetric distribution. Arch Hydrobiol 1974; 73(2):245265.

Pielou, EC. The interpretation ecological data New York, wiley 1984; $263 \mathrm{p}$.

Pontes, LAL. Dados sobre a adução de água na cidade de São Paulo e conclusões estatísticas. Rev DAE 1965; $56(26): 68-70$.

Queiroz, Vos. Abastecimento de Água na Cidade de São Paulo. Rev DAE 1964; 52(25):1-48.

Radford, DS. \& Rowe, RH. A preliminary investigation of botton fauna and invertebrate drift in an unregulated and a regulated stream in Alberta. J. Appl Ecol, New York, $1971 ; 8(3): 883-903$.

Reice, SR. \& Wohlenberg, M. Monitoring Freshwater for Assessment of Ecosytem Health. In: Rosenberg, DM. \& Resh, VM. (eds) - Introdution to freshwater biomonitoring and benthic macroinvertebrates. New York, Chapman e Hall, 1993 .

Rocha, AA. Proliferação de vegetais na represa do Guarapiranga, São Paulo. Relatório COMASP/FESB-CETESB (datilogr.), 1970.

Rocha, AA. Autodepuração dos cursos d'água. Zonas de poluição; depressão de oxigênio, balanço de oxigênio. In: Manual do Curso sobre Poluição das Águas. Brasília, 1971; p. $50-57$.

Rocha, AA. Estudo sobre a Fauna Bentônica da Represa de Americana no Estado de São Paulo. São Paulo; 1972. [Dissertação de Mestrado. Departamento de Zoologia, Instituto de Biociências da USP]. 
Rocha, AA. Informe sobre el estabelecimento de um programa de investigación de Hiidrobiologia (Fitoplâncton, Zooplâncton y Fauna de Fondo) em el rio Bogotá, afluentes y embalses, del cerca de CAR (Corporacion Autonoma Regional de la Sabana de Bogotá y de los Valles de Ubaté y Chiquinquira). OPS/OMS, pp.39 e anexos Bogotá, Colômbia, 1972.

Rocha, AA. Informe sobre o programa de Estudios Hidrobiológicos y Ecológicos em a zona del bajo rio Bogotá para la CAR(Corporacion Autonoma Regional de la Sabana de Bogotá $y$ de los valles de Ubaté y Chiquinquira). OPS/OMS, pp.32 Bogotá, Colômbia, 1973 (a). Rocha, AA. Estudo Hidrobiológico Cuenca del Alto Rio Cauca. Cali, Colômbia para la CVC (Corporacion Autonoma Regional del Cauca). OPS/OMS pp.57 y anexos. Cali, Colômbia, 1973 (b).

Rocha, AA. A limnologia, os aspectos ecológicossanitários e a macrofauna bentônica da represa do Guarapiranga na Região Metropolitana de São Paulo. São Paulo; 1976. [Tese de Doutorado. Departamento de Zoologia, Instituto de Biociências da USP].

Rocha, AA. Informe sobre um Programa de Implantacion de Tecnicas de Byensaio de Atualizacion del estudio hidrobiologico del rio Cauca; observaciones de la biologia de plantas de tratamento tipo lodos ativados; consideraciones preliminares sobre la salvajina su ecologia general y calidad sanitaria del agua CVC (Corporacion Autonoma Regional del Cauca). OPS/OMS pp. 40. Cali, Colômbia, 1979.

Rocha, AA. Limnologia, Recreação e Pesca nas Represas da CESP. Rev. Engenharia Sanitária (Caderno Técnico). Ro de Janeiro, 3 (19): 336-337, 1980. 
Rocha, AA. Ecologia - A Qualidade de Vida In: Saúde e Meio Ambiente - SESC-Serviço Social do Comércio março/1993 p.67-80.

Rocha, A.A. Estado da arte no Brasil: Uma abordagem crítica. 1997 (no prelo).

Rosenberg, DM. \& Resh, VM. - Introduction to freshwater biomonitoring and benthic macroinvertebrates. In: Rosenberg, D.M. \& Resh, VM. eds Freshwater biomonitoring and benthic macroinvertebrates, New York, Chapman e Hall 1993.

Saerkae, J. Meiofauna of the profundal zone of the part of Lake Ladoga as an indicator of pollution. Hydrobiologia, 1996, vol. 322 no 1-3 pp.29-38.

Sala, GM.; Gibson Jr, GE. \& Harrel, RC. Physicochemical conditions and benthic macroinvertebrates of a tertiary sewage treatment system. Hydrobiologia, Den Haag, 1977; $54(2): 161-166$.

Salvador Fo, P. \& Chinez, SJ. Levantamento das Condições Sanitárias do Reservatório do Guarapiranga, São Paulo. Relatório COMASP/FESB-CETESB. Vols. 1 e 2 (datilogr), 1972.

Savelli, M. Histórico do aproveitamento das águas da região paulistana. Rev DAE 1964; 53(25):82-87.

Sendacz, S. \& Kubo, E. Copepoda (Calanoidae Cyclopoida) de reservatórios do Estado de São Paulo. Bol Inst Pesca, $1982 ; 9: 51-89$.

Sendacz, S.; Kubo, E.\& Cestarolli, MA. Limnologia de reservatórios do Estado de São Paulo, Brasil. VII Zooplâncton. Bolm Inst Pesca, 1985; 12(1):187-207. 
Shimizu, GY. Represa de Americana aspectos do bentos litoral. 1978 [Dissertação de Mestrado Departamento de Zoologia do Instituto de Biociências da USP].

Sinha, RK. \& Das, NK. Organic waste and its effect on macro-zoobenthos in Ganga at Patna (Bihar), Índia. $\mathbf{J}$. Freshwat. Biol. 1993, vol. 5, no 1, pp. 33-40.

Siegel, S. Estatística não paramétrica para as ciências do comportamento. Trad. AA.Farias $1^{\mathrm{a}}$ ed São Paulo, Mac Graw-Hill, 1975.

Silva, RJC.; Brasil, AL. \& Silva, CCA. Guaracabí - Plano de um novo sistema sul de abastecimento de água da Grande São Paulo. Rev DAE-SABESP 1986; 46(146):236-246.

SMA - Guarapiranga. SMA Verde Perto. Secretaria de Estado do Meio Ambiente. São Paulo. 7(1): 1-6, novembro, 1996.

Strixino, GBMA. Sobre a ecologia dos macroinvertebrados do fundo na represa do Lobo, São Paulo. 1973. [Tese de Doutorado de Biologia, IB/USP].

Thompson, OB. Dados sobre o abastecimento de água de São Paulo. Bolm. Repart. Águas São Paulo. São Paulo, 9 (4): $32-48,1940$.

Tudorancea, C.; Green, RH.\& Huebner, J. Structure dynamics and production of the benthic fauna in lake Manitoba. Hydrobiologia, 1979 Den Haag, 64(1):59-95.

Tundisi, JG. Typology of reservoirs in Southern Brazil. Verh Internat Verein Limnol; 1981 21:1031-1039.

Valentin, JL. Agrupamento e ordenação - OECOLOGIA BRASILIENSIS, Volume II: Tópicos em tratamento de dados biológicos, 1995; p.27-55.

Welch, PS. Limnology $2^{a}$ ed. New Yor, Mc. Graw Hill, 1952. Wells, HG.; Huxley, J. \& Wells, GP. A ciência da vida; o drama da vida. 3a. Rio de Janeiro: José Olímpio, 1957. 
Wetzel, RG. Limnology Saunders College Publ Philadelphia, 1975.

Wetzel, RG. Reservoir ecosystems: conclusions and speculations in reservoir limnology: ecological perspectives. Thornton, K.W.; Kimmel, B.L. \& Payne, F.E. (Eds); Willey Interscience Publ. John Wiley \& Sons Inc. New York, 1990.

Wilhm, JL. Biological approaches to water pollution problems. In: King, CC. \& Elfner, LF. (eds). Organisms and Biological Communities as Indicators of Environmental Quality - A Syposium. Ohio Biol. Survey, Informative Circular. no 8 . p. 3-11, 1975.

Witley, LS. The resistence of tubificid worms to three common pollutants. Hydrobiologia 1968; 32(1/2):193-205.

Wright, S. Relatório sobre uma investigação preliminar; Limnologia das águas de São Paulo. Archos Inst Biol São Paulo 1936; 7: 65-73.

Wright, S. A review of some species of Diaptomus from São Paulo. Ann Acad Bras Scien 1937; 9(1):65-82.

Xavier, MB.; Monteiro JR. \& Fujiara, LP. Limnologia de reservatórios do sudoeste do Estado de São Paulo. Brasil. VII. Fitoplâncton. Bolm Inst Pesca, 1985; 12(1):145-186. 
Tabela 01: Valores mensais da temperatura do $\operatorname{ar}\left({ }^{\circ} \mathrm{C}\right)$ dos 10 pontos de amostragem no período de março/96 a fevereiro/97 na Represa do Guarapiranga - SP.

\begin{tabular}{|c|c|c|c|c|c|c|c|c|c|c|c|c|}
\hline PontosiColetas & $\mathrm{mar} / 96$ & $\mathrm{abr} / 96$ & mai/96 & jun/96 & jul/96 & ago/96 & set/96 & out/96 & nov/96 & dez/96 & $\mathrm{jan} / 97$ & fev/97 \\
\hline Ponto - 01 & 36,0 & 32,0 & 25,0 & 23,0 & 18,0 & 20,5 & 10,0 & 20,5 & 28,0 & 29,5 & 36,0 & 25,0 \\
\hline Ponto - 02 & 26,0 & 27,5 & 21,0 & 23,0 & 17,5 & 20,5 & 10,0 & 20,5 & 28,0 & 26,5 & 35,0 & 25,0 \\
\hline Ponto - 03 & 28,0 & 35,0 & 33,0 & 25,0 & 19,0 & 19,5 & 12,0 & 21,5 & 25,0 & 29,5 & 35,0 & 24,0 \\
\hline Ponto - 04 & 24,0 & 32,0 & 33,0 & 25,0 & 25,0 & 17,0 & 13,0 & 21,0 & 29,0 & 29,5 & 30,0 & 23,5 \\
\hline Ponto - 05 & 25,0 & 29,0 & 29,0 & 22,0 & 22,0 & 20,5 & 11,0 & 18,0 & 24,0 & 28,0 & 32,0 & 26,0 \\
\hline Ponto - 06 & 24,5 & 28,0 & 30,0 & 24,0 & 25,0 & 20,0 & 12,5 & 21,5 & 29,0 & 32,0 & 29,0 & 24,5 \\
\hline Ponto - 07 & 23,5 & 32,0 & 31,0 & 21,0 & 24,0 & 21,5 & 11,0 & 20,5 & 29,0 & 32,0 & 28,0 & 24,0 \\
\hline Ponto - 08 & 24,0 & 30,0 & 25,0 & 22,0 & 22,0 & 21,5 & 11,0 & 22,0 & 29,0 & 33,0 & ** & 25,0 \\
\hline Ponto - 09 & 25,0 & 28,5 & 25,0 & 20,0 & 18,0 & 22,0 & 11,0 & 19,5 & 24,0 & 32,0 & ** & 24,0 \\
\hline Ponto - 10 & 25,0 & 31,0 & 24,0 & 22,0 & 21,0 & 21,0 & 11,0 & 19,5 & 27,0 & 34,0 & $\star \star$ & 25,0 \\
\hline
\end{tabular}

\section{$(* *)=$ não houve coleta (chuvas intermitentes)}


Tabela 02: Valores mensais da temperatura da água $\left({ }^{\circ} \mathrm{C}\right)$ dos 10 pontos de amostragem - superfície (S), à meia profundidade (M) e fundo (F) no período de março/96 a fevereiro/97 na Represa do Guarapiranga - SP.

\begin{tabular}{|c|c|c|c|c|c|c|c|c|c|c|c|c|c|}
\hline \multicolumn{2}{|c|}{ PontosIColetas } & $\mathrm{mar} / 96$ & $\mathrm{abr} / 96$ & mai/96 & jun/96 & jul/96 & ago/96 & set/96 & out/96 & nov/96 & dez/96 & jan/97 & $\mathrm{fev} / 97$ \\
\hline \multirow{3}{*}{ Ponto - 01} & $\mathrm{~S}$ & 28,0 & 26,5 & 22,0 & 18,0 & 18,0 & 17,0 & 12,0 & 22,0 & 24,0 & 28,0 & 28,0 & 24,5 \\
\hline & $\mathrm{M}$ & * & * & 22,0 & 18,0 & 18,0 & 17,0 & 12,0 & 22,0 & 23,5 & 27,0 & 25,0 & 23,5 \\
\hline & $\mathrm{F}$ & * & * & 21,5 & 18,0 & 17,5 & 17,0 & 12,0 & 21,5 & 23,0 & 27,0 & 24,0 & 23,5 \\
\hline \multirow{3}{*}{ Ponto - 02} & $\mathrm{~S}$ & 28,0 & 26,5 & 22,5 & 18,0 & 18,0 & 17,0 & 12,0 & 21,5 & 24,0 & 25,0 & 27,0 & 25,0 \\
\hline & $M$ & * & * & 22,5 & 18,0 & 18,0 & 17,0 & 11,0 & 21,5 & 24,0 & 25,0 & 26,0 & 24,5 \\
\hline & $\mathrm{F}$ & * & * & 21,5 & 17,0 & 16,5 & 17,0 & 11,0 & 20,5 & 23,5 & 24,5 & 26,0 & 24,5 \\
\hline \multirow{3}{*}{ Ponto - 03} & $\mathrm{~S}$ & 24,0 & 27,0 & 22,0 & 19,0 & 18,5 & 17,0 & 18,0 & 22,5 & 24,0 & 25,5 & 30,0 & 25,5 \\
\hline & $\mathrm{M}$ & * & * & 21,0 & 18,0 & 18,5 & 17,0 & 17,0 & 22,0 & 24,0 & 27,0 & 27,0 & 25,0 \\
\hline & $\mathrm{F}$ & * & * & 21,0 & 18,0 & 17,0 & 16,0 & 17,0 & 22,0 & 23,5 & 28,0 & 27,0 & 25,0 \\
\hline \multirow{3}{*}{ Ponto - 04} & $\mathrm{~S}$ & 25,0 & 27,0 & 22,0 & 19,0 & 22,0 & 16,5 & 17,0 & 22,0 & 23,0 & 27,0 & 28,0 & 26,0 \\
\hline & $\mathrm{M}$ & * & * & 22,0 & 18,0 & 21,5 & 16,0 & 17,0 & 22,0 & 23,0 & 27,0 & 26,0 & 25,0 \\
\hline & $\mathrm{F}$ & * & * & 21,0 & 18,0 & 21,0 & 15,0 & 16,5 & 21,0 & 23,0 & 27,0 & 26,0 & 25,0 \\
\hline \multirow{3}{*}{ Ponto - 05} & $\mathrm{~S}$ & 23,0 & 27,0 & 22,0 & 19,0 & 19,0 & 18,0 & 18,0 & 21,0 & 24,0 & 25,5 & 25,0 & 25,0 \\
\hline & $M$ & * & * & 21,0 & 19,0 & 19,0 & 17,0 & 18,0 & 21,0 & 25,0 & 26,5 & 26,0 & 25,0 \\
\hline & $\mathrm{F}$ & * & * & 21,0 & 18,0 & 18,0 & 17,0 & 17,5 & 20,0 & 24,0 & 27,0 & 26,0 & 24,0 \\
\hline \multirow{3}{*}{ Ponto - 06} & $\mathrm{~S}$ & 25,5 & 26,5 & 22,0 & 19,0 & 22,0 & 18,0 & 17,0 & 22,0 & 24,0 & 28,5 & 27,0 & 26,5 \\
\hline & $M$ & * & * & 22,0 & 18,0 & 22,0 & 18,0 & 17,0 & 21,0 & 24,0 & 27,5 & 26,0 & 25,0 \\
\hline & $\mathrm{F}$ & * & * & 22,0 & 18,0 & 21,0 & 18,0 & 16,5 & 21,0 & 23,5 & 27,5 & 26,0 & 25,0 \\
\hline \multirow{3}{*}{ Ponto - 07} & $\mathrm{~S}$ & 24,0 & 26,5 & 23,0 & 19,0 & 17,0 & 19,5 & 18,0 & 21,0 & 24,5 & 28,0 & 25,5 & 26,0 \\
\hline & $M$ & * & * & 22,0 & 19,0 & 17,0 & 19,0 & 18,0 & 21,0 & 24,0 & 28,0 & 25,5 & 25,0 \\
\hline & $\mathrm{F}$ & * & * & 22,0 & 18,0 & 16,0 & 19,0 & 17,0 & 21,0 & 24,0 & 27,5 & 25,0 & 25,0 \\
\hline \multirow{3}{*}{ Ponto - 08} & $\mathrm{~S}$ & 25,0 & 26,5 & 23,0 & 19,0 & 17,0 & 20,5 & 18,0 & 21,5 & 24,5 & 28,0 & ** & 25,5 \\
\hline & $\mathrm{M}$ & * & * & 22,0 & 19,0 & 17,0 & 20,5 & 18,0 & 21,0 & 24,0 & 28,0 & $\star \star$ & 24,0 \\
\hline & $\mathrm{F}$ & * & * & 22,0 & 19,0 & 16,0 & 20,0 & 17,0 & 21,0 & 23,0 & 27,0 & $\star \star$ & 24,0 \\
\hline \multirow{3}{*}{ Ponto - 09} & $\mathrm{~S}$ & 26,5 & 26,5 & 23,0 & 18,0 & 16,0 & 20,0 & 18,0 & 21,5 & 24,5 & 28,0 & $\star \star$ & 26,0 \\
\hline & $M$ & * & * & 23,0 & 17,0 & 16,0 & 20,0 & 18,0 & 21,0 & 24,5 & 28,0 & 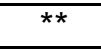 & 24,0 \\
\hline & $\mathrm{F}$ & * & * & 22,0 & 17,0 & 16,0 & 20,0 & 18,0 & 21,0 & 23,5 & 27,5 & ** & 24,0 \\
\hline \multirow{3}{*}{ Ponto - 10} & $\mathrm{~S}$ & 25,0 & 25,0 & 22,5 & 19,0 & 18,0 & 20,0 & 17,0 & 21,5 & 24,5 & 29,0 & ** & 25,5 \\
\hline & $M$ & * & * & 22,0 & 18,0 & 17,0 & 20,0 & 16,0 & 21,0 & 24,5 & 28,5 & $\star \star$ & 25,0 \\
\hline & $\mathrm{F}$ & * & * & 22,0 & 18,0 & 17,0 & 19,5 & 16,0 & 21,0 & 24,0 & 28,0 & ** & 24,5 \\
\hline
\end{tabular}

$\left(^{*}\right)$ = não houve coleta

$\left(^{* *}\right)$ = não houve coleta (chuvas intermitentes) 
Tabela 03: Valores mensais de profundidade $(\mathrm{m})$ e transparência $(\mathrm{m})$ dos 10 pontos de amostragem no período de março/96 a fevereiro/97 na Represa do Guarapiranga - SP.

\begin{tabular}{|c|c|c|c|c|c|c|c|c|c|c|c|c|c|}
\hline PontosIColetas & & $\mathrm{mar} / 96$ & $\mathrm{abr} / 96$ & mai/96 & jun/96 & jul/96 & ago/96 & set/96 & out/96 & nov/96 & dez/96 & jan/97 & fev/97 \\
\hline \multirow[t]{2}{*}{ Ponto - 01} & $\mathrm{~T}$ & 0,5 & 1,0 & 1,5 & 1,0 & 1,2 & 1,0 & 0,5 & 0,5 & 1,1 & 0,5 & 0,5 & 0,2 \\
\hline & $\mathrm{P}$ & 3,0 & 3,5 & 3,5 & 4,0 & 3,5 & 2,5 & 3,5 & 3,5 & 3,5 & 2,5 & 4,0 & 6,0 \\
\hline \multirow[t]{2}{*}{ Ponto - 02} & $\mathrm{~T}$ & 0,5 & 1,0 & 1,5 & 1,5 & 1,2 & 1,0 & 0,4 & 0,5 & 1,0 & 0,5 & 0,7 & 0,2 \\
\hline & $\mathrm{P}$ & 3,0 & 4,0 & 5,0 & 4,5 & 3,5 & 3,0 & 3,0 & 3,5 & 4,0 & 4,0 & 2,5 & 2,5 \\
\hline \multirow[t]{2}{*}{ Ponto - 03} & $\mathrm{~T}$ & 0,5 & 1,0 & 2,0 & 1,5 & 1,5 & 1,0 & 0,8 & 0,5 & 1,0 & 0,5 & 0,5 & 0,5 \\
\hline & $\mathrm{P}$ & 2,0 & 2,5 & 2,5 & 3,0 & 5,5 & 6,0 & 2,5 & 2,5 & 2,5 & 2,5 & 1,5 & 2,0 \\
\hline \multirow[t]{2}{*}{ Ponto - 04} & $\mathrm{~T}$ & 0,5 & 1,5 & 1,2 & 1,5 & 1,5 & 1,0 & 1,0 & 0,8 & 1,2 & 0,5 & 0,5 & 0,5 \\
\hline & $P$ & 3,0 & 3,5 & 3,5 & 3,5 & 4,0 & 3,0 & 2,5 & 3,0 & 2,5 & 3,0 & 3,0 & 3,5 \\
\hline \multirow[t]{2}{*}{ Ponto - 05} & $\mathrm{~T}$ & 1,0 & 1,5 & 1,5 & 2,0 & 1,5 & 0,8 & 1,0 & 1,0 & 1,1 & 0,5 & 1,0 & 0,2 \\
\hline & $\mathrm{P}$ & 6,0 & 4,5 & 8,5 & 5,5 & 5,0 & 3,5 & 6,0 & 5,5 & 4,0 & 4,0 & 4,0 & 4,0 \\
\hline \multirow[t]{2}{*}{ Ponto - 06} & $\mathrm{~T}$ & 1,2 & 1,5 & 1,0 & 1,5 & 1,0 & 1,0 & 1,0 & 1,0 & 1,3 & 0,7 & 0,8 & 0,5 \\
\hline & $P$ & 7,0 & 8,0 & 4,5 & 7,0 & 6,5 & 6,5 & 6,8 & 7,0 & 8,0 & 7,0 & 6,5 & 7,0 \\
\hline \multirow[t]{2}{*}{ Ponto - 07} & $\mathrm{~T}$ & 1,0 & 1,5 & 1,5 & 1,5 & 1,2 & 1,0 & 1,5 & 1,0 & 1,5 & 1,0 & 1,0 & 0,5 \\
\hline & $P$ & 5,0 & 5,0 & 9,0 & 8,0 & 5,5 & 5,0 & 5,5 & 7,0 & 5,5 & 6,0 & 5,5 & 5,0 \\
\hline \multirow[t]{2}{*}{ Ponto - 08} & $\mathrm{~T}$ & 1,5 & 1,5 & 1,0 & 2,5 & 1,0 & 1,5 & 1,5 & 1,0 & 1,1 & 1,0 & ** & 1,0 \\
\hline & $P$ & 10,0 & 10,0 & 10,0 & 10,0 & 9,5 & 8,5 & 10,0 & 10,0 & 9,0 & 10,0 & ** & 9,0 \\
\hline \multirow[t]{2}{*}{ Ponto - 09} & $\mathrm{~T}$ & 1,2 & 1,5 & 1,5 & 1,8 & 1,5 & 1,2 & 1,2 & 1,2 & 0,9 & 1,0 & $\star \star$ & 0,5 \\
\hline & $P$ & 6,0 & 7,0 & 7,5 & 7,0 & 7,5 & 6,0 & 6,5 & 11,0 & 7,0 & 6,0 & $\star \star$ & 6,0 \\
\hline \multirow[t]{2}{*}{ Ponto - 10} & $\mathrm{~T}$ & 1,8 & 1,5 & 1,5 & 2,0 & 1,5 & 1,2 & 1,5 & 1,2 & 1,0 & 0,8 & $\star \star \star$ & 0,5 \\
\hline & $P$ & 11,0 & 11,0 & 11,0 & 11,0 & 11,0 & 8,5 & 10,0 & 11,0 & 2,5 & 1,2 & ** & 10,5 \\
\hline
\end{tabular}

Transparência $=\mathrm{T}$

Profundidade $=P$

$\left.{ }^{* *}\right)=$ não houve coleta (chuvas intermitentes) 
Tabela 04: Valores mensais da turbidez (U.N.T.) dos 10 pontos de amostragem - superfície (S), à meia profundidade (M) e fundo (F), no período de março/96 a fevereiro/97 na Represa do Guarapiranga - SP.

\begin{tabular}{|c|c|c|c|c|c|c|c|c|c|c|c|c|c|}
\hline PontosiColetas & & $\mathrm{mar} / 96$ & $\mathrm{abr} / 96$ & mai/96 & jun/96 & jul/96 & ago/96 & set/96 & out/96 & nov/96 & dez/96 & jan/97 & fev/97 \\
\hline \multirow{3}{*}{ Ponto - 01} & $\mathrm{~S}$ & 33,0 & 6,5 & 4,6 & 6,9 & 3,8 & 2,8 & 4,8 & 20,0 & 4,2 & 20,0 & 9,8 & 35,0 \\
\hline & $M$ & * & 6,5 & 4,9 & 6,5 & 4,5 & 3,3 & 4,5 & 18,0 & 4,3 & 20,0 & 33,0 & 55,0 \\
\hline & $\mathrm{F}$ & * & 6,9 & 4,6 & 6,6 & 4,6 & 3,7 & 4,7 & 12,0 & 4,8 & 29,0 & 37,0 & 62,0 \\
\hline \multirow{3}{*}{ Ponto - 02} & $\mathrm{~S}$ & 36,0 & 6,2 & 4,4 & 4,6 & 4,0 & 5,0 & 12,0 & 26,0 & 4,2 & 8,0 & 19,0 & 18,0 \\
\hline & $\mathrm{M}$ & * & 6,4 & 4,6 & 5,6 & 5,6 & 5,5 & 18,0 & 18,0 & 4,3 & 8,5 & 16,0 & 30,0 \\
\hline & $\mathrm{F}$ & * & 6,4 & 6,0 & 6,3 & 5,3 & 6,3 & 11,0 & 14,0 & 4,8 & 20,0 & 13,0 & 42,0 \\
\hline \multirow{3}{*}{ Ponto - 03} & $\mathrm{~S}$ & 29,0 & 6,2 & 3,7 & 4,4 & 3,1 & 3,0 & 12,0 & 12,5 & 3,4 & 2,7 & 2,6 & 9,7 \\
\hline & $\mathrm{M}$ & * & 6,1 & 3,9 & 7,4 & 4,6 & 8,2 & 16,0 & 11,0 & 3,6 & 3,0 & 2,6 & 19,0 \\
\hline & $\mathrm{F}$ & * & 6,7 & 3,9 & 23,0 & 10,0 & 7,8 & 17,5 & 12,5 & 4,9 & 32,0 & 4,7 & 19,0 \\
\hline \multirow{3}{*}{ Ponto - 04} & $\mathrm{~S}$ & 24,0 & 4,0 & 2,8 & 1,9 & 2,3 & 2,9 & 6,7 & 7,5 & 1,9 & 2,9 & 3,1 & 5,0 \\
\hline & $M$ & $\star$ & 4,0 & 1,9 & 1,8 & 3,4 & 2,7 & 8,4 & 6,8 & 2,1 & 3,8 & 3,5 & 5,5 \\
\hline & $\mathrm{F}$ & * & 4,3 & 2,0 & 2,1 & 4,2 & 3,1 & 7,8 & 11,5 & 2,4 & 4,3 & 6,0 & 6,6 \\
\hline \multirow{3}{*}{ Ponto - 05} & $\mathrm{~S}$ & 10,0 & 2,4 & 2,4 & 1,5 & 2,0 & 2,7 & 2,8 & 6,0 & 2,6 & 2,3 & 1,9 & 10,5 \\
\hline & $\mathrm{M}$ & * & 3,6 & 2,5 & 1,7 & 2,5 & 3,2 & 3,4 & 7,8 & 3,2 & 2,1 & 3,6 & 6,5 \\
\hline & $\mathrm{F}$ & * & 4,8 & 2,6 & 2,9 & 2,3 & 3,7 & 3,7 & 6,5 & 2,4 & 2,5 & 6,2 & 6,1 \\
\hline \multirow{3}{*}{ Ponto - 06} & $\mathrm{~S}$ & 21,0 & 4,4 & 2,6 & 2,0 & 2,5 & 2,5 & 4,2 & 8,0 & 1,5 & 2,3 & 6,3 & 7,6 \\
\hline & $M$ & * & 4,6 & 1,9 & 2,1 & 2,7 & 3,0 & 4,5 & 10,2 & 1,8 & 2,2 & 5,3 & 8,4 \\
\hline & $\mathrm{F}$ & * & 4,8 & 1,9 & 4,1 & 2,7 & 3,2 & 4,4 & 9,7 & 1,9 & 4,0 & 6,7 & 7,5 \\
\hline \multirow{3}{*}{ Ponto - 07} & $\mathrm{~S}$ & 12,0 & 2,5 & 1,4 & 1,6 & 2,1 & 1,5 & 4,3 & 6,0 & 2,0 & 1,8 & 3,1 & 4,9 \\
\hline & $\mathrm{M}$ & * & 2,7 & 1,7 & 1,6 & 2,3 & 2,1 & 4,1 & 6,7 & 1,5 & 1,7 & 2,2 & 5,5 \\
\hline & $\mathrm{F}$ & * & 3,3 & 1,5 & 1,6 & 2,3 & 2,4 & 4,4 & 6,6 & 1,4 & 2,2 & 2,1 & 4,5 \\
\hline \multirow{3}{*}{ Ponto - 08} & $\mathrm{~S}$ & 4,5 & 2,0 & 1,1 & 1,2 & 2,1 & 1,0 & 5,7 & 4,0 & 1,4 & 1,5 & $\star \star$ & 3,2 \\
\hline & $\mathrm{M}$ & * & 2,2 & 1,7 & 1,3 & 3,4 & 2,0 & 4,8 & 6,0 & 1,6 & 1,5 & $\star \star$ & 4,3 \\
\hline & $\mathrm{F}$ & * & 21,0 & 2,3 & 2,8 & 3,7 & 2,2 & 3,3 & 7,0 & 1,6 & 3,0 & 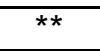 & 4,1 \\
\hline \multirow{3}{*}{ Ponto - 09} & $\mathrm{~S}$ & 4,5 & 2,1 & 1,4 & 1,5 & 2,5 & 2,5 & 6,3 & 4,0 & 1,4 & 1,8 & $\star \star$ & 3,0 \\
\hline & $\mathrm{M}$ & * & 2,6 & 3,4 & 1,5 & 3,3 & 2,4 & 5,4 & 3,8 & 1,6 & 1,7 & $\star \star$ & 4,7 \\
\hline & $\mathrm{F}$ & * & 6,6 & 2,1 & 1,7 & 5,7 & 2,4 & 5,4 & 4,3 & 23,0 & 2,3 & $\star \star$ & 4,8 \\
\hline \multirow{3}{*}{ Ponto - 10} & $\mathrm{~S}$ & 4,0 & 2,0 & 1,2 & 1,2 & 2,1 & 1,2 & 2,7 & 4,0 & 1,2 & 1,1 & ** & 3,5 \\
\hline & $\mathrm{M}$ & * & 2,0 & 1,7 & 1,4 & 2,2 & 1,8 & 3,2 & 6,0 & 1,5 & 1,7 & ** & 5,4 \\
\hline & $\mathrm{F}$ & * & 6,5 & 1,5 & 1,8 & 2,7 & 1,8 & 3,1 & 6,0 & 1,6 & 2,2 & $\star \star$ & 6,9 \\
\hline
\end{tabular}

\section{$\left(^{*}\right)=$ não houve coleta}

$(* *)=$ não houve coleta (chuvas intermitentes) 
Tabela 10: Valores mensais de nitrogênio total (mg/L) dos 10 pontos de amostragem - superfície, no período de maio/96 a dezembro/96 na Represa do Guarapiranga - SP

\begin{tabular}{|c|c|c|c|c|c|c|c|c|}
\hline PontoslColetas & mai/96 & jun/96 & jul/96 & ago/96 & set/96 & out/96 & nov/96 & dez/96 \\
\hline Ponto - 01 & 0,82 & 0,67 & 0,62 & 0,65 & 0,65 & 0,75 & 0,65 & 0,11 \\
\hline Ponto - 02 & 0,22 & 0,55 & 0,21 & 0,35 & 0,80 & 0,85 & 0,77 & 0,61 \\
\hline Ponto - 03 & 0,22 & 0,68 & 0,15 & 0,55 & 0,95 & 1,07 & 0,65 & 0,10 \\
\hline Ponto - 04 & 0,30 & 0,65 & 0,29 & 0,45 & 0,75 & 0,56 & 0,30 & 0,29 \\
\hline Ponto - 05 & 1,10 & 0,75 & 0,80 & 0,95 & 0,85 & 0,70 & 0,90 & 0,80 \\
\hline Ponto - 06 & 0,29 & 0,76 & 0,75 & 0,65 & 0,55 & 0,65 & 0,55 & 0,66 \\
\hline Ponto - 07 & 0,55 & 0,77 & 0,80 & 0,75 & 0,90 & 0,85 & 0,05 & 0,05 \\
\hline Ponto - 08 & 0,32 & 0,66 & 0,90 & 0,85 & 0,58 & 0,45 & 0,20 & 0,21 \\
\hline Ponto - 09 & 0,60 & 0,75 & 0,20 & 0,55 & 0,45 & 0,65 & 0,10 & 0,11 \\
\hline Ponto - 10 & 0,05 & 0,25 & 0,06 & 0,56 & 0,74 & 0,75 & 0,05 & 0,05 \\
\hline
\end{tabular}


Tabela 04: Valores mensais da turbidez (U.N.T.) dos 10 pontos de amostragem - superfície (S), à meia profundidade (M) e fundo (F), no período de março/96 a fevereiro/97 na Represa do Guarapiranga - SP.

\begin{tabular}{|c|c|c|c|c|c|c|c|c|c|c|c|c|c|}
\hline PontosiColetas & & $\mathrm{mar} / 96$ & $\mathrm{abr} / 96$ & mai/96 & jun/96 & jul/96 & ago/96 & set/96 & out/96 & nov/96 & dez/96 & jan/97 & fev/97 \\
\hline \multirow{3}{*}{ Ponto - 01} & $\mathrm{~S}$ & 33,0 & 6,5 & 4,6 & 6,9 & 3,8 & 2,8 & 4,8 & 20,0 & 4,2 & 20,0 & 9,8 & 35,0 \\
\hline & $M$ & * & 6,5 & 4,9 & 6,5 & 4,5 & 3,3 & 4,5 & 18,0 & 4,3 & 20,0 & 33,0 & 55,0 \\
\hline & $\mathrm{F}$ & * & 6,9 & 4,6 & 6,6 & 4,6 & 3,7 & 4,7 & 12,0 & 4,8 & 29,0 & 37,0 & 62,0 \\
\hline \multirow{3}{*}{ Ponto - 02} & $\mathrm{~S}$ & 36,0 & 6,2 & 4,4 & 4,6 & 4,0 & 5,0 & 12,0 & 26,0 & 4,2 & 8,0 & 19,0 & 18,0 \\
\hline & $\mathrm{M}$ & * & 6,4 & 4,6 & 5,6 & 5,6 & 5,5 & 18,0 & 18,0 & 4,3 & 8,5 & 16,0 & 30,0 \\
\hline & $\mathrm{F}$ & * & 6,4 & 6,0 & 6,3 & 5,3 & 6,3 & 11,0 & 14,0 & 4,8 & 20,0 & 13,0 & 42,0 \\
\hline \multirow{3}{*}{ Ponto - 03} & $\mathrm{~S}$ & 29,0 & 6,2 & 3,7 & 4,4 & 3,1 & 3,0 & 12,0 & 12,5 & 3,4 & 2,7 & 2,6 & 9,7 \\
\hline & $\mathrm{M}$ & * & 6,1 & 3,9 & 7,4 & 4,6 & 8,2 & 16,0 & 11,0 & 3,6 & 3,0 & 2,6 & 19,0 \\
\hline & $\mathrm{F}$ & * & 6,7 & 3,9 & 23,0 & 10,0 & 7,8 & 17,5 & 12,5 & 4,9 & 32,0 & 4,7 & 19,0 \\
\hline \multirow{3}{*}{ Ponto - 04} & $\mathrm{~S}$ & 24,0 & 4,0 & 2,8 & 1,9 & 2,3 & 2,9 & 6,7 & 7,5 & 1,9 & 2,9 & 3,1 & 5,0 \\
\hline & $M$ & $\star$ & 4,0 & 1,9 & 1,8 & 3,4 & 2,7 & 8,4 & 6,8 & 2,1 & 3,8 & 3,5 & 5,5 \\
\hline & $\mathrm{F}$ & * & 4,3 & 2,0 & 2,1 & 4,2 & 3,1 & 7,8 & 11,5 & 2,4 & 4,3 & 6,0 & 6,6 \\
\hline \multirow{3}{*}{ Ponto - 05} & $\mathrm{~S}$ & 10,0 & 2,4 & 2,4 & 1,5 & 2,0 & 2,7 & 2,8 & 6,0 & 2,6 & 2,3 & 1,9 & 10,5 \\
\hline & $\mathrm{M}$ & * & 3,6 & 2,5 & 1,7 & 2,5 & 3,2 & 3,4 & 7,8 & 3,2 & 2,1 & 3,6 & 6,5 \\
\hline & $\mathrm{F}$ & * & 4,8 & 2,6 & 2,9 & 2,3 & 3,7 & 3,7 & 6,5 & 2,4 & 2,5 & 6,2 & 6,1 \\
\hline \multirow{3}{*}{ Ponto - 06} & $\mathrm{~S}$ & 21,0 & 4,4 & 2,6 & 2,0 & 2,5 & 2,5 & 4,2 & 8,0 & 1,5 & 2,3 & 6,3 & 7,6 \\
\hline & $M$ & * & 4,6 & 1,9 & 2,1 & 2,7 & 3,0 & 4,5 & 10,2 & 1,8 & 2,2 & 5,3 & 8,4 \\
\hline & $\mathrm{F}$ & * & 4,8 & 1,9 & 4,1 & 2,7 & 3,2 & 4,4 & 9,7 & 1,9 & 4,0 & 6,7 & 7,5 \\
\hline \multirow{3}{*}{ Ponto - 07} & $\mathrm{~S}$ & 12,0 & 2,5 & 1,4 & 1,6 & 2,1 & 1,5 & 4,3 & 6,0 & 2,0 & 1,8 & 3,1 & 4,9 \\
\hline & $\mathrm{M}$ & * & 2,7 & 1,7 & 1,6 & 2,3 & 2,1 & 4,1 & 6,7 & 1,5 & 1,7 & 2,2 & 5,5 \\
\hline & $\mathrm{F}$ & * & 3,3 & 1,5 & 1,6 & 2,3 & 2,4 & 4,4 & 6,6 & 1,4 & 2,2 & 2,1 & 4,5 \\
\hline \multirow{3}{*}{ Ponto - 08} & $\mathrm{~S}$ & 4,5 & 2,0 & 1,1 & 1,2 & 2,1 & 1,0 & 5,7 & 4,0 & 1,4 & 1,5 & $\star \star$ & 3,2 \\
\hline & $\mathrm{M}$ & * & 2,2 & 1,7 & 1,3 & 3,4 & 2,0 & 4,8 & 6,0 & 1,6 & 1,5 & $\star \star$ & 4,3 \\
\hline & $\mathrm{F}$ & * & 21,0 & 2,3 & 2,8 & 3,7 & 2,2 & 3,3 & 7,0 & 1,6 & 3,0 & 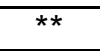 & 4,1 \\
\hline \multirow{3}{*}{ Ponto - 09} & $\mathrm{~S}$ & 4,5 & 2,1 & 1,4 & 1,5 & 2,5 & 2,5 & 6,3 & 4,0 & 1,4 & 1,8 & $\star \star$ & 3,0 \\
\hline & $\mathrm{M}$ & * & 2,6 & 3,4 & 1,5 & 3,3 & 2,4 & 5,4 & 3,8 & 1,6 & 1,7 & $\star \star$ & 4,7 \\
\hline & $\mathrm{F}$ & * & 6,6 & 2,1 & 1,7 & 5,7 & 2,4 & 5,4 & 4,3 & 23,0 & 2,3 & $\star \star$ & 4,8 \\
\hline \multirow{3}{*}{ Ponto - 10} & $\mathrm{~S}$ & 4,0 & 2,0 & 1,2 & 1,2 & 2,1 & 1,2 & 2,7 & 4,0 & 1,2 & 1,1 & ** & 3,5 \\
\hline & $\mathrm{M}$ & * & 2,0 & 1,7 & 1,4 & 2,2 & 1,8 & 3,2 & 6,0 & 1,5 & 1,7 & ** & 5,4 \\
\hline & $\mathrm{F}$ & * & 6,5 & 1,5 & 1,8 & 2,7 & 1,8 & 3,1 & 6,0 & 1,6 & 2,2 & $\star \star$ & 6,9 \\
\hline
\end{tabular}

\section{$\left(^{*}\right)=$ não houve coleta}

$(* *)=$ não houve coleta (chuvas intermitentes) 
Tabela 05: Valores mensais de cor (mgPt/L) dos 10 pontos de amostragem - superfície (S), à meia profundidade (M) e fundo (F), no período de março/96 a fevereiro/97 na Represa do Guarapiranga - SP.

\begin{tabular}{|c|c|c|c|c|c|c|c|c|c|c|c|c|c|}
\hline PontosiColetas & & mar/96 & abr/96 & mai/96 & jun/96 & jul/96 & ago/96 & set/96 & out/96 & nov/96 & dez/96 & jan/97 & fev/97 \\
\hline \multirow{3}{*}{ Ponto - 01} & $\mathrm{~S}$ & 300 & 120 & 140 & 100 & 100 & 60 & 100 & 130 & 100 & 140 & 200 & 200 \\
\hline & $\mathrm{M}$ & * & 100 & 140 & 100 & 100 & 80 & 100 & 110 & 100 & 140 & 240 & 320 \\
\hline & $\mathrm{F}$ & * & 100 & 140 & 100 & 100 & 80 & 100 & 110 & 100 & 160 & 240 & 320 \\
\hline \multirow{3}{*}{ Ponto - 02} & $\mathrm{~S}$ & 200 & 120 & 120 & 100 & 100 & 80 & 100 & 140 & 100 & 80 & 180 & 200 \\
\hline & $\mathrm{M}$ & * & 100 & 120 & 100 & 100 & 80 & 100 & 140 & 100 & 80 & 150 & 320 \\
\hline & $\mathrm{F}$ & * & 100 & 100 & 100 & 100 & 80 & 100 & 110 & 100 & 200 & 180 & 320 \\
\hline \multirow{3}{*}{ Ponto - 03} & $\mathrm{~S}$ & 200 & 100 & 120 & 80 & 70 & 60 & 80 & 80 & 60 & 50 & 100 & 320 \\
\hline & $\mathrm{M}$ & * & 100 & 120 & 80 & 70 & 60 & 80 & 80 & 80 & 40 & 80 & 320 \\
\hline & $\mathrm{F}$ & * & 100 & 120 & 60 & 70 & 60 & 80 & 80 & 70 & 40 & 120 & 320 \\
\hline \multirow{3}{*}{ Ponto - 04} & $\mathrm{~S}$ & 100 & 80 & 80 & 40 & 60 & 50 & 80 & 80 & 40 & 30 & 70 & 100 \\
\hline & $\mathrm{M}$ & * & 80 & 70 & 50 & 50 & 60 & 70 & 70 & 40 & 30 & 80 & 140 \\
\hline & $\mathrm{F}$ & * & 80 & 70 & 50 & 50 & 50 & 70 & 70 & 60 & 30 & 100 & 200 \\
\hline \multirow{3}{*}{ Ponto - 05} & $\mathrm{~S}$ & 100 & 80 & 80 & 30 & 70 & 60 & 70 & 40 & 30 & 30 & 60 & 100 \\
\hline & $\mathrm{M}$ & * & 80 & 80 & 30 & 60 & 60 & 70 & 40 & 30 & 30 & 70 & 120 \\
\hline & $\mathrm{F}$ & * & 80 & 80 & 50 & 60 & 60 & 60 & 40 & 50 & 40 & 80 & 160 \\
\hline \multirow{3}{*}{ Ponto - 06} & $\mathrm{~S}$ & 160 & 90 & 80 & 40 & 60 & 60 & 80 & 60 & 30 & 20 & 60 & 100 \\
\hline & $M$ & * & 80 & 80 & 30 & 60 & 60 & 70 & 60 & 40 & 20 & 80 & 100 \\
\hline & $\mathrm{F}$ & * & 80 & 80 & 50 & 60 & 60 & 70 & 60 & 50 & 20 & 80 & 100 \\
\hline \multirow{3}{*}{ Ponto - 07} & $\mathrm{~S}$ & 80 & 80 & 80 & 30 & 50 & 40 & 70 & 30 & 30 & 20 & 50 & 60 \\
\hline & $\mathrm{M}$ & * & 80 & 80 & 30 & 50 & 50 & 70 & 30 & 30 & 20 & 50 & 70 \\
\hline & $\mathrm{F}$ & * & 80 & 80 & 40 & 60 & 50 & 70 & 40 & 60 & 30 & 70 & 80 \\
\hline \multirow{3}{*}{ Ponto - 08} & $\mathrm{~S}$ & 70 & 40 & 70 & 30 & 40 & 30 & 60 & 30 & 40 & 20 & ** & 50 \\
\hline & $\mathrm{M}$ & * & 40 & 70 & 20 & 50 & 30 & 60 & 30 & 20 & 20 & *夫 & 70 \\
\hline & $\mathrm{F}$ & * & 40 & 60 & 30 & 50 & 30 & 70 & 30 & 60 & 30 & ** & 100 \\
\hline \multirow{3}{*}{ Ponto - 09} & $\mathrm{~S}$ & 70 & 40 & 70 & 10 & 30 & 40 & 70 & 40 & 50 & 20 & $\star \star$ & 50 \\
\hline & $\mathrm{M}$ & * & 40 & 80 & 20 & 30 & 50 & 70 & 40 & 20 & 20 & ** & 80 \\
\hline & $\mathrm{F}$ & * & 40 & 80 & 20 & 30 & 40 & 60 & 40 & 30 & 20 & ** & 80 \\
\hline \multirow{3}{*}{ Ponto - 10} & $\mathrm{~S}$ & 70 & 40 & 70 & 30 & 40 & 40 & 70 & 40 & 20 & 20 & ** & 50 \\
\hline & $\mathrm{M}$ & * & 40 & 70 & 30 & 40 & 50 & 70 & 40 & 20 & 30 & *夫 & 80 \\
\hline & $\mathrm{F}$ & * & 40 & 70 & 30 & 30 & 40 & 70 & 40 & 30 & 30 & ** & 100 \\
\hline
\end{tabular}

\section{$\left({ }^{*}\right)$ = não houve coleta \\ $(* *)$ = não houve coleta (chuvas intermitentes)}


Tabela 06: Valores mensais de pH dos 10 pontos de amostragem - superfície (S), à meia profundidade (M) e fundo (F), no período de março/96 a fevereiro/97 na Represa do Guarapiranga - SP.

\begin{tabular}{|c|c|c|c|c|c|c|c|c|c|c|c|c|c|}
\hline PontosIColetas & & $\mathrm{mar} / 96$ & abr/96 & mai/96 & jun/96 & jul/96 & ago/96 & set/96 & out/96 & nov/96 & dez/96 & jan/97 & fev/97 \\
\hline \multirow{3}{*}{ Ponto - 01} & $S$ & 6,3 & 6,1 & 6,2 & 6,0 & 6,4 & 6,7 & 5,8 & 6,4 & 6,6 & 6,7 & 6,7 & 6,4 \\
\hline & $M$ & * & 6,3 & 6,3 & 6,3 & 6,5 & 6,5 & 6,3 & 6,5 & 6,9 & 6,6 & 6,3 & 6,4 \\
\hline & $\mathrm{F}$ & * & 6,2 & 6,4 & 6,5 & 6,6 & 6,5 & 6,5 & 6,5 & 6,5 & 6,8 & 6,2 & 6,4 \\
\hline \multirow{3}{*}{ Ponto - 02} & $\mathrm{~S}$ & 6,6 & 6,8 & 5,0 & 6,4 & 6,2 & 6,7 & 6,1 & 6,5 & 6,6 & 6,3 & 6,3 & 6,3 \\
\hline & $M$ & * & 6,7 & 6,3 & 6,3 & 6,4 & 6,5 & 6,4 & 6,6 & 6,9 & 6,7 & 6,4 & 6,6 \\
\hline & $\mathrm{F}$ & * & 6,8 & 6,6 & 6,3 & 6,6 & 6,4 & 6,3 & 6,5 & 6,5 & 6,6 & 6,7 & 6,5 \\
\hline \multirow{3}{*}{ Ponto - 03} & $\mathrm{~S}$ & 6,7 & 6,3 & 7,1 & 6,8 & 6,9 & 6,9 & 6,8 & 6,7 & 6,9 & 7,8 & 8,4 & 6,7 \\
\hline & $M$ & * & 6,3 & 7,0 & 6,7 & 6,7 & 6,9 & 6,7 & 6,8 & 6,9 & 8,5 & 8,6 & 7,0 \\
\hline & $\mathrm{F}$ & * & 5,9 & 6,7 & 6,6 & 6,8 & 6,8 & 6,4 & 6,6 & 7,0 & 7,1 & 7,3 & 7,1 \\
\hline \multirow{3}{*}{ Ponto - 04} & $\mathrm{~S}$ & 7,1 & 6,9 & 6,9 & 7,2 & 6,9 & 6,6 & 8,5 & 7,1 & 6,6 & 7,6 & 8,1 & 7,0 \\
\hline & $M$ & * & 6,9 & 6,7 & 7,2 & 6,6 & 6,5 & 7,5 & 7,0 & 6,7 & 7,0 & 7,6 & 7,4 \\
\hline & $\mathrm{F}$ & * & 6,9 & 6,9 & 6,9 & 6,7 & 6,6 & 7,5 & 7,0 & 6,7 & 7,0 & 7,1 & 7,3 \\
\hline \multirow{3}{*}{ Ponto - 05} & $\mathrm{~S}$ & 7,5 & 7,5 & 6,9 & 7,5 & 7,3 & 6,9 & 7,4 & 7,1 & 7,4 & 7,3 & 8,0 & 7,3 \\
\hline & $M$ & * & 6,7 & 6,7 & 7,4 & 7,5 & 7,0 & 7,2 & 6,9 & 7,3 & 7,1 & 7,4 & 7,3 \\
\hline & $\mathrm{F}$ & * & 6,5 & 6,8 & 6,8 & 7,5 & 7,2 & 7,0 & 6,8 & 7,2 & 7,3 & 7,3 & 6,9 \\
\hline \multirow{3}{*}{ Ponto - 06} & $\mathrm{~S}$ & 6,9 & 7,3 & 7,9 & 7,2 & 7,4 & 6,9 & 7,0 & 7,0 & 7,1 & 7,7 & 8,2 & 7,0 \\
\hline & $M$ & * & 6,8 & 7,5 & 7,0 & 7,5 & 7,0 & 7,0 & 7,4 & 6,9 & 7,4 & 7,5 & 7,3 \\
\hline & $\mathrm{F}$ & * & 6,5 & 7,3 & 6,8 & 7,5 & 7,2 & 7,0 & 7,2 & 6,6 & 7,2 & 7,2 & 6,9 \\
\hline \multirow{3}{*}{ Ponto - 07} & $\mathrm{~S}$ & 6,9 & 7,2 & 7,0 & 7,3 & 7,1 & 6,8 & 7,1 & 7,0 & 7,5 & 7,4 & 7,9 & 7,2 \\
\hline & $M$ & * & 7,1 & 7,2 & 6,9 & 7,4 & 6,6 & 7,0 & 6,8 & 7,4 & 7,3 & 7,6 & 7,5 \\
\hline & $\mathrm{F}$ & * & 6,8 & 7,1 & 7,4 & 7,5 & 6,7 & 6,8 & 7,0 & 7,1 & 7,2 & 7,2 & 7,3 \\
\hline \multirow{3}{*}{ Ponto - 08} & $\mathrm{~S}$ & 7,1 & 6,9 & 6,5 & 6,9 & 7,3 & 6,9 & 7,1 & 7,1 & 7,7 & 7,5 & ** & 7,2 \\
\hline & $M$ & * & 6,9 & 6,5 & 7,2 & 7,2 & 7,1 & 7,0 & 7,2 & 7,3 & 7,3 & $\star \star$ & 7,4 \\
\hline & $\mathrm{F}$ & * & 6,3 & 6,7 & 7,0 & 7,3 & 7,0 & 6,9 & 7,0 & 6,6 & 6,9 & $\star \star$ & 7,3 \\
\hline \multirow{3}{*}{ Ponto - 09} & $\mathrm{~S}$ & 7,1 & 6,7 & 6,8 & 7,0 & 6,5 & 6,8 & 7,1 & 7,1 & 8,2 & 7,6 & $\star \star$ & 7,1 \\
\hline & $M$ & * & 6,7 & 6,5 & 7,1 & 6,7 & 6,5 & 6,8 & 7,0 & 7,1 & 7,3 & $\star \star$ & 7,2 \\
\hline & $\mathrm{F}$ & * & 6,7 & 6,7 & 7,3 & 6,5 & 6,5 & 6,8 & 7,0 & 6,9 & 7,3 & $\star \star$ & 7,3 \\
\hline \multirow{3}{*}{ Ponto - 10} & $\mathrm{~S}$ & 7,1 & 6,8 & 6,9 & 7,3 & 6,9 & 7,0 & 7,0 & 7,1 & 7,8 & 7,6 & ** & 7,1 \\
\hline & $M$ & * & 6,9 & 7,0 & 7,1 & 6,8 & 7,0 & 7,0 & 6,8 & 7,6 & 7,4 & $\star \star$ & 7,3 \\
\hline & $\mathrm{F}$ & * & 6,5 & 7,2 & 7,3 & 7,0 & 7,0 & 7,2 & 6,9 & 7,6 & 7,4 & $\star \star$ & 7,1 \\
\hline
\end{tabular}

\section{$\left({ }^{*}\right)$ = não houve coleta}

$(* *)$ = não houve coleta (chuvas intermitentes) 
Tabela 07: Valores mensais de condutividade $(\mathrm{mS} / \mathrm{cm})$ dos 10 pontos de amostragem - superfície (S), à meia profundidade (M) e fundo (F), no período de março/96 a fevereiro/97 na Represa do Guarapiranga - SP.

\begin{tabular}{|c|c|c|c|c|c|c|c|c|c|c|c|c|c|}
\hline PontosIColetas & & mar/96 & $a b r / 96$ & mai/96 & jun/96 & $\mathrm{jul} / 96$ & ago/96 & set/96 & out/96 & nov/96 & dez/96 & jan/97 & fev/97 \\
\hline \multirow{3}{*}{ Ponto - 01} & $\mathrm{~S}$ & 30,0 & 38,0 & 42,0 & 66,0 & 35,0 & 80,0 & 36,0 & 42,0 & 49,0 & 47,0 & 43,0 & 48,0 \\
\hline & $M$ & * & 39,0 & 37,0 & 74,0 & 57,0 & 88,0 & 43,0 & 53,0 & 44,0 & 52,0 & 42,0 & 50,0 \\
\hline & $\mathrm{F}$ & * & 35,0 & 39,0 & 65,0 & 42,0 & 74,0 & 52,0 & 67,0 & 46,0 & 53,0 & 43,0 & 53,0 \\
\hline \multirow{3}{*}{ Ponto - 02} & $\mathrm{~S}$ & 33,0 & 42,0 & 47,0 & 72,0 & 39,0 & 53,0 & 49,0 & 54,0 & 65,0 & 55,0 & 49,0 & 53,0 \\
\hline & $\mathrm{M}$ & * & 44,0 & 44,0 & 88,0 & 43,0 & 68,0 & 53,0 & 44,0 & 65,0 & 57,0 & 52,0 & 55,0 \\
\hline & $\mathrm{F}$ & * & 46,0 & 37,0 & 63,0 & 56,0 & 73,0 & 66,0 & 62,0 & 80,0 & 55,0 & 54,0 & 53,0 \\
\hline \multirow{3}{*}{ Ponto - 03} & $\mathrm{~S}$ & 36,0 & 37,0 & 50,0 & 63,0 & 54,0 & 71,0 & 60,0 & 69,0 & 77,0 & 81,0 & 78,0 & 64,0 \\
\hline & $M$ & * & 38,0 & 51,0 & 92,0 & 57,0 & 66,0 & 87,0 & 87,0 & 66,0 & 82,0 & 83,0 & 67,0 \\
\hline & $F$ & * & 38,0 & 46,0 & 69,0 & 69,0 & 74,0 & 65,0 & 70,0 & 76,0 & 80,0 & 73,0 & 67,0 \\
\hline \multirow{3}{*}{ Ponto - 04} & $\mathrm{~S}$ & 50,0 & 54,0 & 69,0 & 86,0 & 72,0 & 92,0 & 96,0 & 101,0 & 103,0 & 116,0 & 108,0 & 97,0 \\
\hline & $M$ & * & 66,0 & 79,0 & 102,0 & 98,0 & 98,0 & 88,0 & 97,0 & 114,0 & 110,0 & 115,0 & 102,0 \\
\hline & $\mathrm{F}$ & * & 59,0 & 82,0 & 87,0 & 86,0 & 75,0 & 74,0 & 89,0 & 106,0 & 121,0 & 120,0 & 106,0 \\
\hline \multirow{3}{*}{ Ponto - 05} & $\mathrm{~S}$ & 89,0 & 92,0 & 65,0 & 101,0 & 81,0 & 94,0 & 90,0 & 105,0 & 111,0 & 113,0 & 135,0 & 113,0 \\
\hline & $\mathrm{M}$ & * & 70,0 & 68,0 & 114,0 & 87,0 & 95,0 & 97,0 & 101,0 & 114,0 & 116,0 & 142,0 & 116,0 \\
\hline & $\mathrm{F}$ & * & 69,0 & 70,0 & 104,0 & 93,0 & 111,0 & 98,0 & 103,0 & 120,0 & 114,0 & 145,0 & 120,0 \\
\hline \multirow{3}{*}{ Ponto - 06} & $\mathrm{~S}$ & 68,0 & 55,0 & 70,0 & 67,0 & 73,0 & 89,0 & 97,0 & 89,0 & 115,0 & 107,0 & 112,0 & 86,0 \\
\hline & $M$ & * & 62,0 & 75,0 & 71,0 & 75,0 & 97,0 & 111,0 & 101,0 & 108,0 & 119,0 & 98,0 & 86,0 \\
\hline & $\mathrm{F}$ & * & 47,0 & 76,0 & 75,0 & 78,0 & 95,0 & 98,0 & 102,0 & 111,0 & 118,0 & 108,0 & 98,0 \\
\hline \multirow{3}{*}{ Ponto - 07} & $\mathrm{~S}$ & 91,0 & 66,0 & 76,0 & 80,0 & 82,0 & 90,0 & 96,0 & 103,0 & 110,0 & 99,0 & 121,0 & 107,0 \\
\hline & $M$ & * & 72,0 & 79,0 & 80,0 & 84,0 & 101,0 & 98,0 & 112,0 & 108,0 & 113,0 & 117,0 & 113,0 \\
\hline & $\mathrm{F}$ & * & 82,0 & 77,0 & 84,0 & 88,0 & 100,0 & 103,0 & 106,0 & 121,0 & 121,0 & 115,0 & 114,0 \\
\hline \multirow{3}{*}{ Ponto - 08} & $\mathrm{~S}$ & 94,0 & 72,0 & 74,0 & 83,0 & 81,0 & 96,0 & 94,0 & 98,0 & 113,0 & 114,0 & $\star \star$ & 108,0 \\
\hline & $\mathrm{M}$ & * & 76,0 & 78,0 & 83,0 & 81,0 & 95,0 & 89,0 & 98,0 & 102,0 & 117,0 & ** & 107,0 \\
\hline & $\mathrm{F}$ & * & 74,0 & 97,0 & 83,0 & 81,0 & 95,0 & 87,0 & 101,0 & 116,0 & 119,0 & ** & 106,0 \\
\hline \multirow{3}{*}{ Ponto - 09} & $\mathrm{~S}$ & 111,0 & 82,0 & 70,0 & 90,0 & 59,0 & 109,0 & 96,0 & 89,0 & 115,0 & 118,0 & $\star \star$ & 105,0 \\
\hline & $M$ & * & 85,0 & 74,0 & 99,0 & 61,0 & 97,0 & 87,0 & 78,0 & 130,0 & 118,0 & $\star \star$ & 109,0 \\
\hline & $\mathrm{F}$ & * & 128,0 & 74,0 & 92,0 & 82,0 & 100,0 & 92,0 & 64,0 & 143,0 & 133,0 & $\star \star$ & 111,0 \\
\hline \multirow{3}{*}{ Ponto - 10} & $\mathrm{~S}$ & 97,0 & 72,0 & 74,0 & 82,0 & 77,0 & 95,0 & 94,0 & 89,0 & 112,0 & 115,0 & ** & 107,0 \\
\hline & $\mathrm{M}$ & * & 70,0 & 86,0 & 75,0 & 87,0 & 98,0 & 76,0 & 89,0 & 102,0 & 116,0 & ** & 111,0 \\
\hline & $\mathrm{F}$ & * & 79,0 & 88,0 & 78,0 & 100,0 & 77,0 & 84,0 & 98,0 & 109,0 & 116,0 & $\star \star$ & 114,0 \\
\hline
\end{tabular}

\section{$\left({ }^{*}\right)$ = não houve coleta}


${ }^{(* *}$ = não houve coleta (chuvas intermitentes) 
Tabela 08: Valores mensais de oxigênio dissolvido (mg/L) dos 10 pontos de amostragem - superfície (S), à meia profundidade (M) e fundo (F), no período de março/96 a fevereiro/97 na Represa do Guarapiranga - SP.

\begin{tabular}{|c|c|c|c|c|c|c|c|c|c|c|c|c|c|}
\hline PontosiColetas & & mar/96 & abr/96 & mai/96 & jun/96 & jul/96 & ago/96 & set/96 & out/96 & nov/96 & dez/96 & jan/97 & fev/97 \\
\hline \multirow{3}{*}{ Ponto - 01} & $\mathrm{~S}$ & 7,4 & 6,7 & 6,4 & 6,7 & 7,4 & 8,4 & 7,2 & 3,4 & 5,5 & 5,8 & 6,2 & 5,6 \\
\hline & $\mathrm{M}$ & * & 5,2 & 6,0 & 8,0 & 6,4 & 6,7 & 7,4 & 4,6 & 5,2 & 5,6 & 3,2 & 4,0 \\
\hline & $\mathrm{F}$ & * & 5,0 & 5,7 & 6,5 & 6,0 & 5,3 & 6,6 & 4,2 & 1,1 & 2,0 & 2,4 & 3,2 \\
\hline \multirow{3}{*}{ Ponto - 02} & $\mathrm{~S}$ & 7,2 & 8,1 & 7,7 & 8,0 & 7,8 & 8,2 & 6,8 & 3,1 & 5,2 & 6,2 & 5,8 & 5,4 \\
\hline & $\mathrm{M}$ & * & 7,9 & 6,2 & 7,2 & 7,5 & 8,5 & 7,3 & 4,4 & 4,2 & 5,8 & 5,4 & 5,4 \\
\hline & $\mathrm{F}$ & * & 7,7 & 5,3 & 6,7 & 7,9 & 8,0 & 6,9 & 5,2 & 3,3 & 5,2 & 3,4 & 5,0 \\
\hline \multirow{3}{*}{ Ponto - 03} & $\mathrm{~S}$ & 7,2 & 7,3 & 8,3 & 8,6 & 9,2 & 8,6 & 8,4 & 3,3 & 6,0 & 8,0 & 8,2 & 4,8 \\
\hline & $\mathrm{M}$ & * & 5,6 & 8,1 & 8,2 & 9,5 & 8,0 & 8,2 & 4,5 & 6,1 & 7,8 & 8,8 & 4,8 \\
\hline & $\mathrm{F}$ & * & 3,1 & 8,1 & 8,2 & 9,0 & 7,7 & 8,7 & 5,6 & 6,1 & 7,8 & 6,0 & 5,2 \\
\hline \multirow{3}{*}{ Ponto - 04} & $\mathrm{~S}$ & 7,6 & 7,9 & 7,0 & 8,4 & 8,8 & 6,4 & 6,2 & 3,5 & 3,5 & 7,8 & 7,8 & 5,4 \\
\hline & $M$ & * & 7,7 & 6,6 & 8,2 & 8,5 & 7,0 & 6,5 & 3,8 & 3,3 & 6,0 & 6,1 & 5,2 \\
\hline & $\mathrm{F}$ & * & 6,9 & 6,6 & 8,2 & 8,5 & 7,0 & 6,7 & 4,5 & 2,8 & 4,2 & 4,6 & 5,0 \\
\hline \multirow{3}{*}{ Ponto - 05} & $\mathrm{~S}$ & 6,0 & 8,9 & 6,6 & 8,6 & 9,6 & 7,8 & 8,4 & 3,3 & 6,3 & 6,6 & 7,8 & 6,4 \\
\hline & $M$ & * & 4,4 & 6,2 & 8,5 & 9,4 & 7,9 & 7,3 & 3,8 & 5,8 & 6,2 & 6,2 & 5,4 \\
\hline & $\mathrm{F}$ & * & 2,1 & 5,5 & 8,7 & 9,6 & 8,0 & 7,7 & 5,7 & 5,4 & 6,4 & 2,6 & 3,6 \\
\hline \multirow{3}{*}{ Ponto - 06} & $\mathrm{~S}$ & 6,6 & 8,3 & 9,8 & 8,8 & 8,6 & 7,4 & 6,6 & 3,5 & 5,5 & 7,8 & 7,6 & 5,4 \\
\hline & $M$ & * & 6,4 & 9,8 & 8,9 & 7,8 & 8,8 & 6,9 & 4,5 & 4,6 & 6,6 & 6,8 & 4,1 \\
\hline & $\mathrm{F}$ & * & 4,6 & 8,3 & 8,5 & 7,7 & 7,8 & 7,4 & 5,2 & 3,9 & 4,2 & 5,6 & 4,8 \\
\hline \multirow{3}{*}{ Ponto - 07} & $\mathrm{~S}$ & 7,8 & 8,1 & 7,1 & 9,0 & 9,0 & 7,4 & 7,0 & 3,4 & 6,8 & 8,8 & 6,6 & 5,2 \\
\hline & $\mathrm{M}$ & * & 7,9 & 7,0 & 8,0 & 9,0 & 7,5 & 8,0 & 3,8 & 6,5 & 7,8 & 6,6 & 4,6 \\
\hline & $\mathrm{F}$ & * & 3,5 & 7,0 & 8,0 & 8,2 & 6,8 & 8,0 & 4,4 & 5,5 & 6,8 & 5,0 & 4,8 \\
\hline \multirow{3}{*}{ Ponto - 08} & $\mathrm{~S}$ & 6,4 & 7,3 & 6,9 & 8,6 & 9,4 & 8,0 & 7,4 & 3,7 & 6,1 & 8,2 & $\star \star$ & 4,8 \\
\hline & $M$ & * & 6,2 & 7,2 & 8,8 & 9,4 & 8,2 & 7,2 & 3,7 & 5,5 & 7,2 & $\star \star$ & 5,2 \\
\hline & $\mathrm{F}$ & * & 0,6 & 6,8 & 8,9 & 8,9 & 7,9 & 6,8 & 4,2 & 0,5 & 2,2 & ** & 4,0 \\
\hline \multirow{3}{*}{ Ponto - 09} & $\mathrm{~S}$ & 6,0 & 6,4 & 6,7 & 7,8 & 8,4 & 7,0 & 7,6 & 3,7 & 7,6 & 7,8 & $\star \star$ & 4,8 \\
\hline & $M$ & * & 3,7 & 7,0 & 7,6 & 8,6 & 7,0 & 7,4 & 4,3 & 5,4 & 6,0 & ** & 4,6 \\
\hline & $\mathrm{F}$ & * & & 7,4 & 7,5 & 8,8 & 7,0 & 7,7 & 3,5 & 2,5 & 3,4 & ** & 3,0 \\
\hline \multirow{3}{*}{ Ponto - 10} & $\mathrm{~S}$ & 6,4 & 7,1 & 6,9 & 9,0 & 9,0 & 8,4 & 7,6 & 3,7 & 7,1 & 7,4 & $\star \star$ & 4,6 \\
\hline & $\mathrm{M}$ & * & 6,2 & 7,0 & 8,7 & 7,5 & 8,5 & 7,0 & 3,5 & 6,9 & 7,2 & ** & 3,8 \\
\hline & $\mathrm{F}$ & * & 0,8 & 7,2 & 8,5 & 7,5 & 8,0 & 7,5 & 3,3 & 6,6 & 5,4 & ** & 2,4 \\
\hline
\end{tabular}

\section{$\left(^{*}\right)$ = não houve coleta}

$\left({ }^{* *}\right)=$ não houve coleta (chuvas intermitentes) 
Tabela 09: Valores mensais da demanda bioquímica de oxigênio (mg/L) dos 10 pontos de amostragem - superfície (S), à meia profundidade (M) e fundo (F), no período de março/96 a fevereiro/97 na Represa do Guarapiranga - SP.

\begin{tabular}{|c|c|c|c|c|c|c|c|c|c|c|c|c|c|}
\hline PontosiColetas & & $\mathrm{mar} / 96$ & $a b r / 96$ & mai/96 & jun/96 & jul/96 & ago/96 & set/96 & out/96 & nov/96 & dez/96 & jan/97 & fev/97 \\
\hline \multirow{3}{*}{ Ponto - 01} & $\mathrm{~S}$ & 3,0 & 1,0 & 1,0 & 1,5 & 1,0 & 2,0 & 1,4 & 1,5 & 1,5 & 1,2 & 1,2 & 1,4 \\
\hline & $\mathrm{M}$ & * & 1,0 & 1,0 & 2,5 & 2,0 & 1,5 & 2,0 & 1,3 & 1,3 & 1,0 & 1,0 & 1,0 \\
\hline & $\mathrm{F}$ & * & 3,0 & 3,0 & 2,0 & 2,0 & 2,0 & 2,0 & 1,5 & 1,3 & 0,4 & 0,2 & 0,6 \\
\hline \multirow{3}{*}{ Ponto - 02} & $\mathrm{~S}$ & 2,0 & 2,0 & 2,5 & 2,3 & 2,0 & 1,8 & 0,6 & 2,0 & 1,7 & 1,2 & 1,6 & 1,0 \\
\hline & $\mathrm{M}$ & * & 2,0 & 2,0 & 2,0 & 3,0 & 2,0 & 1,0 & 1,0 & 1,5 & 1,4 & 1,0 & 1,0 \\
\hline & $\mathrm{F}$ & * & 2,0 & 2,0 & 2,0 & 3,0 & 1,0 & 1,0 & 2,0 & 1,3 & 0,4 & 0,6 & 0,8 \\
\hline \multirow{3}{*}{ Ponto - 03} & $\mathrm{~S}$ & 2,0 & 1,0 & 2,5 & 2,3 & 2,0 & 1,8 & 0,6 & 2,0 & 1,7 & 1,2 & 1,6 & 1,0 \\
\hline & $\mathrm{M}$ & * & 1,0 & 2,0 & 2,0 & 3,0 & 2,0 & 1,0 & 1,0 & 1,5 & 1,4 & 1,0 & 1,0 \\
\hline & $\mathrm{F}$ & * & 0,0 & 2,0 & 2,0 & 3,0 & 1,0 & 1,0 & 2,0 & 1,3 & 0,4 & 0,6 & 0,8 \\
\hline \multirow{3}{*}{ Ponto - 04} & $S$ & 3,0 & 2,0 & 3,0 & 1,6 & 1,8 & 1,0 & 1,4 & 2,0 & 1,7 & 2,2 & 1,2 & 1,0 \\
\hline & $\mathrm{M}$ & $\star$ & 1,0 & 2,0 & 1,0 & 2,0 & 1,0 & 2,0 & 2,0 & 1,4 & 2,0 & 1,1 & 1,0 \\
\hline & $\mathrm{F}$ & * & 1,0 & 2,0 & 1,0 & 2,0 & 1,0 & 2,0 & 3,0 & 1,4 & 1,8 & 1,0 & 0,8 \\
\hline \multirow{3}{*}{ Ponto - 05} & $\mathrm{~S}$ & 2,0 & 2,0 & 2,0 & 1,7 & 1,8 & 2,2 & 0,8 & 1,7 & 1,7 & 2,0 & 1,4 & 1,6 \\
\hline & $\mathrm{M}$ & * & 0,0 & 3,0 & 1,5 & 2,0 & 2,5 & 1,0 & 1,4 & 1,4 & 2,2 & 1,0 & 1,2 \\
\hline & $\mathrm{F}$ & * & 0,0 & 3,0 & 2,0 & 2,0 & 3,0 & 1,0 & 1,5 & 1,5 & 2,2 & 1,0 & 0,8 \\
\hline \multirow{3}{*}{ Ponto - 06} & $S$ & 3,0 & 2,0 & 3,0 & 1,8 & 1,4 & 2,2 & 1,6 & 2,0 & 1,8 & 1,2 & 1,2 & 1,0 \\
\hline & $\mathrm{M}$ & * & 1,0 & 2,0 & 2,0 & 1,5 & 3,0 & 1,5 & 3,0 & 1,5 & 1,0 & 1,0 & 1,0 \\
\hline & $\mathrm{F}$ & * & 2,0 & 2,0 & 2,0 & 2,0 & 2,5 & 2,0 & 3,0 & 2,0 & 3,0 & 2,8 & 0,6 \\
\hline \multirow{3}{*}{ Ponto - 07} & $\mathrm{~S}$ & 2,0 & 1,0 & 2,0 & 2,2 & 1,9 & 2,2 & 1,0 & 1,6 & 1,5 & 0,6 & 1,8 & 1,2 \\
\hline & $\mathrm{M}$ & * & 1,0 & 4,0 & 2,0 & 2,0 & 3,0 & 1,0 & 1,7 & 1,7 & 1,2 & 1,4 & 1,0 \\
\hline & $\mathrm{F}$ & * & 0,0 & 4,0 & 2,0 & 2,0 & 1,0 & 1,0 & 1,7 & 1,7 & 3,0 & 3,2 & 1,0 \\
\hline \multirow{3}{*}{ Ponto - 08} & $S$ & 3,0 & 0,0 & 2,0 & 4,3 & 2,0 & 1,4 & 0,4 & 1,8 & 1,8 & 1,4 & ** & 1,6 \\
\hline & $\mathrm{M}$ & * & 0,0 & 2,0 & 4,5 & 3,0 & 1,5 & 1,0 & 1,8 & 1,6 & 1,4 & ** & 1,4 \\
\hline & $\mathrm{F}$ & * & 0,0 & 2,0 & 4,0 & 3,0 & 1,5 & 1,0 & 1,5 & 1,5 & 1,4 & ** & 0,4 \\
\hline \multirow{3}{*}{ Ponto - 09} & $\mathrm{~S}$ & 2,0 & 1,0 & 3,0 & 2,0 & 2,2 & 1,8 & 1,2 & 1,8 & 1,8 & 1,6 & $\star \star$ & 1,6 \\
\hline & $\mathrm{M}$ & * & 1,0 & 2,0 & 2,0 & 3,0 & 1,0 & 1,8 & 1,6 & 1,6 & 1,2 & ** & 1,0 \\
\hline & $\mathrm{F}$ & * & & 2,0 & 3,0 & 2,0 & 1,5 & 2,0 & 1,9 & 1,9 & 2,2 & ** & 0,4 \\
\hline \multirow{3}{*}{ Ponto - 10} & $\mathrm{~S}$ & 3,0 & 1,0 & 2,0 & 2,1 & 1,2 & 1,8 & 0,6 & 1,5 & 1,5 & 1,3 & $\star \star$ & 1,0 \\
\hline & $\mathrm{M}$ & * & 1,0 & 2,0 & 2,0 & 1,2 & 2,0 & 0,5 & 1,3 & 1,3 & 1,2 & $\star \star$ & 0,8 \\
\hline & $\mathrm{F}$ & * & 0,0 & 2,0 & 2,0 & 1,0 & 2,0 & 1,0 & 1,3 & 1,3 & 2,2 & $\star \star$ & 0,4 \\
\hline
\end{tabular}

$\left({ }^{*}\right)=$ não houve coleta

$(* *)=$ não houve coleta (chuvas intermitentes) 
Tabela 11: Valores mensais de fósforo total (mg/L) dos 10 pontos de amostragem - superfície (S), no período de maio/96 a dezembro/96 na Represa do Guarapiranga - SP.

\begin{tabular}{|c|c|c|c|c|c|c|c|c|}
\hline PontosiColetas & mai/96 & jun/96 & jul/96 & ago/96 & set/96 & out/96 & nov/96 & dez/96 \\
\hline Ponto - 01 & 0,06 & 0,03 & 0,04 & 0,04 & 0,04 & 0,04 & 0,02 & 0,02 \\
\hline Ponto - 02 & 0,02 & 0,03 & 0,01 & 0,03 & 0,06 & 0,06 & 0,02 & 0,02 \\
\hline Ponto - 03 & 0,01 & 0,05 & 0,02 & 0,03 & 0,08 & 0,08 & 0,01 & 0,02 \\
\hline Ponto - 04 & 0,02 & 0,04 & 0,02 & 0,03 & 0,07 & 0,06 & 0,02 & 0,02 \\
\hline Ponto - 05 & 0,07 & 0,08 & 0,07 & 0,06 & 0,13 & 0,06 & 0,08 & 0,08 \\
\hline Ponto - 06 & 0,02 & 0,07 & 0,06 & 0,06 & 0,11 & 0,07 & 0,02 & 0,02 \\
\hline Ponto - 07 & 0,03 & 0,08 & 0,06 & 0,05 & 0,05 & 0,12 & 0,02 & 0,02 \\
\hline Ponto - 08 & 0,02 & 0,08 & 0,03 & 0,07 & 0,08 & 0,06 & 0,02 & 0,02 \\
\hline Ponto - 09 & 0,04 & 0,05 & 0,04 & 0,04 & 0,06 & 0,06 & 0,02 & 0,02 \\
\hline Ponto - 10 & 0,03 & 0,10 & 0,03 & 0,07 & 0,05 & 0,04 & 0,03 & 0,03 \\
\hline
\end{tabular}


Tabela 12: Densidade total acumulada dos Macroinvertebrados Bentônicos (orgs/角) na Represa do Guarapiranga - SP - 1996/1997

\begin{tabular}{|c|c|c|c|c|c|c|c|c|c|c|c|c|c|}
\hline PontosiColetas & mar/96 & abr/96 & mai/96 & jun/96 & $\mathrm{jul} / 96$ & ago/96 & set/96 & out/96 & nov/96 & dez/96 & jan/97 & fev/97 & Total \\
\hline Ponto - 01 & 278 & 15 & 60 & 919 & 577 & 148 & 89 & 15 & 30 & 0 & 15 & 0 & 2146 \\
\hline Ponto - 02 & 104 & 238 & 119 & 104 & 3704 & 178 & 89 & 148 & 15 & 0 & 45 & 111 & 4855 \\
\hline Ponto - 03 & 370 & 504 & 30 & 267 & 1393 & 119 & 74 & 133 & 15 & 59 & 0 & 104 & 3068 \\
\hline Ponto - 04 & * & 0 & 30 & 104 & 489 & 45 & 15 & 59 & 0 & 15 & 30 & 0 & 787 \\
\hline Ponto - 05 & 222 & 60 & 0 & 2340 & 489 & 726 & 207 & 119 & 75 & * & 15 & 30 & 4283 \\
\hline Ponto - 06 & 556 & 67 & 0 & 504 & 1999 & 59 & 148 & 89 & 74 & 30 & 74 & 119 & 3719 \\
\hline Ponto - 07 & 155 & 0 & 75 & 15 & 7703 & 1051 & 163 & 60 & 88 & 30 & 110 & 126 & 9576 \\
\hline Ponto - 08 & 1074 & * & 59 & 134 & 2150 & 118 & 1244 & 133 & 59 & 30 & $* *$ & 474 & 5475 \\
\hline Ponto - 09 & 1319 & 178 & 0 & 192 & 726 & 267 & 266 & 44 & 163 & 637 & $\star \star$ & 244 & 4036 \\
\hline Ponto - 10 & 2355 & 59 & 119 & 213 & 562 & 222 & 177 & 60 & 89 & 30 & $\star \star$ & 251 & 4137 \\
\hline Total & 6433 & 1121 & 492 & 4792 & 19792 & 2933 & 2472 & 860 & 608 & 831 & 289 & 1459 & 42082 \\
\hline
\end{tabular}

$(*)$ draga quebrou

$\left.{ }^{* *}\right)=$ não houve coleta (chuvas intermitentes) 
Tabela 13: Variação temporal da densidade total acumulada (orgs $/ \mathrm{m}^{2}$ ) e abundância relativa (\%) dos Macroinvertebrados Bentônicos na Represa do Guarapiranga-SP - 1996/1997

\begin{tabular}{|c|c|c|c|c|c|c|c|c|c|c|c|c|c|c|c|c|c|c|c|c|c|c|c|c|c|c|}
\hline \multirow[t]{2}{*}{ TaxalColetas } & \multicolumn{2}{|c|}{ mar/96 } & \multicolumn{2}{|c|}{$\mathrm{abr} / 96$} & \multicolumn{2}{|c|}{ mai/96 } & \multicolumn{2}{|c|}{ jun/96 } & \multicolumn{2}{|c|}{ jul/96 } & \multicolumn{2}{|c|}{ ago/96 } & \multicolumn{2}{|c|}{ set/96 } & \multicolumn{2}{|c|}{ out/96 } & \multicolumn{2}{|c|}{ nov/96 } & \multicolumn{2}{|c|}{ dez/96 } & \multicolumn{2}{|c|}{ jan/97 } & \multicolumn{2}{|c|}{ fev/97 } & \multicolumn{2}{|c|}{ Total } \\
\hline & No & $\%$ & $\mathrm{~N}^{\mathrm{o}}$ & $\%$ & $\mathrm{~N}^{\circ}$ & $\%$ & $\mathrm{~N}^{\circ}$ & $\%$ & $\mathrm{~N}^{\circ}$ & $\%$ & No & $\%$ & $\mathrm{~N}^{\circ}$ & $\%$ & $\mathrm{~N}^{\mathrm{O}}$ & $\%$ & $\mathrm{~N}^{\mathrm{o}}$ & $\%$ & $\mathrm{~N}^{\mathrm{O}}$ & $\%$ & $\mathrm{~N}^{\circ}$ & $\%$ & $\mathrm{~N}^{\mathrm{O}}$ & $\%$ & $\mathrm{~N}^{\mathrm{O}}$ & $\%$ \\
\hline Chironomidae & 332 & 5,2 & 172 & 15,3 & 120 & 24,4 & 356 & 7,4 & 1445 & 7,3 & 563 & 19,2 & 408 & 16,5 & 252 & 29,3 & 267 & 43,9 & 60 & 7,2 & 82 & 31,7 & 103 & 7,1 & 4160 & 9,9 \\
\hline Tanypodinae & 93 & 1,4 & 15 & 1,3 & 44 & 8,9 & 675 & 14,1 & 326 & 1,6 & 104 & 3,5 & 192 & 7,8 & 30 & 3,5 & 0 & 0,0 & 0 & 0,0 & 0 & 0,0 & 15 & 1,0 & 1494 & 3,6 \\
\hline Chaoboridae & 3909 & 60,8 & 371 & 33,1 & 223 & 45,3 & 2056 & 42,9 & 6442 & 32,5 & 563 & 19,2 & 636 & 25,7 & 266 & 30,9 & 82 & 13,5 & 15 & 1,8 & 66 & 25,5 & 252 & 17,3 & 14881 & 35,4 \\
\hline Tubificidae & 2040 & 31,7 & 533 & 47,5 & 45 & 9,1 & 1570 & 32,8 & 11163 & 56,4 & 1673 & 57,0 & 1155 & 46,7 & 297 & 34,5 & 229 & 37,7 & 696 & 83,8 & 59 & 22,8 & 1089 & 74,6 & 20549 & 48,9 \\
\hline Glossiphoniidae & 44 & 0,7 & 30 & 2,7 & 0 & 0,0 & 75 & 1,6 & 401 & 2,0 & 15 & 0,5 & 15 & 0,6 & 0 & 0,0 & 0 & 0,0 & 0 & 0,0 & 22 & 8,5 & 0 & 0,0 & 602 & 1,4 \\
\hline Pelecycopa & 15 & 0,2 & 0 & 0,0 & 60 & 12,2 & 60 & 1,3 & 15 & 0,1 & 15 & 0,5 & 66 & 2,7 & 15 & 1,7 & 30 & 4,9 & 60 & 7,2 & 30 & 11,6 & 0 & 0,0 & 366 & 0,9 \\
\hline Total & 6433 & & 1121 & & 492 & & 4792 & & 19792 & & 2933 & & 2472 & & 860 & & 608 & & 831 & & 259 & & 1459 & & 42082 & \\
\hline
\end{tabular}


Tabela 14: Densidades Numéricas (orgs/m2) e Abundância Relativa (\%) dos Macroinvertebrados Bentônicos do ponto 01 no período de março/96 a fevereiro/97 na Represa do Guarapiranga - SP.

\begin{tabular}{|c|c|c|c|c|c|c|c|c|c|c|c|c|c|c|c|c|c|c|c|c|c|c|c|c|}
\hline \multirow[t]{2}{*}{ TaxalColetas } & \multicolumn{2}{|c|}{$\mathrm{mar} / 96$} & \multicolumn{2}{|c|}{$\mathrm{abr} / 96$} & \multicolumn{2}{|c|}{ mai/96 } & \multicolumn{2}{|c|}{ jun/96 } & \multicolumn{2}{|c|}{$\mathrm{jul} / 96$} & \multicolumn{2}{|c|}{ ago/96 } & \multicolumn{2}{|c|}{ set/96 } & \multicolumn{2}{|c|}{ out/96 } & \multicolumn{2}{|c|}{ nov/96 } & \multicolumn{2}{|c|}{ dez/96 } & \multicolumn{2}{|c|}{ jan/97 } & \multicolumn{2}{|c|}{ fev/97 } \\
\hline & No & $\%$ & $\mathrm{~N}^{\mathrm{O}}$ & $\%$ & $\mathrm{~N}^{\circ}$ & $\%$ & $\mathrm{~N}^{\mathrm{O}}$ & $\%$ & $\mathrm{~N}^{\mathrm{O}}$ & $\%$ & $\mathrm{~N}^{\mathrm{o}}$ & $\%$ & $\mathrm{~N}^{\circ}$ & $\%$ & $\mathrm{~N}^{\circ}$ & $\%$ & $\mathrm{~N}^{\circ}$ & $\%$ & $\mathrm{~N}^{\circ}$ & $\%$ & $\mathrm{~N}^{\circ}$ & $\%$ & $\mathrm{~N}^{\mathrm{O}}$ & $\%$ \\
\hline Chironomidae & 11 & 4,0 & 0 & 0,0 & 15 & 25,0 & 252 & 27,4 & 296 & 51,3 & 89 & 60,1 & 74 & 83,1 & 0 & 0,0 & 15 & 50,0 & 0 & 0,0 & 15 & 100,0 & 0 & 0,0 \\
\hline Tanypodinae & 0 & 0,0 & 0 & 0,0 & 0 & 0,0 & 0 & 0,0 & 0 & 0,0 & 0 & 0,0 & 0 & 0,0 & 0 & 0,0 & 0 & 0,0 & 0 & 0,0 & 0 & 0,0 & 0 & 0,0 \\
\hline Chaoboridae & 200 & 71,9 & 15 & 100,0 & 30 & 50,0 & 622 & 67,7 & 237 & 41,1 & 59 & 39,9 & 15 & 16,9 & 0 & 0,0 & 0 & 0,0 & 0 & 0,0 & 0 & 0,0 & 0 & 0,0 \\
\hline Tubificidae & 67 & 24,1 & 0 & 0,0 & 15 & 25,0 & 15 & 1,6 & 44 & 7,6 & 0 & 0,0 & 0 & 0,0 & 15 & 100,0 & 15 & 50,0 & 0 & 0,0 & 0 & 0,0 & 0 & 0,0 \\
\hline Glossiphoniidae & 0 & 0,0 & 0 & 0,0 & 0 & 0,0 & 0 & 0,0 & 0 & 0,0 & 0 & 0,0 & 0 & 0,0 & 0 & 0,0 & 0 & 0,0 & 0 & 0,0 & 0 & 0,0 & 0 & 0,0 \\
\hline Pelecycopa & 0 & 0,0 & 0 & 0,0 & 0 & 0,0 & 30 & 3,3 & 0 & 0,0 & 0 & 0,0 & 0 & 0,0 & 0 & 0,0 & 0 & 0,0 & 0 & 0,0 & 0 & 0,0 & 0 & 0,0 \\
\hline Total & 278 & & 15 & & 60 & & 919 & & 577 & & 148 & & 89 & & 15 & & 30 & & 0 & & 15 & & 0 & \\
\hline
\end{tabular}


Tabela 15: Densidades numéricas (em organismos $/ \mathrm{m}^{2}$ ) e abundância relativa (\%) dos Macroinvertebrados Bentônicos do ponto 02 no período de março/96 a fevereiro/97 na Represa do Guarapiranga-SP

\begin{tabular}{|c|c|c|c|c|c|c|c|c|c|c|c|c|c|c|c|c|c|c|c|c|c|c|c|c|}
\hline \multirow[t]{2}{*}{ TaxalColetas } & \multicolumn{2}{|c|}{$\mathrm{mar} / 96$} & \multicolumn{2}{|c|}{$\mathrm{abr} / 96$} & \multicolumn{2}{|c|}{ mai/96 } & \multicolumn{2}{|c|}{ jun/96 } & \multicolumn{2}{|c|}{$\mathrm{jul} / 96$} & \multicolumn{2}{|c|}{ ago/96 } & \multicolumn{2}{|c|}{ set/96 } & \multicolumn{2}{|c|}{ out/96 } & \multicolumn{2}{|c|}{ nov/96 } & \multicolumn{2}{|c|}{ dez/96 } & \multicolumn{2}{|c|}{ jan/97 } & \multicolumn{2}{|c|}{ fev/97 } \\
\hline & $\mathrm{N}^{\circ}$ & $\%$ & No & $\%$ & $\mathrm{~N}^{\mathrm{o}}$ & $\%$ & $\mathrm{~N}^{\circ}$ & $\%$ & $\mathrm{~N}^{\circ}$ & $\%$ & $\mathrm{~N}^{\mathrm{o}}$ & $\%$ & $\mathrm{~N}^{\mathrm{o}}$ & $\%$ & $\mathrm{~N}^{\circ}$ & $\%$ & $\mathrm{~N}^{\circ}$ & $\%$ & $\mathrm{~N}^{\circ}$ & $\%$ & $\mathrm{~N}^{\circ}$ & $\%$ & $\mathrm{~N}^{\circ}$ & $\%$ \\
\hline Chironomidae & 74 & 71,2 & 30 & 12,6 & 30 & 25,2 & 15 & 14,4 & 400 & 10,8 & 15 & 8,4 & 0 & 0,0 & 30 & 20,3 & 0 & 0,0 & 0 & 0,0 & 15 & 33,3 & 44 & 39,6 \\
\hline Tanypodinae & 0 & 0,0 & 15 & 6,3 & 0 & 0,0 & 0 & 0,0 & 44 & 1,2 & 0 & 0,0 & 0 & 0,0 & 0 & 0,0 & 0 & 0,0 & 0 & 0,0 & 0 & 0,0 & 0 & 0,0 \\
\hline Chaoboridae & 0 & 0,0 & 193 & 81,1 & 59 & 49,6 & 59 & 56,7 & 2104 & 56,8 & 30 & 16,9 & 0 & 0,0 & 44 & 29,7 & 15 & 100,0 & 0 & 0,0 & 0 & 0,0 & 0 & 0,0 \\
\hline Tubificidae & 30 & 28,8 & 0 & 0,0 & 0 & 0,0 & 0 & 0,0 & 1156 & 31,2 & 133 & 74,7 & 89 & 100,0 & 74 & 50,0 & 0 & 0,0 & 0 & 0,0 & 30 & 66,7 & 67 & 60,4 \\
\hline Glossiphoniidae & 0 & 0,0 & 0 & 0,0 & 0 & 0,0 & 0 & 0,0 & 0 & 0,0 & 0 & 0,0 & 0 & 0,0 & 0 & 0,0 & 0 & 0,0 & 0 & 0,0 & 0 & 0,0 & 0 & 0,0 \\
\hline Pelecycopa & 0 & 0,0 & 0 & 0,0 & 30 & 25,2 & 30 & 28,8 & 0 & 0,0 & 0 & 0,0 & 0 & 0,0 & 0 & 0,0 & 0 & 0,0 & 0 & 0,0 & 0 & 0,0 & 0 & 0,0 \\
\hline TOTAL & 104 & & 238 & & 119 & & 104 & & 3704 & & 178 & & 89 & & 148 & & 15 & & 0 & & 45 & & 111 & \\
\hline
\end{tabular}


Tabela 16: Densidades númericas (em organismos $/ \mathrm{m}^{2}$ ) e abundância relativa (\%) dos Macroinvertebrados Bentônicos do ponto 03 no período de março/96 a fevereiro/97 na Represa do Guarapiranga-SP

\begin{tabular}{|c|c|c|c|c|c|c|c|c|c|c|c|c|c|c|c|c|c|c|c|c|c|c|c|c|}
\hline \multirow[t]{2}{*}{ TaxalColetas } & \multicolumn{2}{|c|}{$\mathrm{mar} / 96$} & \multicolumn{2}{|c|}{$\mathrm{abr} / 96$} & \multicolumn{2}{|c|}{ mai/96 } & \multicolumn{2}{|c|}{ jun/96 } & \multicolumn{2}{|c|}{ jul/96 } & \multicolumn{2}{|c|}{ ago/96 } & \multicolumn{2}{|c|}{ set/96 } & \multicolumn{2}{|c|}{ out/96 } & \multicolumn{2}{|c|}{ nov/96 } & \multicolumn{2}{|c|}{ dez/96 } & \multicolumn{2}{|c|}{$\mathrm{jan} / 97$} & \multicolumn{2}{|c|}{$\mathrm{fev} / 97$} \\
\hline & $\mathrm{N}^{\circ}$ & $\%$ & $\mathrm{~N}^{\circ}$ & $\%$ & $\mathrm{~N}^{\circ}$ & $\%$ & $\mathrm{~N}^{\mathrm{O}}$ & $\%$ & $\mathrm{~N}^{\circ}$ & $\%$ & $\mathrm{~N}^{\circ}$ & $\%$ & $\mathrm{~N}^{\mathrm{o}}$ & $\%$ & $\mathrm{~N}^{\mathrm{O}}$ & $\%$ & $\mathrm{~N}^{\mathrm{o}}$ & $\%$ & $\mathrm{~N}^{\circ}$ & $\%$ & $\mathrm{~N}^{\mathrm{O}}$ & $\%$ & $\mathrm{~N}^{\circ}$ & $\%$ \\
\hline Chironomidae & 74 & 20,0 & 30 & 6,0 & 15 & 50,0 & 15 & 5,6 & 178 & 12,8 & 30 & 25,2 & 15 & 20,3 & 59 & 44,4 & 15 & 100,0 & 0 & 0,0 & 0 & 0,0 & 0 & 0,0 \\
\hline Tanypodinae & 0 & 0,0 & 0 & 0,0 & 0 & 0,0 & 0 & 0,0 & 0 & 0,0 & 0 & 0,0 & 0 & 0,0 & 0 & 0,0 & 0 & 0,0 & 0 & 0,0 & 0 & 0,0 & 0 & 0,0 \\
\hline Chaoboridae & 119 & 32,2 & 148 & 29,4 & 0 & 0,0 & 163 & 61,0 & 859 & 61,7 & 74 & 62,2 & 44 & 59,5 & 44 & 33,1 & 0 & 0,0 & 0 & 0,0 & 0 & 0,0 & 30 & 28,8 \\
\hline Tubificidae & 133 & 35,9 & 311 & 61,7 & 15 & 50,0 & 59 & 22,1 & 326 & 23,4 & 0 & 0,0 & 0 & 0,0 & 30 & 22,6 & 0 & 0,0 & 59 & 100,0 & 0 & 0,0 & 74 & 71,2 \\
\hline Glossiphoniidae & 44 & 11,9 & 15 & 3,0 & 0 & 0,0 & 30 & 11,2 & 30 & 2,2 & 15 & 12,6 & 15 & 20,3 & 0 & 0,0 & 0 & 0,0 & 0 & 0,0 & 0 & 0,0 & 0 & 0,0 \\
\hline Pelecycopa & 0 & 0,0 & 0 & 0,0 & 0 & 0,0 & 0 & 0,0 & 0 & 0,0 & 0 & 0,0 & 0 & 0,0 & 0 & 0,0 & 0 & 0,0 & 0 & 0,0 & 0 & 0,0 & 0 & 0,0 \\
\hline Total & 370 & & 504 & & 30 & & 267 & & 1393 & & 119 & & 74 & & 133 & & 15 & & 59 & & 0 & & 104 & \\
\hline
\end{tabular}


Tabela 17: Densidades numéricas (em organimos $/ \mathrm{m}^{2}$ ) e abundância relativa dos Macroinvertebrados Bentônicos do ponto 04 no período de março/96 a fevereiro/97 na Represa do Guarapiranga-SP

\begin{tabular}{|c|c|c|c|c|c|c|c|c|c|c|c|c|c|c|c|c|c|c|c|c|c|c|c|c|}
\hline \multirow[t]{2}{*}{ TaxalColetas } & \multicolumn{2}{|c|}{ mar/96 } & \multicolumn{2}{|c|}{$\mathrm{abr} / 96$} & \multicolumn{2}{|c|}{ mai/96 } & \multicolumn{2}{|c|}{ jun/96 } & \multicolumn{2}{|c|}{$\mathrm{jul} / 96$} & \multicolumn{2}{|c|}{ ago/96 } & \multicolumn{2}{|c|}{ set/96 } & \multicolumn{2}{|c|}{ out/96 } & \multicolumn{2}{|c|}{ nov/96 } & \multicolumn{2}{|c|}{ dez/96 } & \multicolumn{2}{|c|}{$\mathrm{jan} / 97$} & \multicolumn{2}{|c|}{$\mathrm{fev} / 97$} \\
\hline & $\mathrm{N}^{\mathrm{O}}$ & $\%$ & $\mathrm{~N}^{\mathrm{O}}$ & $\%$ & $\mathrm{~N}^{\circ}$ & $\%$ & $\mathrm{~N}^{\mathrm{O}}$ & $\%$ & $\mathrm{~N}^{\mathrm{O}}$ & $\%$ & $\mathrm{~N}^{\circ}$ & $\%$ & No & $\%$ & $\mathrm{~N}^{\circ}$ & $\%$ & $\mathrm{~N}^{\circ}$ & $\%$ & $\mathrm{~N}^{\circ}$ & $\%$ & $\mathrm{~N}^{\circ}$ & $\%$ & $\mathrm{~N}^{\circ}$ & $\%$ \\
\hline Chironomidae & * & & 0 & 0,0 & 15 & 50,0 & 0 & 0,0 & 67 & 13,7 & 0 & 0,0 & 0 & 0,0 & 0 & 0,0 & 0 & 0,0 & 0 & 0,0 & 15 & 50,0 & 0 & 0,0 \\
\hline Tanypodinae & * & & 0 & 0,0 & 0 & 0,0 & 0 & 0,0 & 0 & 0,0 & 0 & 0,0 & 0 & 0,0 & 0 & 0,0 & 0 & 0,0 & 0 & 0,0 & 0 & 0,0 & 0 & 0,0 \\
\hline Chaoboridae & * & & 0 & 0,0 & 15 & 50,0 & 0 & 0,0 & 400 & 81,8 & 30 & 66,7 & 15 & 100,0 & 15 & 25,4 & 0 & 0,0 & 0 & 0,0 & 0 & 0,0 & 0 & 0,0 \\
\hline Tubificidae & * & & 0 & 0,0 & 0 & 0,0 & 89 & 85,6 & 22 & 4,5 & 15 & 33,3 & 0 & 0,0 & 44 & 74,6 & 0 & 0,0 & 0 & 0,0 & 15 & 50,0 & 0 & 0,0 \\
\hline Glossiphoniidae & * & & 0 & 0,0 & 0 & 0,0 & 15 & 14,4 & 0 & 0,0 & 0 & 0,0 & 0 & 0,0 & 0 & 0,0 & 0 & 0,0 & 0 & 0,0 & 0 & 0,0 & 0 & 0,0 \\
\hline Pelecycopa & * & & 0 & 0,0 & 0 & 0,0 & 0 & 0,0 & 0 & 0,0 & 0 & 0,0 & 0 & 0,0 & 0 & 0,0 & 0 & 0,0 & 15 & 100,0 & 0 & 0,0 & 0 & 0,0 \\
\hline Total & & & 0 & & 30 & & 104 & & 489 & & 45 & & 15 & & 59 & & 0 & & 15 & & 30 & & 0 & \\
\hline
\end{tabular}

\section{$(*)=$ Quebra da Draga de Eckman-Birge}


Tabela 18: Densidades numéricas (em organismos $/ \mathrm{m}^{2}$ ) e abundância relativa (\%) dos Macroinvertebrados Bentônicos do ponto 05 no período de março/96 a fevereiro/97 na Represa do Guarapiranga-SP

\begin{tabular}{|c|c|c|c|c|c|c|c|c|c|c|c|c|c|c|c|c|c|c|c|c|c|c|c|c|}
\hline \multirow[t]{2}{*}{ TaxalColetas } & \multicolumn{2}{|c|}{ mar/96 } & \multicolumn{2}{|c|}{$\mathrm{abr} / 96$} & \multicolumn{2}{|c|}{ mai/96 } & \multicolumn{2}{|c|}{ jun/96 } & \multicolumn{2}{|c|}{ jul/96 } & \multicolumn{2}{|c|}{ ago/96 } & \multicolumn{2}{|c|}{ set/96 } & \multicolumn{2}{|c|}{ out/96 } & \multicolumn{2}{|c|}{ nov/96 } & \multicolumn{2}{|c|}{ dez/96 } & \multicolumn{2}{|c|}{ jan/97 } & \multicolumn{2}{|c|}{ fev/97 } \\
\hline & $\mathrm{N}^{0}$ & $\%$ & $\mathrm{~N}^{\mathrm{O}}$ & $\%$ & $\mathrm{~N}^{\circ}$ & $\%$ & $\mathrm{~N}^{\mathrm{O}}$ & $\%$ & $\mathrm{~N}^{\circ}$ & $\%$ & $\mathrm{~N}^{\mathrm{O}}$ & $\%$ & $\mathrm{~N}^{\mathrm{o}}$ & $\%$ & $\mathrm{~N}^{\circ}$ & $\%$ & $\mathrm{~N}^{\mathrm{O}}$ & $\%$ & $\mathrm{~N}^{\mathrm{o}}$ & $\%$ & $\mathrm{~N}^{\circ}$ & $\%$ & $\mathrm{~N}^{\mathrm{O}}$ & $\%$ \\
\hline Chironomidae & 44 & 19,8 & 30 & 50,0 & 0 & 0,0 & 44 & 1,9 & 89 & 18,2 & 104 & 14,3 & 30 & 14,5 & 15 & 12,6 & 15 & 20,0 & * & * & 0 & 0,0 & 15 & 50,0 \\
\hline Tanypodinae & 0 & 0,0 & 0 & 0,0 & 0 & 0,0 & 474 & 20,3 & 0 & 0 & 0 & 0,0 & 0 & 0,0 & 30 & 25,2 & 0 & 0,0 & * & * & 0 & 0,0 & 0 & 0,0 \\
\hline Chaoboridae & 178 & 80,2 & 0 & 0,0 & 0 & 0,0 & 578 & 24,7 & 0 & 0 & 237 & 32,6 & 118 & 57,0 & 30 & 25,2 & 15 & 20,0 & * & * & 0 & 0,0 & 0 & 0,0 \\
\hline Tubificidae & 0 & 0,0 & 30 & 50,0 & 0 & 0,0 & 1244 & 53,2 & 326 & 66,7 & 385 & 53,0 & 59 & 28,5 & 44 & 37,0 & 30 & 40,0 & * & * & 0 & 0,0 & 15 & 50,0 \\
\hline Glossiphoniidae & 0 & 0,0 & 0 & 0,0 & 0 & 0,0 & 0 & 0,0 & 74 & 15,1 & 0 & 0,0 & 0 & 0,0 & 0 & 0,0 & 0 & 0,0 & * & * & 0 & 0,0 & 0 & 0,0 \\
\hline Pelecycopa & 0 & 0,0 & 0 & 0,0 & 0 & 0,0 & 0 & 0,0 & 0 & 0 & 0 & 0,0 & 0 & 0,0 & 0 & 0,0 & 15 & 20,0 & * & * & 15 & 100,0 & 0 & 0,0 \\
\hline Total & 222 & & 60 & & 0 & & 2340 & & 489 & & 726 & & 207 & & 119 & & 75 & & * & * & 15 & & 30 & \\
\hline
\end{tabular}

\section{$(*)=$ Quebra da Draga de Eckman-Birge}


Tabela 19: Densidades numéricas (em organismos $/ \mathrm{m}^{2}$ ) e abundância relativa (\%) dos Macroinvertebrados Bentônicos do ponto 06 no período de março/96 a fevereiro/97 na Represa do Guarapiranga-SP

\begin{tabular}{|c|c|c|c|c|c|c|c|c|c|c|c|c|c|c|c|c|c|c|c|c|c|c|c|c|}
\hline \multirow[t]{2}{*}{ TaxalColetas } & \multicolumn{2}{|c|}{$\mathrm{mar} / 96$} & \multicolumn{2}{|c|}{$\mathrm{abr} / 06$} & \multicolumn{2}{|c|}{ mai/96 } & \multicolumn{2}{|c|}{ jun/96 } & \multicolumn{2}{|c|}{ jul/96 } & \multicolumn{2}{|c|}{ ago/96 } & \multicolumn{2}{|c|}{ set/96 } & \multicolumn{2}{|c|}{ out/96 } & \multicolumn{2}{|c|}{ nov/96 } & \multicolumn{2}{|c|}{ dez/96 } & \multicolumn{2}{|c|}{$\mathrm{jan} / 97$} & \multicolumn{2}{|c|}{$\mathrm{fev} / 97$} \\
\hline & $\mathrm{N}^{\circ}$ & $\%$ & $\mathrm{~N}^{\mathrm{o}}$ & $\%$ & $\mathrm{~N}^{\circ}$ & $\%$ & $\mathrm{~N}^{\mathrm{O}}$ & $\%$ & $\mathrm{~N}^{\circ}$ & $\%$ & $\mathrm{~N}^{0}$ & $\%$ & $\mathrm{~N}^{\mathrm{O}}$ & $\%$ & $\mathrm{~N}^{\mathrm{O}}$ & $\%$ & $\mathrm{~N}^{\mathrm{o}}$ & $\%$ & $\mathrm{~N}^{\circ}$ & $\%$ & $\mathrm{~N}^{\mathrm{o}}$ & $\%$ & $\mathrm{~N}^{\circ}$ & $\%$ \\
\hline Chironomidae & 22 & 4,0 & 67 & 100,0 & 0 & 0,0 & 15 & 3,0 & 178 & 8,9 & 44 & 74,6 & 30 & 20,3 & 15 & 16,9 & 15 & 20,3 & 15 & 50,0 & 15 & 20,3 & 0 & 0,0 \\
\hline Tanypodinae & 0 & 0,0 & 0 & 0,0 & 0 & 0,0 & 0 & 0,0 & 15 & 0,8 & 0 & 0,0 & 0 & 0,0 & 0 & 0,0 & 0 & 0,0 & 0 & 0,0 & 0 & 0,0 & 15 & 12,6 \\
\hline Chaoboridae & 156 & 28,1 & 0 & 0,0 & 0 & 0,0 & 459 & 91,1 & 384 & 19,2 & 15 & 25,4 & 74 & 50,0 & 44 & 49,4 & 0 & 0,0 & 0 & 0,0 & 44 & 59,5 & 45 & 37,8 \\
\hline Tubificidae & 378 & 68,0 & 0 & 0,0 & 0 & 0,0 & 15 & 3,0 & 1422 & 71,1 & 0 & 0,0 & 0 & 0,0 & 30 & 33,7 & 44 & 59,5 & 0 & 0,0 & 0 & 0,0 & 59 & 49,6 \\
\hline Glossiphoniidae & 0 & 0,0 & 0 & 0,0 & 0 & 0,0 & 15 & 3,0 & 0 & 0,0 & 0 & 0,0 & 0 & 0,0 & 0 & 0,0 & 0 & 0,0 & 0 & 0,0 & 0 & 0,0 & 0 & 0,0 \\
\hline Pelecycopa & 0 & 0,0 & 0 & 0,0 & 0 & 0,0 & 0 & 0,0 & 0 & 0,0 & 0 & 0,0 & 44 & 29,7 & 0 & 0,0 & 15 & 20,3 & 15 & 50,0 & 15 & 20,3 & 0 & 0,0 \\
\hline Total & 556 & & 67 & & 0 & & 504 & & 1999 & & 59 & & 148 & & 89 & 0,0 & 74 & & 30 & & 74 & & 119 & \\
\hline
\end{tabular}


Tabela 20: Densidades numéricas (em organismos $/ \mathrm{m}^{2}$ ) e abundância relativa (\%) dos Macroinvertebrados Bentônicos do ponto 07 no período de março/96 a fevereiro/97 na Represa do Guarapiranga-SP

\begin{tabular}{|c|c|c|c|c|c|c|c|c|c|c|c|c|c|c|c|c|c|c|c|c|c|c|c|c|}
\hline \multirow[t]{2}{*}{ TaxalColetas } & \multicolumn{2}{|c|}{$\mathrm{mar} / 96$} & \multicolumn{2}{|c|}{$\mathrm{abr} / 96$} & \multicolumn{2}{|c|}{ mai/96 } & \multicolumn{2}{|c|}{ jun/96 } & \multicolumn{2}{|c|}{ jul/96 } & \multicolumn{2}{|c|}{ ago/96 } & \multicolumn{2}{|c|}{ set/96 } & \multicolumn{2}{|c|}{ out/96 } & \multicolumn{2}{|c|}{ nov/96 } & \multicolumn{2}{|c|}{ dez/96 } & \multicolumn{2}{|c|}{$\mathrm{jan} / 97$} & \multicolumn{2}{|c|}{$\mathrm{fev} / 97$} \\
\hline & $\mathrm{N}^{\circ}$ & $\%$ & $\mathrm{~N}^{\circ}$ & $\%$ & $\mathrm{~N}^{\circ}$ & $\%$ & $\mathrm{~N}^{\mathrm{O}}$ & $\%$ & $\mathrm{~N}^{\circ}$ & $\%$ & $\mathrm{~N}^{\circ}$ & $\%$ & $\mathrm{~N}^{\mathrm{O}}$ & $\%$ & $\mathrm{~N}^{\circ}$ & $\%$ & $\mathrm{~N}^{\mathrm{o}}$ & $\%$ & $\mathrm{~N}^{\circ}$ & $\%$ & $\mathrm{~N}^{\circ}$ & $\%$ & $\mathrm{~N}^{\circ}$ & $\%$ \\
\hline Chironomidae & 44 & 28,4 & 0 & 0,0 & 30 & 40,0 & 15 & 100,0 & 0 & 0,0 & 44 & 4,2 & 74 & 45,4 & 15 & 25,0 & 44 & 50,0 & 15 & 50,0 & 22 & 20,0 & 22 & 17,5 \\
\hline Tanypodinae & 0 & 0,0 & 0 & 0,0 & 0 & 0,0 & 0 & 0,0 & 0 & 0,0 & 0 & 0,0 & 0 & 0,0 & 0 & 0,0 & 0 & 0,0 & 0 & 0,0 & 0 & 0,0 & 0 & 0,0 \\
\hline Chaoboridae & 67 & 43,2 & 0 & 0,0 & 30 & 40,0 & 0 & 0,0 & 266 & 3,5 & 44 & 4,2 & 15 & 9,2 & 15 & 25,0 & 22 & 25,0 & 0 & 0,0 & 22 & 20,0 & 0 & 0,0 \\
\hline Tubificidae & 44 & 28,4 & 0 & 0,0 & 15 & 20,0 & 0 & 0,0 & 7170 & 93,1 & 963 & 91,6 & 74 & 45,4 & 30 & 50,0 & 22 & 25,0 & 0 & 0,0 & 44 & 40,0 & 104 & 82,5 \\
\hline Glossiphoniidae & 0 & 0,0 & 0 & 0,0 & 0 & 0,0 & 0 & 0,0 & 267 & 3,5 & 0 & 0,0 & 0 & 0,0 & 0 & 0,0 & 0 & 0,0 & 0 & 0,0 & 22 & 20,0 & 0 & 0,0 \\
\hline Pelecycopa & 0 & 0,0 & 0 & 0,0 & 0 & 0,0 & 0 & 0,0 & 0 & 0,0 & 0 & 0,0 & 0 & 0,0 & 0 & 0,0 & 0 & 0,0 & 15 & 50,0 & 0 & 0,0 & 0 & 0,0 \\
\hline Total & 155 & & 0 & & 75 & & 15 & & 7703 & & 1051 & & 163 & & 60 & & 88 & & 30 & & 110 & & 126 & \\
\hline
\end{tabular}


Tabela 21: Densidades numéricas (em organismos $/ \mathrm{m}^{2}$ ) e abundância relativa (\%) dos Macroinvertebrados Bentônicos do ponto 08 no período de março/96 a fevereiro/97 na Represa do Guarapiranga-SP

\begin{tabular}{|c|c|c|c|c|c|c|c|c|c|c|c|c|c|c|c|c|c|c|c|c|c|c|c|c|}
\hline \multirow[t]{2}{*}{ TaxalColetas } & \multicolumn{2}{|c|}{$\mathrm{mar} / 96$} & \multicolumn{2}{|c|}{$\mathrm{abr} / 96$} & \multicolumn{2}{|c|}{ mai/96 } & \multicolumn{2}{|c|}{ jun/96 } & \multicolumn{2}{|c|}{ jul/96 } & \multicolumn{2}{|c|}{ ago/96 } & \multicolumn{2}{|c|}{ set/96 } & \multicolumn{2}{|c|}{ out/96 } & \multicolumn{2}{|c|}{ nov/96 } & \multicolumn{2}{|c|}{ dez/96 } & \multicolumn{2}{|c|}{$\mathrm{jan} / 97$} & \multicolumn{2}{|c|}{$\mathrm{fev} / 97$} \\
\hline & $\mathrm{N}^{\circ}$ & $\%$ & $\mathrm{~N}^{\circ}$ & $\%$ & $\mathrm{~N}^{\circ}$ & $\%$ & $\mathrm{~N}^{\circ}$ & $\%$ & $\mathrm{~N}^{\circ}$ & $\%$ & $\mathrm{~N}^{\mathrm{o}}$ & $\%$ & $\mathrm{~N}^{\circ}$ & $\%$ & $\mathrm{~N}^{\circ}$ & $\%$ & $\mathrm{~N}^{\mathrm{o}}$ & $\%$ & $\mathrm{~N}^{\mathrm{O}}$ & $\%$ & $\mathrm{~N}^{\mathrm{o}}$ & $\%$ & $\mathrm{~N}^{\mathrm{O}}$ & $\%$ \\
\hline Chironomidae & 0 & 0,0 & * & * & 0 & 0,0 & 0 & 0,0 & 30 & 1,4 & 15 & 12,7 & 89 & 7,2 & 44 & 33,1 & 0 & 0,0 & 0 & 0,0 & $\star *$ & $* *$ & 0 & 0,0 \\
\hline Tanypodinae & 0 & 0,0 & * & * & 44 & 74,6 & 0 & 0,0 & 15 & 0,7 & 0 & 0,0 & 0 & 0,0 & 0 & 0,0 & 0 & 0,0 & 0 & 0,0 & $\star \star$ & $* *$ & 0 & 0,0 \\
\hline Chaoboridae & 1052 & 98,0 & * & * & 15 & 25,4 & 15 & 11,2 & 1704 & 79,3 & 44 & 37,3 & 222 & 17,8 & 74 & 55,6 & 0 & 0,0 & 15 & 50,0 & $* *$ & $* *$ & 74 & 15,6 \\
\hline Tubificidae & 22 & 2,0 & * & * & 0 & 0,0 & 104 & 77,6 & 371 & 17,3 & 44 & 37,3 & 933 & 75,0 & 15 & 11,3 & 59 & 100,0 & 0 & 0,0 & $\star *$ & $* *$ & 400 & 84,4 \\
\hline Glossiphoniidae & 0 & 0,0 & * & * & 0 & 0,0 & 15 & 11,2 & 30 & 1,4 & 0 & 0,0 & 0 & 0,0 & 0 & 0,0 & 0 & 0,0 & 0 & 0,0 & $\star *$ & $\star \star$ & 0 & 0,0 \\
\hline Pelecycopa & 0 & 0,0 & * & * & 0 & 0,0 & 0 & 0,0 & 0 & 0,0 & 15 & 12,7 & 0 & 0,0 & 0 & 0,0 & 0 & 0,0 & 15 & 50,0 & $\star \star *$ & $* *$ & 0 & 0,0 \\
\hline Total & 1074 & & * & & 59 & & 134 & & 2150 & & 118 & & 1244 & & 133 & & 59 & & 30 & & & & 474 & \\
\hline
\end{tabular}

$\left.{ }^{*}\right)=$ Quebra da Draga de Eckman-Birge

$\left.{ }^{(* *}\right)$ - não houve coleta (chuvas intermitentes) 
Tabela 22: Densidades numéricas (em organismos $/ \mathrm{m}^{2}$ ) e abundância relativa (\%) dos Macroinvertebrados Bentônicos do ponto 09 no período de março/96 a fevereiro/97 na Represa do Guarapiranga-SP

\begin{tabular}{|c|c|c|c|c|c|c|c|c|c|c|c|c|c|c|c|c|c|c|c|c|c|c|c|c|}
\hline \multirow[t]{2}{*}{ TaxalColetas } & \multicolumn{2}{|c|}{ mar/96 } & \multicolumn{2}{|c|}{$\mathrm{abr} / 96$} & \multicolumn{2}{|c|}{ mai/96 } & \multicolumn{2}{|c|}{ jun/96 } & \multicolumn{2}{|c|}{ jul/96 } & \multicolumn{2}{|c|}{ ago/96 } & \multicolumn{2}{|c|}{ set/96 } & \multicolumn{2}{|c|}{ out/96 } & \multicolumn{2}{|c|}{ nov/96 } & \multicolumn{2}{|c|}{$\mathrm{dez} / 96$} & \multicolumn{2}{|c|}{ jan/97 } & \multicolumn{2}{|c|}{ fev/97 } \\
\hline & $\mathrm{N}^{\circ}$ & $\%$ & $\mathrm{~N}^{\mathrm{O}}$ & $\%$ & $\mathrm{~N}^{\circ}$ & $\%$ & $\mathrm{~N}^{\mathrm{O}}$ & $\%$ & $\mathrm{~N}^{\mathrm{O}}$ & $\%$ & $\mathrm{~N}^{\mathrm{O}}$ & $\%$ & $\mathrm{~N}^{\mathrm{o}}$ & $\%$ & $\mathrm{~N}^{\circ}$ & $\%$ & $\mathrm{~N}^{\mathrm{O}}$ & $\%$ & $\mathrm{~N}^{\circ}$ & $\%$ & $\mathrm{~N}^{\mathrm{O}}$ & $\%$ & $\mathrm{~N}^{\circ}$ & $\%$ \\
\hline Chironomidae & 30 & 2,3 & 15 & 8,4 & 0 & 0,0 & 0 & 0,0 & 163 & 22,5 & 148 & 55,4 & 74 & 27,8 & 44 & 100,0 & 133 & 81,6 & 0 & 0,0 & $\star *$ & $\star *$ & 22 & 9,0 \\
\hline Tanypodinae & 15 & 1,1 & 0 & 0,0 & 0 & 0,0 & 192 & 100,0 & 252 & 34,7 & 104 & 39,0 & 192 & 72,2 & 0 & 0,0 & 0 & 0,0 & 0 & 0,0 & $\star \star$ & ** & 0 & 0,0 \\
\hline Chaoboridae & 504 & 38,2 & 0 & 0,0 & 0 & 0,0 & 0 & 0,0 & 44 & 6,1 & 0 & 0,0 & 0 & 0,0 & 0 & 0,0 & 30 & 18,4 & 0 & 0,0 & $\star *$ & ** & 0 & 0,0 \\
\hline Tubificidae & 755 & 57,2 & 148 & 83,1 & 0 & 0,0 & 0 & 0,0 & 267 & 36,8 & 15 & 5,6 & 0 & 0,0 & 0 & 0,0 & 0 & 0,0 & 637 & 100,0 & $\star \star$ & ** & 222 & 91,0 \\
\hline Glossiphoniidae & 0 & 0,0 & 15 & 8,4 & 0 & 0,0 & 0 & 0,0 & 0 & 0,0 & 0 & 0,0 & 0 & 0,0 & 0 & 0,0 & 0 & 0,0 & 0 & 0,0 & $\star \star$ & $\star \star$ & 0 & 0,0 \\
\hline Pelecycopa & 15 & 1,1 & 0 & 0,0 & 0 & 0,0 & 0 & 0,0 & 0 & 0,0 & 0 & 0,0 & 0 & 0,0 & 0 & 0,0 & 0 & 0,0 & 0 & 0,0 & $\star \star$ & $\star *$ & 0 & 0,0 \\
\hline Total & 1319 & & 178 & & 0 & & 192 & & 726 & & 267 & & 266 & & 44 & & 163 & & 637 & & & & 244 & \\
\hline
\end{tabular}

\section{$(* *)=$ não houve coleta (chuvas intermitentes)}


Tabela 23: Densidades numéricas (em orgs $/ \mathrm{m}^{2}$ ) e abundância relativa (\%) dos Macroinvertebrados Bentônicos do ponto 10 no período de março/96 a fevereiro/97 na Represa do Guarapiranga-SP

\begin{tabular}{|c|c|c|c|c|c|c|c|c|c|c|c|c|c|c|c|c|c|c|c|c|c|c|c|c|}
\hline \multirow[t]{2}{*}{ TaxalColetas } & \multicolumn{2}{|c|}{ mar/96 } & \multicolumn{2}{|c|}{$\mathrm{abr} / 96$} & \multicolumn{2}{|c|}{ mai/96 } & \multicolumn{2}{|c|}{ jun/96 } & \multicolumn{2}{|c|}{$\mathrm{jul} / 96$} & \multicolumn{2}{|c|}{ ago/96 } & \multicolumn{2}{|c|}{ set/96 } & \multicolumn{2}{|c|}{ out/96 } & \multicolumn{2}{|c|}{ nov/96 } & \multicolumn{2}{|c|}{ dez/96 } & \multicolumn{2}{|c|}{ jan/97 } & \multicolumn{2}{|c|}{ fev/97 } \\
\hline & $\mathrm{N}^{\mathrm{o}}$ & $\%$ & $\mathrm{~N}^{\circ}$ & $\%$ & $\mathrm{~N}^{\circ}$ & $\%$ & $\mathrm{~N}^{\circ}$ & $\%$ & $\mathrm{~N}^{\mathrm{o}}$ & $\%$ & $\mathrm{~N}^{\mathrm{o}}$ & $\%$ & $\mathrm{~N}^{\mathrm{O}}$ & $\%$ & $\mathrm{~N}^{\circ}$ & $\%$ & $\mathrm{~N}^{\circ}$ & $\%$ & $\mathrm{~N}^{\circ}$ & $\%$ & $\mathrm{~N}^{\mathrm{O}}$ & $\%$ & $\mathrm{~N}^{\circ}$ & $\%$ \\
\hline Chironomidae & 33 & 1,4 & 0 & 0,0 & 15 & 12,6 & 0 & 0,0 & 44 & 7,8 & 74 & 33,3 & 22 & 12,4 & 30 & 50,0 & 30 & 33,7 & 30 & 100,0 & $* *$ & $* *$ & 0 & 0,0 \\
\hline Tanypodinae & 78 & 3,3 & 0 & 0,0 & 0 & 0,0 & 9 & 4,2 & 0 & 0,0 & 0 & 0,0 & 0 & 0,0 & 0 & 0,0 & 0 & 0,0 & 0 & 0,0 & $\star \star$ & ** & 0 & 0,0 \\
\hline Chaoboridae & 1633 & 69,3 & 15 & 25,4 & 74 & 62,2 & 160 & 75,1 & 444 & 79,0 & 30 & 13,5 & 133 & 75,1 & 0 & 0,0 & 0 & 0,0 & 0 & 0,0 & $\star \star$ & ** & 103 & 41,0 \\
\hline Tubificidae & 611 & 25,9 & 44 & 74,6 & 0 & 0,0 & 44 & 20,7 & 59 & 10,5 & 118 & 53,2 & 0 & 0,0 & 15 & 25,0 & 59 & 66,3 & 0 & 0,0 & $\star *$ & ** & 148 & 59,0 \\
\hline Glossiphoniidae & 0 & 0,0 & 0 & 0,0 & 0 & 0,0 & 0 & 0,0 & 0 & 0,0 & 0 & 0,0 & 0 & 0,0 & 0 & 0,0 & 0 & 0,0 & 0 & 0,0 & $\star *$ & ** & 0 & 0,0 \\
\hline Pelecycopa & 0 & 0,0 & 0 & 0,0 & 30 & 25,2 & 0 & 0,0 & 15 & 2,7 & 0 & 0,0 & 22 & 12,4 & 15 & 25,0 & 0 & 0,0 & 0 & 0,0 & $\star \star$ & ** & 0 & 0,0 \\
\hline Total & 2355 & & 59 & & 119 & & 213 & & 562 & & 222 & & 177 & & 60 & & 89 & & 30 & & $\star \star$ & & 251 & \\
\hline
\end{tabular}

\section{$(* *)=$ não houve coleta (chuvas intermitentes)}


Tabela 24: Variação espacial da densidade total acumulada (orgs $\left./ \mathrm{m}^{2}\right)$ e abundância relativa (\%) dos Macroinvertebrados Bentônicos na Represa do Guarapiranga - SP - 1996/1997

\begin{tabular}{|c|c|c|c|c|c|c|c|c|c|c|c|c|c|c|c|c|c|c|c|c|c|c|}
\hline \multirow[t]{2}{*}{ TaxalPontos } & \multicolumn{2}{|c|}{ Ponto - 01} & \multicolumn{2}{|c|}{ Ponto - 02} & \multicolumn{2}{|c|}{ Ponto - 03} & \multicolumn{2}{|c|}{ Ponto - 04} & \multicolumn{2}{|c|}{ Ponto - 05} & \multicolumn{2}{|c|}{ Ponto - 06} & \multicolumn{2}{|c|}{ Ponto - 07} & \multicolumn{2}{|c|}{ Ponto - 08} & \multicolumn{2}{|c|}{ Ponto - 09} & \multicolumn{2}{|c|}{ Ponto - 10} & \multicolumn{2}{|c|}{ Total } \\
\hline & $\mathrm{N}^{\mathrm{O}}$ & $\%$ & $\mathrm{~N}^{\circ}$ & $\%$ & $\mathrm{~N}^{\mathrm{O}}$ & $\%$ & No & $\%$ & $\mathrm{~N}^{\circ}$ & $\%$ & $\mathrm{~N}^{\circ}$ & $\%$ & $\mathrm{~N}^{\mathrm{O}}$ & $\%$ & $\mathrm{~N}^{\circ}$ & $\%$ & $\mathrm{~N}^{\mathrm{O}}$ & $\%$ & $\mathrm{~N}^{\circ}$ & $\%$ & $\mathrm{~N}^{\circ}$ & $\%$ \\
\hline Chironomidae & 767 & 35,7 & 653 & 13,5 & 431 & 14,0 & 97 & 12,3 & 386 & 9,0 & 416 & 11,2 & 325 & 3,4 & 178 & 3,3 & 629 & 15,6 & 278 & 6,7 & 4160 & 9,9 \\
\hline Tanypodinae & 0 & 0,0 & 59 & 1,2 & 0 & 0,0 & 0 & 0,0 & 504 & 11,8 & 30 & 0,8 & 0 & 0,0 & 59 & 1,1 & 755 & 18,7 & 87 & 2,1 & 1494 & 3,6 \\
\hline Chaoboridae & 1178 & 54,9 & 2504 & 51,6 & 1481 & 48,3 & 475 & 60,4 & 1156 & 27,0 & 1221 & 32,8 & 481 & 5,0 & 3215 & 58,7 & 578 & 14,3 & 2592 & 62,7 & |14881 & 35,4 \\
\hline Tubificidae & 171 & 8,0 & 1579 & 32,5 & 1007 & 32,8 & 185 & 23,5 & 2133 & 49,8 & 1948 & 52,4 & 8466 & 88,4 & 1948 & 35,6 & 2044 & 50,6 & 1098 & 26,5 & 20579 & 48,9 \\
\hline Glossiphoniidae & 0 & 0,0 & 0 & 0,0 & 149 & 4,9 & 15 & 1,9 & 74 & 1,7 & 15 & 0,4 & 289 & 3,0 & 45 & 0,8 & 15 & 0,4 & 0 & 0,0 & 602 & 1,4 \\
\hline Pelecycopa & 30 & 1,4 & 60 & 1,2 & 0 & 0,0 & 15 & 1,9 & 30 & 0,7 & 89 & 2,4 & 15 & 0,2 & 30 & 0,5 & 15 & 0,4 & 82 & 2,0 & 366 & 0,9 \\
\hline Total & 2146 & & 4855 & & 3068 & & 787 & & 4283 & & 3719 & & 9576 & & 5475 & & 4036 & & 4137 & & 42082 & \\
\hline
\end{tabular}


Tabela 25: Densidades númericas (em organismos $/ \mathrm{m}^{2}$ ) e abundância relativa (\%) dos Macroinvertebrados Bentônicos na Represa do Guarapiranga - SP em Março/96

\begin{tabular}{|c|c|c|c|c|c|c|c|c|c|c|c|c|c|c|c|c|c|c|c|c|}
\hline \multirow[t]{2}{*}{ TaxalPontos } & \multicolumn{2}{|c|}{ Ponto - 01} & \multicolumn{2}{|c|}{ Ponto -02 } & \multicolumn{2}{|c|}{ Ponto - 03} & \multicolumn{2}{|c|}{ Ponto -04 } & \multicolumn{2}{|c|}{ Ponto - 05} & \multicolumn{2}{|c|}{ Ponto - 06} & \multicolumn{2}{|c|}{ Ponto - 07} & \multicolumn{2}{|c|}{ Ponto - 08} & \multicolumn{2}{|c|}{ Ponto - 09} & \multicolumn{2}{|c|}{ Ponto - 10} \\
\hline & $\mathrm{N}$ & $\%$ & $\mathrm{~N}$ & $\%$ & $\mathrm{~N}$ & $\%$ & $\mathrm{~N}$ & $\%$ & $\mathrm{~N}$ & $\%$ & $\mathrm{~N}$ & $\%$ & $\mathrm{~N}$ & $\%$ & $\mathrm{~N}$ & $\%$ & $\mathrm{~N}$ & $\%$ & $\mathrm{~N}$ & $\%$ \\
\hline Chironomidae & 11 & 4,0 & 74 & 71,2 & 74 & 20,0 & * & * & 44 & 19,8 & 22 & 4,0 & 44 & 28,4 & 0 & 0,0 & 30 & 2,3 & 33 & 1,4 \\
\hline Tanypodinae & 0 & 0,0 & 0 & 0,0 & 0 & 0,0 & * & * & 0 & 0,0 & 0 & 0,0 & 0 & 0,0 & 0 & 0,0 & 15 & 1,1 & 78 & 3,3 \\
\hline Chaoboridae & 200 & 71,9 & 0 & 0,0 & 119 & 32,1 & * & * & 178 & 80,2 & 156 & 28,1 & 67 & 43,2 & 1052 & 98,0 & 504 & 38,2 & 1633 & 69,3 \\
\hline Tubificidae & 67 & 24,1 & 30 & 28,8 & 133 & 35,9 & * & * & 0 & 0,0 & 378 & 68,0 & 44 & 28,4 & 22 & 2,0 & 755 & 57,2 & 611 & 25,9 \\
\hline Glossiphoniidae & 0 & 0,0 & 0 & 0,0 & 44 & 12,0 & * & * & 0 & 0,0 & 0 & 0,0 & 0 & 0,0 & 0 & 0,0 & 0 & 0,0 & 0 & 0,0 \\
\hline Pelecycopa & 0 & 0,0 & 0 & 0,0 & 0 & 0,0 & * & * & 0 & 0,0 & 0 & 0,0 & 0 & 0,0 & 0 & 0,0 & 15 & 1,1 & 0 & 0,0 \\
\hline Total & 278 & 100,0 & 104 & 100,0 & 370 & 100,0 & * & * & 222 & 100,0 & 556 & 100,0 & 155 & 100,0 & 1074 & 100,0 & 1319 & 100,0 & 2355 & 100,0 \\
\hline
\end{tabular}


Tabela 26: Densidades numéricas (em organismos $/ \mathrm{m}^{2}$ ) e abundância relativa (\%) dos Macroinvertebrados Bentônicos na Represa do Guarapiranga - SP - Abril/96

\begin{tabular}{|c|c|c|c|c|c|c|c|c|c|c|c|c|c|c|c|c|c|c|c|c|}
\hline \multirow{2}{*}{ TaxalPontos } & \multicolumn{2}{|c|}{ Ponto-01 } & \multicolumn{2}{|c|}{ Ponto-02 } & \multicolumn{2}{|c|}{ Ponto-03 } & \multicolumn{2}{|c|}{ Ponto-04 } & \multicolumn{2}{|c|}{ Ponto-05 } & \multicolumn{2}{|c|}{ Ponto-06 } & \multicolumn{2}{|c|}{ Ponto-07 } & \multicolumn{2}{|c|}{ Ponto-08 } & \multicolumn{2}{|c|}{ Ponto-09 } & \multicolumn{2}{|c|}{ Ponto-10 } \\
\hline & $\mathrm{N}^{\circ}$ & $\%$ & No & $\%$ & $\mathrm{~N}^{\circ}$ & $\%$ & $\mathrm{~N}^{\circ}$ & $\%$ & $\mathrm{~N}^{\mathrm{O}}$ & $\%$ & $\mathrm{~N}^{\mathrm{O}}$ & $\%$ & $\mathrm{~N}^{\mathrm{O}}$ & $\%$ & $\mathrm{~N}^{\circ}$ & $\%$ & $\mathrm{~N}^{\mathrm{O}}$ & $\%$ & $\mathrm{~N}^{\circ}$ & $\%$ \\
\hline Chironomidae & 0 & 0,0 & 30 & 12,6 & 30 & 6,0 & 0 & 0,0 & 30 & 50,0 & 67 & 100,0 & 0 & 0,0 & * & * & 16 & 8,9 & 0 & 0,0 \\
\hline Tanypodinae & 0 & 0,0 & 15 & 6,3 & 0 & 0,0 & 0 & 0,0 & 0 & 0,0 & 0 & 0,0 & 0 & 0,0 & * & * & 0 & 0,0 & 0 & 0,0 \\
\hline Chaoboridae & 15 & 100,0 & 193 & 81,1 & 148 & 29,4 & 0 & 0,0 & 0 & 0,0 & 0 & 0,0 & 0 & 0,0 & * & $*$ & 0 & 0,0 & 15 & 25,4 \\
\hline Tubificidae & 0 & 0,0 & 0 & 0,0 & 311 & 61,7 & 0 & 0,0 & 30 & 50,0 & 0 & 0,0 & 0 & 0,0 & * & * & 148 & 82,7 & 44 & 74,6 \\
\hline Glossiphoniidae & 0 & 0,0 & 0 & 0,0 & 15 & 3,0 & 0 & 0,0 & 0 & 0,0 & 0 & 0,0 & 0 & 0,0 & * & * & 15 & 8,4 & 0 & 0,0 \\
\hline Pelecycopa & 0 & 0,0 & 0 & 0,0 & 0 & 0,0 & 0 & 0,0 & 0 & 0,0 & 0 & 0,0 & 0 & 0,0 & * & * & 0 & 0,0 & 0 & 0,0 \\
\hline Total & 15 & & 238 & & 504 & & 0 & & 60 & & 67 & & 0 & & 0 & & 179 & & 59 & \\
\hline
\end{tabular}

$(*)=$ Quebra da Draga de Eckman-Birge 
Tabela 27: Densidades numéricas (em organismos $/ \mathrm{m}^{2}$ ) e abundância relativa (\%) dos Macroinvertebrados Bentônicos na Represa do Guarapiranga - SP - Maio/96

\begin{tabular}{|c|c|c|c|c|c|c|c|c|c|c|c|c|c|c|c|c|c|c|c|c|}
\hline \multirow[t]{2}{*}{ TaxalPontos } & \multicolumn{2}{|c|}{ Ponto -01 } & \multicolumn{2}{|c|}{ Ponto -02 } & \multicolumn{2}{|c|}{ Ponto -03 } & \multicolumn{2}{|c|}{ Ponto -04 } & \multicolumn{2}{|c|}{ Ponto -05 } & \multicolumn{2}{|c|}{ Ponto -06 } & \multicolumn{2}{|c|}{ Ponto -07} & \multicolumn{2}{|c|}{ Ponto -08 } & \multicolumn{2}{|c|}{ Ponto -09 } & \multicolumn{2}{|c|}{ Ponto -10 } \\
\hline & $\mathrm{N}^{\circ}$ & $\%$ & $\mathrm{~N}^{\circ}$ & $\%$ & $\mathrm{~N}^{\circ}$ & $\%$ & No & $\%$ & No & $\%$ & $\mathrm{~N}^{\circ}$ & $\%$ & $\mathrm{~N}^{\circ}$ & $\%$ & $\mathrm{~N}^{\circ}$ & $\%$ & $\mathrm{~N}^{\mathrm{O}}$ & $\%$ & $\mathrm{~N}^{\circ}$ & $\%$ \\
\hline Chironomidae & 15 & 25,0 & 30 & 25,2 & 15 & 50,0 & 15 & 50,0 & 0 & 0,0 & 0 & 0,0 & 30 & 40,0 & 0 & 0,0 & 0 & 0,0 & 15 & 12,6 \\
\hline Tanypodinae & 0 & 0,0 & 0 & 0,0 & 0 & 0,0 & 0 & 0,0 & 0 & 0,0 & 0 & 0,0 & 0 & 0,0 & 44 & 74,6 & 0 & 0,0 & 0 & 0,0 \\
\hline Chaoboridae & 30 & 50,0 & 59 & 49,6 & 0 & 0,0 & 15 & 50,0 & 0 & 0,0 & 0 & 0,0 & 30 & 40,0 & 15 & 25,4 & 0 & 0,0 & 74 & 62,2 \\
\hline Tubificidae & 15 & 25,0 & 0 & 0,0 & 15 & 50,0 & 0 & 0,0 & 0 & 0,0 & 0 & 0,0 & 15 & 20,0 & 0 & 0,0 & 0 & 0,0 & 0 & 0,0 \\
\hline Glossiphoniidae & 0 & 0,0 & 0 & 0,0 & 0 & 0,0 & 0 & 0,0 & 0 & 0,0 & 0 & 0,0 & 0 & 0,0 & 0 & 0,0 & 0 & 0,0 & 0 & 0,0 \\
\hline Pelecycopa & 0 & 0,0 & 30 & 25,2 & 0 & 0,0 & 0 & 0,0 & 0 & 0,0 & 0 & 0,0 & 0 & 0,0 & 0 & 0,0 & 0 & 0,0 & 30 & 25,2 \\
\hline Total & 60 & & 119 & & 30 & & 30 & & 0 & & 0 & & 75 & & 59 & & 0 & & 119 & \\
\hline
\end{tabular}


Tabela 28: Densidades númericas (em organismos/m²) e abundância relativa (\%) dos Macroinvertebrados Bentônicos na Represa do Guarapiranga -SP - Junho/96

\begin{tabular}{|c|c|c|c|c|c|c|c|c|c|c|c|c|c|c|c|c|c|c|c|c|}
\hline \multirow[t]{2}{*}{ TaxalPontos } & \multicolumn{2}{|c|}{ Ponto -01 } & \multicolumn{2}{|c|}{ Ponto -02 } & \multicolumn{2}{|c|}{ Ponto -03 } & \multicolumn{2}{|c|}{ Ponto -04 } & \multicolumn{2}{|c|}{ Ponto -05 } & \multicolumn{2}{|c|}{ Ponto -06 } & \multicolumn{2}{|c|}{ Ponto -07 } & \multicolumn{2}{|c|}{ Ponto -08 } & \multicolumn{2}{|c|}{ Ponto -09 } & \multicolumn{2}{|c|}{ Ponto -10 } \\
\hline & $\mathrm{N}^{\circ}$ & $\%$ & $\mathrm{~N}^{\circ}$ & $\%$ & $\mathrm{~N}^{\mathrm{O}}$ & $\%$ & $\mathrm{~N}^{\mathrm{O}}$ & $\%$ & $\mathrm{~N}^{\circ}$ & $\%$ & $\mathrm{~N}^{\circ}$ & $\%$ & $\mathrm{~N}^{\circ}$ & $\%$ & $\mathrm{~N}^{\circ}$ & $\%$ & $\mathrm{~N}^{\circ}$ & $\%$ & $\mathrm{~N}^{\circ}$ & $\%$ \\
\hline Chironomidae & 252 & 27,4 & 15 & 14,4 & 15 & 5,6 & 0 & 0,0 & 44 & 1,9 & 15 & 3,0 & 15 & 100,0 & 0 & 0,0 & 0 & 0,0 & 0 & 0,0 \\
\hline Tanypodinae & 0 & 0,0 & 0 & 0,0 & 0 & 0,0 & 0 & 0,0 & 474 & 20,3 & 0 & 0,0 & 0 & 0,0 & 0 & 0,0 & 192 & 100,0 & 9 & 4,2 \\
\hline Chaoboridae & 622 & 67,7 & 59 & 56,7 & 163 & 61,0 & 0 & 0,0 & 578 & 24,7 & 459 & 91,1 & 0 & 0,0 & 15 & 0,0 & 0 & 0,0 & 160 & 75,1 \\
\hline Tubificidae & 15 & 1,6 & 0 & 0,0 & 59 & 22,1 & 89 & 85,6 & 1244 & 53,2 & 15 & 3,0 & 0 & 0,0 & 104 & 77,6 & 0 & 0,0 & 44 & 20,7 \\
\hline Glossiphoniidae & 0 & 0,0 & 0 & 0,0 & 30 & 11,2 & 15 & 14,4 & 0 & 0,0 & 15 & 3,0 & 0 & 0,0 & 15 & 11,2 & 0 & 0,0 & 0 & 0,0 \\
\hline Pelecycopa & 30 & 3,3 & 30 & 28,8 & 0 & 0,0 & 0 & 0,0 & 0 & 0,0 & 0 & 0,0 & 0 & 0,0 & 0 & 0,0 & 0 & 0,0 & 0 & 0,0 \\
\hline Total & 919 & & 104 & & 267 & & 104 & & 2340 & & 504 & & 15 & & 134 & & 192 & & 213 & \\
\hline
\end{tabular}


Tabela 29: Densidades númericas (em organismos $/ \mathrm{m}^{2}$ ) e abundância relativa (\%) dos Macroinvertebrados Bentônicos na Represa do Guarapiranga - SP - Julho/96

\begin{tabular}{|c|c|c|c|c|c|c|c|c|c|c|c|c|c|c|c|c|c|c|c|c|}
\hline \multirow[t]{2}{*}{ TaxalPonto } & \multicolumn{2}{|c|}{ Ponto -01 } & \multicolumn{2}{|c|}{ Ponto -02 } & \multicolumn{2}{|c|}{ Ponto -03 } & \multicolumn{2}{|c|}{ Ponto -04 } & \multicolumn{2}{|c|}{ Ponto -05 } & \multicolumn{2}{|c|}{ Ponto -06 } & \multicolumn{2}{|c|}{ Ponto -07 } & \multicolumn{2}{|c|}{ Ponto -08 } & \multicolumn{2}{|c|}{ Ponto -09 } & \multicolumn{2}{|c|}{ Ponto -10 } \\
\hline & $\mathrm{N}^{\circ}$ & $\%$ & No & $\%$ & No & $\%$ & $\mathrm{~N}^{\circ}$ & $\%$ & No & $\%$ & $\mathrm{~N}^{\mathrm{o}}$ & $\%$ & $\mathrm{~N}^{0}$ & $\%$ & $\mathrm{~N}^{\circ}$ & $\%$ & $\mathrm{~N}^{\circ}$ & $\%$ & $\mathrm{~N}^{\circ}$ & $\%$ \\
\hline Chironomidae & 296 & 51,3 & 400 & 10,8 & 178 & 12,8 & 67 & 13,7 & 89 & 18,2 & 178 & 8,9 & 0 & 0,0 & 30 & 1,4 & 163 & 22,5 & 44 & 7,8 \\
\hline Tanypodinae & 0 & 0 & 44 & 1,2 & 0 & 0 & 0 & 0 & 0 & 0 & 15 & 0,8 & 0 & 0,0 & 15 & 0,7 & 252 & 34,7 & 0 & 0,0 \\
\hline Chaoboridae & 237 & 41,1 & 2104 & 56,8 & 859 & 61,7 & 400 & 81,8 & 0 & 0 & 384 & 19,2 & 266 & 3,5 & 1704 & 79,3 & 44 & 6,1 & 444 & 79,0 \\
\hline Tubificidae & 44 & 7,6 & 1156 & 31,2 & 326 & 23,4 & 22 & 4,5 & 326 & 66,7 & 1422 & 71,1 & 7170 & 93,1 & 371 & 17,3 & 267 & 36,8 & 59 & 10,5 \\
\hline Glossiphoniidae & 0 & 0 & 0 & 0 & 30 & 2,2 & 0 & 0 & 74 & 15,1 & 0 & 0 & 267 & 3,5 & 30 & 1,4 & 0 & 0,0 & 0 & 0,0 \\
\hline Pelecycopa & 0 & 0 & 0 & 0 & 0 & 0 & 0 & 0 & 0 & 0 & 0 & 0 & 0 & 0 & 0 & 0,0 & 0 & 0,0 & 15 & 2,7 \\
\hline Total & 577 & & 3704 & & 1393 & & 489 & & 489 & & 1999 & & 7703 & & 2150 & & 726 & & 562 & \\
\hline
\end{tabular}


Tabela 30: Densidades númericas (em organismos $/ \mathbf{m}^{2}$ ) e abundância relativa (\%) dos Macroinvertebrados Bemtônicos na Represa do Guarapiranga - SP - Agosto/96

\begin{tabular}{|c|c|c|c|c|c|c|c|c|c|c|c|c|c|c|c|c|c|c|c|c|}
\hline \multirow[t]{2}{*}{ TaxalPonto } & \multicolumn{2}{|c|}{ Ponto -01 } & \multicolumn{2}{|c|}{ Ponto -02 } & \multicolumn{2}{|c|}{ Ponto -03 } & \multicolumn{2}{|c|}{ Ponto -04 } & \multicolumn{2}{|c|}{ Ponto -05 } & \multicolumn{2}{|c|}{ Ponto -06 } & \multicolumn{2}{|c|}{ Ponto -07 } & \multicolumn{2}{|c|}{ Ponto -08 } & \multicolumn{2}{|c|}{ Ponto -09 } & \multicolumn{2}{|c|}{ Ponto -10 } \\
\hline & $\mathrm{N}^{\circ}$ & $\%$ & $\mathrm{~N}^{\circ}$ & $\%$ & $\mathrm{~N}^{\mathrm{O}}$ & $\%$ & No & $\%$ & No & $\%$ & $\mathrm{~N}^{\circ}$ & $\%$ & $\mathrm{~N}^{\circ}$ & $\%$ & $\mathrm{~N}^{0}$ & $\%$ & $\mathrm{~N}^{\circ}$ & $\%$ & $\mathrm{~N}^{\circ}$ & $\%$ \\
\hline Chironomidae & 89 & 60,1 & 15 & 8,4 & 30 & 25,2 & 0 & 0,0 & 104 & 14,3 & 44 & 74,6 & 44 & 4,2 & 15 & 12,7 & 148 & 55,4 & 74 & 33,3 \\
\hline Tanypodinae & 0 & 0,0 & 0 & 0,0 & 0 & 0,0 & 0 & 0,0 & 0 & 0,0 & 0 & 0,0 & 0 & 0,0 & 0 & 0,0 & 104 & 39,0 & 0 & 0,0 \\
\hline Chaoboridae & 59 & 39,9 & 30 & 16,9 & 74 & 62,2 & 30 & 66,7 & 237 & 32,6 & 15 & 25,4 & 44 & 4,2 & 44 & 37,3 & 0 & 0,0 & 30 & 13,5 \\
\hline Tubificidae & 0 & 0,0 & 133 & 74,7 & 0 & 0,0 & 15 & 33,3 & 385 & 53,0 & 0 & 0,0 & 963 & 91,6 & 44 & 37,3 & 15 & 5,6 & 118 & 53,2 \\
\hline Glossiphoniidae & 0 & 0,0 & 0 & 0,0 & 15 & 12,6 & 0 & 0,0 & 0 & 0,0 & 0 & 0,0 & 0 & 0,0 & 0 & 0,0 & 0 & 0,0 & 0 & 0,0 \\
\hline Pelecycopa & 0 & 0,0 & 0 & 0,0 & 0 & 0,0 & 0 & 0,0 & 0 & 0,0 & 0 & 0,0 & 0 & 0,0 & 15 & 12,7 & 0 & 0,0 & 0 & 0,0 \\
\hline Total & 148 & & 178 & & 119 & & 45 & & 726 & & 59 & & 1051 & & 118 & & 267 & & 222 & \\
\hline
\end{tabular}


Tabela 31: Densidades númericas (em organismos $/ \mathrm{m}^{2}$ ) e abundância relativa (\%) dos Macroinvertebrados Bentônicos na Represa do Guarapiranga - SP - Setembro/96

\begin{tabular}{|c|c|c|c|c|c|c|c|c|c|c|c|c|c|c|c|c|c|c|c|c|}
\hline \multirow[t]{2}{*}{ TaxalPonto } & \multicolumn{2}{|c|}{ Ponto -01 } & \multicolumn{2}{|c|}{ Ponto -02 } & \multicolumn{2}{|c|}{ Ponto -03 } & \multicolumn{2}{|c|}{ Ponto -04 } & \multicolumn{2}{|c|}{ Ponto -05 } & \multicolumn{2}{|c|}{ Ponto -06 } & \multicolumn{2}{|c|}{ Ponto -07} & \multicolumn{2}{|c|}{ Ponto -08 } & \multicolumn{2}{|c|}{ Ponto -09 } & \multicolumn{2}{|c|}{ Ponto -10 } \\
\hline & $\mathrm{N}^{\circ}$ & $\%$ & $\mathrm{~N}^{\circ}$ & $\%$ & $\mathrm{~N}^{\circ}$ & $\%$ & No & $\%$ & No & $\%$ & $\mathrm{~N}^{\circ}$ & $\%$ & $\mathrm{~N}^{\mathrm{o}}$ & $\%$ & $\mathrm{~N}^{0}$ & $\%$ & $\mathrm{~N}^{\circ}$ & $\%$ & $\mathrm{~N}^{\circ}$ & $\%$ \\
\hline Chironomidae & 74 & 83,1 & 0 & 0,0 & 15 & 20,0 & 0 & 0,0 & 30 & 14,5 & 30 & 20,3 & 74 & 45,1 & 89 & 7,2 & 74 & 27,8 & 22 & 12,2 \\
\hline Tanypodinae & 0 & 0,0 & 0 & 0,0 & 0 & 0,0 & 0 & 0,0 & 0 & 0,0 & 0 & 0,0 & 0 & 0,0 & 0 & 0,0 & 192 & 72,2 & 0 & 0,0 \\
\hline Chaoboridae & 15 & 16,9 & 0 & 0,0 & 45 & 60,0 & 15 & 100,0 & 118 & 57,0 & 74 & 50,0 & 16 & 9,8 & 222 & 17,8 & 0 & 0,0 & 136 & 75,6 \\
\hline Tubificidae & 0 & 0,0 & 89 & 100,0 & 0 & 0,0 & 0 & 0,0 & 59 & 28,5 & 0 & 0,0 & 74 & 45,1 & 933 & 75,0 & 0 & 0,0 & 0 & 0,0 \\
\hline Glossiphoniidae & 0 & 0,0 & 0 & 0,0 & 15 & 20,0 & 0 & 0,0 & 0 & 0,0 & 0 & 0,0 & 0 & 0,0 & 0 & 0,0 & 0 & 0,0 & 0 & 0,0 \\
\hline Pelecycopa & 0 & 0,0 & 0 & 0,0 & 0 & 0,0 & 0 & 0,0 & 0 & 0,0 & 44 & 29,7 & 0 & 0,0 & 0 & 0,0 & 0 & 0,0 & 22 & 12,2 \\
\hline Total & 89 & & 89 & & 75 & & 15 & & 207 & & 148 & & 164 & & 1244 & & 266 & & 180 & \\
\hline
\end{tabular}


Tabela 32: Densidades númericas (em organismos $/ \mathrm{m}^{2}$ ) e abundância relativa (\%) dos Macroinvertebrados Bentônicos na Represa do Guarapiranga - SP - Outubro/96

\begin{tabular}{|c|c|c|c|c|c|c|c|c|c|c|c|c|c|c|c|c|c|c|c|c|}
\hline \multirow[t]{2}{*}{ TaxalPontos } & \multicolumn{2}{|c|}{ Ponto - 01} & \multicolumn{2}{|c|}{ Ponto - 02} & \multicolumn{2}{|c|}{ Ponto - 03} & \multicolumn{2}{|c|}{ Ponto - 04} & \multicolumn{2}{|c|}{ Ponto - 05} & \multicolumn{2}{|c|}{ Ponto - 06} & \multicolumn{2}{|c|}{ Ponto - 07} & \multicolumn{2}{|c|}{ Ponto - 08} & \multicolumn{2}{|c|}{ Ponto - 09} & \multicolumn{2}{|c|}{ Ponto - 10} \\
\hline & $\mathrm{N}^{\circ}$ & $\%$ & $\mathrm{~N}^{\circ}$ & $\%$ & $\mathrm{~N}^{\circ}$ & $\%$ & $\mathrm{~N}^{\circ}$ & $\%$ & No & $\%$ & $\mathrm{~N}^{\circ}$ & $\%$ & $\mathrm{~N}^{\circ}$ & $\%$ & $\mathrm{~N}^{\circ}$ & $\%$ & $\mathrm{~N}^{\mathrm{O}}$ & $\%$ & $\mathrm{~N}^{\circ}$ & $\%$ \\
\hline Chironomidae & 0 & 0,0 & 30 & 20,3 & 59 & 44,4 & 0 & 0,0 & 15 & 12,6 & 15 & 16,9 & 15 & 25,0 & 44 & 33,1 & 44 & 100,0 & 30 & 50,0 \\
\hline Tanypodinae & 0 & 0,0 & 0 & 0,0 & 0 & 0,0 & 0 & 0,0 & 30 & 25,2 & 0 & 0,0 & 0 & 0,0 & 0 & 0,0 & 0 & 0,0 & 0 & 0,0 \\
\hline Chaoboridae & 0 & 0,0 & 44 & 29,7 & 44 & 33,1 & 15 & 25,4 & 30 & 25,2 & 44 & 49,4 & 15 & 25,0 & 74 & 55,6 & 0 & 0,0 & 0 & 0,0 \\
\hline Tubificidae & 15 & 100,0 & 74 & 50,0 & 30 & 22,6 & 44 & 74,6 & 44 & 37,0 & 30 & 33,7 & 30 & 50,0 & 15 & 11,3 & 0 & 0,0 & 15 & 25,0 \\
\hline Glossiphoniidae & 0 & 0,0 & 0 & 0,0 & 0 & 0,0 & 0 & 0,0 & 0 & 0,0 & 0 & 0,0 & 0 & 0,0 & 0 & 0,0 & 0 & 0,0 & 0 & 0,0 \\
\hline Pelecycopa & 0 & 0,0 & 0 & 0,0 & 0 & 0,0 & 0 & 0,0 & 0 & 0,0 & 0 & 0,0 & 0 & 0,0 & 0 & 0,0 & 0 & 0,0 & 15 & 25,0 \\
\hline Total & 15 & & 148 & & 133 & & 59 & & 119 & & 89 & & 60 & & 133 & & 44 & & 60 & \\
\hline
\end{tabular}


Tabela 33: Densidades númericas (em organismos $/ \mathrm{m}^{2}$ ) e abundância relativa (\%) dos Macroinvertebrados Bentônicos na Represa do Guarapiranga - SP - Novembro/96

\begin{tabular}{|c|c|c|c|c|c|c|c|c|c|c|c|c|c|c|c|c|c|c|c|c|}
\hline \multirow[t]{2}{*}{ TaxalPontos } & \multicolumn{2}{|c|}{ Ponto -01 } & \multicolumn{2}{|c|}{ Ponto -02 } & \multicolumn{2}{|c|}{ Ponto -03 } & \multicolumn{2}{|c|}{ Ponto -04 } & \multicolumn{2}{|c|}{ Ponto -05 } & \multicolumn{2}{|c|}{ Ponto -06 } & \multicolumn{2}{|c|}{ Ponto -07} & \multicolumn{2}{|c|}{ Ponto -08 } & \multicolumn{2}{|c|}{ Ponto -09 } & \multicolumn{2}{|c|}{ Ponto -10 } \\
\hline & $\mathrm{N}^{\circ}$ & $\%$ & $\mathrm{~N}^{\circ}$ & $\%$ & $\mathrm{~N}^{\circ}$ & $\%$ & No & $\%$ & No & $\%$ & $\mathrm{~N}^{\circ}$ & $\%$ & $\mathrm{~N}^{\circ}$ & $\%$ & $\mathrm{~N}^{\circ}$ & $\%$ & $\mathrm{~N}^{\circ}$ & $\%$ & $\mathrm{~N}^{\mathrm{O}}$ & $\%$ \\
\hline Chironomidae & 15 & 50,0 & 0 & 0,0 & 15 & 100,0 & 0 & 0,0 & 15 & 20,0 & 15 & 20,0 & 44 & 50,0 & 0 & 0,0 & 133 & 81,6 & 30 & 33,7 \\
\hline Tanypodinae & 0 & 0,0 & 0 & 0,0 & 0 & 0,0 & 0 & 0,0 & 0 & 0,0 & 0 & 0,0 & 0 & 0,0 & 0 & 0,0 & 0 & 0 & 0 & 0,0 \\
\hline Chaoboridae & 0 & 0,0 & 15 & 100,0 & 0 & 0,0 & 0 & 0,0 & 15 & 20,0 & 0 & 0,0 & 22 & 25,0 & 0 & 0,0 & 30 & 18,4 & 0 & 0,0 \\
\hline Tubificidae & 15 & 50,0 & 0 & 0,0 & 0 & 0,0 & 0 & 0,0 & 30 & 40,0 & 45 & 60,0 & 22 & 25,0 & 59 & 100,0 & 0 & 0 & 59 & 66,3 \\
\hline Glossiphoniidae & 0 & 0,0 & 0 & 0,0 & 0 & 0,0 & 0 & 0,0 & 0 & 0,0 & 0 & 0,0 & 0 & 0,0 & 0 & 0,0 & 0 & 0 & 0 & 0,0 \\
\hline Pelecycopa & 0 & 0,0 & 0 & 0,0 & 0 & 0,0 & 0 & 0,0 & 15 & 20,0 & 15 & 20,0 & 0 & 0,0 & 0 & 0,0 & 0 & 0 & 0 & 0,0 \\
\hline Total & 30 & & 15 & & 15 & & 0 & 0,0 & 75 & & 75 & & 88 & & 59 & & 163 & & 89 & \\
\hline
\end{tabular}


Tabela 34: Densidades númericas (em organismos $/ \mathrm{m}^{2}$ ) e abundância relativa (\%) dos Macroinvertebrados Bentônicos na Represa do Guarapiranga - SP - Dezembro/96

\begin{tabular}{|c|c|c|c|c|c|c|c|c|c|c|c|c|c|c|c|c|c|c|c|c|}
\hline \multirow[t]{2}{*}{ TaxalPontos } & \multicolumn{2}{|c|}{ Ponto -01 } & \multicolumn{2}{|c|}{ Ponto -02 } & \multicolumn{2}{|c|}{ Ponto -03 } & \multicolumn{2}{|c|}{ Ponto -04 } & \multicolumn{2}{|c|}{ Ponto -05 } & \multicolumn{2}{|c|}{ Ponto -06 } & \multicolumn{2}{|c|}{ Ponto -07} & \multicolumn{2}{|c|}{ Ponto -08 } & \multicolumn{2}{|c|}{ Ponto -09 } & \multicolumn{2}{|c|}{ Ponto -10 } \\
\hline & $\mathrm{N}^{\mathrm{O}}$ & $\%$ & $\mathrm{~N}^{\mathrm{O}}$ & $\%$ & $\mathrm{~N}^{\circ}$ & $\%$ & No & $\%$ & $\mathrm{~N}^{\mathrm{o}}$ & $\%$ & $\mathrm{~N}^{\circ}$ & $\%$ & $\mathrm{~N}^{\circ}$ & $\%$ & $\mathrm{~N}^{\circ}$ & $\%$ & $\mathrm{~N}^{\circ}$ & $\%$ & $\mathrm{~N}^{\circ}$ & $\%$ \\
\hline Chironomidae & 0 & 0,0 & 0 & 0,0 & 0 & 0,0 & 0 & 0,0 & * & * & 15 & 50,0 & 15 & 50,0 & 0 & 0,0 & 0 & 0,0 & 30 & 100,0 \\
\hline Tanypodinae & 0 & 0,0 & 0 & 0,0 & 0 & 0,0 & 0 & 0,0 & * & * & 0 & 0,0 & 0 & 0,0 & 0 & 0,0 & 0 & 0,0 & 0 & 0,0 \\
\hline Chaoboridae & 0 & 0,0 & 0 & 0,0 & 0 & 0,0 & 0 & 0,0 & * & * & 0 & 0,0 & 0 & 0,0 & 15 & 50,0 & 0 & 0,0 & 0 & 0,0 \\
\hline Tubificidae & 0 & 0,0 & 0 & 0,0 & 59 & 100,0 & 0 & 0,0 & * & * & 0 & 0,0 & 0 & 0,0 & 0 & 0,0 & 637 & 100,0 & 0 & 0,0 \\
\hline Glossiphoniidae & 0 & 0,0 & 0 & 0,0 & 0 & 0,0 & 0 & 0,0 & * & * & 0 & 0,0 & 0 & 0,0 & 0 & 0,0 & 0 & 0,0 & 0 & 0,0 \\
\hline Pelecycopa & 0 & 0,0 & 0 & 0,0 & 0 & 0,0 & 15 & 100,0 & * & * & 15 & 50,0 & 15 & 50,0 & 15 & 50,0 & 0 & 0,0 & 0 & 0,0 \\
\hline Total & 0 & & 0 & & 59 & & 15 & & * & * & 30 & & 30 & & 30 & & 637 & & 30 & \\
\hline
\end{tabular}

$(*)=$ Quebra da Draga de Eckman-Birge 
Tabela 35: Densidades numéricas (em organismos $/ \mathrm{m}^{2}$ ) e abundância relativa (\%) dos Macroinvertebrados Bentônicos na Represa do Guarapiranga - SP - Janeiro/97

\begin{tabular}{|c|c|c|c|c|c|c|c|c|c|c|c|c|c|c|c|c|c|c|c|c|}
\hline \multirow[t]{2}{*}{ TaxalPontos } & \multicolumn{2}{|c|}{ Ponto -01 } & \multicolumn{2}{|c|}{ Ponto -02 } & \multicolumn{2}{|c|}{ Ponto -03 } & \multicolumn{2}{|c|}{ Ponto -04 } & \multicolumn{2}{|c|}{ Ponto -05 } & \multicolumn{2}{|c|}{ Ponto -06 } & \multicolumn{2}{|c|}{ Ponto -07} & \multicolumn{2}{|c|}{ Ponto -08 } & \multicolumn{2}{|c|}{ Ponto -09 } & \multicolumn{2}{|c|}{ Ponto -10 } \\
\hline & $\mathrm{N}^{\mathrm{O}}$ & $\%$ & No & $\%$ & $\mathrm{~N}^{\mathrm{O}}$ & $\%$ & $\mathrm{~N}^{\circ}$ & $\%$ & $\mathrm{~N}^{\mathrm{O}}$ & $\%$ & $\mathrm{~N}^{\mathrm{O}}$ & $\%$ & $\mathrm{~N}^{\mathrm{O}}$ & $\%$ & $\mathrm{~N}^{0}$ & $\%$ & $\mathrm{~N}^{\circ}$ & $\%$ & No & $\%$ \\
\hline Chironomidae & 15 & 100,0 & 15 & 33,3 & 0 & 0,0 & 15 & 50,0 & 0 & 0,0 & 15 & 20,0 & 22 & 20,0 & * & * & * & * & * & * \\
\hline Tanypodinae & 0 & 0,0 & 0 & 0,0 & 0 & 0,0 & 0 & 0,0 & 0 & 0,0 & 0 & 0,0 & 0 & 0,0 & * & * & * & * & * & * \\
\hline Chaoboridae & 0 & 0,0 & 0 & 0,0 & 0 & 0,0 & 0 & 0,0 & 0 & 0,0 & 45 & 60,0 & 22 & 20,0 & * & * & * & * & * & * \\
\hline Tubificidae & 0 & 0,0 & 30 & 66,7 & 0 & 0,0 & 15 & 50,0 & 0 & 0,0 & 0 & 0,0 & 44 & 40,0 & * & * & * & * & * & * \\
\hline Glossiphoniidae & 0 & 0,0 & 0 & 0,0 & 0 & 0,0 & 0 & 0,0 & 0 & 0,0 & 0 & 0,0 & 22 & 20,0 & * & * & * & * & * & * \\
\hline Pelecycopa & 0 & 0,0 & 0 & 0,0 & 0 & 0,0 & 0 & 0,0 & 15 & 100,0 & 15 & 20,0 & 0 & 0,0 & * & * & * & * & * & * \\
\hline Total & 15 & & 45 & & 0 & & 30 & & 15 & & 75 & & 110 & & & & & & & \\
\hline
\end{tabular}

$\left(^{*}\right)=$ não houve coleta (chuvas intermitentes) 
Tabela 36: Densidades numéricas (em organismos $/ \mathrm{m}^{2}$ ) e abundância relativa (\%) dos Macroinvertebrados Bentônicos na Represa do Guarapiranga - SP - Fevereiro/97

\begin{tabular}{|c|c|c|c|c|c|c|c|c|c|c|c|c|c|c|c|c|c|c|c|c|}
\hline \multirow[t]{2}{*}{ TaxalPontos } & \multicolumn{2}{|c|}{ Ponto -01 } & \multicolumn{2}{|c|}{ Ponto -02 } & \multicolumn{2}{|c|}{ Ponto -03 } & \multicolumn{2}{|c|}{ Ponto -04 } & \multicolumn{2}{|c|}{ Ponto -05 } & \multicolumn{2}{|c|}{ Ponto -06 } & \multicolumn{2}{|c|}{ Ponto -07} & \multicolumn{2}{|c|}{ Ponto -08 } & \multicolumn{2}{|c|}{ Ponto -09 } & \multicolumn{2}{|c|}{ Ponto -10 } \\
\hline & $\mathrm{N}^{\circ}$ & $\%$ & $\mathrm{~N}^{\circ}$ & $\%$ & $\mathrm{~N}^{\mathrm{O}}$ & $\%$ & No & $\%$ & No & $\%$ & $\mathrm{~N}^{\circ}$ & $\%$ & $\mathrm{~N}^{\mathrm{o}}$ & $\%$ & $\mathrm{~N}^{0}$ & $\%$ & $\mathrm{~N}^{\circ}$ & $\%$ & $\mathrm{~N}^{\circ}$ & $\%$ \\
\hline Chironomidae & 0 & 0,0 & 44 & 39,6 & 0 & 0,0 & 0 & 0,0 & 15 & 50,0 & 0 & 0,0 & 22 & 17,5 & 0 & 0,0 & 22 & 9,0 & 0 & 0,0 \\
\hline Tanypodinae & 0 & 0,0 & 0 & 0,0 & 0 & 0,0 & 0 & 0,0 & 0 & 0,0 & 15 & 12,6 & 0 & 0,0 & 0 & 0,0 & 0 & 0,0 & 0 & 0,0 \\
\hline Chaoboridae & 0 & 0,0 & 0 & 0,0 & 30 & 28,8 & 0 & 0,0 & 0 & 0,0 & 45 & 37,8 & 0 & 0,0 & 74 & 15,6 & 0 & 0,0 & 103 & 41,0 \\
\hline Tubificidae & 0 & 0,0 & 67 & 60,4 & 74 & 71,2 & 0 & 0,0 & 15 & 50,0 & 59 & 49,6 & 104 & 82,5 & 400 & 84,4 & 222 & 91,0 & 148 & 59,0 \\
\hline Glossiphoniidae & 0 & 0,0 & 0 & 0,0 & 0 & 0,0 & 0 & 0,0 & 0 & 0,0 & 0 & 0,0 & 0 & 0,0 & 0 & 0,0 & 0 & 0,0 & 0 & 0,0 \\
\hline Pelecycopa & 0 & 0,0 & 0 & 0,0 & 0 & 0,0 & 0 & 0,0 & 0 & 0,0 & 0 & 0,0 & 0 & 0,0 & 0 & 0,0 & 0 & 0,0 & 0 & 0,0 \\
\hline Total & 0 & & 111 & & 104 & & 0 & & 30 & & 119 & & 126 & & 474 & & 244 & & 251 & \\
\hline
\end{tabular}


Tabela 37: Valores mensais do índice de diversidade (bits.ind ${ }^{-1}$ ) dos Macroinvertebrados Bentônicos dos 10 pontos de coleta no período de março/96 a fevereiro/97 na Represa do Guarapiranga - SP

\begin{tabular}{l|c|c|c|c|c|c|c|c|c|c}
\hline ColetasIPontos & Ponto - 01 & Ponto - 02 & Ponto - 03 & Ponto - 04 & Ponto - 05 & Ponto - 06 & Ponto - 07 & Ponto - 08 & Ponto - 09 & Ponto - 10 \\
\hline mar/96 & 1,02 & 0,87 & 1,89 & $*$ & 0,72 & 1,08 & 1,55 & 0,14 & 1,26 & 1,12 \\
\hline abr/96 & 0,00 & 0,87 & 1,34 & - & 1,00 & 0,00 & - & $*$ & 0,82 & 0,82 \\
\hline mai/96 & 1,50 & 1,50 & 1,00 & 1,00 & - & - & 1,52 & 0,82 & - & 1,30 \\
\hline jun/96 & 1,15 & 1,38 & 1,50 & 0,60 & 1,56 & 0,58 & 0,00 & 0,99 & 0,00 & 0,97 \\
\hline jul/96 & 1,30 & 1,41 & 1,42 & 0,83 & 1,25 & 1,17 & 0,43 & 0,93 & 1,79 & 1,04 \\
\hline ago/96 & 0,97 & 1,05 & 1,30 & 0,92 & 1,41 & 0,82 & 0,50 & 1,82 & 1,24 & 1,40 \\
\hline set/96 & 0,65 & 0,00 & 1,37 & 0,00 & 1,38 & 1,49 & 1,35 & 1,03 & 0,85 & 1,06 \\
\hline nout/96 & 0,00 & 1,49 & 1,53 & 0,82 & 1,91 & 1,46 & 1,50 & 1,35 & 0,00 & 1,50 \\
\hline dez/96 & 1,00 & 0,00 & 0,00 & - & 1,92 & 1,38 & 1,50 & 0,00 & 0,69 & 0,92 \\
\hline jan/97 & - & - & 0,00 & 0,00 & $*$ & 1,00 & 1,00 & 1,00 & 0,00 & 0,00 \\
\hline fev/97 & 0,00 & 0,92 & 0,00 & 1,00 & 0,00 & 1,38 & 1,92 & $*$ & $*$ \\
\hline
\end{tabular}

$\left.{ }^{*}\right)$ = Quebra da Draga de Eckman-Birge $(* *)=$ não houve coleta (chuvas intermitentes) 
Tabela 38: Valores mensais de eqüitatividade (e) dos Macroinvertebrados Bentônicos dos 10 pontos de coleta no período de março/96 a fevereiro/97 na Represa do Guarapiranga - SP.

\begin{tabular}{l|c|c|c|c|c|c|c|c|c|c}
\hline ColetaslPontos & Ponto - 01 & Ponto - 02 & Ponto - 03 & Ponto - 04 & Ponto - 05 & Ponto - 06 & Ponto - 07 & Ponto - 08 & Ponto - 09 & Ponto - 10 \\
\hline mar/96 & 0,64 & 0,87 & 0,94 & $*$ & 0,72 & 0,68 & 0,98 & 0,14 & 0,54 & 0,56 \\
\hline abr/96 & 0,00 & 0,55 & 0,67 & - & 1,00 & 0,00 & - & $*$ & 0,52 & 0,82 \\
\hline mai/96 & 0,95 & 0,95 & 1,00 & 1,00 & - & - & 0,96 & 0,82 & - & 0,82 \\
\hline jun/96 & 0,58 & 0,87 & 0,75 & 0,60 & 0,78 & 0,29 & - & 0,63 & - & 0,61 \\
\hline jul/96 & 0,82 & 0,71 & 0,90 & 0,52 & 0,79 & 0,59 & 0,27 & 0,40 & 0,89 & 0,52 \\
\hline ago/96 & 0,97 & 0,66 & 0,65 & 0,92 & 0,89 & 0,82 & 0,31 & 0,91 & 0,78 & 0,89 \\
\hline set/96 & 0,65 & 0,00 & 1,37 & 0,00 & 0,87 & 0,94 & 0,85 & 0,65 & 0,85 & 0,67 \\
\hline out/96 & 0,00 & 0,94 & 0,97 & 0,82 & 0,95 & 0,92 & 0,95 & 0,85 & 0,00 & 0,95 \\
\hline nov/96 & 1,00 & 0,00 & 0,00 & - & 0,96 & 0,87 & 0,95 & 0,00 & 0,69 & 0,92 \\
\hline dez/96 & - & - & 0,00 & 0,00 & $*$ & 1,00 & 1,00 & 1,00 & 0,00 & 0,00 \\
\hline jan/97 & 0,00 & 0,92 & 0,00 & 1,00 & 0,00 & 0,87 & 0,96 & $* *$ & $*$ & $*$ \\
\hline fev/97 & - & 0,97 & 0,86 & - & 1,00 & 0,89 & 0,67 & 0,62 & 0,44 & 0,98 \\
\hline
\end{tabular}

$\left(^{*}\right)=$ Quebra da Draga de Eckman-Birge

$\left({ }^{* *}\right)=$ não houve coleta (chuvas intermitentes) 
Tabela 39: Valores mensais do índice de riqueza (S) dos Macroinvertebrados Bentônicos dos 10 pontos de coleta no período de março/96 a fevereiro/97 na Represa do Guarapiranga - SP.

\begin{tabular}{l|c|c|c|c|c|c|c|c|c|c}
\hline Coletas/Pontos & Ponto - 01 & Ponto - 02 & Ponto - 03 & Ponto - 04 & Ponto - 05 & Ponto - 06 & Ponto - 07 & Ponto - 08 & Ponto - 09 & Ponto - 10 \\
\hline mar/96 & 3 & 2 & 4 & $*$ & 2 & 3 & 3 & 2 & 5 & 4 \\
\hline abr/96 & 1 & 3 & 4 & 0 & 2 & 1 & 0 & $*$ & 3 & 2 \\
\hline mai/96 & 3 & 3 & 2 & 2 & 0 & 0 & 3 & 2 & 0 & 3 \\
\hline jun/96 & 4 & 3 & 4 & 2 & 4 & 4 & 1 & 3 & 1 & 3 \\
\hline ju/96 & 3 & 4 & 3 & 3 & 3 & 4 & 3 & 5 & 4 & 4 \\
\hline ago/96 & 2 & 3 & 4 & 2 & 3 & 2 & 3 & 4 & 3 & 3 \\
\hline set/96 & 2 & 1 & 2 & 1 & 3 & 3 & 3 & 3 & 2 & 3 \\
\hline out/96 & 1 & 3 & 3 & 2 & 4 & 3 & 3 & 3 & 1 & 3 \\
\hline nov/96 & 2 & 1 & 1 & 0 & 4 & 3 & 3 & 1 & 2 & 2 \\
\hline dez/96 & 0 & 0 & 1 & 1 & $*$ & 2 & 2 & 2 & 1 & 1 \\
\hline jan/97 & 1 & 2 & 0 & 2 & 1 & 3 & 4 & $* *$ & $* *$ & $*$ \\
\hline fev/97 & 0 & 2 & 2 & 0 & 2 & 3 & 2 & 2 & 2 & 2 \\
\hline
\end{tabular}

$\left(^{*}\right)=$ Quebra da Draga de Eckman-Birge

$(* *)=$ não houve coleta (chuvas intermitentes) 


\begin{tabular}{|c|c|c|c|c|c|c|c|c|c|c|c|c|c|c|c|c|c|c|c|c|}
\hline & pluv & plvme & prof & tag & tear & $\mathrm{pH}$ & turb & cond & OD & DBO & chiro & tany & chao & tubi & glossi & pele & densi & diver & equi & riqu \\
\hline$\overline{\text { pluv }}$ & & & & & & $\begin{array}{c}-0,67 \\
\left({ }^{*}\right)\end{array}$ & & & & & & & & & & & & $\begin{array}{c}-0,71 \\
\left({ }^{*}\right)\end{array}$ & & \\
\hline$\overline{\text { plvme }}$ & & & & $\begin{array}{c}0,65 \\
\left({ }^{*}\right) \\
\end{array}$ & & & $\begin{array}{c}0,69 \\
\left({ }^{*}\right) \\
\end{array}$ & & & $\begin{array}{c}-0,72 \\
(* *) \\
\end{array}$ & & & & & & & & & & \\
\hline \multicolumn{21}{|l|}{$\overline{\text { prof }}$} \\
\hline$\overline{\operatorname{tag}}$ & & & & & & & $\begin{array}{c}0,76 \\
(* *)\end{array}$ & & $\begin{array}{c}-0,84 \\
(* *)\end{array}$ & $\begin{array}{c}-0,80 \\
(* \star)\end{array}$ & & & & & & & $\begin{array}{c}-0,82 \\
(* *)\end{array}$ & & & $\begin{array}{c}-0,66 \\
(*)\end{array}$ \\
\hline$\overline{\text { tear }}$ & & & & & & & & & $\begin{array}{c}-0,72 \\
(* *) \\
\end{array}$ & & & & & & & & & & & \\
\hline \multicolumn{21}{|l|}{$\overline{\mathrm{pH}}$} \\
\hline$\overline{\text { turb }}$ & & & & & & & & & & $\begin{array}{c}-0,69 \\
\left({ }^{\star}\right)\end{array}$ & & & & & & & $\begin{array}{c}-0,79 \\
(* \star)\end{array}$ & $\begin{array}{c}-0,70 \\
\left({ }^{*}\right)\end{array}$ & $\begin{array}{c}-0,80 \\
(* *)\end{array}$ & $\begin{array}{c}-0,76 \\
(\star \star)\end{array}$ \\
\hline \multicolumn{21}{|l|}{ cond } \\
\hline$\overline{\mathrm{OD}}$ & & & & & & & & & & & & & & & & & $\begin{array}{c}0,75 \\
(* *)\end{array}$ & & & $\begin{array}{c}0,68 \\
(*)\end{array}$ \\
\hline \multicolumn{21}{|l|}{$\overline{\mathrm{DBO}}$} \\
\hline$\overline{\text { chiro }}$ & & & & $\begin{array}{c}-0,75 \\
(* *)\end{array}$ & & & $\begin{array}{c}-0,70 \\
(* *)\end{array}$ & & $\begin{array}{c}0,64 \\
\left.{ }^{*}\right)\end{array}$ & & & & $\begin{array}{c}0,68 \\
(* *)\end{array}$ & & & & $\begin{array}{l}0,83 \\
\left({ }^{\star \star \star}\right) \\
\end{array}$ & & & $\begin{array}{c}0,75 \\
(\star *) \\
\end{array}$ \\
\hline \multicolumn{21}{|l|}{ tany } \\
\hline chao & & & & $\begin{array}{c}-0,74 \\
\left.{ }^{*}\right)\end{array}$ & & & $\begin{array}{c}-0,72 \\
(* *)\end{array}$ & & $\begin{array}{c}0,82 \\
(* *)\end{array}$ & $\begin{array}{c}0,73 \\
(* *)\end{array}$ & & & & & & & $\begin{array}{l}0,90 \\
\left({ }^{* \star \star}\right)\end{array}$ & $\begin{array}{c}0,70 \\
\left({ }^{\star}\right)\end{array}$ & & $\begin{array}{l}0,85 \\
(\star *)\end{array}$ \\
\hline tubi & & & & & & & & & & & & & & & & & $\begin{array}{c}0,60 \\
\left({ }^{*}\right)\end{array}$ & $\begin{array}{c}0,65 \\
(*)\end{array}$ & & $\begin{array}{c}0,70 \\
(\star *)\end{array}$ \\
\hline \multicolumn{21}{|l|}{$\overline{\text { glossi }}$} \\
\hline \multicolumn{21}{|l|}{$\overline{\text { pele }}$} \\
\hline$\overline{\text { densi }}$ & & & & & & & & & & & & & & & & & & & & $\begin{array}{l}0,94 \\
(\star \star *)\end{array}$ \\
\hline diver & & & & & & & & & & & & & & & & & $\begin{array}{c}0,73 \\
(\star *)\end{array}$ & & & $\begin{array}{l}0,92 \\
(\star \star *)\end{array}$ \\
\hline \multicolumn{21}{|l|}{ equi } \\
\hline$\overline{\text { riqu }}$ & & & & & & & & & & & & & & & & & & & & \\
\hline
\end{tabular}

pluv = pluviosidade acumulada do dia anterior + dia da coleta; pluvm = pluviosidade mensal; prof = profundidade; tag = temperatura da água; tear = temperatura do ar $\mathrm{pH}=\mathrm{pH}$; turb = turbidez; cond = condutividade; $\mathrm{OD}=$ oxigênio dissolvido; $\mathrm{DBO}=$ demanda bioquímica de oxigênio; chiro = Chironomidae; tany = Tanypodinae;

chao $=$ Chaoboridae $;$ tubi $=$ Tubificidae $;$ glossi $=$ Glossiphoniidae; pele $=$ Pelecycopa; densi $=$ densidade total; diver $=$ diversidade $;$ equi $=$ equitatividade; riqu $=$ riqueza 


\begin{tabular}{|c|c|c|c|c|c|c|c|c|c|c|c|c|c|c|c|c|c|c|c|c|}
\hline & pluv & plvme & prof & tag & tear & $\mathrm{pH}$ & turb & cond & OD & DBO & chiro & tany & chao & tubi & glossi & pele & densi & diver & equi & riqu \\
\hline pluv & & & $\begin{array}{c}-0,63 \\
\left({ }^{*}\right) \\
\end{array}$ & & & & & & & & & & & & & & & & & \\
\hline plvme & & & & & & & $\begin{array}{c}0,70 \\
\left.{ }^{*}\right)\end{array}$ & & $\begin{array}{c}-0,71 \\
(* *)\end{array}$ & $\begin{array}{c}-0,69 \\
(\star *)\end{array}$ & & & & & & & $\begin{array}{c}-0,72 \\
(* *)\end{array}$ & & & $\begin{array}{c}-0,73 \\
(\star *)\end{array}$ \\
\hline prof & & & & & & & & & & & & & & & & & & & & \\
\hline tag & & & & & & & & & $\begin{array}{c}-0,82 \\
(* *)\end{array}$ & & & & & & & & & & & \\
\hline tear & & & & & & & & & & & & & & & & & & & & \\
\hline $\mathrm{pH}$ & & & & & & & & $\begin{array}{c}-0,71 \\
(* *)\end{array}$ & & & & & & & & & & & & \\
\hline turb & & & & & & & & & & & & & & & & & & & & \\
\hline cond & & & & & & & & & & & & & & & & & & & & \\
\hline$\overline{O D}$ & & & & & & & & & & & & & & & & & $\begin{array}{c}0,71 \\
(* *)\end{array}$ & & & \\
\hline DBO & & & & & & & & & & & & & & & & & $\begin{array}{c}0,70 \\
(* *)\end{array}$ & & & $\begin{array}{c}0,84 \\
(\star *)\end{array}$ \\
\hline chiro & & & & & & & & & & & & & & & & & $\begin{array}{c}0,70 \\
(* *)\end{array}$ & & & $\begin{array}{c}0,63 \\
\left.{ }^{*}\right)\end{array}$ \\
\hline tany & & $\begin{array}{c}-0,59 \\
\left({ }^{\star}\right)\end{array}$ & & & & & & & & & & & & & & & $\begin{array}{c}0,65 \\
\left({ }^{*}\right)\end{array}$ & & & \\
\hline chao & & $\begin{array}{c}-0,80 \\
(\star *)\end{array}$ & $\begin{array}{c}0,61 \\
\left({ }^{*}\right)\end{array}$ & & & & & & & $\begin{array}{l}0,93 \\
(\star \star \star)\end{array}$ & & $\begin{array}{c}0,67 \\
(\star *)\end{array}$ & & & & & $\begin{array}{c}0,74 \\
(* *)\end{array}$ & & & $\begin{array}{l}0,85 \\
(\star \star \star)\end{array}$ \\
\hline tubi & & & $\begin{array}{c}0,65 \\
(*)\end{array}$ & & $\begin{array}{c}-0,68 \\
\left({ }^{\star *}\right) \\
\end{array}$ & & & & & & & & & & & & & & & \\
\hline glossi & & & & & & & & & & & & & & & & & & & & \\
\hline pele & & & $\begin{array}{c}0,65 \\
\left({ }^{* *}\right)\end{array}$ & & & & & & & & & & & & & & & & & \\
\hline densi & & & & & & & & & & & & & & & & & & & & $\begin{array}{l}0,89 \\
(\star \star \star)\end{array}$ \\
\hline diver & & & & & & & & & & & & & & & & & & & $\begin{array}{c}0,66 \\
\left(^{*}\right) \\
\end{array}$ & $\begin{array}{c}0,79 \\
(\star *) \\
\end{array}$ \\
\hline equi & & & & & & & & & & & & & & & & & & & & \\
\hline riqu & & & & & & & & & & & & & & & & & & & & \\
\hline
\end{tabular}

pluv = pluviosidade acumulada do dia anterior + dia da coleta; pluvm = pluviosidade mensal; prof = profundidade; tag = temperatura da água; tear = temperatura do ar $\mathrm{pH}=\mathrm{pH}$; turb = turbidez; cond = condutividade; $\mathrm{OD}=$ oxigênio dissolvido; $\mathrm{DBO}=$ demanda bioquímica de oxigênio; chiro = Chironomidae; tany = Tanypodinae;

chao = Chaoboridae; tubi = Tubificidae; glossi = Glossiphoniidae; pele = Pelecycopa; densi = densidade total; diver = diversidade; equi = equitatividade; riqu = riqueza 


\begin{tabular}{|c|c|c|c|c|c|c|c|c|c|c|c|c|c|c|c|c|c|c|c|c|}
\hline & pluv & plvme & prof & $\operatorname{tag}$ & tear & $\mathrm{pH}$ & turb & cond & OD & DBO & chiro & tany & chao & tubi & glossi & pele & densi & diver & equi & riqu \\
\hline pluv & & & & & & & & & $\begin{array}{c}-0,78 \\
(* *) \\
\end{array}$ & & & & & & & & & & & \\
\hline plvme & & & $\begin{array}{c}-0,64 \\
\left(^{*}\right)\end{array}$ & $\begin{array}{c}0,77 \\
(* *)\end{array}$ & & & & & & & & & & & & & & & & \\
\hline prof & & & & & & & & & & & & & & & & & & & & \\
\hline tag & & & & & & $\begin{array}{c}0,69 \\
\left({ }^{*}\right)\end{array}$ & & & & & & & & & & & & & & $\begin{array}{c}-0,77 \\
(\star *)\end{array}$ \\
\hline tear & & & & & & & & & & & & & & & & & & & & \\
\hline $\mathrm{pH}$ & & & & & & & & & & & & & & & & & & & & \\
\hline turb & & & & & & & & & & & & & & & & & & & & \\
\hline cond & & & & & & $\begin{array}{c}0,63 \\
\left({ }^{*}\right)\end{array}$ & & & & & & & & & & & & & & \\
\hline OD & & & & & & & & & & & & & & & & & & & & \\
\hline DBO & & & & & & & & & & & & & & & & & & & & \\
\hline chiro & & & & $\begin{array}{c}-0,75 \\
(* \star)\end{array}$ & & & & & & & & & $\begin{array}{c}0,71 \\
(* *)\end{array}$ & & $\begin{array}{c}0,64 \\
\left({ }^{*}\right)\end{array}$ & & $\begin{array}{c}0,76 \\
(* *)\end{array}$ & $\begin{array}{c}0,73 \\
(* *)\end{array}$ & & $\begin{array}{c}0,70 \\
(* *)\end{array}$ \\
\hline tany & & & & & & & & & & & & & & & & & & & & \\
\hline chao & & & & $\begin{array}{c}-0,76 \\
(* *)\end{array}$ & & & & & & & & & & $\begin{array}{c}0,60 \\
\left(^{*}\right)\end{array}$ & $\begin{array}{l}0,87 \\
(* \star \star)\end{array}$ & & $\begin{array}{l}0,93 \\
(\star * \star)\end{array}$ & $\begin{array}{c}0,72 \\
(* *)\end{array}$ & & $\begin{array}{l}0,84 \\
(\star \star \star)\end{array}$ \\
\hline tubi & & & & & & & & & & & & & & & & & $\begin{array}{c}0,78 \\
(*)\end{array}$ & & & \\
\hline glossi & & & & $\begin{array}{c}-0,78 \\
(* \star\end{array}$ & & & & & & & & & & & & & $\begin{array}{c}0,76 \\
(* *)\end{array}$ & $\begin{array}{c}0,70 \\
\left(^{*}\right)\end{array}$ & & $\begin{array}{c}0,76 \\
(\star \star)\end{array}$ \\
\hline pele & & & & & & & & & & & & & & & & & & & & \\
\hline densi & & & & & & & & & & & & & & & & & & & & \\
\hline diver & & & & & & $\begin{array}{c}-0,69 \\
\left({ }^{*}\right)\end{array}$ & & & & & & & & & & & $\begin{array}{c}0,72 \\
(* *)\end{array}$ & & & $\begin{array}{c}0,71 \\
(\star *)\end{array}$ \\
\hline equi & & & & & & & & & & & & & & & & & & & & \\
\hline riqu & & & & & & $\begin{array}{c}-0,69 \\
\left(^{\star}\right)\end{array}$ & & & & & & & & & & & $\begin{array}{l}0,84 \\
(\star * *)\end{array}$ & & & \\
\hline
\end{tabular}

pluv = pluviosidade acumulada do dia anterior + dia da coleta; pluvm = pluviosidade mensal; prof = profundidade; tag = temperatura da água; tear = temperatura do ar $\mathrm{pH}=\mathrm{pH}$; turb = turbidez; cond = condutividade; $\mathrm{OD}=$ oxigênio dissolvido; $\mathrm{DBO}=$ demanda bioquímica de oxigênio; chiro = Chironomidae; tany = Tanypodinae;

chao = Chaoboridae; tubi = Tubificidae; glossi = Glossiphoniidae; pele = Pelecycopa; densi = densidade total; diver = diversidade; equi $=$ equitatividade; riqu = riqueza 


\begin{tabular}{|c|c|c|c|c|c|c|c|c|c|c|c|c|c|c|c|c|c|c|c|c|}
\hline & pluv & plvme & prof & tag & tear & $\mathrm{pH}$ & turb & cond & OD & $\mathrm{DBO}$ & chiro & tany & chao & tubi & glossi & pele & densi & diver & equi & riqu \\
\hline pluv & & & & & & & $\begin{array}{c}0,63 \\
\left(^{*}\right) \\
\end{array}$ & & & & & & & & & & & & & \\
\hline$\overline{\text { plvme }}$ & & & & & & $\begin{array}{c}0,75 \\
(\star \star)\end{array}$ & & $\begin{array}{c}0,66 \\
\left({ }^{*}\right)\end{array}$ & $\begin{array}{c}-0,79 \\
(\star *)\end{array}$ & & & & & & & & & & & \\
\hline prof & & & & & & & & & & & & & & & & & & & & \\
\hline tag & & & & & & & & $\begin{array}{l}0,94 \\
(\star * \star)\end{array}$ & & & & & & & & & & & & \\
\hline tear & & & & & & & & & & & & & & & & & & & & \\
\hline $\mathrm{pH}$ & & & & & & & $\begin{array}{c}0,72 \\
(\star \star) \\
\end{array}$ & & & & & & & & & & & & & \\
\hline turb & & & & & & & & & & & & & & & & & & & & \\
\hline cond & & & & & & & & & $\begin{array}{c}-0,67 \\
\left({ }^{*}\right) \\
\end{array}$ & & & & & & & & & & & \\
\hline OD & & & & & & & & & & & & & & & & & & & & \\
\hline DBO & & & & & & & & & & & & & & & & & & & & \\
\hline chiro & & & & & & & & & & & & & & & & & & & & $\begin{array}{c}0,64 \\
\left(^{*}\right)\end{array}$ \\
\hline tany & & & & & & & & & & & & & & & & & & & & \\
\hline chao & & & & $\begin{array}{c}-0,84 \\
(\star *) \\
\end{array}$ & & & & & & & & & & & & & & & & $\begin{array}{c}0,65 \\
\left(^{*}\right) \\
\end{array}$ \\
\hline tubi & & & & & & & & & & & & & & & & & $\begin{array}{l}0,87 \\
(\star * \star)\end{array}$ & & & $\begin{array}{c}0,75 \\
(\star *) \\
\end{array}$ \\
\hline glossi & & & & & & & & & & & & & & & & & & & & \\
\hline pele & & & & & & & & & & & & & & & & & & & & \\
\hline densi & & & & & & & & & & & & & & & & & & & & \\
\hline diver & & & & & & & & & & & & & & & & & & & & $\begin{array}{c}0,92 \\
(\star *)\end{array}$ \\
\hline equi & & & & & & & & & & & & & & & & & & & & \\
\hline riqu & & & & & & & & & & & & & & & & & $\begin{array}{l}0,95 \\
(\star \star \star)\end{array}$ & & & \\
\hline
\end{tabular}

pluv = pluviosidade acumulada do dia anterior + dia da coleta; pluvm = pluviosidade mensal; prof = profundidade; tag = temperatura da água; tear = temperatura do ar $\mathrm{pH}=\mathrm{pH}$; turb = turbidez; cond = condutividade; $\mathrm{OD}=$ oxigênio dissolvido; $\mathrm{DBO}=$ demanda bioquímica de oxigênio; chiro = Chironomidae; tany = Tanypodinae;

chao = Chaoboridae; tubi = Tubificidae; glossi = Glossiphoniidae; pele = Pelecycopa; densi = densidade total; diver = diversidade; equi $=$ equitatividade; riqu = riqueza 
Tabela 44: Valores dos coeficientes de correlação de Spearman $\left(r_{s}\right)$ no ponto 05 na Represa do Guarapiranga - SP-1996/1997

\begin{tabular}{|c|c|c|c|c|c|c|c|c|c|c|c|c|c|c|c|c|c|c|c|c|}
\hline & pluv & plvme & prof & tag & tear & $\mathrm{pH}$ & turb & cond & OD & DBO & chiro & tany & chao & tubi & glossi & pele & densi & diver & equi & riqu \\
\hline pluv & & & & & & & $\begin{array}{c}0,80 \\
(* *)\end{array}$ & & $\begin{array}{c}-0,69 \\
\left({ }^{\star}\right)\end{array}$ & $\begin{array}{c}-0,87 \\
(* *)\end{array}$ & & & & & & & & & & \\
\hline$\overline{\text { plvme }}$ & & & & $\begin{array}{c}0,67 \\
\left(^{*}\right)\end{array}$ & & & & & & & & & & & & & & & & \\
\hline prof & & & & & & & & $\begin{array}{c}-0,68 \\
(* *) \\
\end{array}$ & & & & & & & & & & & & \\
\hline $\operatorname{tag}$ & & & & & & & & & $\begin{array}{c}-0,71 \\
(\star \star)\end{array}$ & & & & & & & & $\begin{array}{c}-0,79 \\
(* *)\end{array}$ & & & \\
\hline tear & & & & & & & & & $\begin{array}{c}-0,68 \\
\left({ }^{\star \star}\right) \\
\end{array}$ & & & & & & & & $\begin{array}{c}-0,70 \\
(* *)\end{array}$ & $\begin{array}{c}-0,74 \\
\left({ }^{*}\right)\end{array}$ & & $\begin{array}{c}-0,77 \\
(* \star)\end{array}$ \\
\hline $\mathrm{pH}$ & & & & & & & & & & & & & & & & & & & & \\
\hline turb & & & & & & & & & & & & & & & & & & & & \\
\hline cond & & & & & & & & & & & & & & & & & & & & \\
\hline OD & & & & & & & & & & $\begin{array}{c}0,62 \\
\left({ }^{*}\right) \\
\end{array}$ & & & & & & & $\begin{array}{c}0,80 \\
(* *)\end{array}$ & & & \\
\hline DBO & & & & & & & & & & & & & & & & & & & & \\
\hline chiro & & & & $\begin{array}{c}-0,84 \\
(* *)\end{array}$ & & & & & $\begin{array}{c}0,66 \\
\left({ }^{*}\right) \\
\end{array}$ & & & & & $\begin{array}{c}0,69 \\
(*) \\
\end{array}$ & & & $\begin{array}{l}0,90 \\
(\star \star \star)\end{array}$ & & & \\
\hline tany & & & & & & & & & & & & & & & & & & & & \\
\hline chao & & & & & $\begin{array}{c}-0,65 \\
\left(^{*}\right)\end{array}$ & & & & & & & & & & & & $\begin{array}{c}0,78 \\
(* *)\end{array}$ & & & \\
\hline tubi & & & & $\begin{array}{c}-0,82 \\
(* \star)\end{array}$ & $\begin{array}{c}-0,75 \\
\left({ }^{* *}\right)\end{array}$ & & & & $\begin{array}{c}0,81 \\
\left({ }^{\star \star}\right)\end{array}$ & & & & & & & & $\begin{array}{c}0,80 \\
(*)\end{array}$ & & & $\begin{array}{c}0,75 \\
(* \star)\end{array}$ \\
\hline glossi & & & & & & & & & & & & & & & & & & & & \\
\hline pele & & & & & & & & $\begin{array}{c}0,65 \\
\left(^{*}\right)\end{array}$ & & & & & & & & & & & & \\
\hline densi & & & & & & & & & & & & & & & & & & & & \\
\hline diver & & & & & & & & & & & & & & & & & & & & $\begin{array}{l}0,97 \\
(\star \star \star)\end{array}$ \\
\hline equi & & & & & & & & & & & & & & & & & & & & \\
\hline riqu & & & & & & & & & & & & & & & & & $\begin{array}{c}0,66 \\
\left.{ }^{*}\right)\end{array}$ & & & \\
\hline
\end{tabular}

pluv = pluviosidade acumulada do dia anterior + dia da coleta; pluvm = pluviosidade mensal; prof = profundidade; tag = temperatura da água; tear = temperatura do ar $\mathrm{pH}=\mathrm{pH}$; turb = turbidez; cond = condutividade; $\mathrm{OD}=$ oxigênio dissolvido; $\mathrm{DBO}=$ demanda bioquímica de oxigênio; chiro = Chironomidae; tany = Tanypodinae;

chao = Chaoboridae; tubi = Tubificidae; glossi = Glossiphoniidae; pele = Pelecycopa; densi = densidade total; diver = diversidade; equi = equitatividade; riqu = riqueza 
Tabela 45: Valores dos coeficientes de correlação de Spearman $\left(r_{s}\right)$ no ponto 06 na Represa do Guarapiranga - SP-1996/1997

\begin{tabular}{|c|c|c|c|c|c|c|c|c|c|c|c|c|c|c|c|c|c|c|c|c|}
\hline & pluv & plvme & prof & tag & tear & $\mathrm{pH}$ & turb & cond & OD & DBO & chiro & tany & chao & tubi & glossi & pele & densi & diver & equi & riqu \\
\hline pluv & & & & & & & $\begin{array}{c}0,77 \\
(* *)\end{array}$ & & & & & & & & & & & & & \\
\hline plvme & & & & & & & & $\begin{array}{c}0,76 \\
(* *)\end{array}$ & & & & & & & & & & & $\begin{array}{c}0,65 \\
\left({ }^{*}\right)\end{array}$ & \\
\hline prof & & & & & & $\begin{array}{c}-0,83 \\
(* *) \\
\end{array}$ & & & $\begin{array}{c}-0,70 \\
\left({ }^{* *}\right)\end{array}$ & & & & & & & & & & & \\
\hline tag & & & & & & & & & & & & & & & & & & & & \\
\hline tear & & & & & & & & & & & & & & & & & & & & \\
\hline $\mathrm{pH}$ & & & & & & & & & & & & & & & & & & & & \\
\hline turb & & & & & & & & & & & & & & & & & & & & \\
\hline cond & & & & & & & & & & & & & & & & & & & $\begin{array}{c}0,82 \\
(\star \star)\end{array}$ & \\
\hline OD & & & & & & & & & & & & & & & & & & & & \\
\hline DBO & & & & & & & & & & & & & & & & & & & & \\
\hline chiro & & & & & & & & & & & & & & & & & & & & \\
\hline tany & & & & & & & & & & & & & & & & & & & & \\
\hline chao & & & & & & & & & & & & & & & & & $\begin{array}{l}0,91 \\
(\star \star \star)\end{array}$ & & & $\begin{array}{l}0,84 \\
(\star \star \star)\end{array}$ \\
\hline tubi & & & & & & & & & & & & $\begin{array}{c}0,62 \\
\left(^{*}\right)\end{array}$ & & & & & $\begin{array}{c}0,74 \\
(*)\end{array}$ & & & $\begin{array}{c}0,67 \\
(\star *) \\
\end{array}$ \\
\hline glossi & & & & & & & & & & & & & & & & & & & & \\
\hline pele & & & & & & & & $\begin{array}{c}0,67 \\
\left(^{*}\right) \\
\end{array}$ & & & & & & & & & & & $\begin{array}{c}0,61 \\
(-) \\
\end{array}$ & \\
\hline densi & & & & & & & & & & & & & & & & & & & & \\
\hline diver & & & & & & & & & & & & & & & & & & & $\begin{array}{c}0,68 \\
\left({ }^{*}\right)\end{array}$ & \\
\hline equi & & & & & & & & & & & & & & & & & & & & \\
\hline riqu & & & & & & & & & & & & & & & & & $\begin{array}{l}0,88 \\
\left(^{\star \star \star}\right)\end{array}$ & & & \\
\hline
\end{tabular}

pluv = pluviosidade acumulada do dia anterior + dia da coleta; pluvm = pluviosidade mensal; prof = profundidade; tag = temperatura da água; tear = temperatura do ar $\mathrm{pH}=\mathrm{pH}$; turb = turbidez; cond = condutividade; $\mathrm{OD}=$ oxigênio dissolvido; $\mathrm{DBO}=$ demanda bioquímica de oxigênio; chiro = Chironomidae; tany = Tanypodinae;

chao = Chaoboridae; tubi = Tubificidae; glossi = Glossiphoniidae; pele = Pelecycopa; densi = densidade total; diver = diversidade; equi = equitatividade; riqu = riqueza 
Tabela 46: Valores dos coeficientes de correlação de Spearman $\left(r_{s}\right)$ no ponto 07 na Represa do Guarapiranga - SP-1996/1997

\begin{tabular}{|c|c|c|c|c|c|c|c|c|c|c|c|c|c|c|c|c|c|c|c|c|}
\hline & pluv & plvme & prof & tag & tear & $\mathrm{pH}$ & turb & cond & OD & $\mathrm{DBO}$ & chiro & tany & chao & tubi & glossi & pele & densi & diver & equi & riqu \\
\hline pluv & & & $\begin{array}{c}-0,65 \\
\left({ }^{\star}\right)\end{array}$ & & & & & & $\begin{array}{c}-0,76 \\
(* *)\end{array}$ & & & & & & & & & & & \\
\hline$\overline{\text { plvme }}$ & & & & $\begin{array}{c}0,68 \\
\left({ }^{\star}\right)\end{array}$ & & & & $\begin{array}{c}0,69 \\
\left({ }^{*}\right)\end{array}$ & & & & & & & & & & $\begin{array}{c}0,67 \\
\left({ }^{*}\right)\end{array}$ & $\begin{array}{c}0,82 \\
(\star \star)\end{array}$ & \\
\hline prof & & & & & & & & & & $\begin{array}{c}0,74 \\
(\star \star)\end{array}$ & & & & & & & & & & \\
\hline tag & & & & & & & & $\begin{array}{c}0,70 \\
\left({ }^{*}\right)\end{array}$ & $\begin{array}{c}-0,67 \\
(* *) \\
\end{array}$ & & & & & & & & & & $\begin{array}{c}0,73 \\
\left({ }^{*}\right)\end{array}$ & \\
\hline tear & & & & & & & & & & & & & & & & & & & & \\
\hline $\mathrm{pH}$ & & & & & & & & & & & & & & & & & & & & \\
\hline turb & & & & & & & & & & $\begin{array}{c}-0,64 \\
\left(^{*}\right) \\
\end{array}$ & & & & & & & & & & \\
\hline cond & & & & & & & & & & & & & & & & & & & & \\
\hline OD & & & & & & & & & & & & & & & & & & & & \\
\hline DBO & & & & & & & & & & & & & & & & & & & & \\
\hline chiro & & & & & & & & & & & & & & & & & & & & \\
\hline tany & & & & & & & & & & & & & & & & & & & & \\
\hline chao & & & & & & & & & & & & & & & & & $\begin{array}{c}0,71 \\
(* \star)\end{array}$ & & & $\begin{array}{c}0,73 \\
(* *)\end{array}$ \\
\hline tubi & & & & & & & & & & & & & & & & & $\begin{array}{l}0,94 \\
(\star * \star)\end{array}$ & & & \\
\hline glossi & & & & & & & & & & & & & & & & & & & & \\
\hline pele & & & & & & & & & & & & & & & & & & & & \\
\hline densi & & & & & & & & & & & & & & & & & & & & \\
\hline diver & & & & & & & & & & & & & & & & & & & $\begin{array}{c}0,83 \\
(* *)\end{array}$ & $\begin{array}{c}0,67 \\
\left({ }^{*}\right)\end{array}$ \\
\hline equi & & & & & & & & & & & & & & & & & & & & \\
\hline riqu & & & & & & & & & & & & & & & & & $\begin{array}{c}0,59 \\
\left({ }^{*}\right)\end{array}$ & & & \\
\hline
\end{tabular}

pluv = pluviosidade acumulada do dia anterior + dia da coleta; pluvm = pluviosidade mensal; prof = profundidade; tag = temperatura da água; tear = temperatura do ar $\mathrm{pH}=\mathrm{pH}$; turb = turbidez; cond = condutividade; $\mathrm{OD}=$ oxigênio dissolvido; $\mathrm{DBO}=$ demanda bioquímica de oxigênio; chiro = Chironomidae; tany = Tanypodinae;

chao = Chaoboridae; tubi = Tubificidae; glossi = Glossiphoniidae; pele = Pelecycopa; densi = densidade total; diver = diversidade; equi = equitatividade; riqu = riqueza 
Tabela 47 : Valores dos coeficientes de correlação de Spearman $\left(r_{s}\right)$ no ponto 08 na Represa do Guarapiranga - SP-1996/1997

\begin{tabular}{|c|c|c|c|c|c|c|c|c|c|c|c|c|c|c|c|c|c|c|c|c|}
\hline & pluv & plvme & prof & tag & tear & $\mathrm{pH}$ & turb & cond & OD & DBO & chiro & tany & chao & tubi & glossi & pele & densi & diver & equi & riqu \\
\hline pluv & & & & & & & & & & $\begin{array}{c}-0,70 \\
\left(^{*}\right) \\
\end{array}$ & & & & & & & & & & \\
\hline plvme & & & & & & & & $\begin{array}{c}0,72 \\
\left(^{*}\right)\end{array}$ & & & & & & & & & & & & \\
\hline prof & & & & & & & & & & & & & & & & & & & & \\
\hline tag & & & & & & & & $\begin{array}{c}0,95 \\
(* *)\end{array}$ & $\begin{array}{c}-0,84 \\
(* *)\end{array}$ & & & & & & & & $\begin{array}{c}-0,72 \\
\left.{ }^{*}\right)\end{array}$ & & & $\begin{array}{c}-0,82 \\
(\star \star)\end{array}$ \\
\hline tear & & & & & & & & & $\begin{array}{c}-0,74 \\
\left.{ }^{*}\right)\end{array}$ & & & & & & & & & & & \\
\hline $\mathrm{pH}$ & & & & & & & & & & & & & & & & & & & & \\
\hline turb & & & & & & & & & & & & & & & & & & & & \\
\hline cond & & & & & & & & & & & & & & & & & $\begin{array}{c}-0,72 \\
\left.{ }^{*}\right)\end{array}$ & & & $\begin{array}{c}-0,81 \\
(* *)\end{array}$ \\
\hline OD & & & & & & & & & & $\begin{array}{c}0,68 \\
\left(^{*}\right) \\
\end{array}$ & & & & & & & & & & $\begin{array}{c}0,83 \\
(\star *)\end{array}$ \\
\hline DBO & & & & & & & & & & & & & & & & & & & & \\
\hline chiro & & & & & $\begin{array}{c}-0,78 \\
(* *)\end{array}$ & & & & & & & & & & & & & $\begin{array}{c}0,66 \\
\left({ }^{*}\right)\end{array}$ & & $\begin{array}{c}0,72 \\
\left(^{\star}\right)\end{array}$ \\
\hline tany & & & & & & & & & & & & & & & & & & & & \\
\hline chao & & & & & & & $\begin{array}{c}0,74 \\
\left(^{*}\right) \\
\end{array}$ & & & & & & & & & & $\begin{array}{c}0,87 \\
(* *)\end{array}$ & & & \\
\hline tubi & & & & & & & & & & & & & & & & & $\begin{array}{c}0,72 \\
(*)\end{array}$ & & & \\
\hline glossi & & & & & & & & $\begin{array}{c}-0,73 \\
\left(^{\star}\right) \\
\end{array}$ & $\begin{array}{c}0,72 \\
\left({ }^{*}\right) \\
\end{array}$ & $\begin{array}{c}0,71 \\
\left(^{*}\right) \\
\end{array}$ & & & & & & & & & & \\
\hline pele & & & & & & & & & & & & & & & & & & & $\begin{array}{c}0,69 \\
\left(^{\star}\right)\end{array}$ & \\
\hline densi & & & & & & & & & & & & & & & & & & & & \\
\hline diver & & & & & & & & & & & & & & & & & & & $\begin{array}{l}0,81 \\
\left({ }^{* *}\right)\end{array}$ & $\begin{array}{c}0,70 \\
\left({ }^{*}\right)\end{array}$ \\
\hline equi & & & & & & & & & & & & & & & & & & & & \\
\hline riqu & & & & & & & & & & & & & & & & & & & & \\
\hline
\end{tabular}

pluv = pluviosidade acumulada do dia anterior + dia da coleta; pluvm = pluviosidade mensal; prof = profundidade; tag = temperatura da água; tear = temperatura do ar $\mathrm{pH}=\mathrm{pH}$; turb = turbidez; cond = condutividade; $\mathrm{OD}=$ oxigênio dissolvido; $\mathrm{DBO}=$ demanda bioquímica de oxigênio; chiro = Chironomidae; tany = Tanypodinae;

chao = Chaoboridae; tubi = Tubificidae; glossi = Glossiphoniidae; pele = Pelecycopa; densi = densidade total; diver = diversidade; equi = equitatividade; riqu = riqueza 


\begin{tabular}{|c|c|c|c|c|c|c|c|c|c|c|c|c|c|c|c|c|c|c|c|c|}
\hline & pluv & plvme & prof & tag & tear & $\mathrm{pH}$ & turb & cond & OD & $\mathrm{DBO}$ & chiro & tany & chao & tubi & glossi & pele & densi & diver & equi & riqu \\
\hline & & & & & & & & & & & & & & & & & & & & \\
\hline$\overline{\text { plvme }}$ & & & & & & $\begin{array}{c}0,71 \\
\left(^{\star}\right)\end{array}$ & & & & & & & & & & & & & & \\
\hline prof & & & & & & & & $\begin{array}{c}-0,66 \\
\left.{ }^{\star}\right)\end{array}$ & & & & & & & & & & & & \\
\hline tag & & & & & & & & & $\begin{array}{c}-0,86 \\
(\star \star)\end{array}$ & & & & & & & & & & & \\
\hline tear & & & & & & & & & & & & & & & & & & & & \\
\hline $\mathrm{pH}$ & & & & & & & & & & & & & & & & & & $\begin{array}{c}-0,90 \\
(\star *)\end{array}$ & $\begin{array}{c}-0,83 \\
(\star *)\end{array}$ & \\
\hline turb & & & & & & & & & & & & & & & & & & & & $\begin{array}{c}0,68 \\
\left(^{*}\right)\end{array}$ \\
\hline cond & & & & & & & & & & & & & & & & & & & & \\
\hline OD & & & & & & & & & & & & & & & & & & & & \\
\hline DBO & & & & & & & & & & & & & & & & & & & & \\
\hline chiro & & & & & & & & & & & & & & & & & & $\begin{array}{c}0,68 \\
\left({ }^{*}\right)\end{array}$ & $\begin{array}{c}0,83 \\
(\star \star)\end{array}$ & \\
\hline tany & & & & $\begin{array}{c}-0,90 \\
(\star \star)\end{array}$ & $\begin{array}{c}-0,67 \\
\left.{ }^{*}\right)\end{array}$ & & & & $\begin{array}{c}0,85 \\
\left({ }^{\star \star}\right)\end{array}$ & & & & & & & & & & & \\
\hline chao & & & & & & & & & & & & & & & & $\begin{array}{c}0,63 \\
\left({ }^{*}\right)\end{array}$ & & & & $\begin{array}{c}0,64 \\
\left(^{*}\right)\end{array}$ \\
\hline tubi & & & & & & & & & & & & & & & & & $\begin{array}{c}0,79 \\
(*)\end{array}$ & & & \\
\hline glossi & & & & & & & & & & & & & & & & & & & & \\
\hline pele & & & & & & & & & & & & & & & & & & & & \\
\hline densi & & & & & & & & & & & & & & & & & & & & \\
\hline diver & & & & & & & & & & & & & & & & & & & $\begin{array}{c}0,88 \\
(\star \star)\end{array}$ & $\begin{array}{l}0,94 \\
(* \star *)\end{array}$ \\
\hline equi & & & & & & & & & & & & & & & & & & & & \\
\hline riqu & & & & & & & & & & & & & & & & & $\begin{array}{c}0,66 \\
\left(^{*}\right)\end{array}$ & & $\begin{array}{c}0,71 \\
\left.{ }^{*}\right)\end{array}$ & \\
\hline
\end{tabular}

pluv = pluviosidade acumulada do dia anterior + dia da coleta; pluvm = pluviosidade mensal; prof = profundidade; tag = temperatura da água; tear = temperatura do ar $\mathrm{pH}=\mathrm{pH}$; turb = turbidez; cond = condutividade; $\mathrm{OD}=$ oxigênio dissolvido; $\mathrm{DBO}=$ demanda bioquímica de oxigênio; chiro = Chironomidae; tany = Tanypodinae;

chao = Chaoboridae; tubi = Tubificidae; glossi = Glossiphoniidae; pele = Pelecycopa; densi = densidade total; diver = diversidade; equi = equitatividade; riqu = riqueza 


\begin{tabular}{|c|c|c|c|c|c|c|c|c|c|c|c|c|c|c|c|c|c|c|c|c|}
\hline & pluv & plvme & prof & tag & tear & $\mathrm{pH}$ & turb & cond & OD & DBO & chiro & tany & chao & tubi & glossi & pele & densi & diver & equi & riqu \\
\hline pluv & & & & & & & $\begin{array}{c}0,72 \\
\left(^{*}\right) \\
\end{array}$ & & & $\begin{array}{c}-0,71 \\
\left(^{*}\right) \\
\end{array}$ & & & & & & & & & & \\
\hline plvme & & & & & & & & & & & & & & & & & & & & \\
\hline prof & & & & & & & & & & & & & & & & & & & & \\
\hline tag & & & & & & & & $\begin{array}{c}0,71 \\
\left({ }^{*}\right)\end{array}$ & $\begin{array}{c}-0,72 \\
\left({ }^{\star}\right)\end{array}$ & & & & & & & & & & & $\begin{array}{c}-0,85 \\
(\star *)\end{array}$ \\
\hline tear & & & & & & & & & & & & & & & & & & $\begin{array}{c}-0,74 \\
(\star *)\end{array}$ & & $\begin{array}{c}-0,65 \\
\left({ }^{*}\right)\end{array}$ \\
\hline $\mathrm{pH}$ & & & & & & & & & & & & & & & & & & & & \\
\hline turb & & & & & & & & & & $\begin{array}{c}-0,73 \\
\left(^{*}\right) \\
\end{array}$ & & & & & & & & & & \\
\hline cond & & & & & & & & & & & & & & & & & & & & \\
\hline OD & & & & & & & & & & & & & & & & & & & & \\
\hline DBO & & & & & & & & & & & & & & & & & & & & \\
\hline chiro & & & & & & & & & & & & & & & & & & & & \\
\hline tany & & & & & & & & & & & & & & & & & & & & \\
\hline chao & & & & & & & & & & & & & & & & & $\begin{array}{c}0,85 \\
(* \star)\end{array}$ & & & $\begin{array}{c}0,73 \\
(\star *)\end{array}$ \\
\hline tubi & & & & & & & & & & & & & & & & & $\begin{array}{c}0,71 \\
(* *)\end{array}$ & & & \\
\hline glossi & & & & & & & & & & & & & & & & & & & & \\
\hline pele & & & & & $\begin{array}{c}-0,62 \\
\left({ }^{*}\right) \\
\end{array}$ & & & & & & & & & & & & & & & \\
\hline densi & & & & & & & & & & & & & & & & & & & & \\
\hline diver & & & & & & & & & & & & & & & & & & & & $\begin{array}{c}0,66 \\
\left({ }^{*}\right)\end{array}$ \\
\hline equi & & & & & & & & & & & & & & & & & & & & \\
\hline riqu & & & & & & & & & & & & & & & & & $\begin{array}{c}0,70 \\
(* *)\end{array}$ & & & \\
\hline
\end{tabular}

pluv = pluviosidade acumulada do dia anterior + dia da coleta; pluvm = pluviosidade mensal; prof = profundidade; tag = temperatura da água; tear = temperatura do ar $\mathrm{pH}=\mathrm{pH}$; turb = turbidez; cond = condutividade; $\mathrm{OD}=$ oxigênio dissolvido; $\mathrm{DBO}=$ demanda bioquímica de oxigênio; chiro = Chironomidae; tany = Tanypodinae;

chao = Chaoboridae; tubi = Tubificidae; glossi = Glossiphoniidae; pele = Pelecycopa; densi = densidade total; diver = diversidade; equi $=$ equitatividade; riqu = riqueza 
Tabela 50: Concentrações de Coliformes Totais (CT) e Coliformes Fecais (CF) na Represa do Guarapiranga nos 10 (dez) pontos de amostragem no período de março/96 a fevereiro/97.

\begin{tabular}{|c|c|c|c|c|c|c|c|c|c|c|c|c|c|c|c|c|c|c|c|c|c|c|c|c|}
\hline \multirow[b]{3}{*}{ Ponto } & \multicolumn{2}{|c|}{ Março/96 } & \multicolumn{2}{|c|}{ Abril/96 } & \multicolumn{2}{|c|}{ Maio/96 } & \multicolumn{2}{|c|}{ Junho/96 } & \multicolumn{2}{|c|}{ Julho/96 } & \multicolumn{2}{|c|}{ Agosto/96 } & \multicolumn{2}{|c|}{ Setembro/96 } & \multicolumn{2}{|c|}{ Outubro/96 } & \multicolumn{2}{|c|}{ Novembro/96 } & \multicolumn{2}{|c|}{ Dezembro/96 } & \multicolumn{2}{|c|}{ Janeiro/97 } & \multicolumn{2}{|c|}{ Fevereiro/97 } \\
\hline & NMP/1 & $00 \mathrm{ml}$ & NMP/1 & $00 \mathrm{ml}$ & NMP/1 & $00 \mathrm{ml}$ & NMP/1 & $00 \mathrm{ml}$ & NMP/1 & $00 \mathrm{ml}$ & NMP/1 & $0 \mathrm{ml}$ & $\mathrm{NMP} / 1$ & $00 \mathrm{ml}$ & NMP/1 & $00 \mathrm{ml}$ & NMP/1 & $00 \mathrm{ml}$ & NMPI & $100 \mathrm{ml}$ & $\mathrm{NMP/}$ & $100 \mathrm{ml}$ & NMPI & $100 \mathrm{~m}$ \\
\hline & СT & $\mathrm{CF}$ & CT & $\mathrm{CF}$ & СT & $\mathrm{CF}$ & Ст & $\mathrm{CF}$ & ст & CF & CT & $\mathrm{CF}$ & CT & $\mathrm{CF}$ & СT & $\mathrm{CF}$ & Ст & $\mathrm{CF}$ & Ст & CF & ст & $\mathrm{CF}$ & Ст & CF \\
\hline 1 & 11000 & 90 & 140 & 9 & 350 & 9 & 27 & 6 & 170 & 2 & 8 & $<2$ & 140 & 17 & 30 & 12 & 13 & 2 & 230 & 4 & 2 & 2 & 8000 & 5000 \\
\hline 2 & 1700 & 27 & 130 & 13 & 27 & 7 & 8 & 2 & 12 & $<2$ & $<2$ & $<2$ & 700 & 12 & 2800 & 1400 & 130 & 7 & 1700 & 1700 & 1700 & 27 & 8000 & 3000 \\
\hline 3 & 2 & $<2$ & 7 & 4 & 110 & 2 & 1100 & 2 & 23 & $<2$ & 130 & 4 & 7 & 2 & 1300 & 80 & 30 & 4 & 800 & $\leq 2$ & 12 & 2 & 500 & 230 \\
\hline 4 & 22 & 4 & 1700 & 17 & 280 & 220 & 1400 & 80 & 23 & 23 & 70 & 70 & $<2$ & $<2$ & 17000 & 11000 & 500 & 80 & 1400 & 80 & 2400 & 800 & 3000 & 3000 \\
\hline 5 & 1700 & 50 & 3500 & 800 & 33 & 2 & 90 & 22 & 8000 & $<2$ & 23 & 23 & $<2$ & $<2$ & 170 & 26 & 110 & 11 & 50000 & 34 & 800 & 13 & 13000 & 11000 \\
\hline 6 & 800 & 27 & 600 & 600 & 13 & 4 & 1100 & 6 & 700 & 27 & 700 & 34 & 700 & 140 & 13 & 8 & 1100 & 30 & 500 & 34 & 3000 & 220 & 8000 & 700 \\
\hline 7 & 11000 & 7000 & 340 & 220 & 230 & 17 & $<2$ & $<2$ & 3500 & 80 & 170 & 22 & 110 & 27 & 3000 & 2300 & 2300 & 26 & 230 & 17 & 8000 & 1700 & 50000 & 11000 \\
\hline 8 & 350 & 27 & 300 & 130 & 17000 & 130 & 17 & 7 & 8000 & 22 & 11 & 8 & 110 & 70 & 170 & 26 & 5000 & 2100 & 1300 & 270 & 1400 & 70 & \begin{tabular}{|l|l|} 
\\
\end{tabular} & 5000 \\
\hline$y$ & 50000 & 50000 & 3000 & 2300 & 3000 & 3000 & 11000 & 7000 & 3000 & 5000 & 2300 & 33 & 2300 & 80 & 11000 & 5000 & 6000 & 1700 & 1300 & 170 & 50000 & 2200 & 3000 & 13000 \\
\hline 10 & 3000 & 2300 & 5000 & 3000 & 30 & 6 & 70 & 8 & 220 & 4 & $<2$ & $<2$ & 130 & 7 & 800 & 230 & 900 & 17 & 220 & 17 & 700 & 33 & 3000 & 3000 \\
\hline
\end{tabular}

\section{$(*)$ = não houve coleta (chuvas intermitentes)}


Tabela 51: Datas e Horários das Coletas realizadas no período de março/96 a fevereiro/97 na Represa do Guarapiranga - SP

\begin{tabular}{|c|c|c|c|c|c|c|c|c|c|c|c|c|c|c|c|c|c|c|c|c|c|c|c|c|}
\hline \multirow[t]{2}{*}{ Pontos } & \multicolumn{2}{|c|}{ Coleta 1} & \multicolumn{2}{|c|}{ Coleta 2} & \multicolumn{2}{|c|}{ Coleta 3} & \multicolumn{2}{|c|}{ Coleta 4} & \multicolumn{2}{|c|}{ Coleta 5} & \multicolumn{2}{|c|}{ Coleta 6} & \multicolumn{2}{|c|}{ Coleta 7} & \multicolumn{2}{|c|}{ Coleta 8} & \multicolumn{2}{|c|}{ Coleta 9} & \multicolumn{2}{|c|}{ Coleta 10} & \multicolumn{2}{|c|}{ Coleta 11} & \multicolumn{2}{|c|}{ Coleta 12} \\
\hline & Data & Horário & Data & Horário & Data & Horário & Data & Horário & Data & Horário & Data & Horário & Data & Horário & Data & Horário & Data & Horário & Data & Horário & Data & Horário & Data & Horário \\
\hline 01 & 14.03 .96 & 11:45 & 10.04 .06 & $10: 40$ & 07.05 .96 & $10: 30$ & 12.06 .96 & \begin{tabular}{|l|}
$10: 25$ \\
\end{tabular} & 18.07 .96 & \begin{tabular}{|l|}
$10: 20$ \\
\end{tabular} & 13.08 .96 & \begin{tabular}{|l|}
$11: 25$ \\
\end{tabular} & 18.09 .96 & \begin{tabular}{|l|}
$11: 45$ \\
\end{tabular} & 15.10 .96 & $12: 15$ & 12.11 .96 & $12: 35$ & 26.12 .96 & \begin{tabular}{|l|}
$12: 30$ \\
\end{tabular} & 15.01 .97 & \begin{tabular}{|l|}
$12: 05$ \\
\end{tabular} & 18.02 .97 & \begin{tabular}{|l|}
$13: 40$ \\
\end{tabular} \\
\hline 02 & 14.03.96 & 12:25 & 10.04 .96 & 11:40 & 07.05 .96 & 11:10 & 12.06 .96 & \begin{tabular}{|l|}
$11: 50$ \\
\end{tabular} & 18.07 .96 & \begin{tabular}{|l|}
$10: 45$ \\
\end{tabular} & 13.08 .96 & \begin{tabular}{|l|}
$11: 00$ \\
\end{tabular} & 18.09 .96 & \begin{tabular}{|l|}
$11: 20$ \\
\end{tabular} & 15.10 .96 & \begin{tabular}{|l|}
$1: 55$ \\
\end{tabular} & 12.11 .96 & \begin{tabular}{|l|}
$11: 55$ \\
\end{tabular} & 26.12 .96 & 12:00 & 15.01 .97 & \begin{tabular}{|l|}
$11: 40$ \\
\end{tabular} & 18.02 .97 & \begin{tabular}{|l|}
$13: 15$ \\
\end{tabular} \\
\hline 03 & 14.03 .96 & \begin{tabular}{|l|}
$12: 55$ \\
\end{tabular} & 10.04 .96 & 12:10 & 07.05.96 & 11:50 & 12.06 .96 & $12: 30$ & 3.07 .96 & $11: 20$ & 13.08 .96 & $10: 25$ & 18.09 .96 & \begin{tabular}{|l|}
$10: 55$ \\
\end{tabular} & 15.10 .96 & \begin{tabular}{|l|}
$11: 25$ \\
\end{tabular} & 12.11 .96 & \begin{tabular}{|l|}
$11: 25$ \\
\end{tabular} & 26.12 .96 & 11:30 & $\mid 15.01 .97$ & 11:10 & $|18.02 .97|$ & \begin{tabular}{|l|}
$12: 50$ \\
\end{tabular} \\
\hline 04 & 14.03.96 & 13:50 & 10.04 .96 & $13: 00$ & 07.05 .96 & 12:30 & 12.06 .96 & 13:00 & 18.07 .96 & \begin{tabular}{|l|}
$13: 20$ \\
\end{tabular} & 13.08 .96 & \begin{tabular}{|l|}
$12: 20$ \\
\end{tabular} & 18.09.96 & \begin{tabular}{|l|}
$12: 40$ \\
\end{tabular} & 15.10 .96 & 13:10 & 12.11 .96 & \begin{tabular}{|l|}
$13: 55$ \\
\end{tabular} & 26.12 .96 & 13:40 & 15.01 .97 & \begin{tabular}{|l|}
$13: 05$ \\
\end{tabular} & 18.02 .97 & \begin{tabular}{|l|}
$12: 10$ \\
\end{tabular} \\
\hline 05 & 15.03 .96 & \begin{tabular}{|l|}
$10: 50$ \\
\end{tabular} & 10.04 .96 & \begin{tabular}{|l|}
$14: 35$ \\
\end{tabular} & 07.05.96 & \begin{tabular}{|l|}
$13: 20$ \\
\end{tabular} & 12.06 .96 & $14: 20$ & 18.07.96 & \begin{tabular}{|l|}
$12: 30$ \\
\end{tabular} & 13.08 .96 & \begin{tabular}{|l|}
$09: 45$ \\
\end{tabular} & 18.09 .96 & \begin{tabular}{|l|}
$09: 55$ \\
\end{tabular} & 15.10 .96 & \begin{tabular}{|l|}
$10: 30$ \\
\end{tabular} & 12.11 .96 & \begin{tabular}{|l|}
$10: 25$ \\
\end{tabular} & 26.12 .96 & \begin{tabular}{|l|}
$10: 30$ \\
\end{tabular} & $\mid 15.01 .97$ & $10: 15$ & $|18.02 .97|$ & \begin{tabular}{|l|}
$14: 45$ \\
\end{tabular} \\
\hline 06 & 15.03 .96 & 11:35 & 10.04 .96 & 13:25 & 07.05.96 & $14: 10$ & 12.06 .96 & $13: 30$ & 18.07 .96 & \begin{tabular}{|l|}
$13: 50$ \\
\end{tabular} & 13.08 .96 & \begin{tabular}{|l|}
$12: 40$ \\
\end{tabular} & 18.09 .96 & \begin{tabular}{|l|}
$13: 00$ \\
\end{tabular} & 15.10 .96 & 13:35 & 12.11 .96 & \begin{tabular}{|l|}
$14: 25$ \\
\end{tabular} & 26.12 .96 & \begin{tabular}{|l|}
$14: 10$ \\
\end{tabular} & 15.01 .97 & 13:30 & 18.02 .97 & \begin{tabular}{|l|}
$11: 45$ \\
\end{tabular} \\
\hline 07 & 15.03 .96 & $12: 05$ & 10.04 .96 & $14: 00$ & 07.05 .96 & $15: 10$ & 12.06 .96 & $15: 00$ & 18.07 .96 & \begin{tabular}{|l|}
$14: 35$ \\
\end{tabular} & 13.08 .96 & \begin{tabular}{|l|}
$13: 10$ \\
\end{tabular} & 18.09 .96 & \begin{tabular}{|l|}
$13: 35$ \\
\end{tabular} & 15.10 .96 & \begin{tabular}{|l|}
$4: 05$ \\
\end{tabular} & 12.11 .96 & $14: 55$ & 26.12 .96 & \begin{tabular}{|l|}
$4: 35$ \\
\end{tabular} & 15.01 .97 & \begin{tabular}{|l|}
$14: 10$ \\
\end{tabular} & 18.02 .97 & 11:15 \\
\hline 08 & 15.03 .96 & 12:35 & 10.04 .96 & $15: 15$ & 07.05.96 & 15:40 & 12.06 .96 & \begin{tabular}{|l|}
$15: 35$ \\
\end{tabular} & 18.07 .96 & \begin{tabular}{|l|}
$15: 05$ \\
\end{tabular} & 13.08 .96 & \begin{tabular}{|l|}
$13: 40$ \\
\end{tabular} & 18.09 .96 & \begin{tabular}{|l|}
$14: 05$ \\
\end{tabular} & 15.10.96 & \begin{tabular}{|l|}
$14: 35$ \\
\end{tabular} & 12.11 .96 & \begin{tabular}{|l|}
$15: 40$ \\
\end{tabular} & 26.12 .96 & \begin{tabular}{|l|}
$15: 05$ \\
\end{tabular} & 15.01 .97 & * & 18.02 .97 & \begin{tabular}{|l|}
$10: 40$ \\
\end{tabular} \\
\hline 09 & 15.03 .96 & 13:20 & 10.04 .96 & 16:35 & 07.05.96 & 16:35 & 12.06 .96 & \begin{tabular}{|l|}
$16: 25$ \\
\end{tabular} & 18.07 .96 & \begin{tabular}{|l|}
$16: 15$ \\
\end{tabular} & 13.08 .96 & \begin{tabular}{|l|}
$14: 40$ \\
\end{tabular} & 18.09 .96 & \begin{tabular}{|l|}
$15: 00$ \\
\end{tabular} & 15.10 .96 & \begin{tabular}{|l|}
$15: 45$ \\
\end{tabular} & 12.11 .96 & 17:00 & 26.12 .96 & \begin{tabular}{|l|}
$16: 10$ \\
\end{tabular} & 15.01 .97 & * & 18.02 .97 & \begin{tabular}{|l|}
$09: 40$ \\
\end{tabular} \\
\hline 10 & 15.03 .96 & 12:55 & 10.04 .96 & $16: 00$ & 07.05.96 & \begin{tabular}{|l|}
$16: 05$ \\
\end{tabular} & 12.06 .96 & \begin{tabular}{|l|}
$16: 00$ \\
\end{tabular} & 18.07.96 & \begin{tabular}{|l|}
$15: 40$ \\
\end{tabular} & 13.08 .96 & \begin{tabular}{|l|}
$14: 05$ \\
\end{tabular} & 18.09 .96 & \begin{tabular}{|l|}
$14: 30$ \\
\end{tabular} & 15.10 .96 & 15:15 & 12.11 .96 & \begin{tabular}{|l|}
$16: 15$ \\
\end{tabular} & 26.12 .96 & \begin{tabular}{|l|}
$15: 35$ \\
\end{tabular} & 15.01 .97 & * & 18.02 .97 & \begin{tabular}{|l|}
$10: 10$ \\
\end{tabular} \\
\hline
\end{tabular}

* = chuvas intermitentes (não houve possibilidade de coletar) 

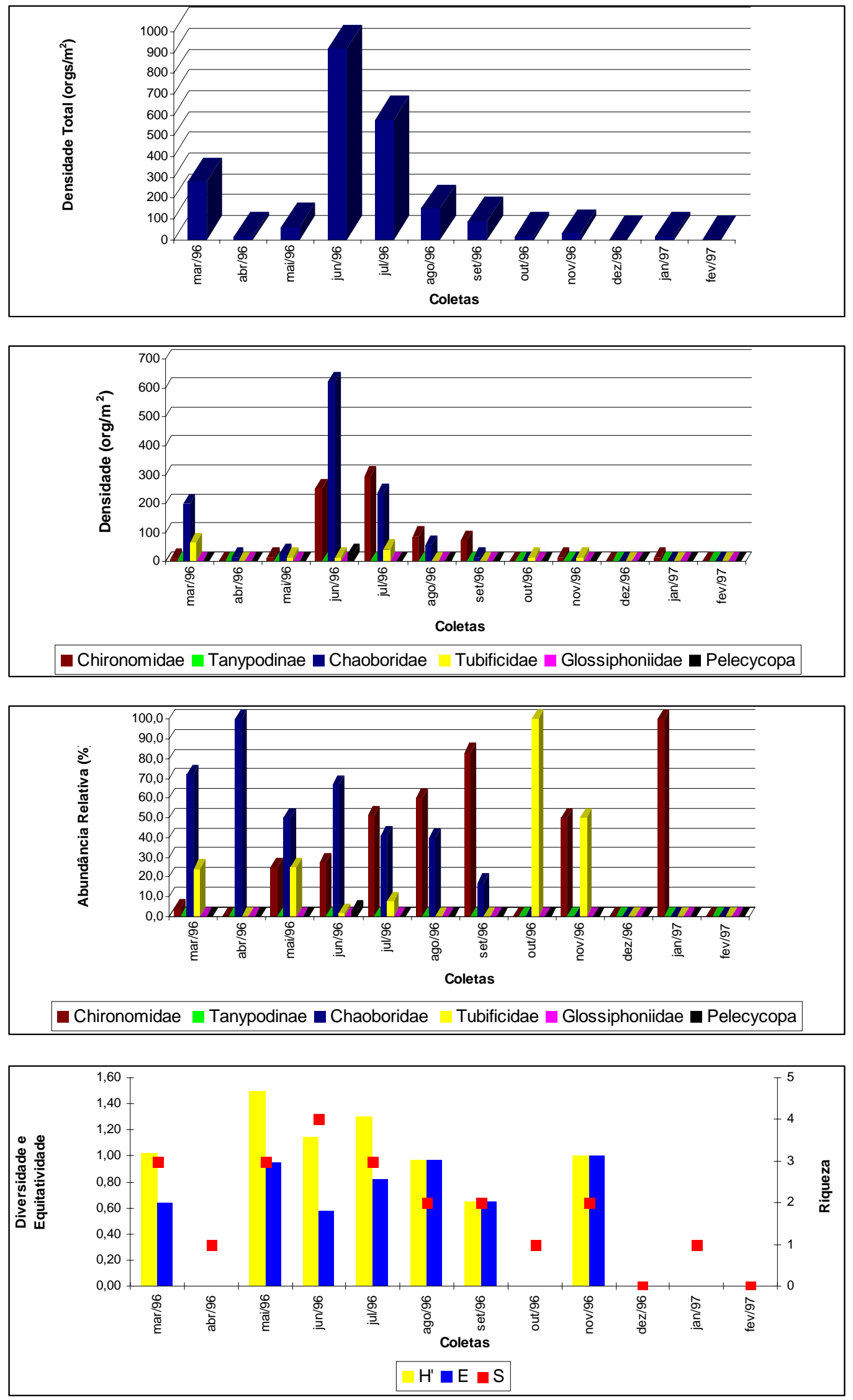

Figura 01: Ponto 01 - Distribuição temporal dos índices da estrutura da comunidade de Macroinvertebrados Bentônicos na Represa do Guarapiranga - SP - 1996/1997 

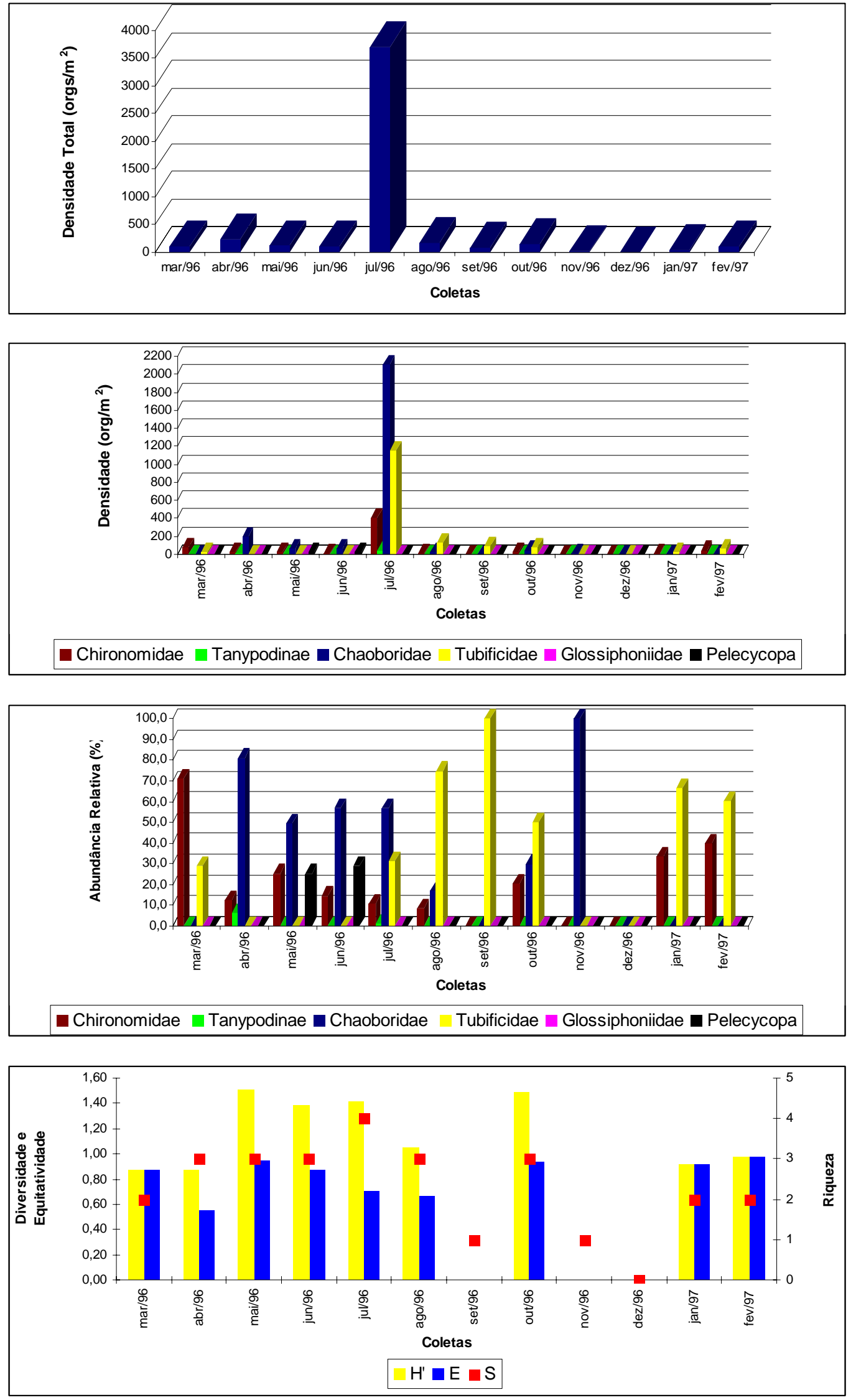

Figura 02: Ponto 02 - Distribuição temporal dos índices da estrutura da comunidade de Macroinvertebrados Bentônicos na Represa do Guarapiranga - SP - 1996/1997 

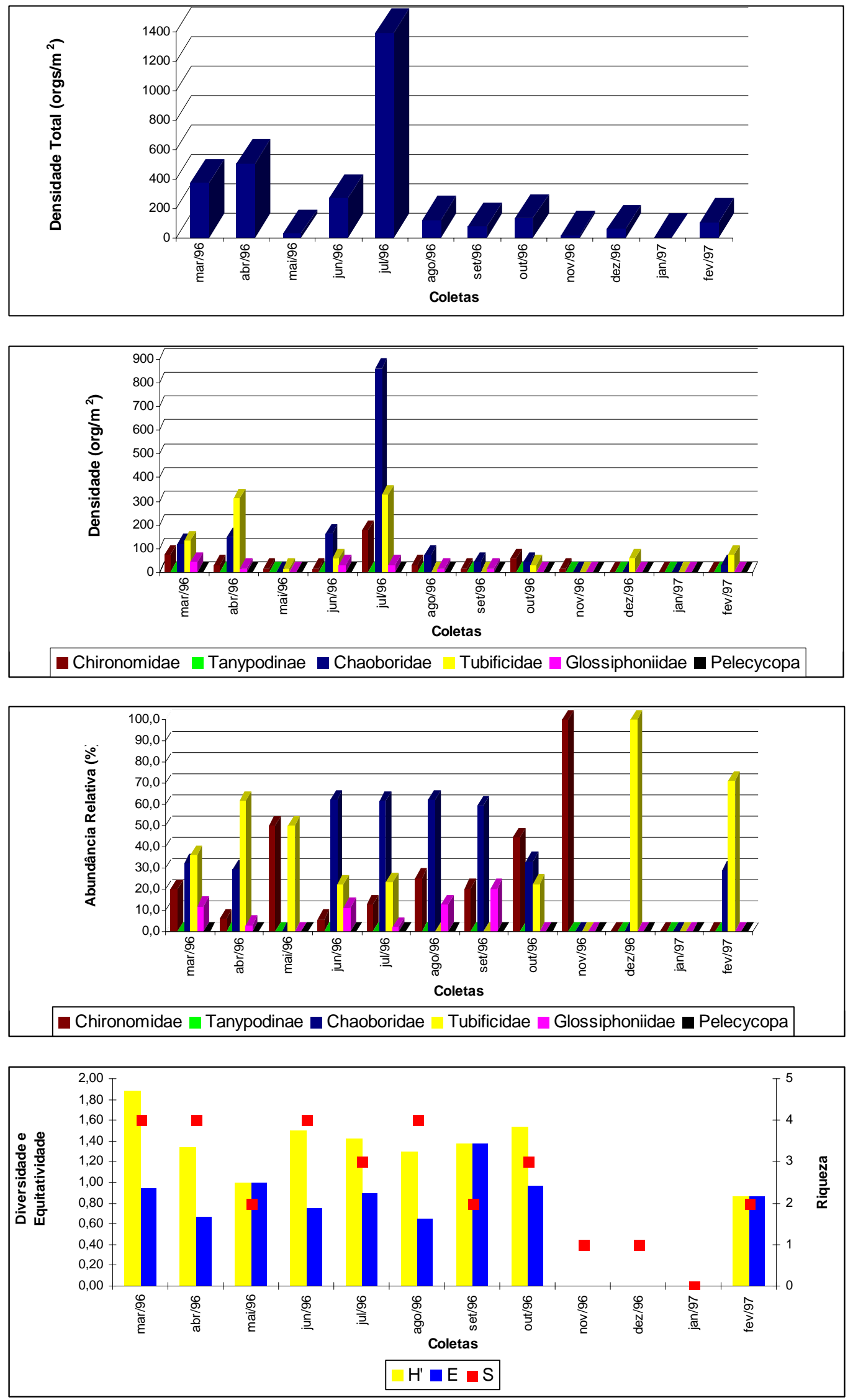

Figura 03: Ponto 03 - Distribuição temporal dos índices da estrutura da comunidade de Macroinvertebrados Bentônicos na Represa do Guarapiranga - SP - 1996/1997 

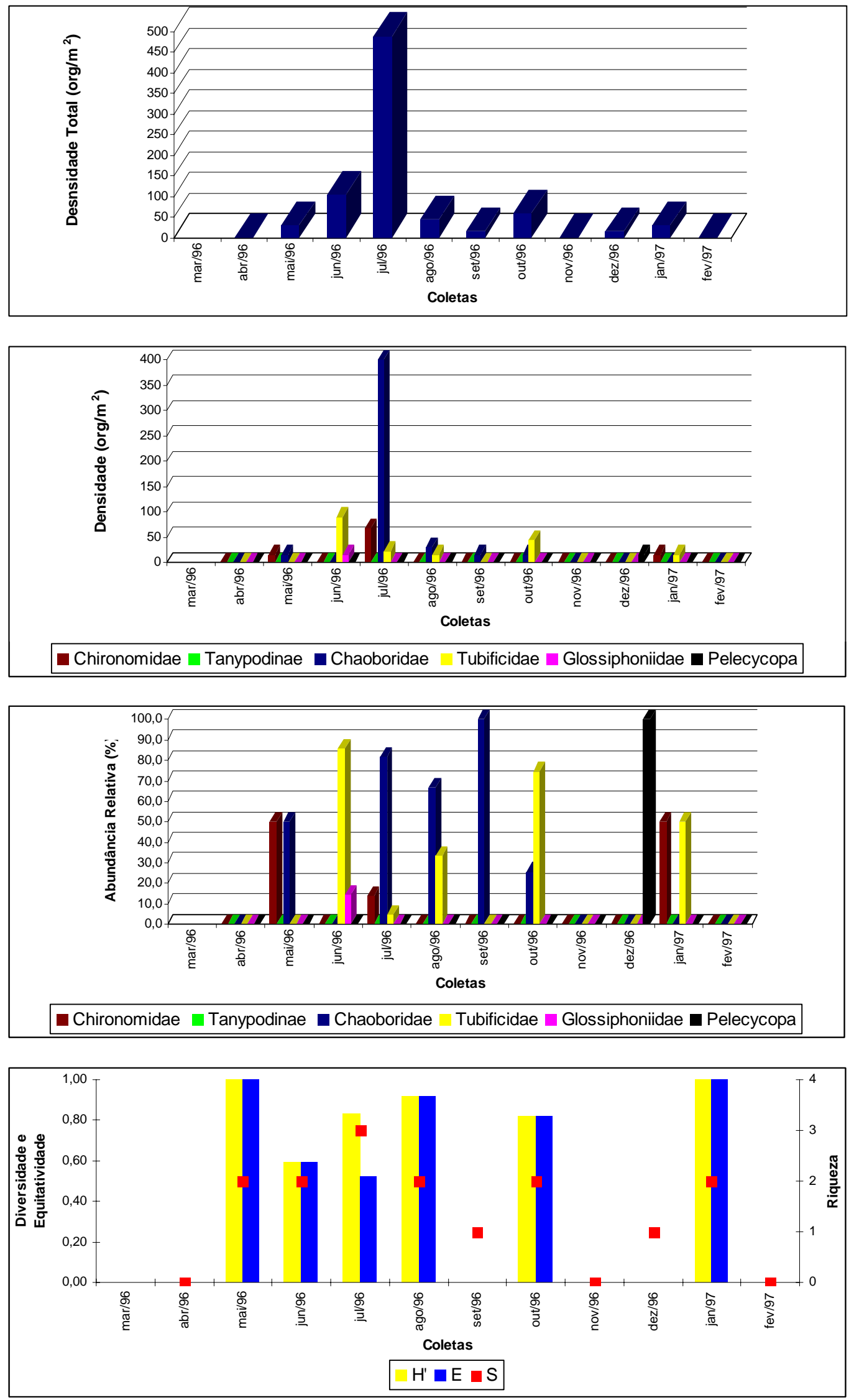

Figura 04: Ponto 04 - Distribuição temporal os índices da estrutura da comunidade de Macroinvertebrados Bentônicos na Represa do Guarapiranga - SP - 1996/1997 

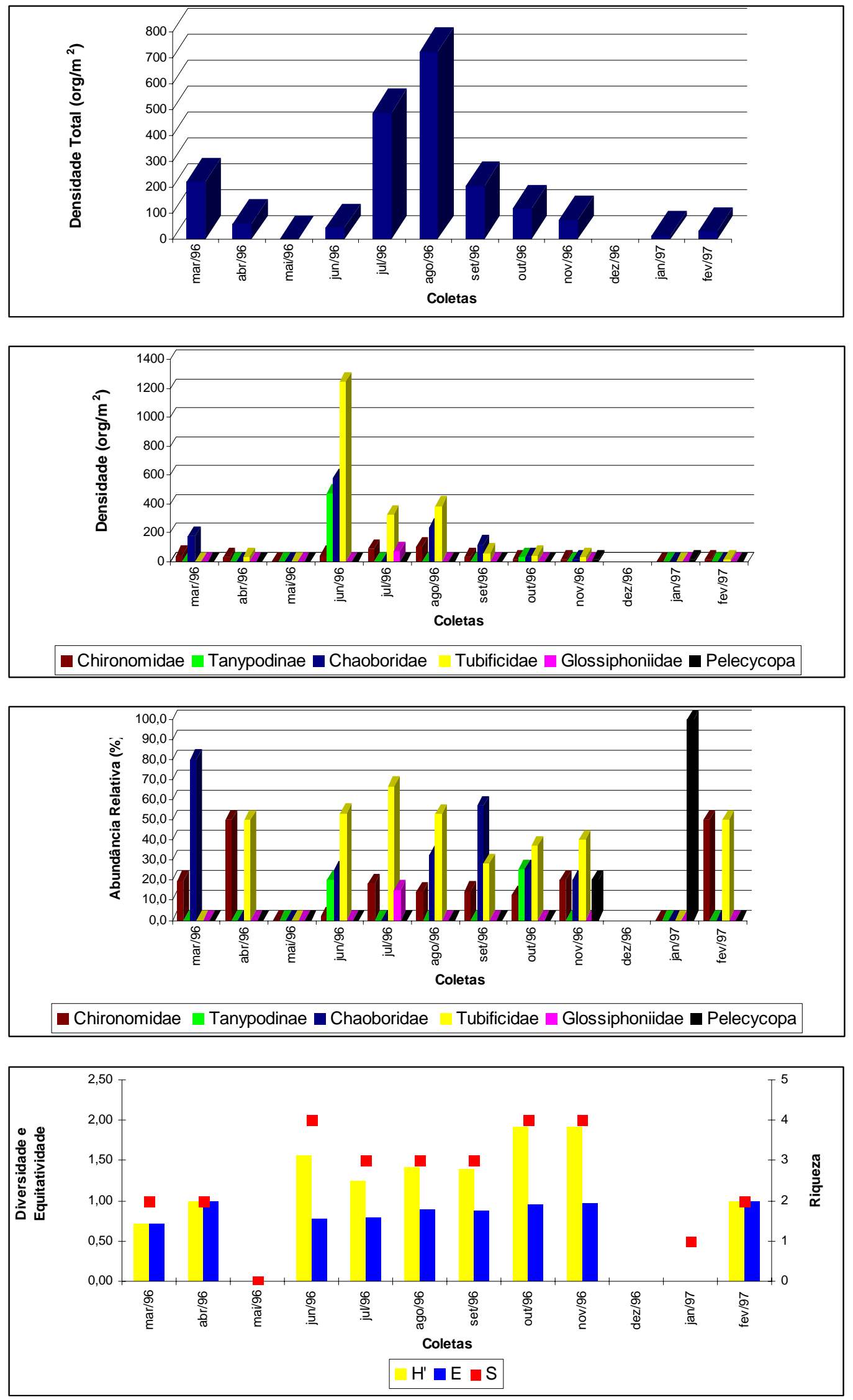

Figura 05: Ponto 05 - Distribuição temporal dos índices da estrutura da comunidade de Macroinvertebrados Bentônicos na Represa do Guarapiranga - SP - 1996/1997 

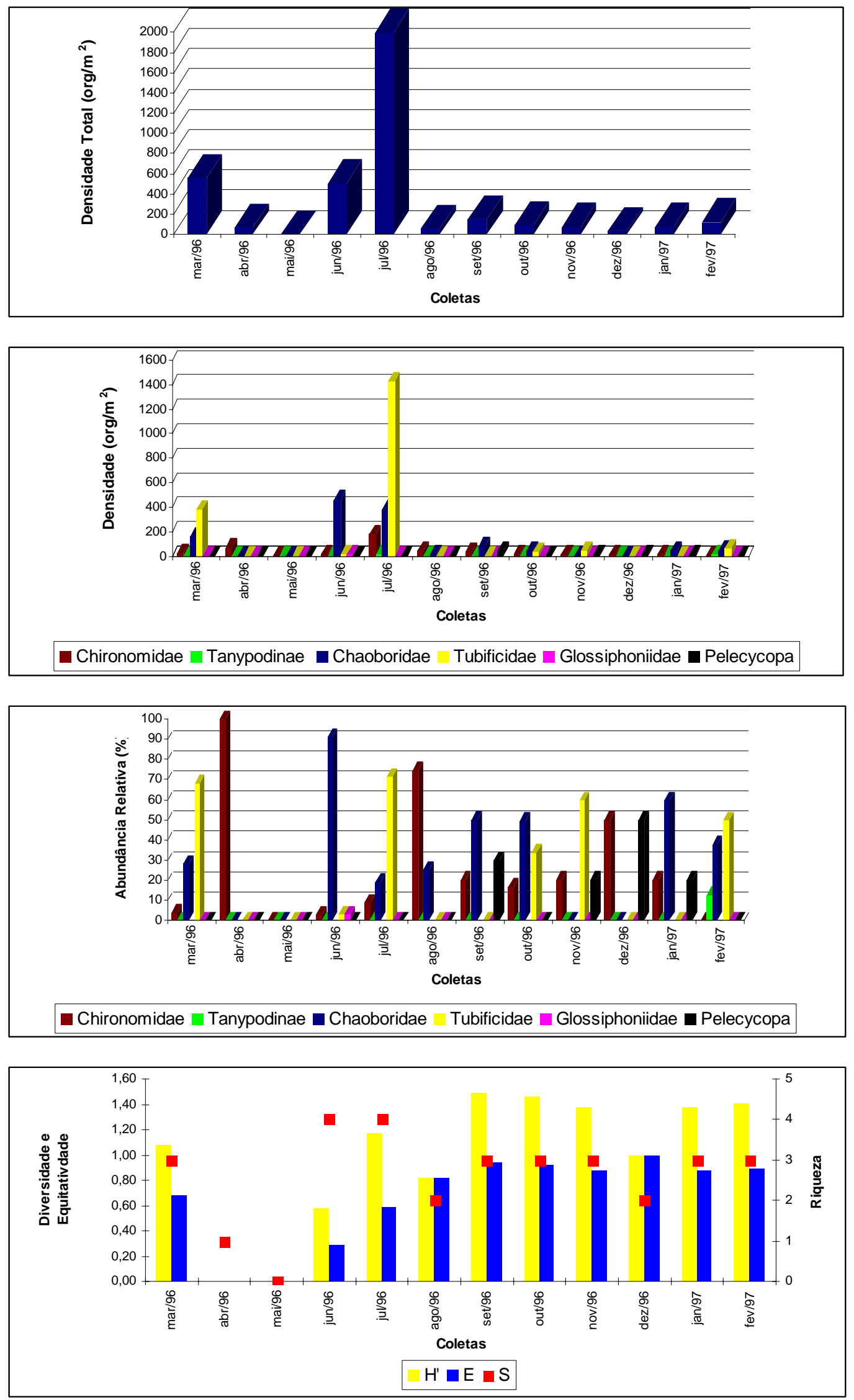

Figura 06: Ponto 06 - Distribuição temporal dos índices da estrutura da comunidade de Macroinvertebrados Bentônicos na Represa do Guarapiranga - SP - 1996/1997 

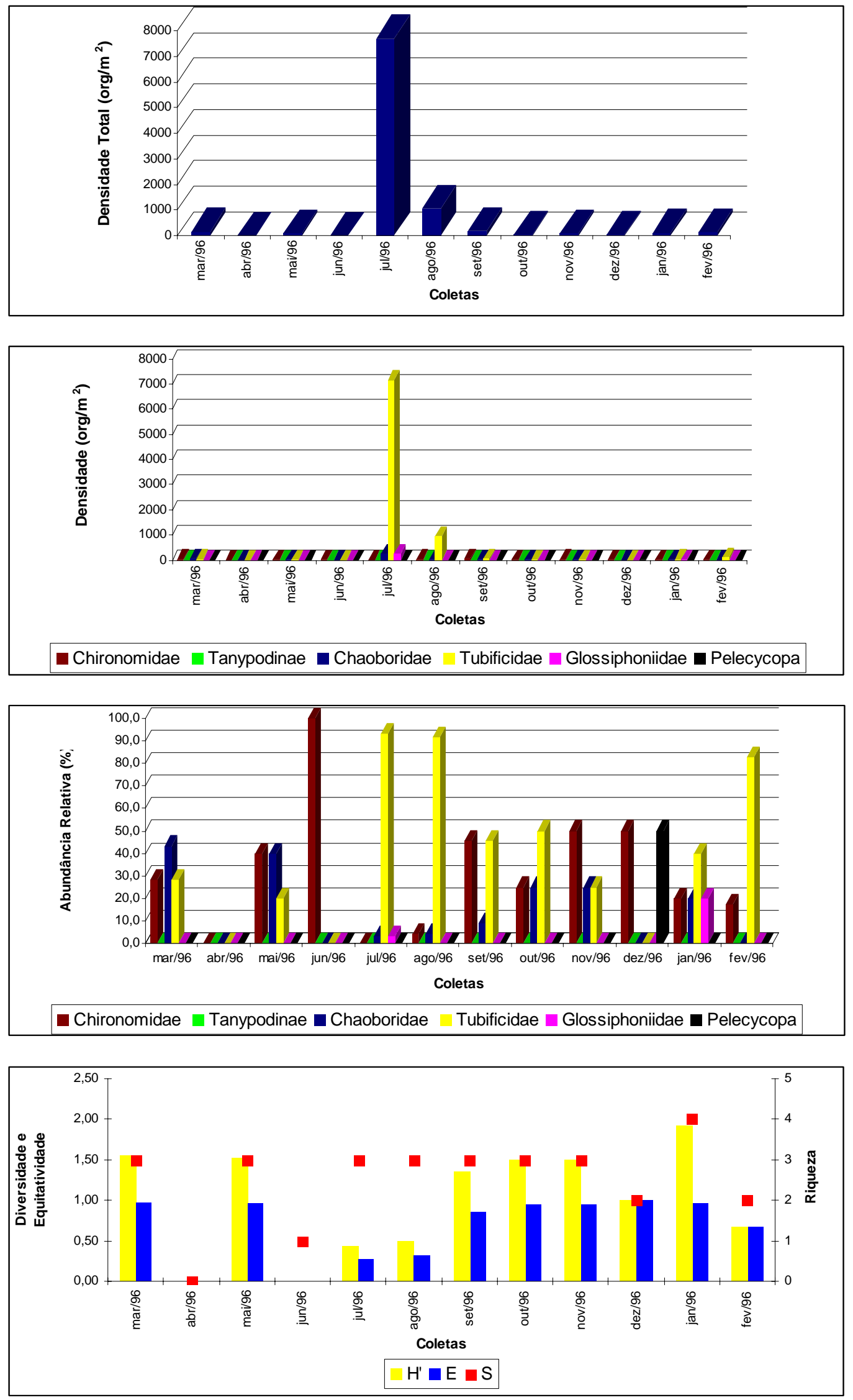

Figura 07: Ponto 07 - Distribuição temporal dos índices da estrutura da comunidade de Macroinvertebrados Bentônicos na Represa do Guarapiranga - SP - 1996/1997 

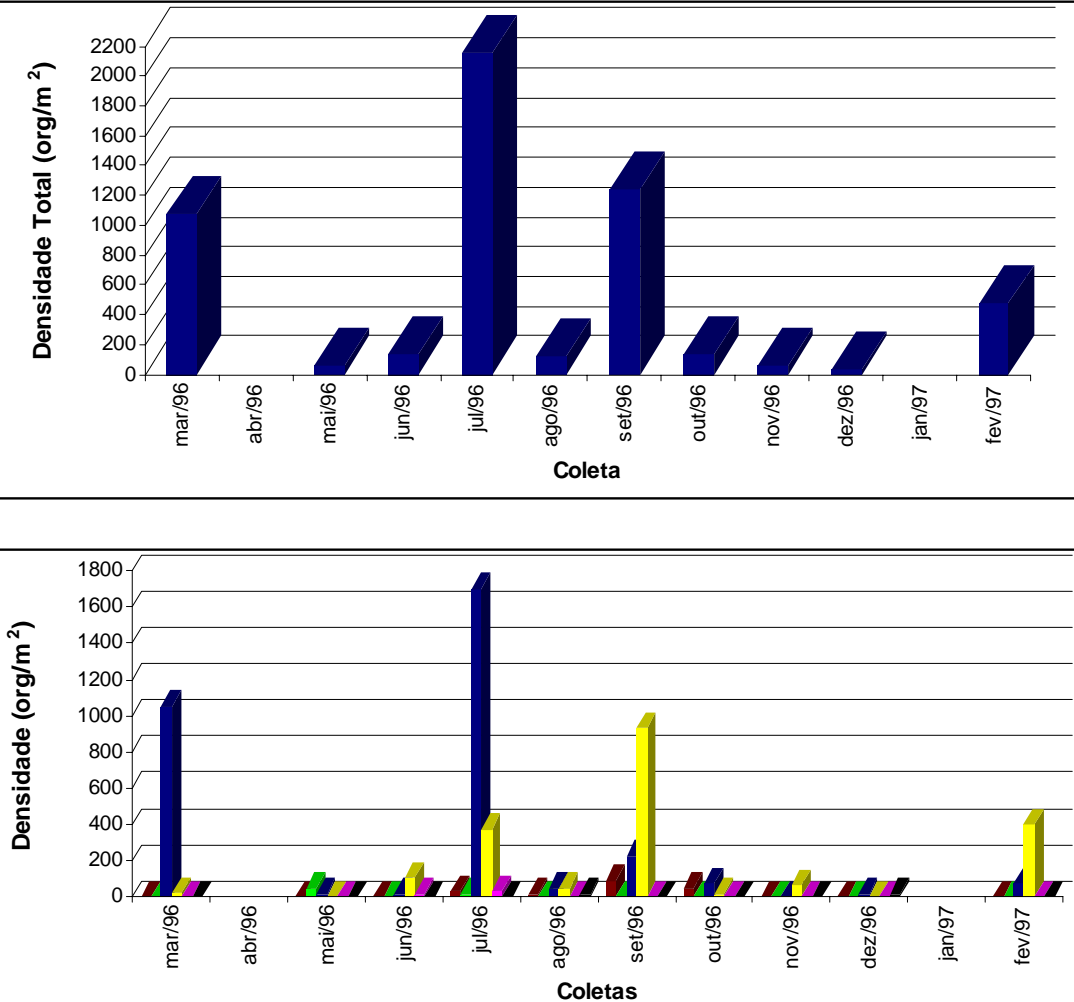

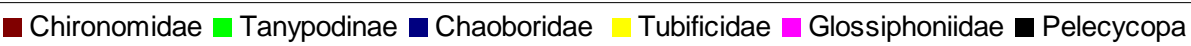
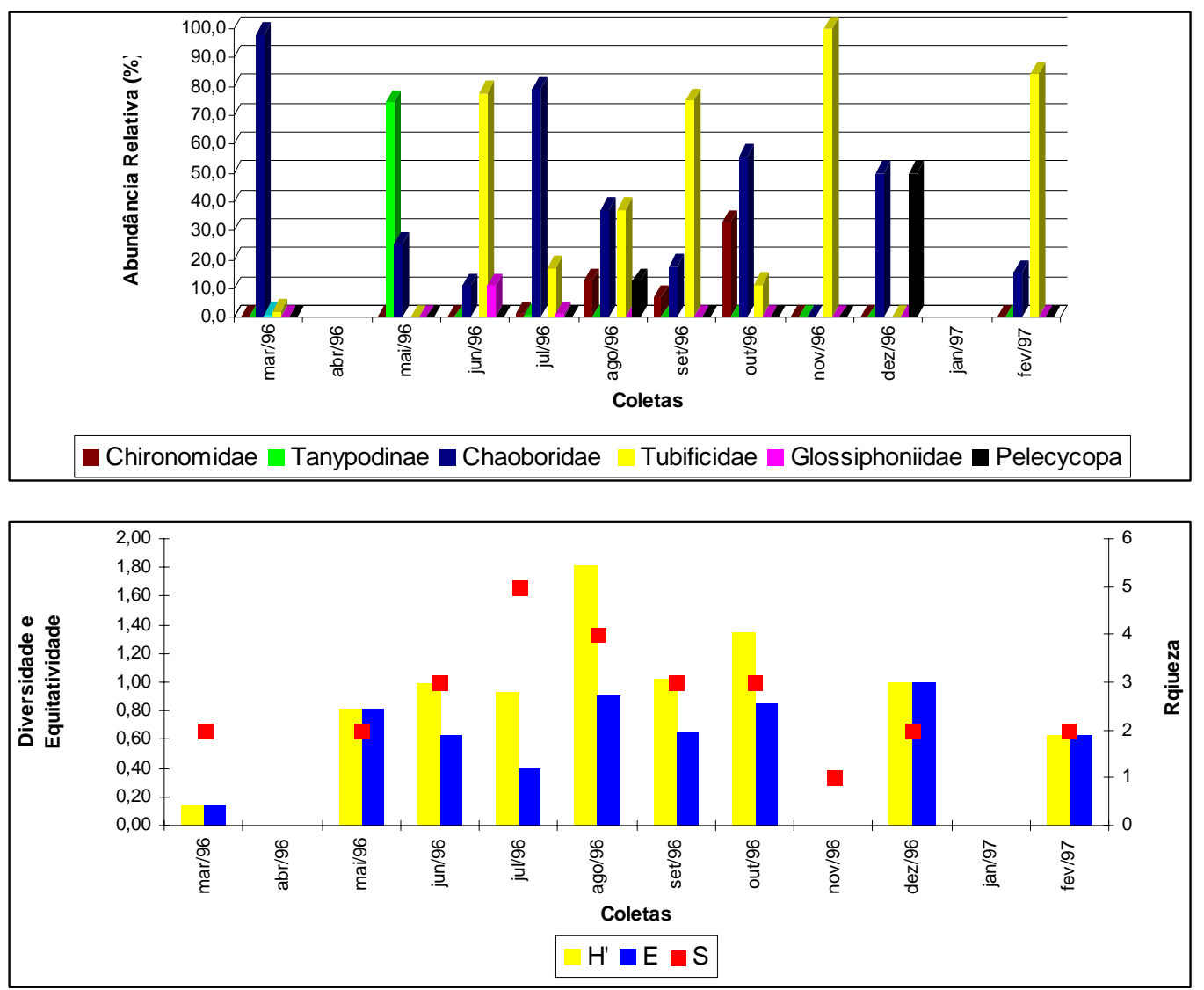

Figura 08: Ponto 08 - Distribuição temporal dos índices da estrutura da comunidade de Macroinvertebrados Bentônicos na Represa do Guarapiranga - SP - 1996/1997 

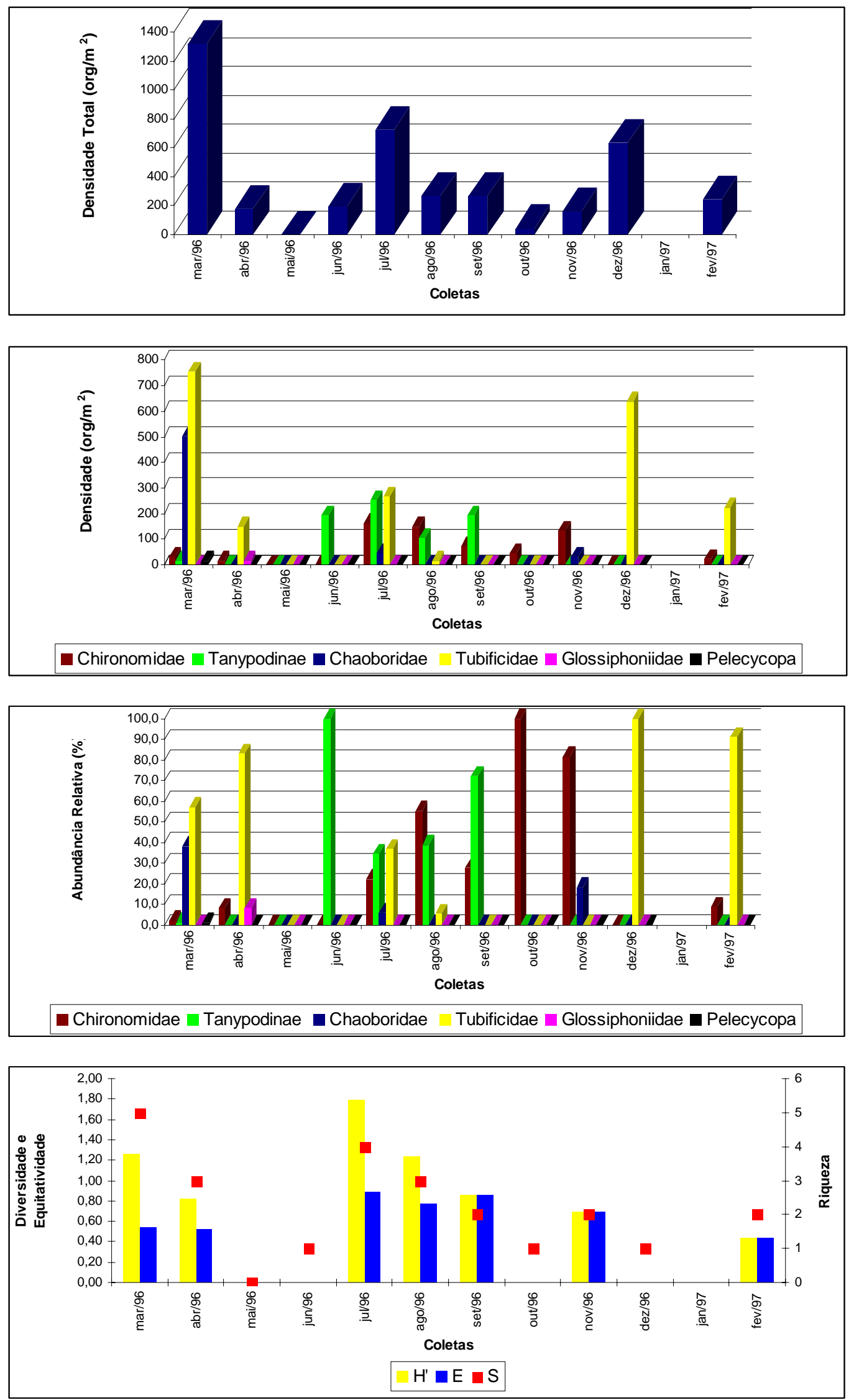

Figura 09: Ponto 09 - Distribuição temporal dos Índices da estrutura da comunidade de Macroinvertebrados Bentônicos na Represa do Guarapiranga - SP - 1996/1997 

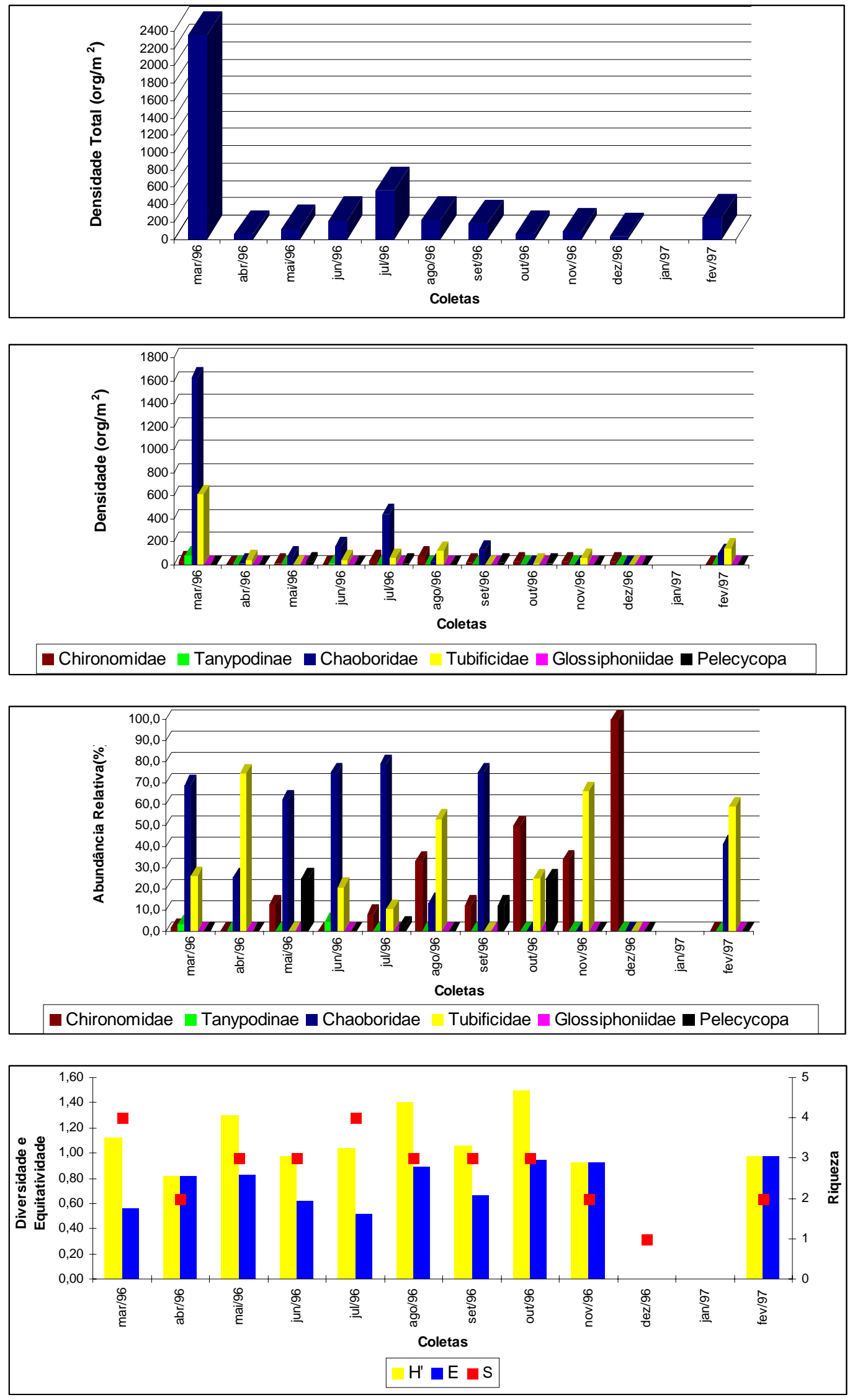

Figura 10: Ponto 10 - Distribuição temporal dos índices da estrutura da comunidade de Macroinvertebrados Bentônicos na Represa do Guarapiranga - SP - 1996/1997 

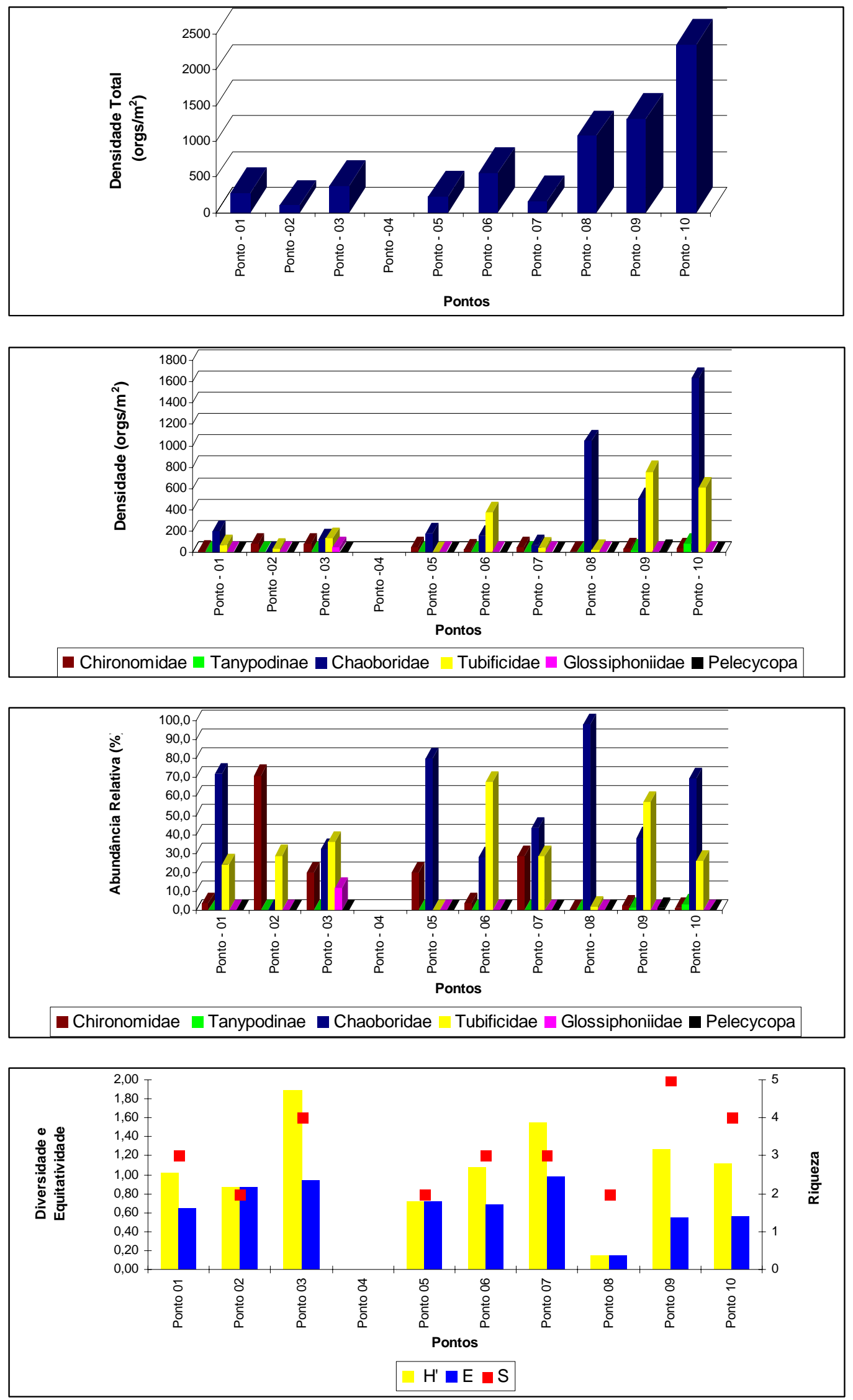

Figura 11: Março/96 - Distribuição espacial dos índices da estrutura da comunidade de Macroinvertebrados Bentônicos na Represa do Guarapiranga - SP 

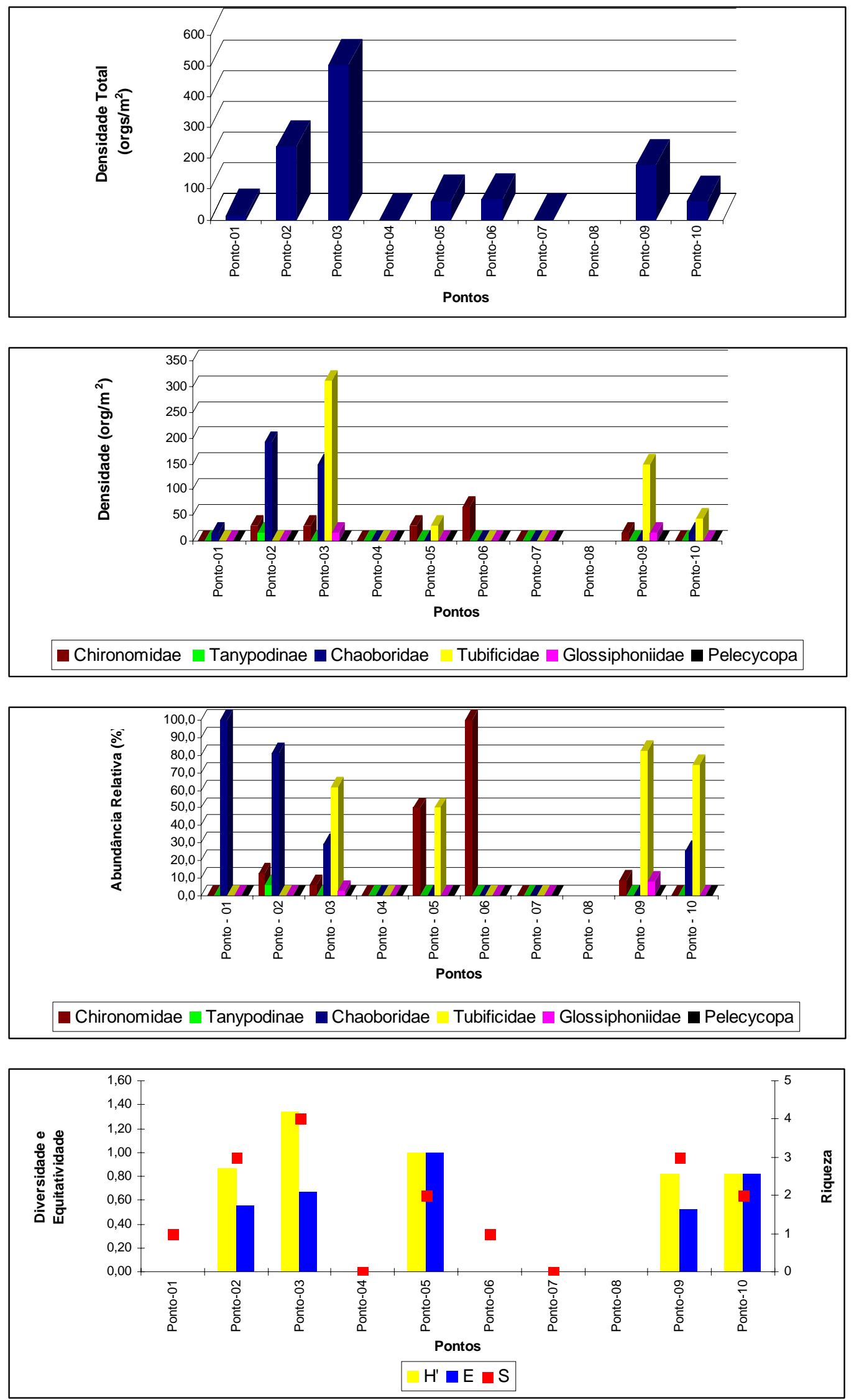

Figura 12: Abril/96 - Distribuição espacial dos índices da estrutura da comunidade de Macroinvertebrados Bentônicos na Represa do Guarapiranga - SP 

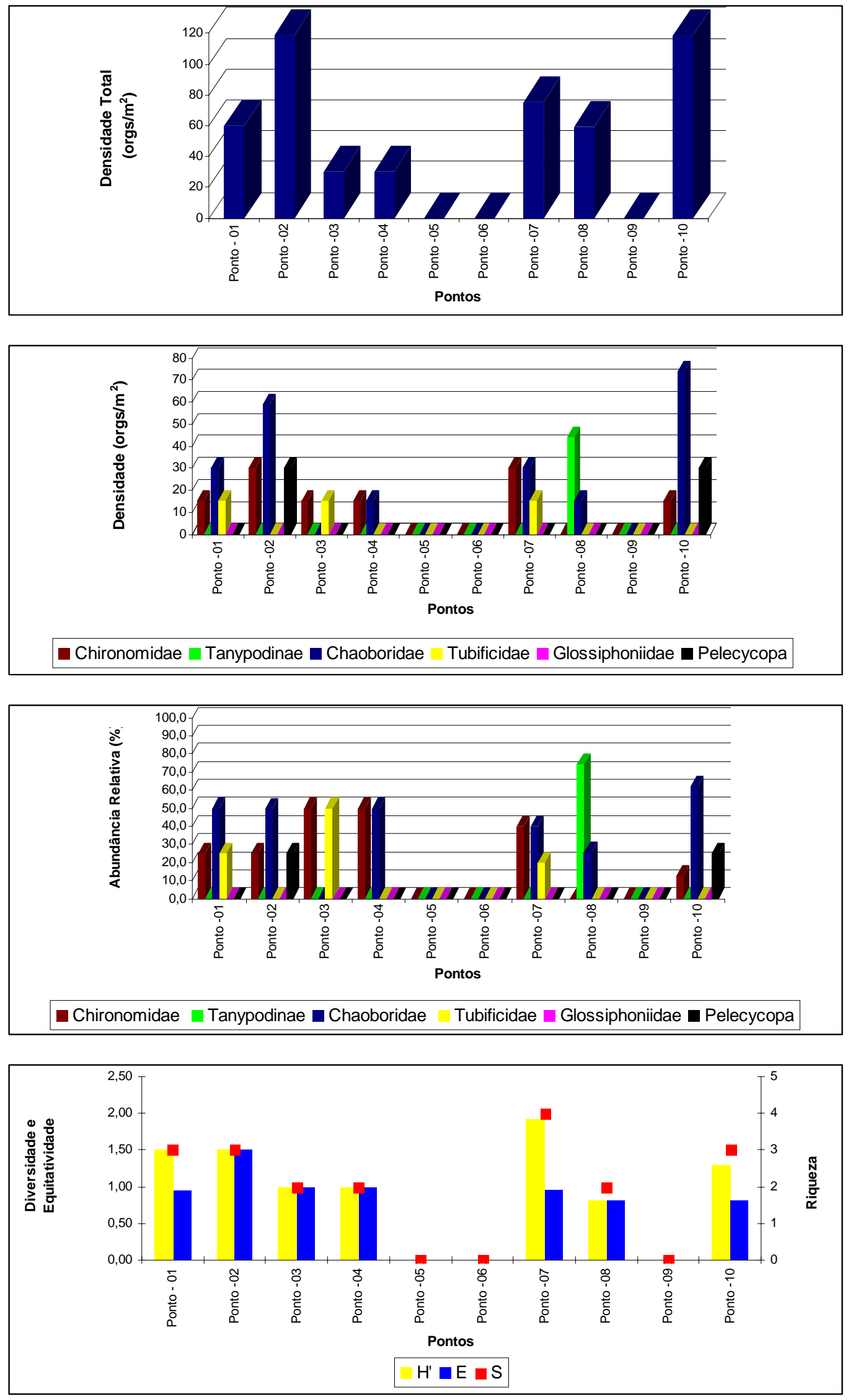

Figura 13: Maio/96 - Distribuição espacial dos índices da estrutura da comunidade de Macroinvertebrados Bentônicos na Represa do Guarapiranga - SP 

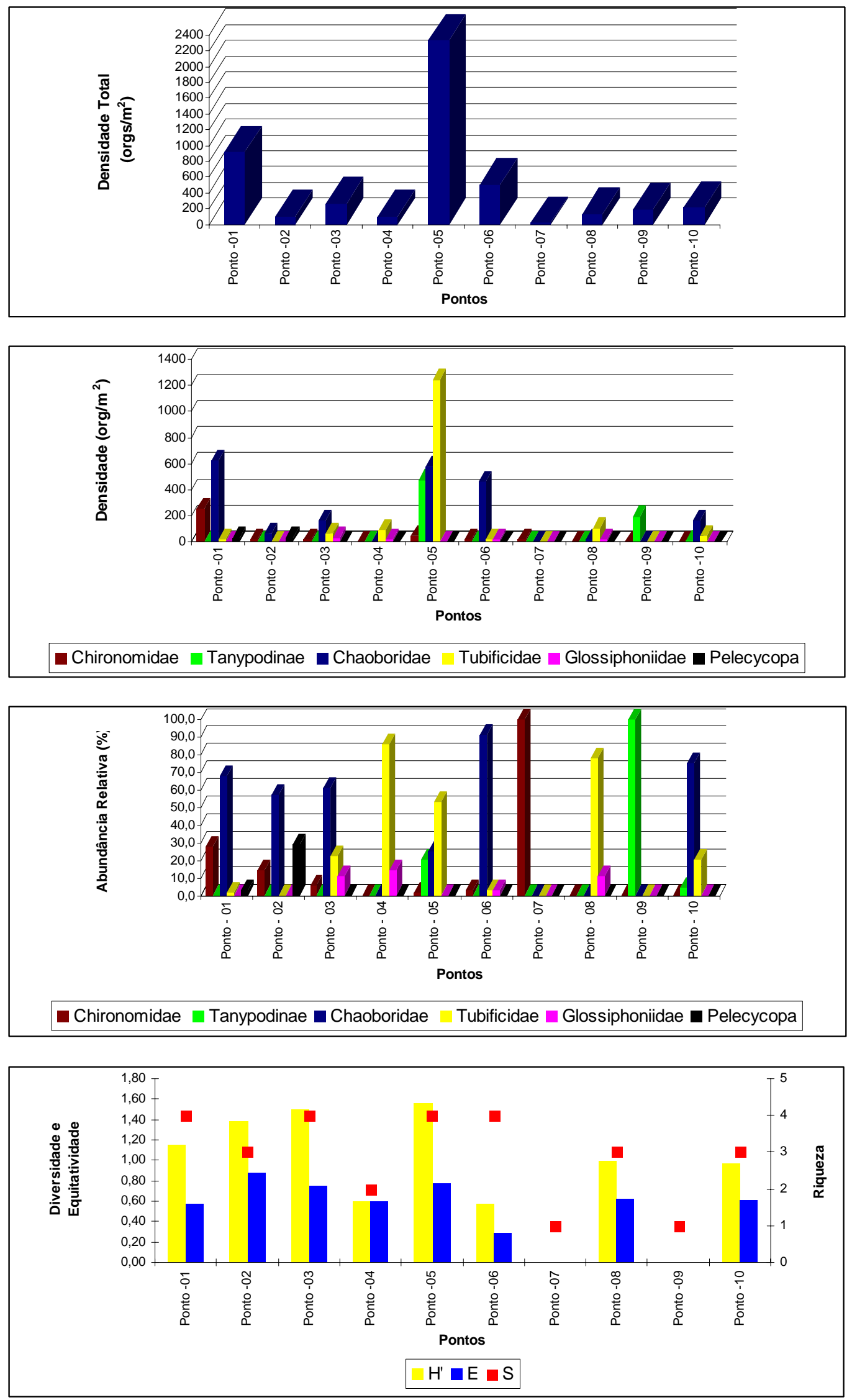

Figura 14: Junho/96 - Distribuição espacial dos índices da estrutura da comunidade de Macroinvertebrados Bentônicos na Represa do Guarapiranga - SP 

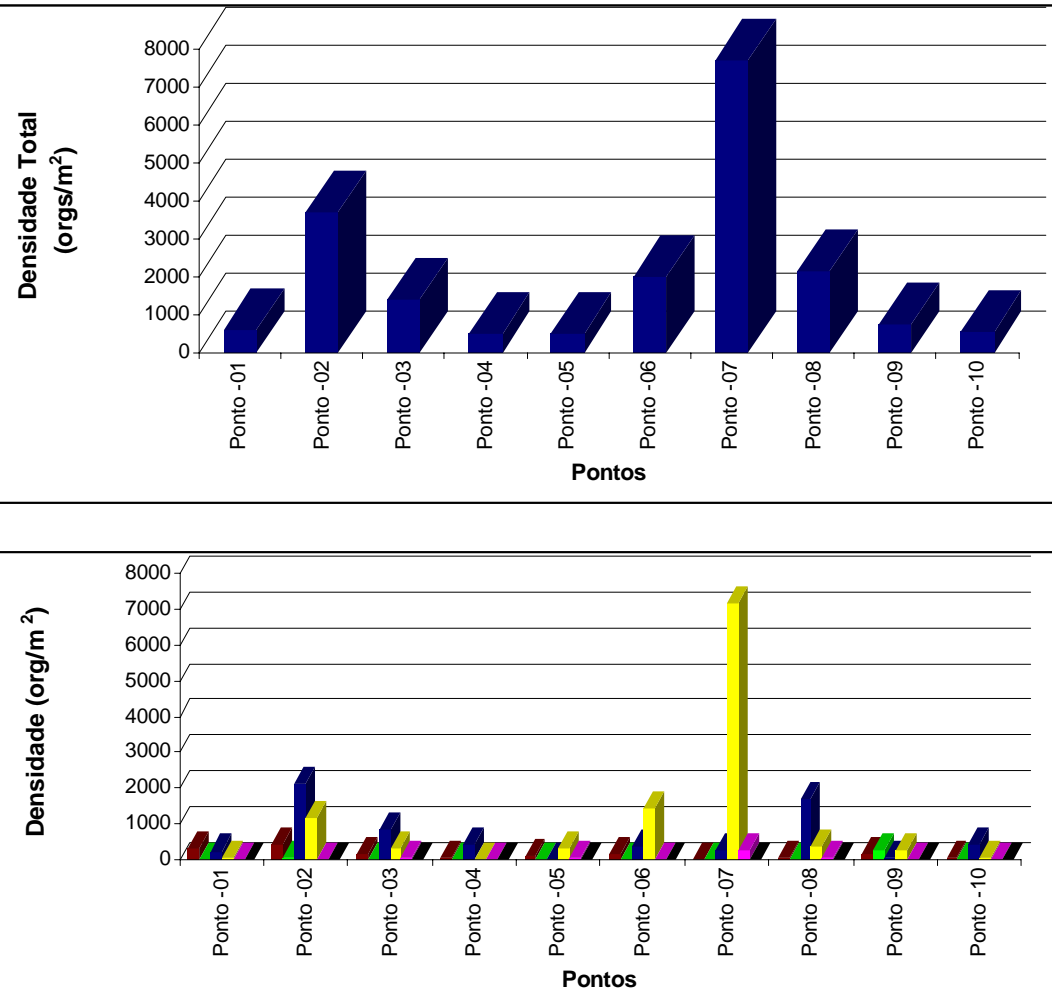

口Chironomidae $\square$ Tanypodinae $\square$ Chaoboridae Tubificidae $\square$ Glossiphoniidae $\square$ Pelecycopa
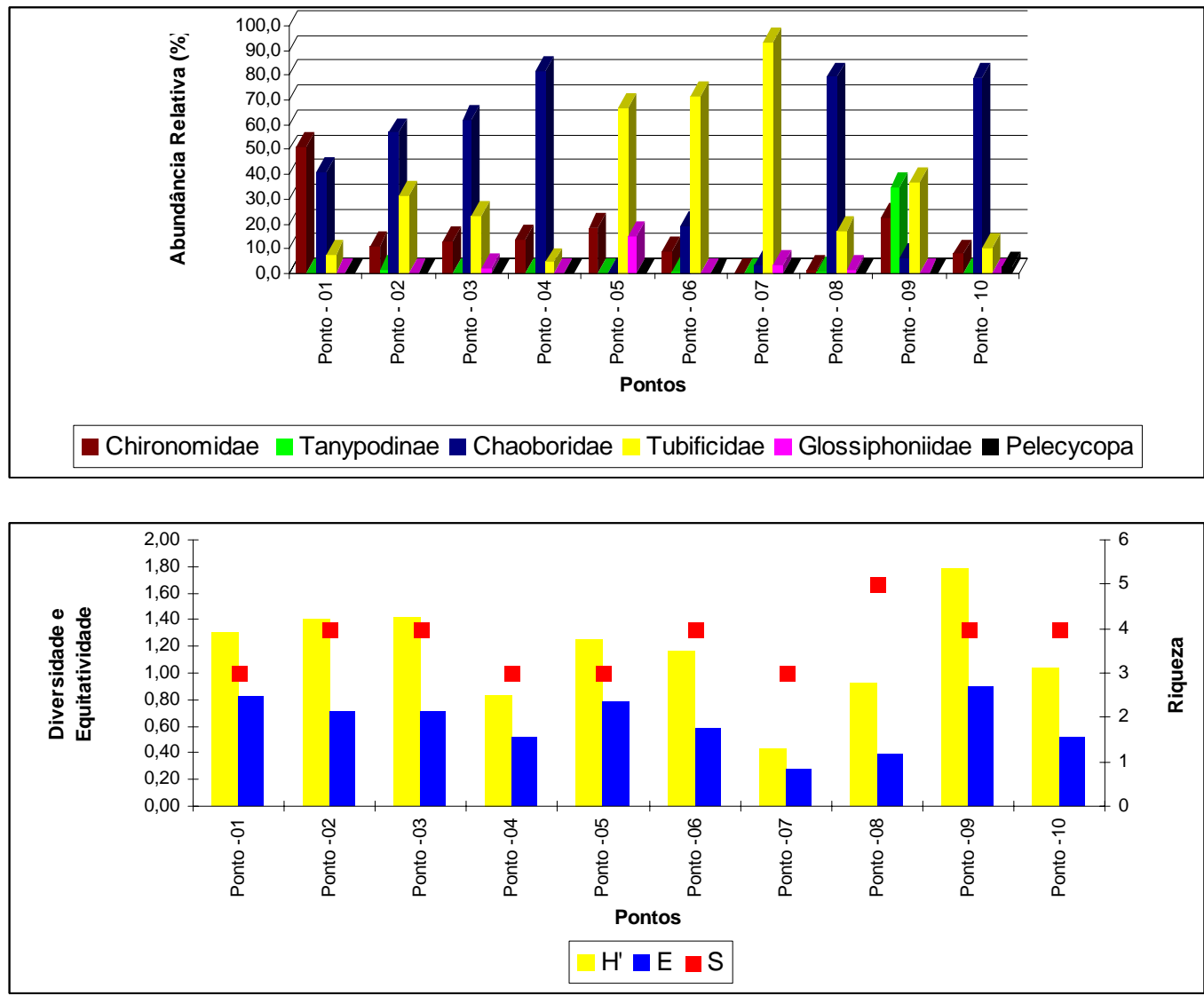

Figura 15: Julho/96 - Distribuição espacial dos índices da estrutura da comunidade de Macroinvertebrados Bentônicos na Represa do Guarapiranga - SP 

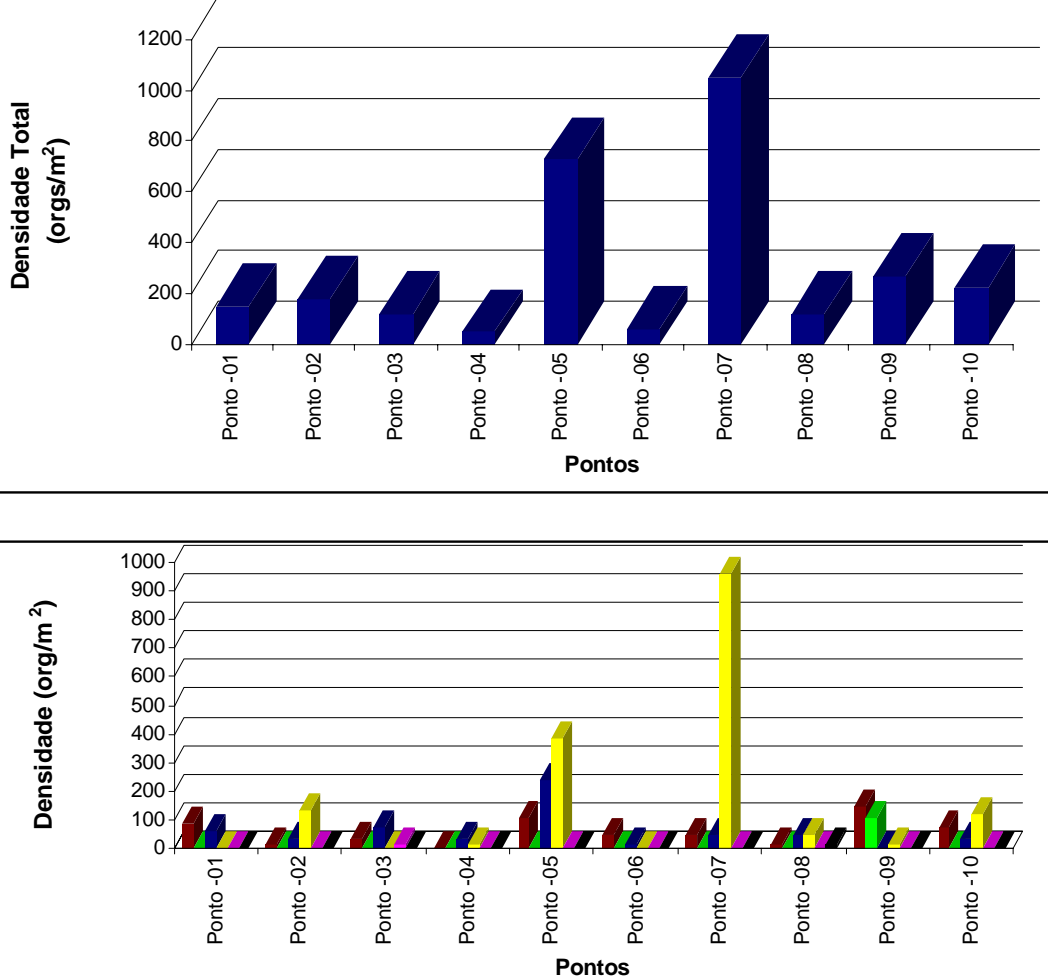

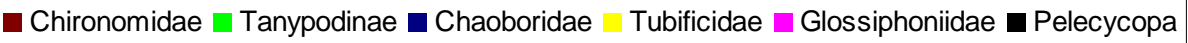

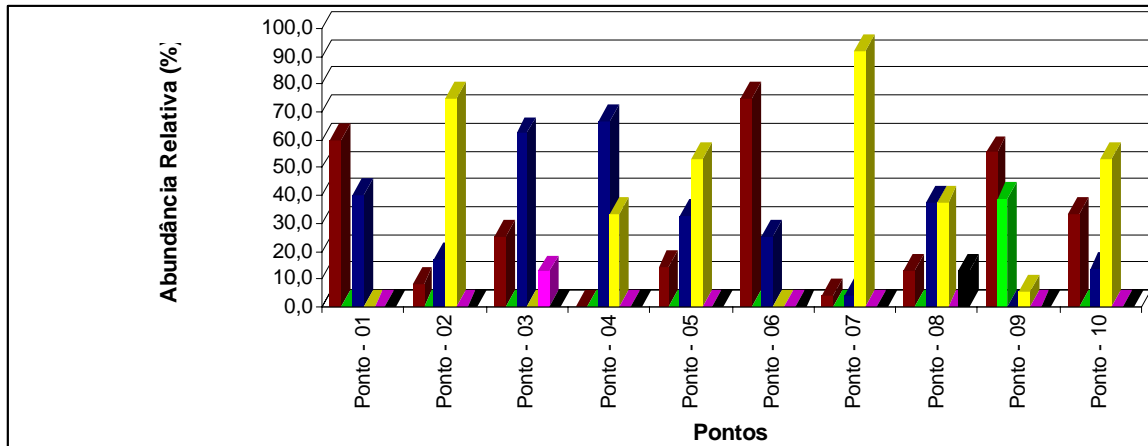

Chironomidae $\square$ Tanypodinae $\square$ Chaoboridae Tubificidae $\square$ Glossiphoniidae $\square$ Pelecycopa

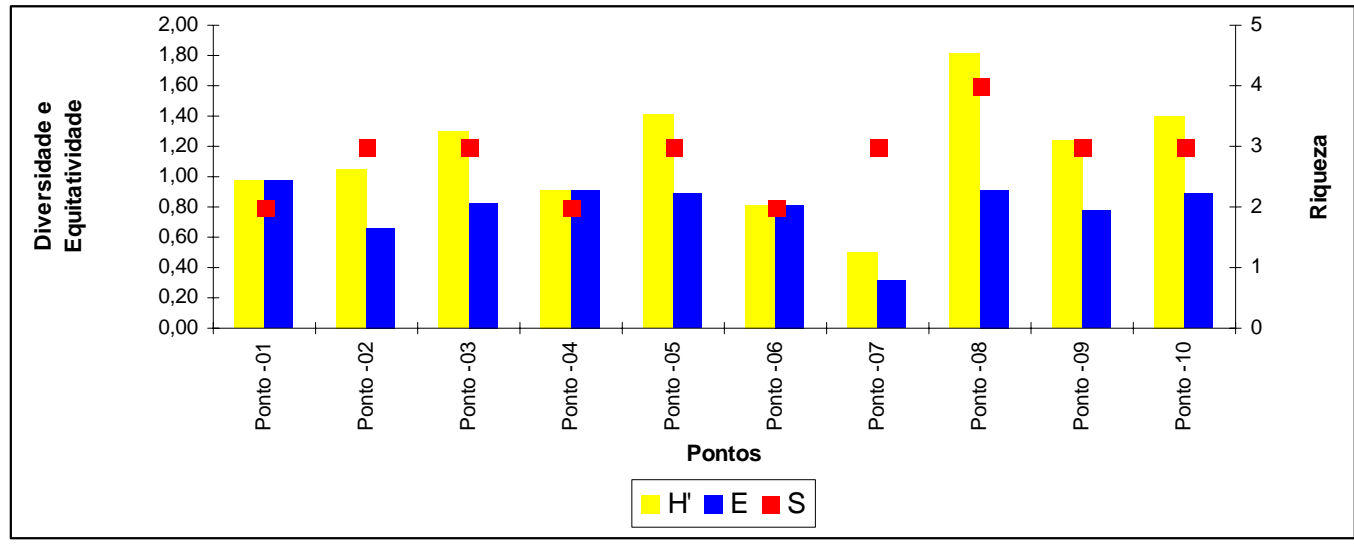

Figura 16: Agosto/96 - Distribuição espacial dos índices da estrutura da comunidade de Macroinvertebrados Bentônicos na Represa do Guarapiranga - SP 

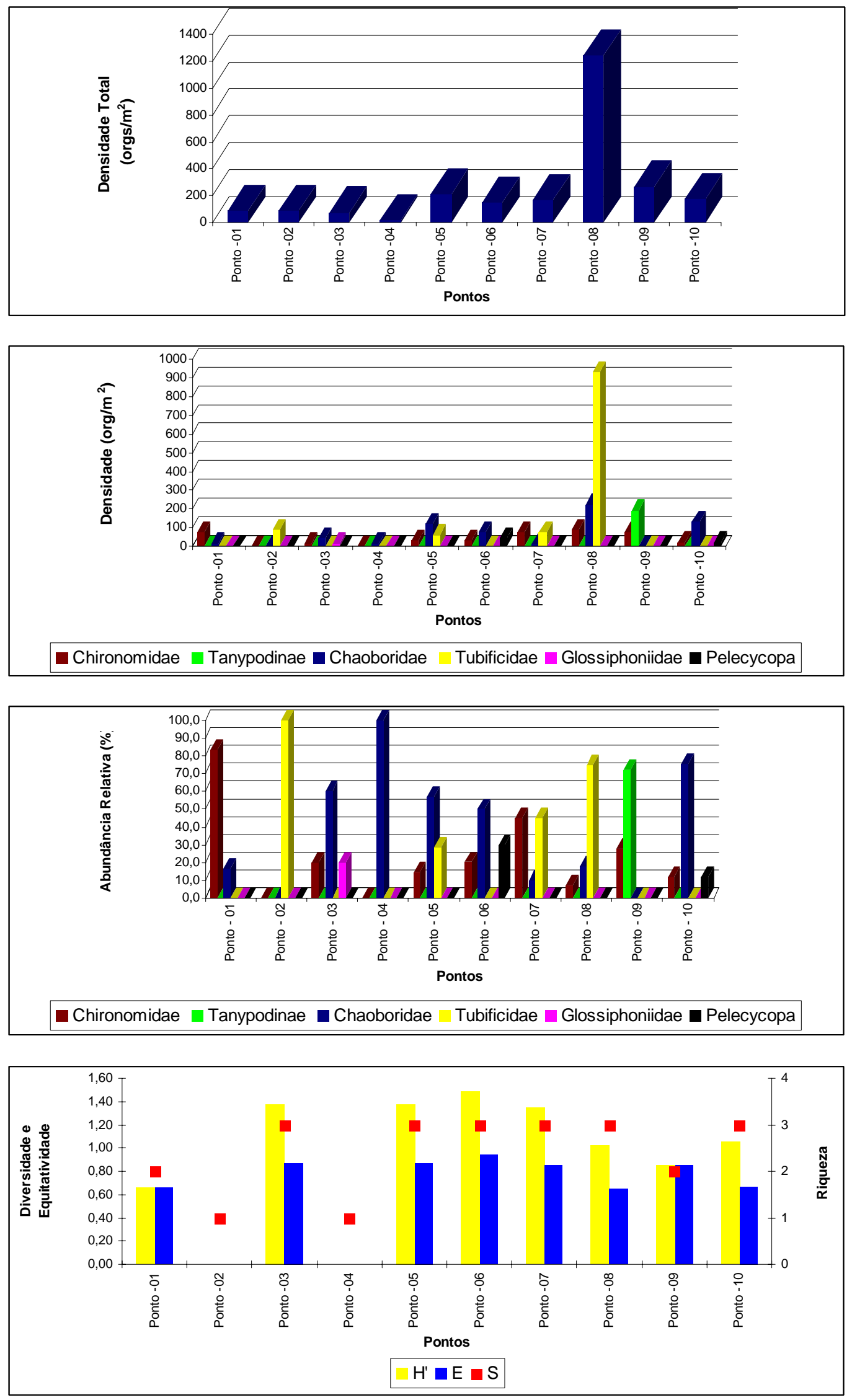

Figura 17: Setembro/96 - Distribuição espacial dos índices da estrutura da comunidade de Macroinvertebrados Bentônicos na Represa do Guarapiranga - SP 

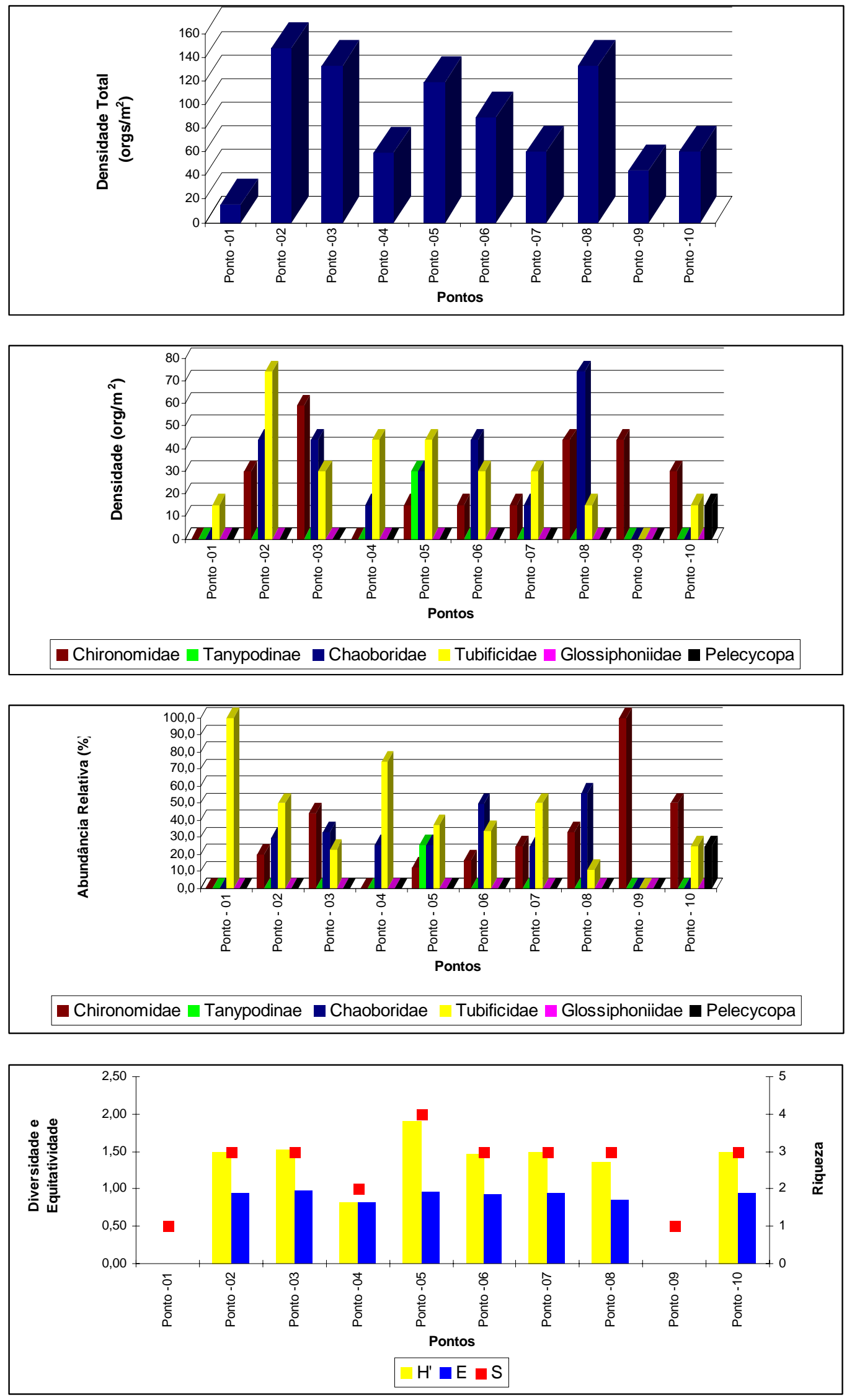

Figura 18: Outubro/96 - Distribuição espacial dos índices da estrutura da comunidade de Macroinvertebrados Bentônicos na Represa do Guarapiranga - SP 

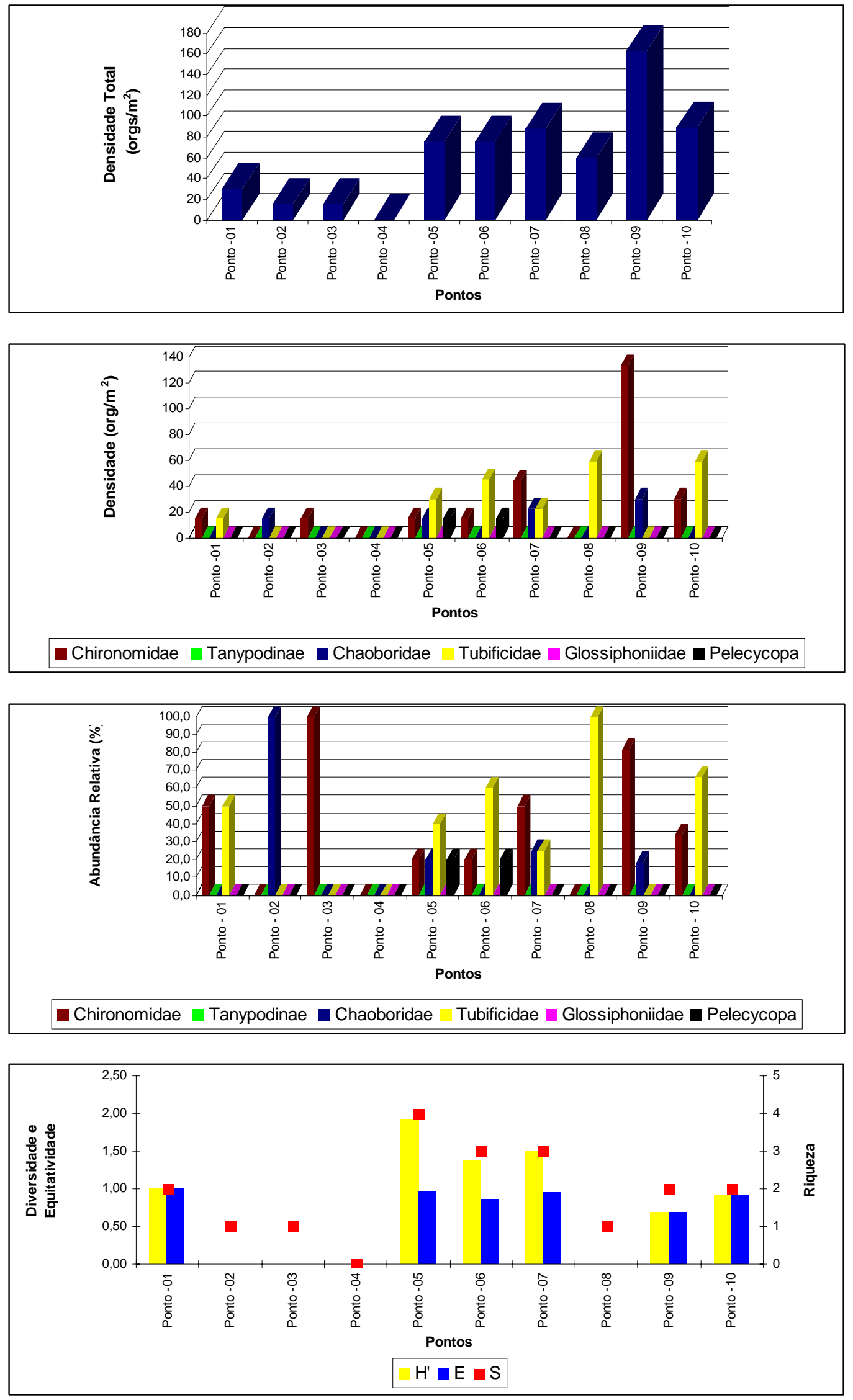

Figura 19: Novembro/96 - Distribuição espacial dos índices da estrutura da comunidade de Macroinvertebrados Bentônicos na Represa do Guarapiranga - SP 

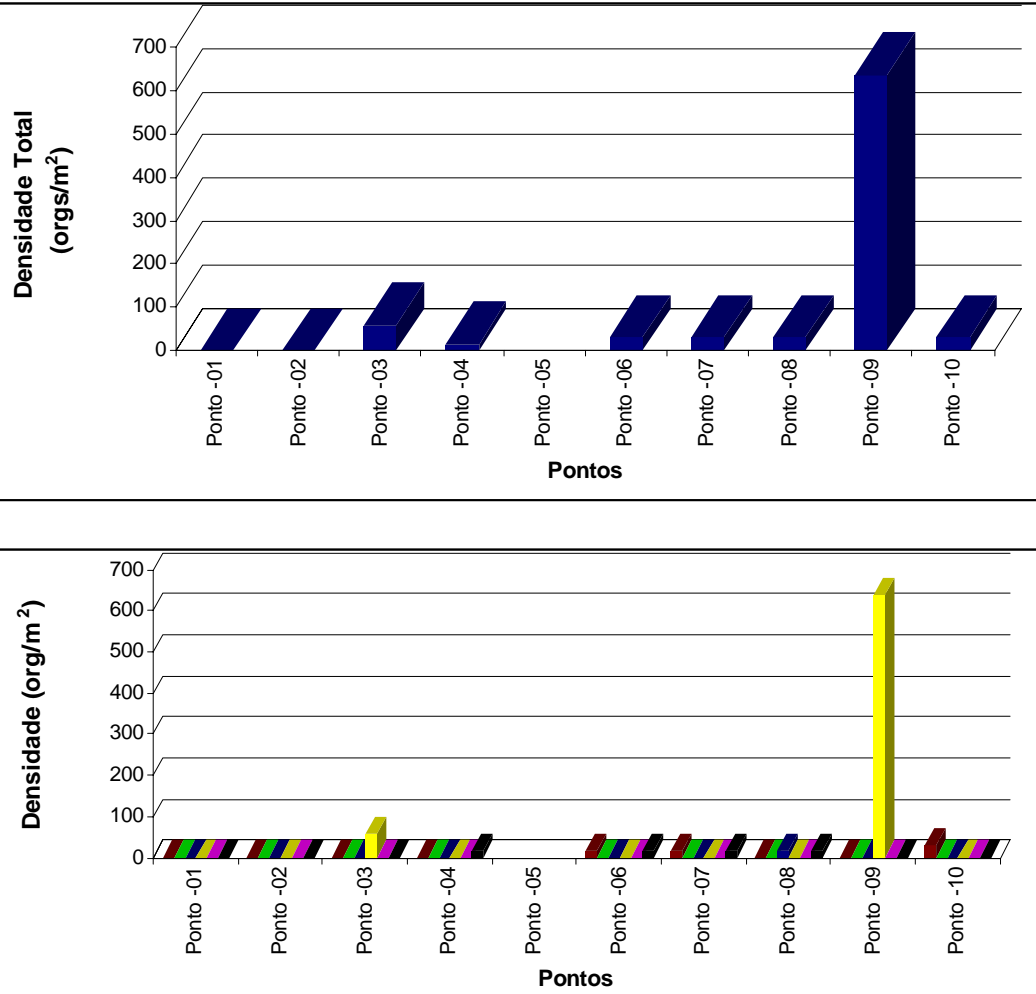

—Chironomidae $\square$ Tanypodinae $\square$ Chaoboridae Tubificidae $\square$ Glossiphoniidae $\square$ Pelecycopa
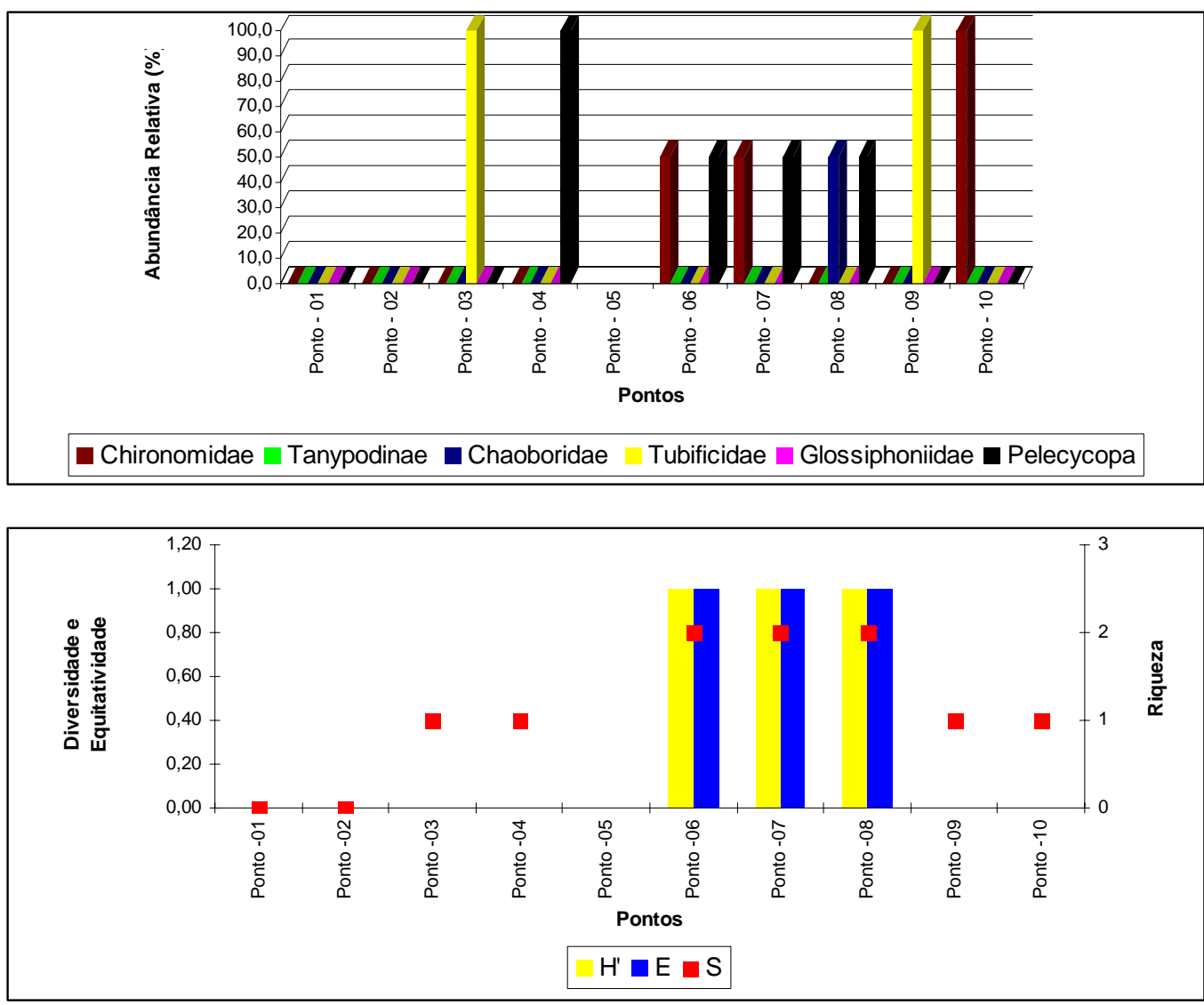

Figura 20: Dezembro/96 - Distribuição espacial dos índices da estrutura da comunidade de Macroinvertebrados Bentônicos na Represa do Guarapiranga - SP 

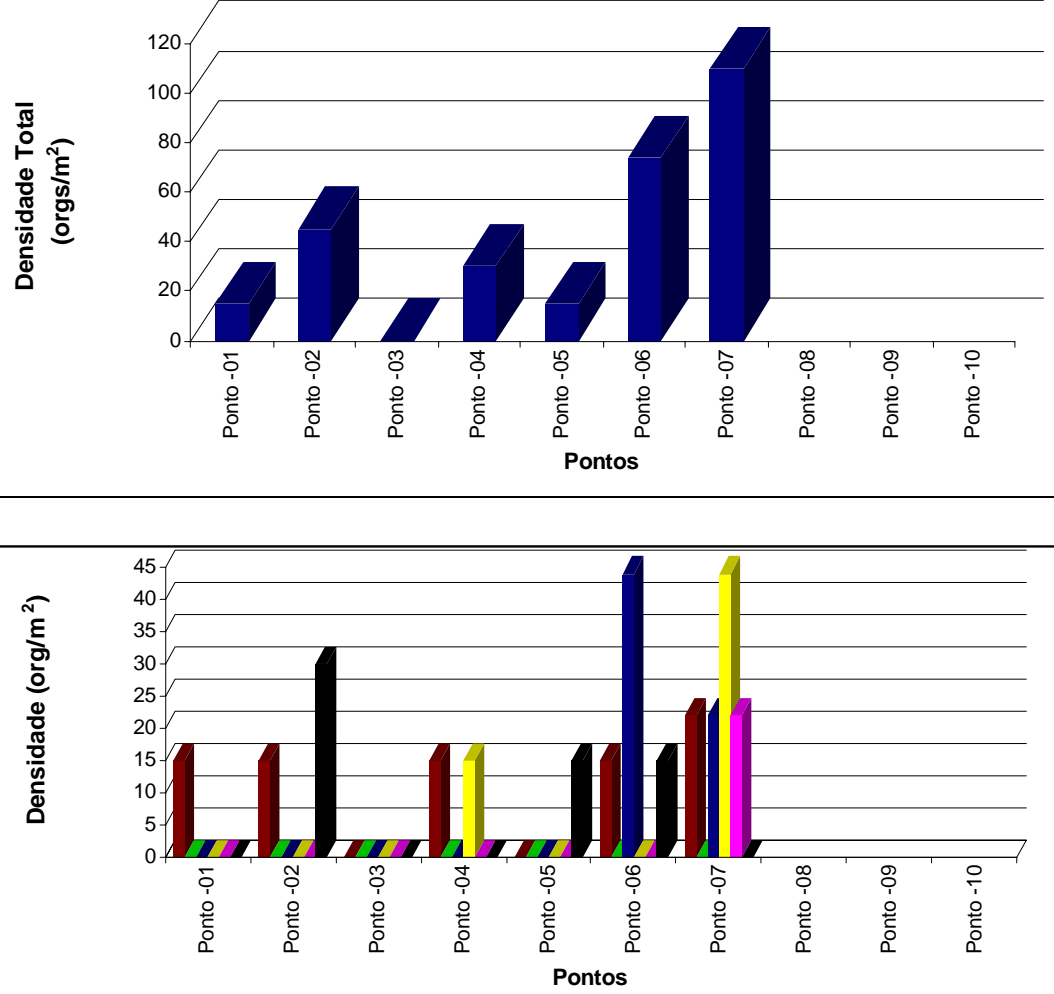

Chironomidae $n$ Tanypodinae $\mathbf{n}$ Chaoboridae Tubificidae $\square$ Glossiphoniidae $\mathbf{a}$ Pelecycopa
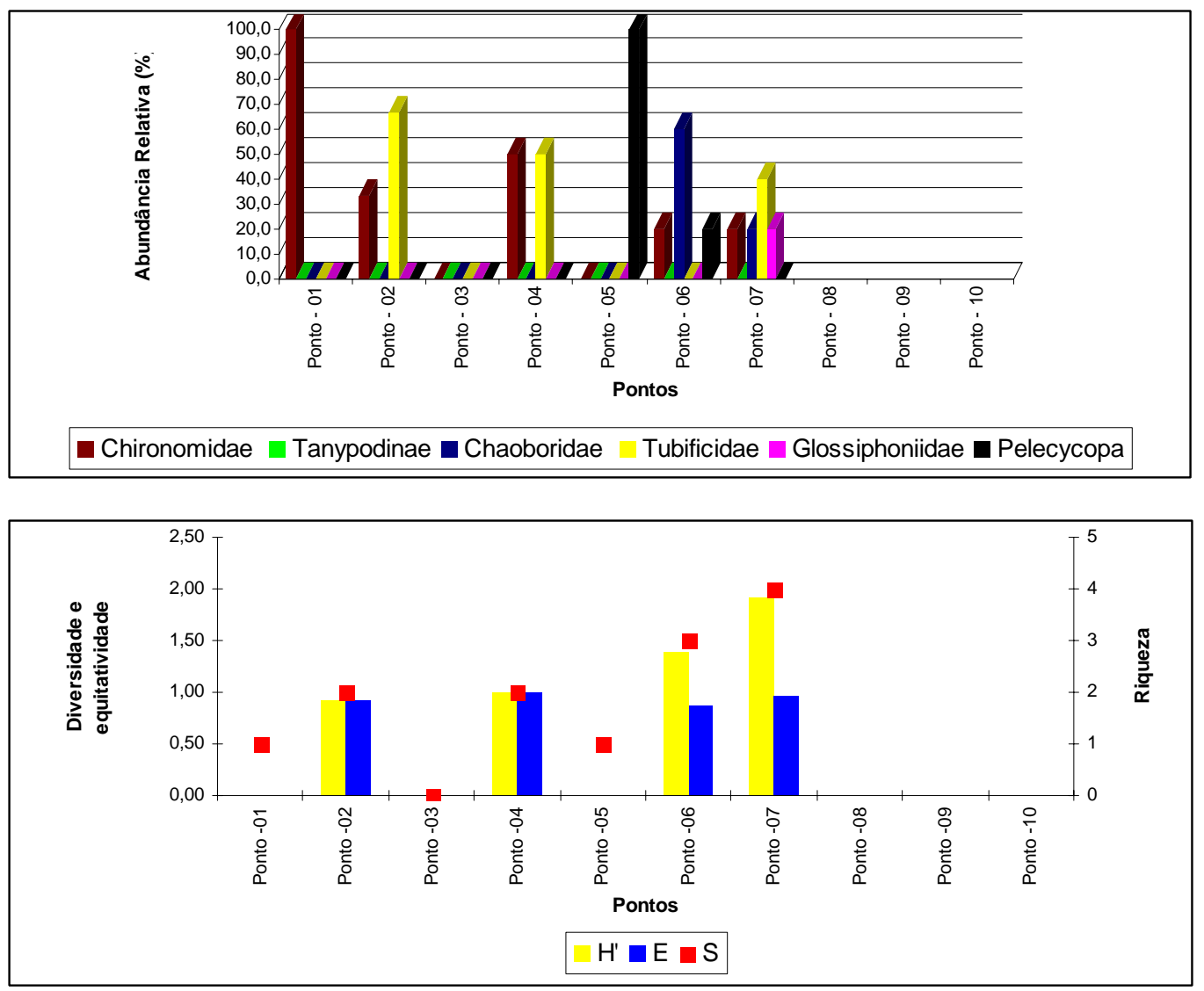

Figura 21: Janeiro/97 - Distribuição espacial dos índices da estrutura da comunidade de Macroinvertebrados Bentônicos na Represa do Guarapiranga - SP 

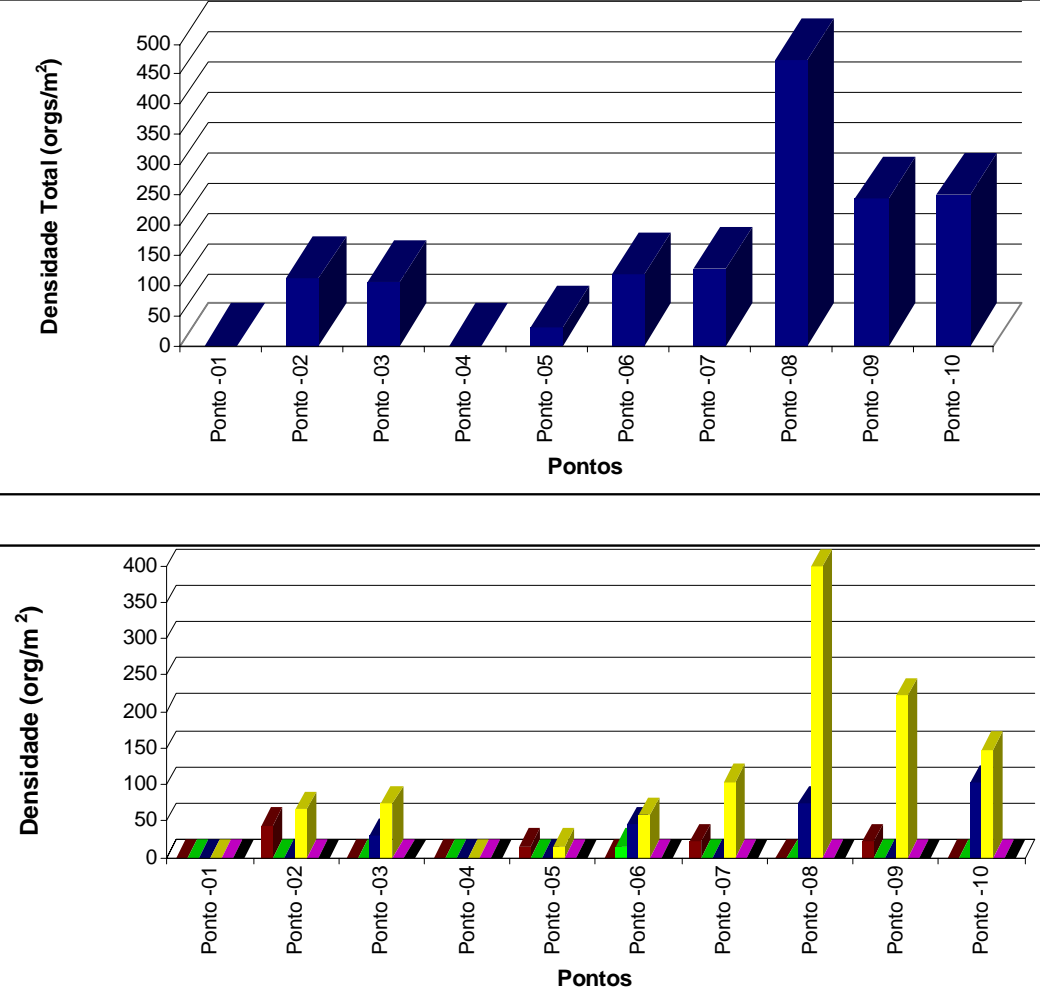

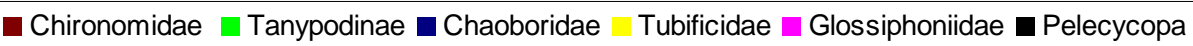
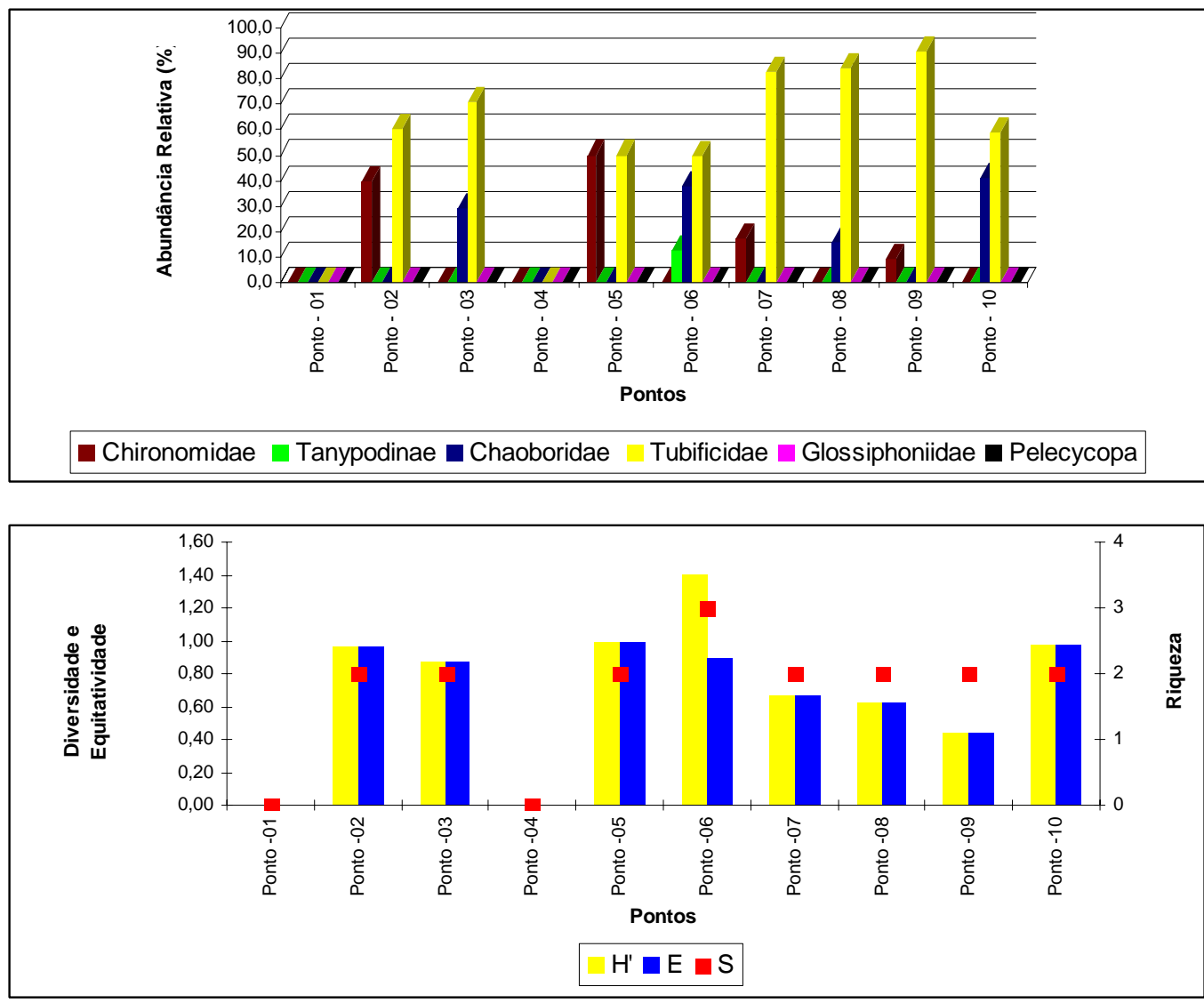

Figura 22: Fevereiro/97 - Distribuição espacial dos índices da estrutura da comunidade Macroinvertebrados Bentônicos na Represa do Guarapiranga - SP 
Figura 23: Dendrograma de Similaridade entre as estações de Coleta na Represa do Guarapiranga - SP

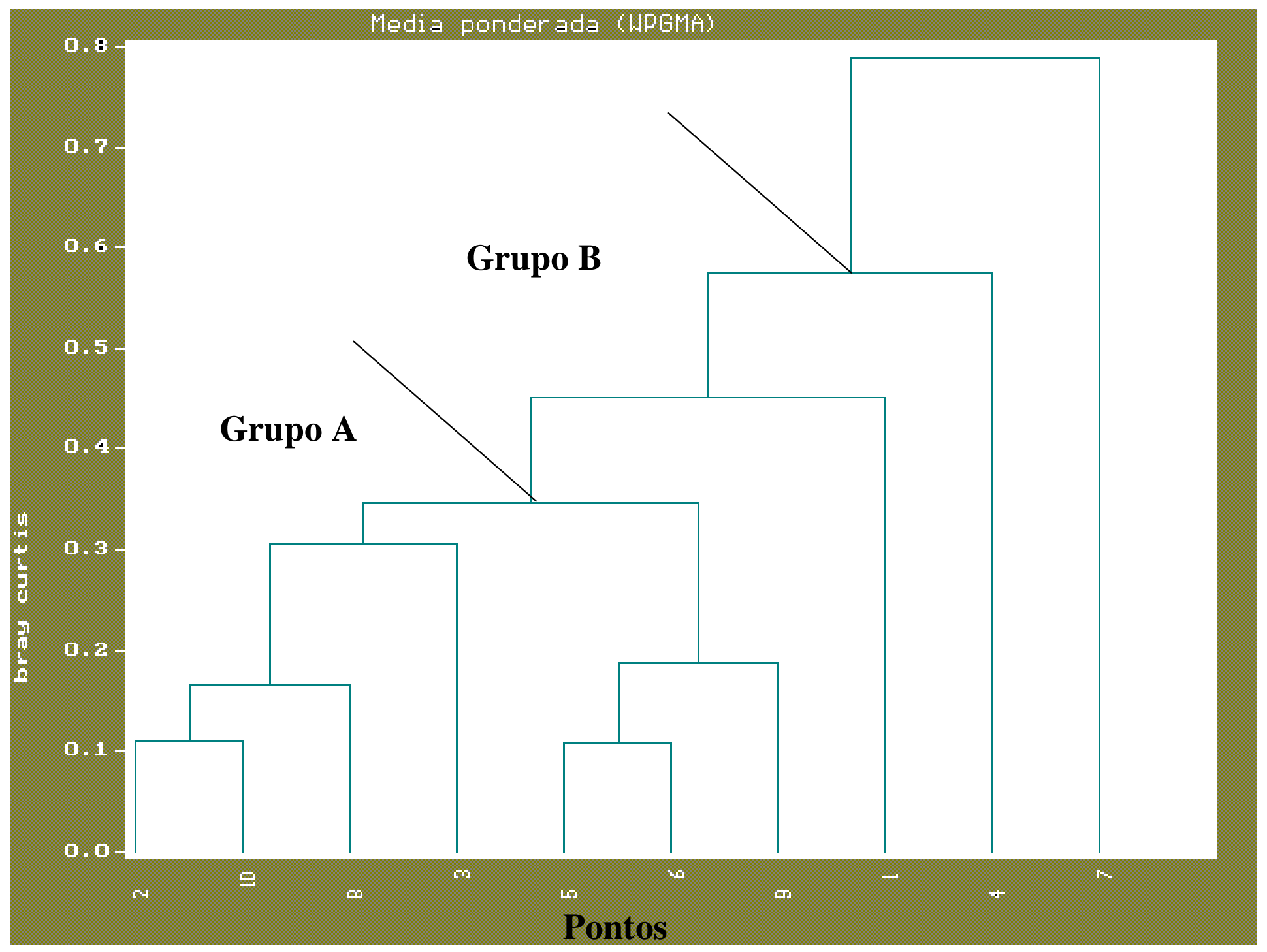



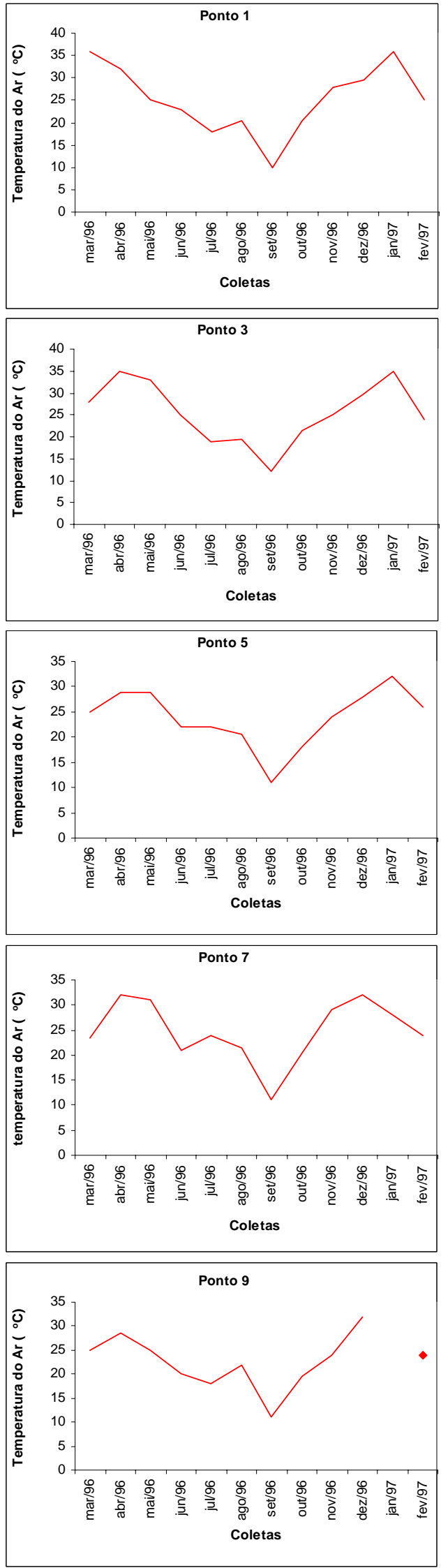
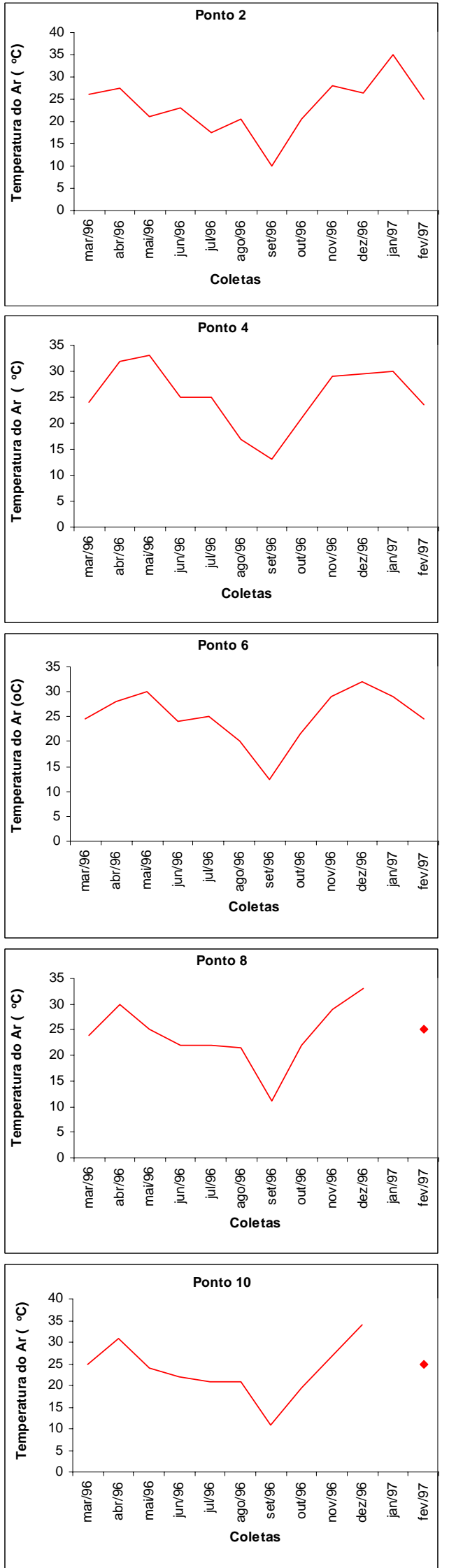

Figura 24: Variação temporal da temperatura do ar na Represa do Guarapiranga - SP 1996/1997 

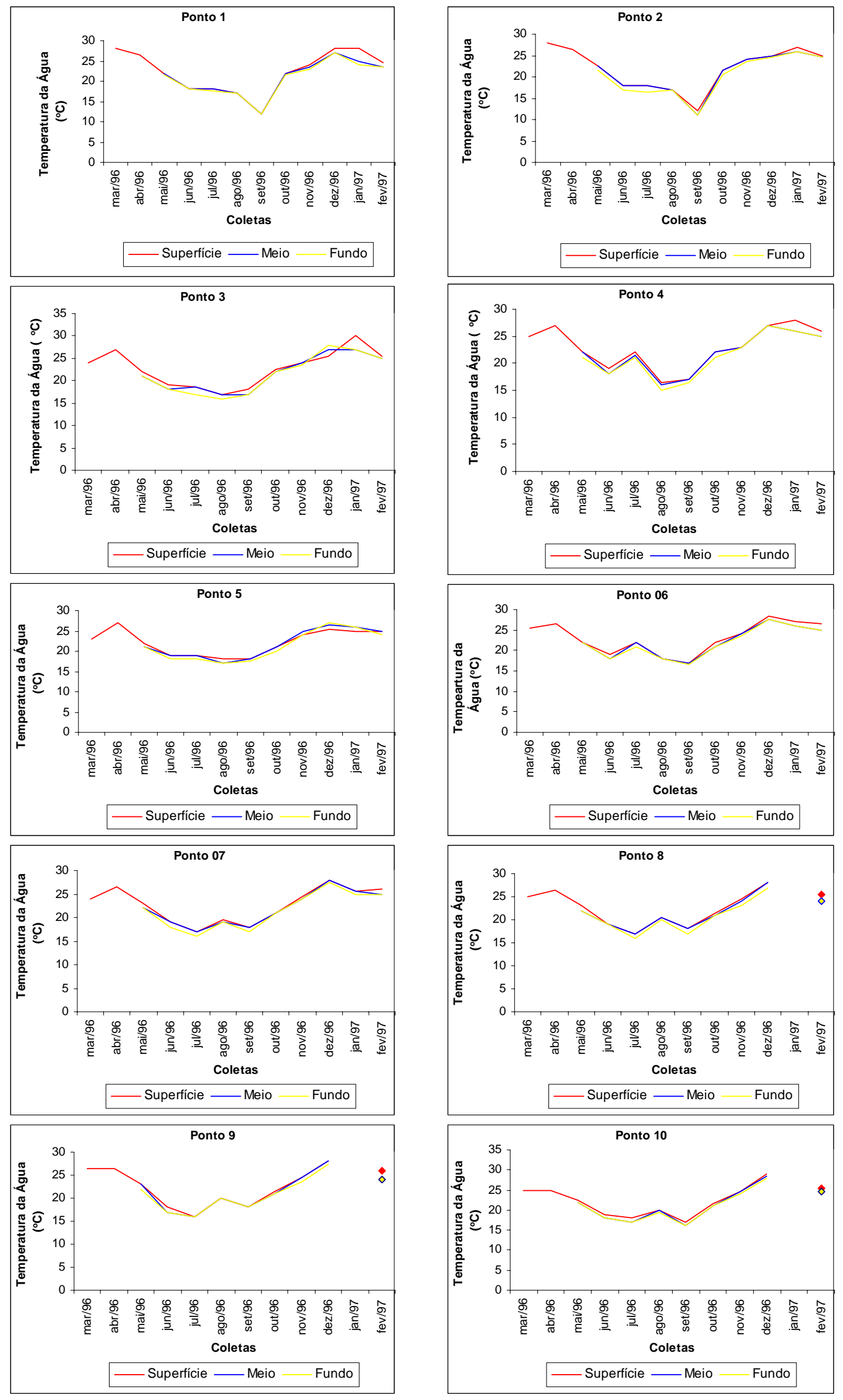

Figura 25: Variação temporal da temperatura da água na Represa do Guarapiranga - SP 1996/1997 

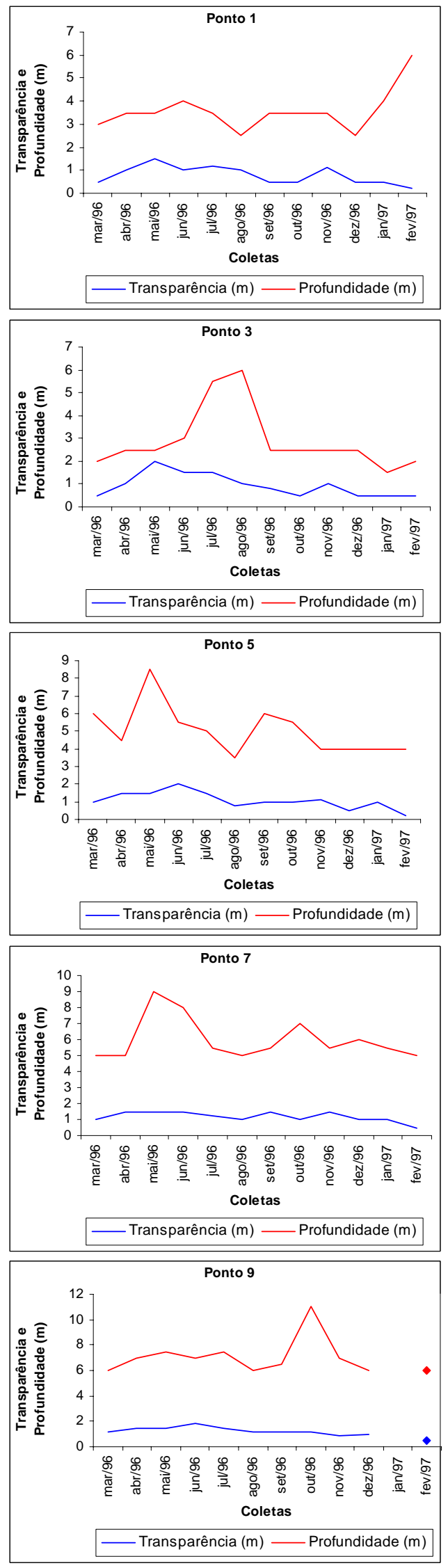
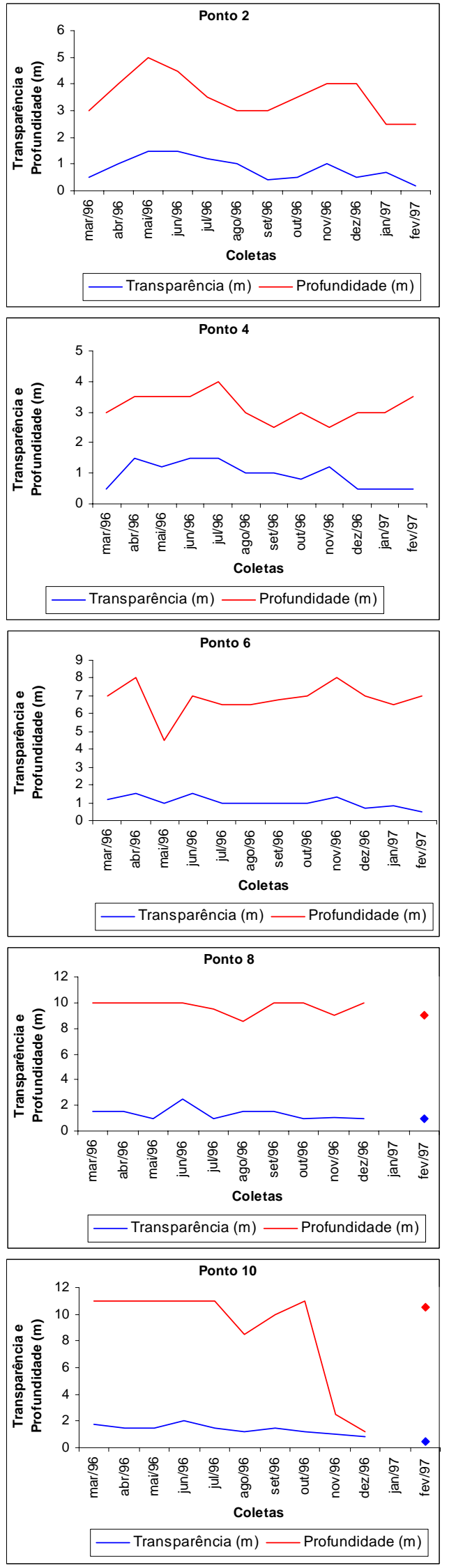

Figura 26: Variação temporal da transparência e Profundidade da água na Represa do Guarapiranga - SP - 1996/1997 

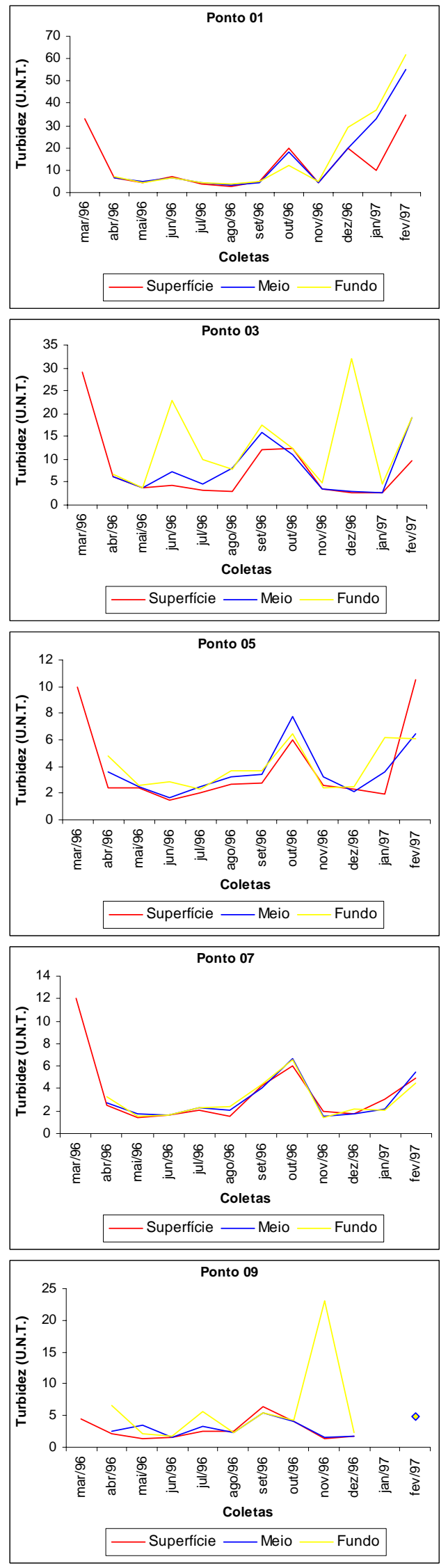
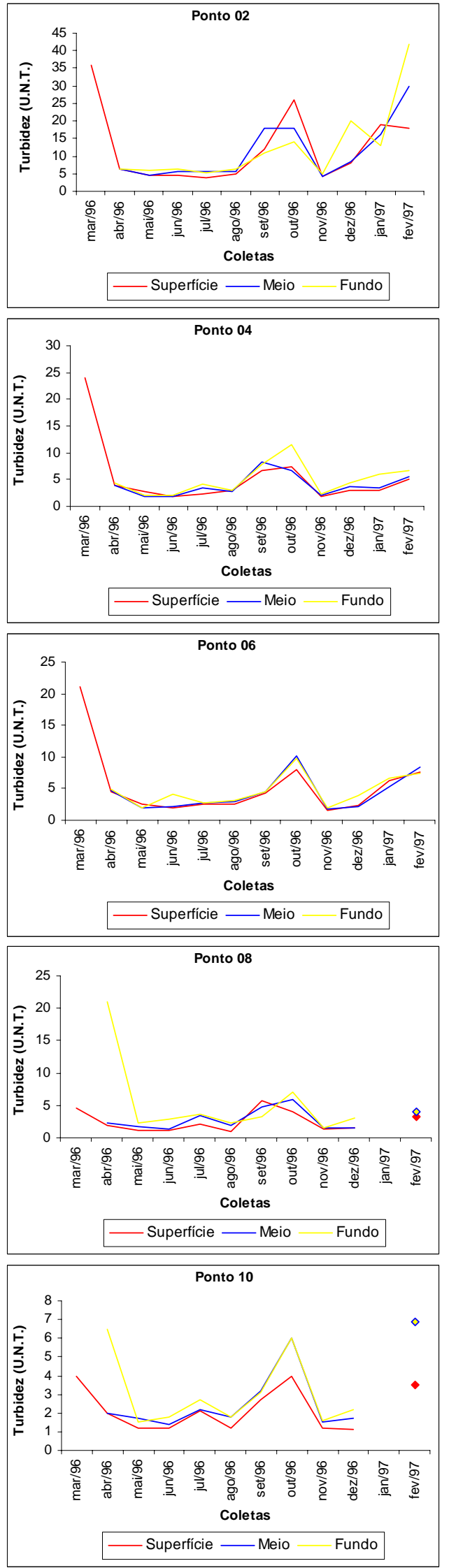

Figura 27: Variação temporal da turbidez na água na Represa do Guarapiranga - SP 1996/1997 

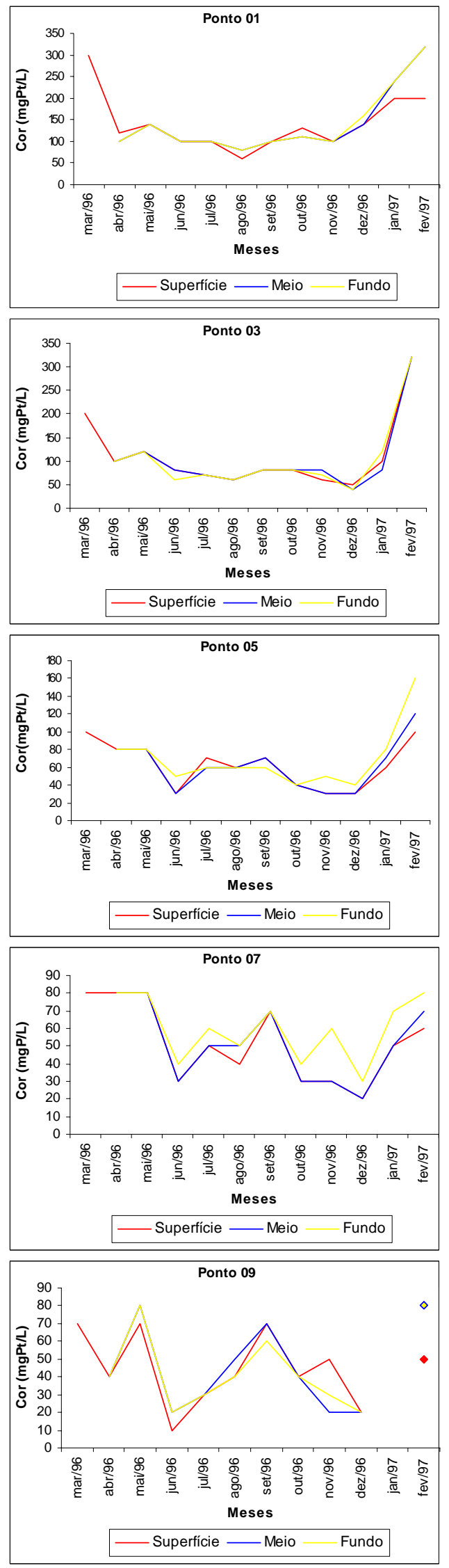
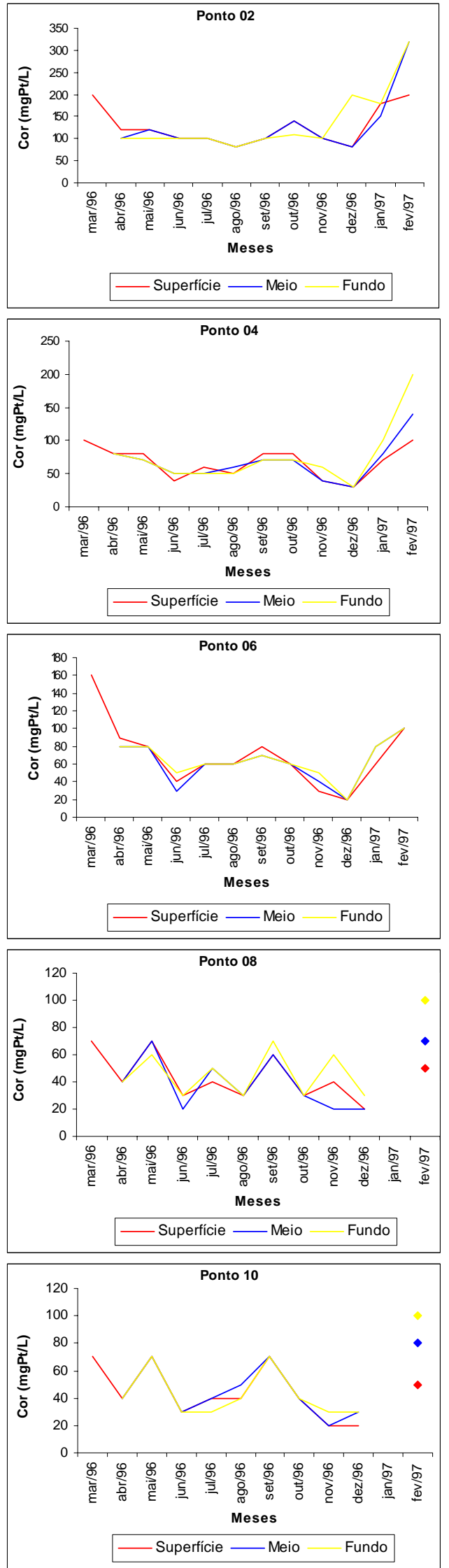

Figura 28: Variação Temporal da Cor da água na Represa do Guarapiranga - SP 1996/1997 

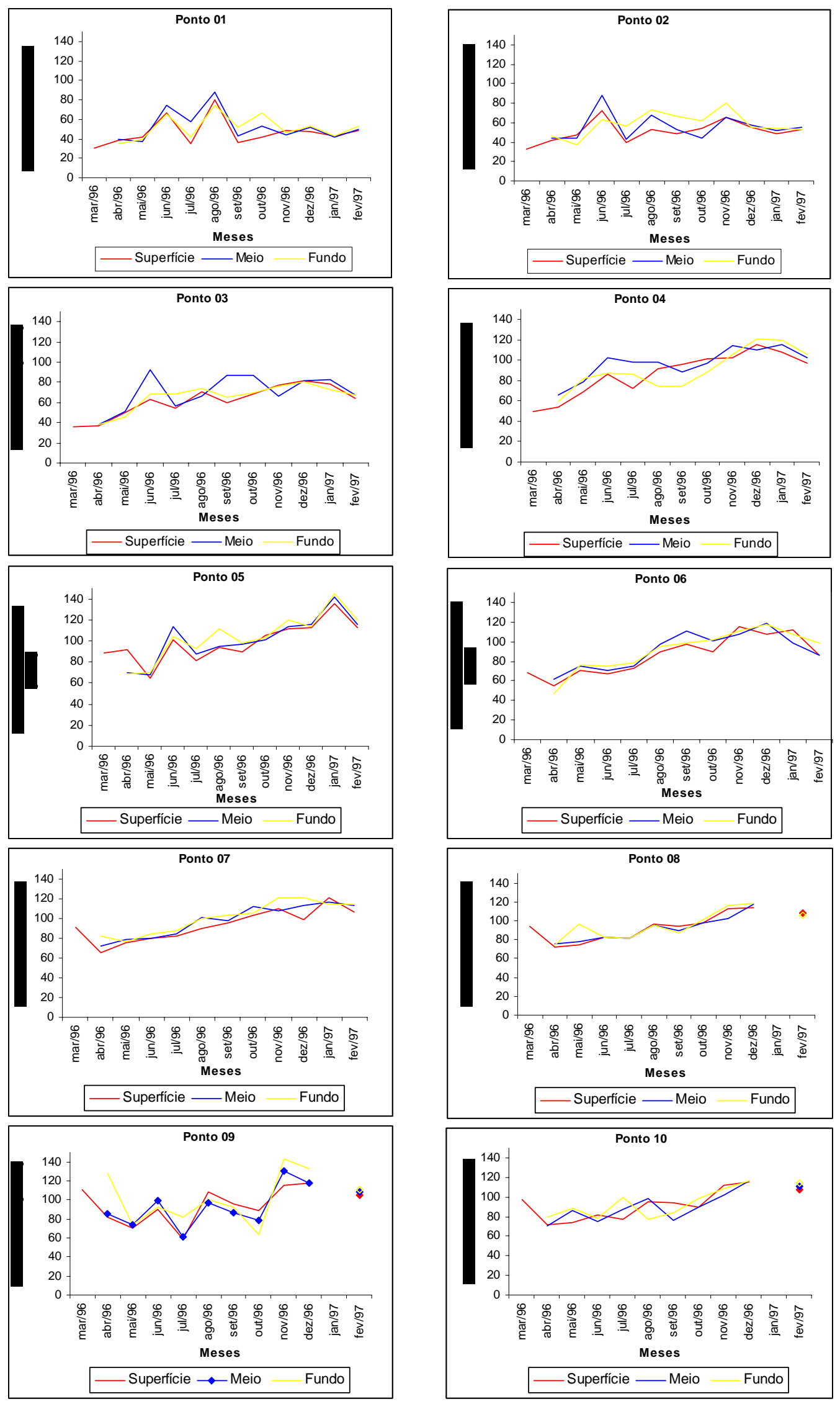

Figura 30: Variação temporal da condutividade elétrica da água na Represa do Guarapiranga - SP - 1996/1997 

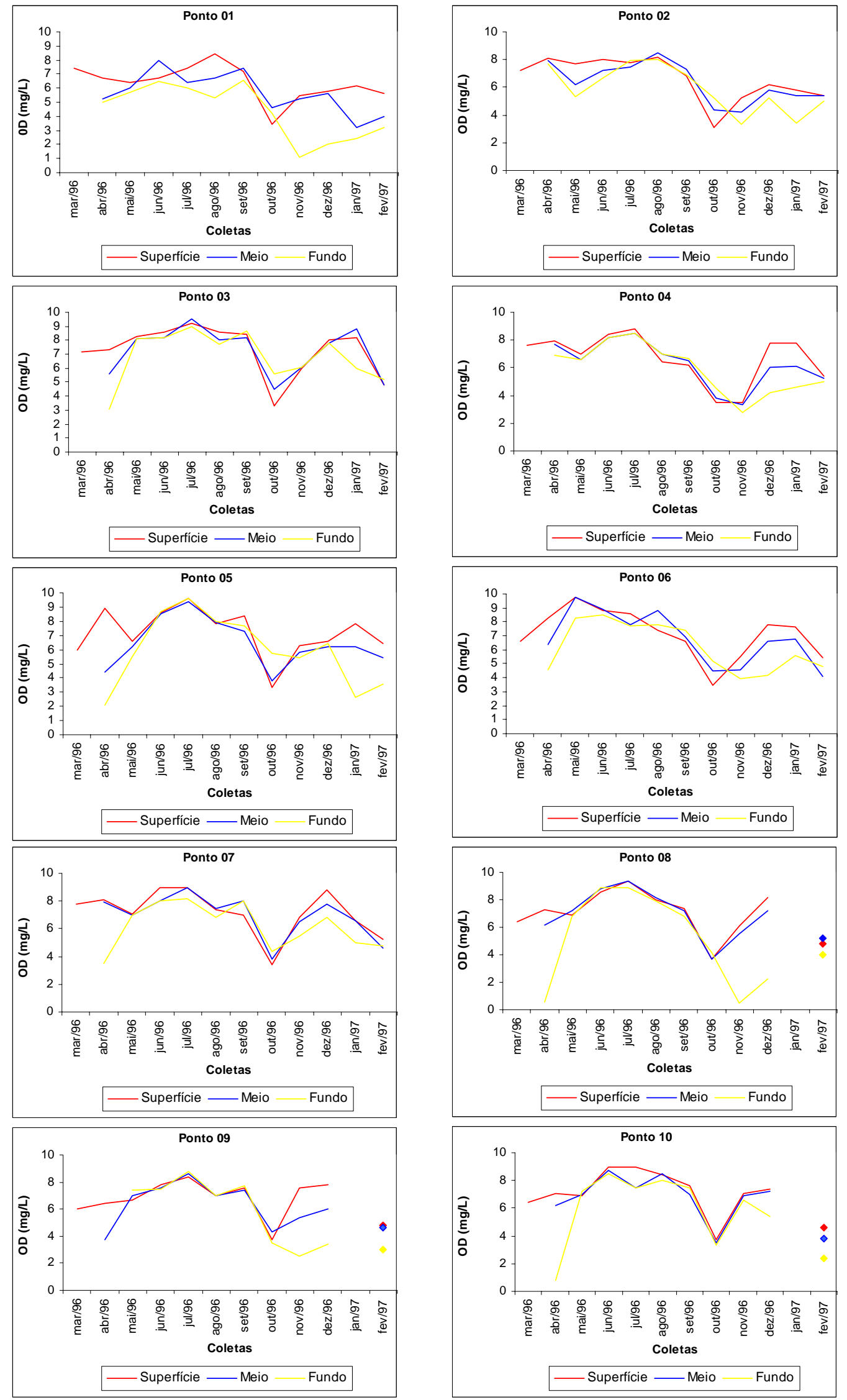

Figura 31: Variação temporal do oxigênio dissolvido da água na Represa do Guarapiranga - SP - 1996/1997 

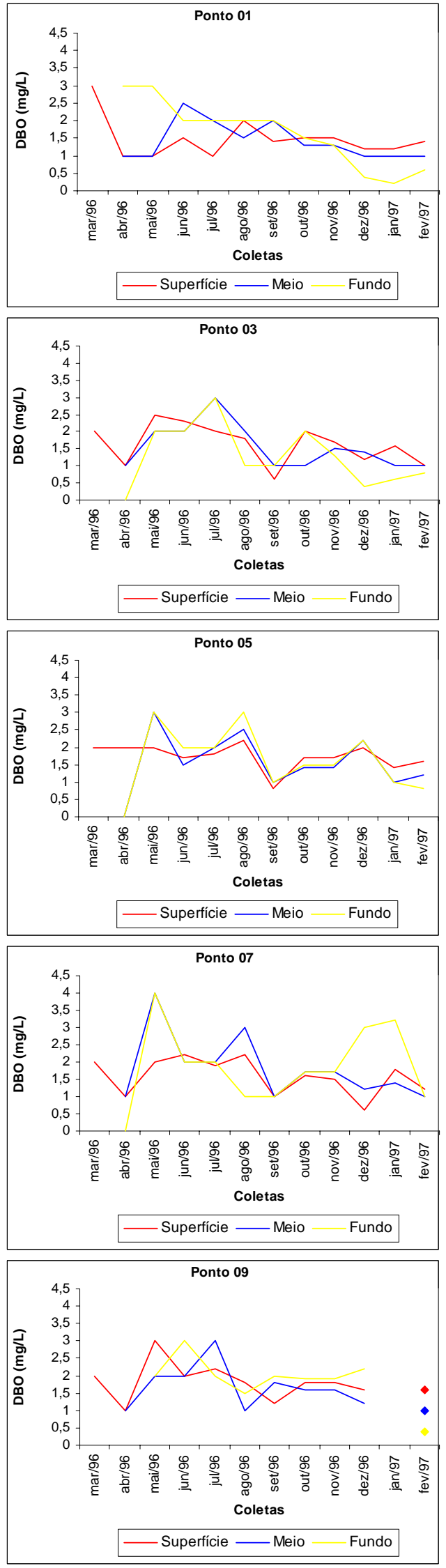
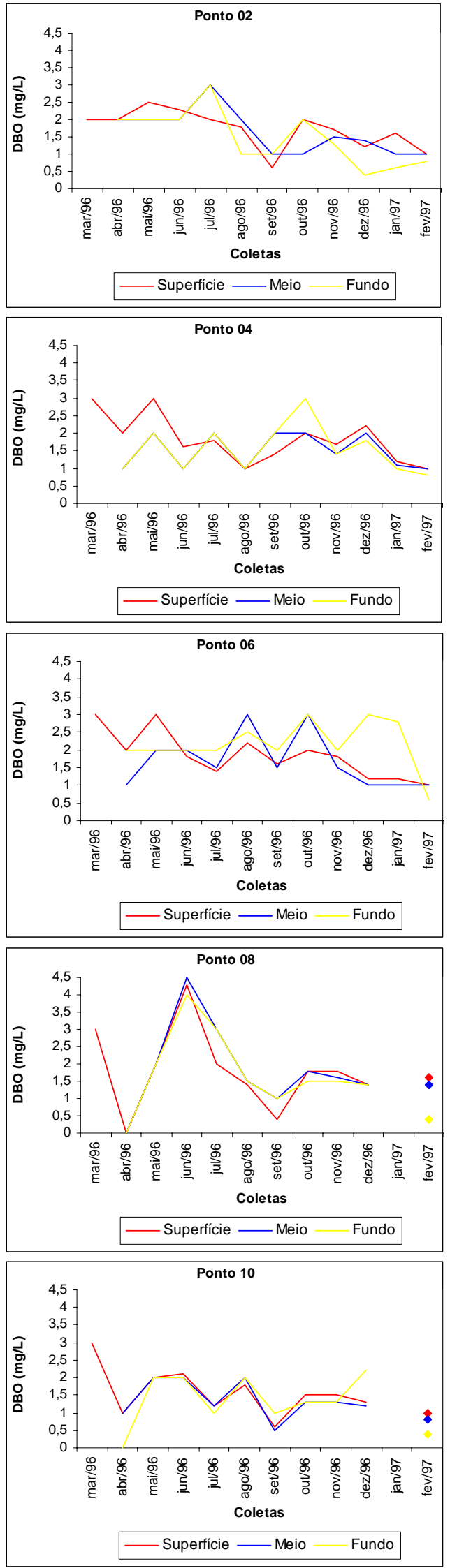

Figura 32: Variação temporal da demanda bioquímica de oxigênio da água na Represa do Guarapiranga-SP-1996/1997 

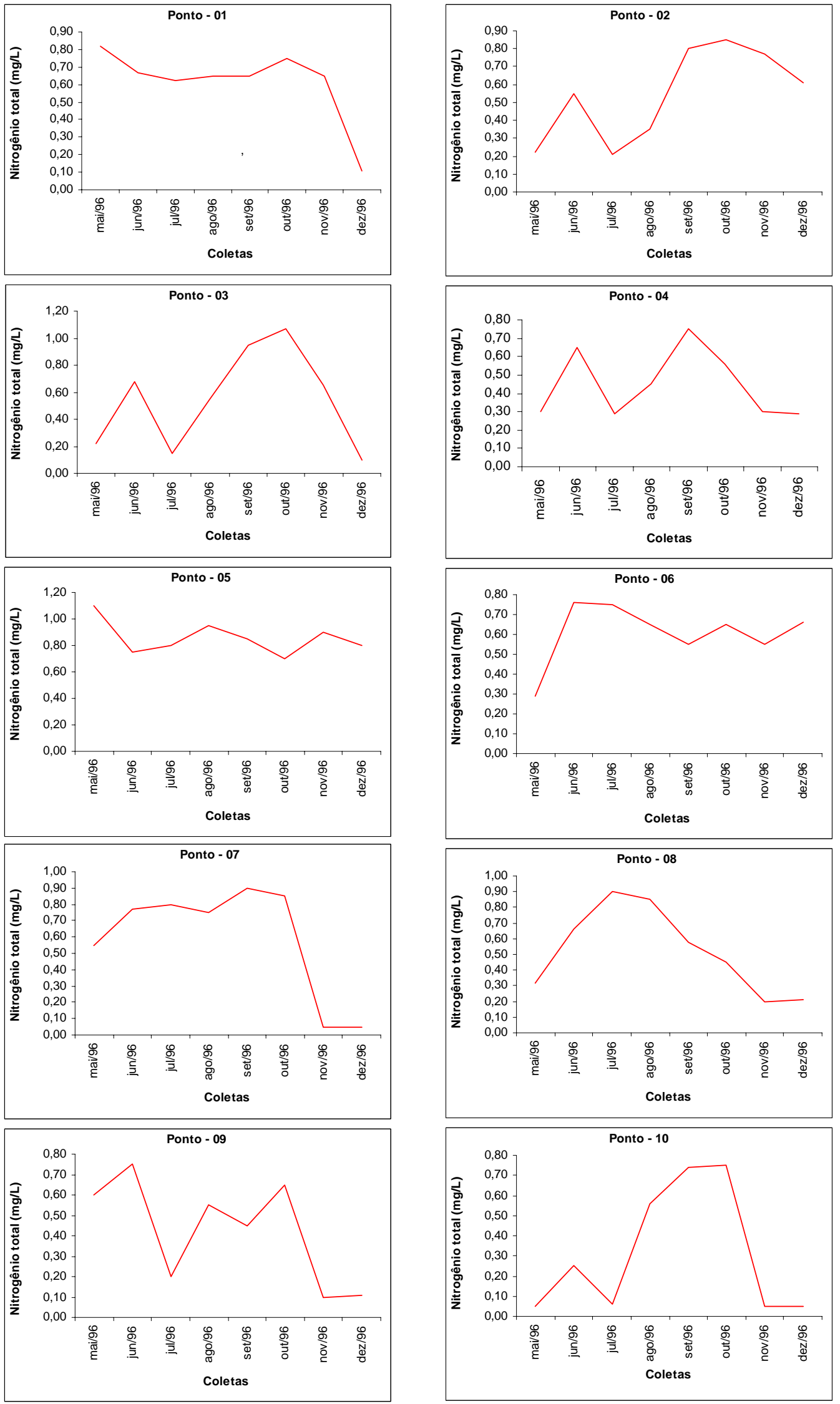

Figura 33: Variação temporal do nitrogênio total da água na Represa do Guarapiranga - SP maio a dezembro/1996 

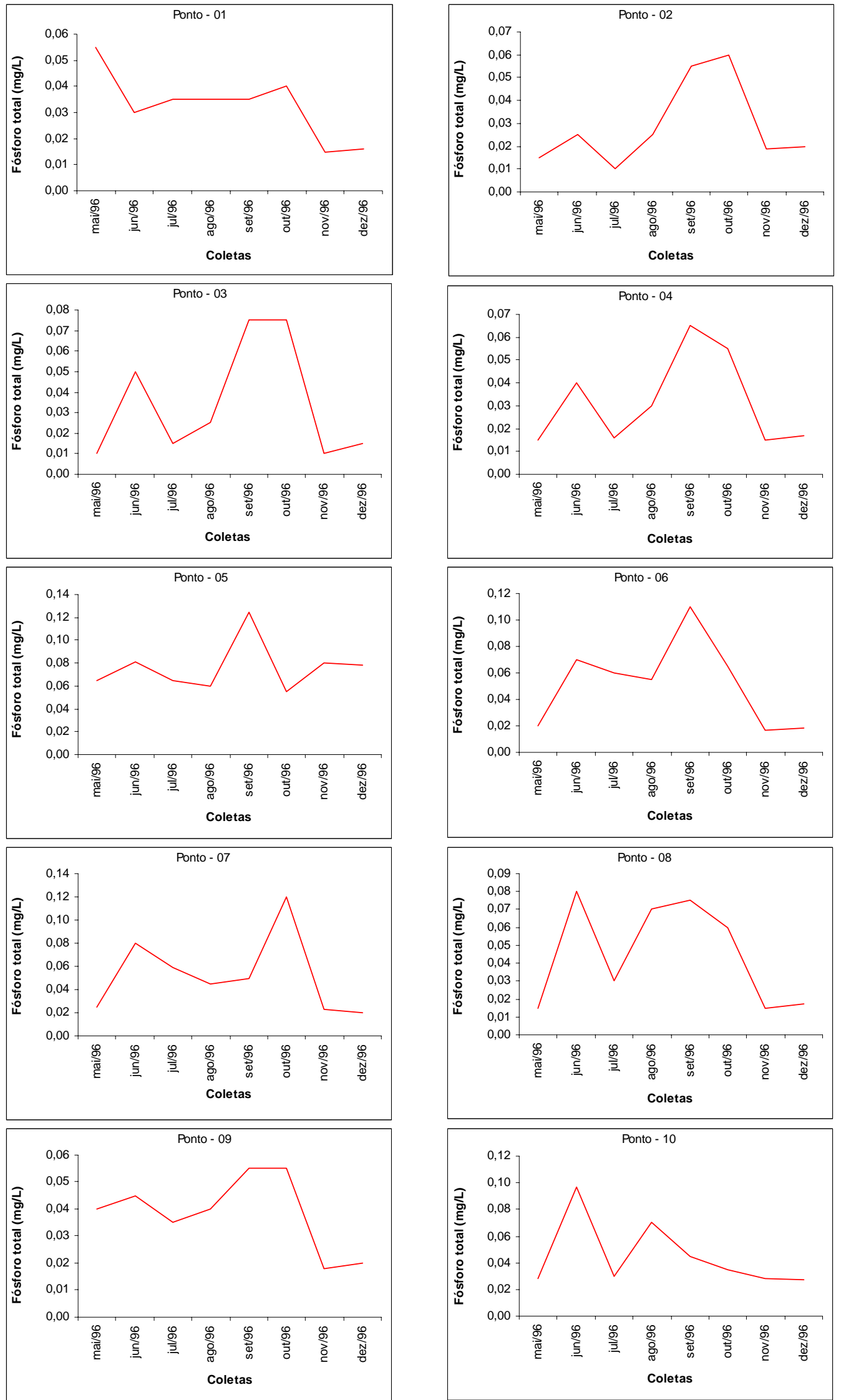

Figura 34: Variação temporal de fósforo total da água na Represa do Guarapiranga - SP - maio a dezembro/1996 
